\title{
Muscarinic M1 receptor modulation of cognition using a translational approach : relevance for dementia and schizophrenia
}

Citation for published version (APA):

Klinkenberg, I. (2012). Muscarinic M1 receptor modulation of cognition using a translational approach : relevance for dementia and schizophrenia. [Doctoral Thesis, Maastricht University]. Datawyse / Universitaire Pers Maastricht. https://doi.org/10.26481/dis.20121213ik

Document status and date:

Published: 01/01/2012

DOI:

10.26481/dis.20121213ik

Document Version:

Publisher's PDF, also known as Version of record

Please check the document version of this publication:

- A submitted manuscript is the version of the article upon submission and before peer-review. There can be important differences between the submitted version and the official published version of record.

People interested in the research are advised to contact the author for the final version of the publication, or visit the DOI to the publisher's website.

- The final author version and the galley proof are versions of the publication after peer review.

- The final published version features the final layout of the paper including the volume, issue and page numbers.

Link to publication

\footnotetext{
General rights rights.

- You may freely distribute the URL identifying the publication in the public portal. please follow below link for the End User Agreement:

www.umlib.nl/taverne-license

Take down policy

If you believe that this document breaches copyright please contact us at:

repository@maastrichtuniversity.nl

providing details and we will investigate your claim.
}

Copyright and moral rights for the publications made accessible in the public portal are retained by the authors and/or other copyright owners and it is a condition of accessing publications that users recognise and abide by the legal requirements associated with these

- Users may download and print one copy of any publication from the public portal for the purpose of private study or research.

- You may not further distribute the material or use it for any profit-making activity or commercial gain

If the publication is distributed under the terms of Article $25 \mathrm{fa}$ of the Dutch Copyright Act, indicated by the "Taverne" license above, 


\section{Muscarinic $\mathrm{M}_{1}$ receptor modulation of cognition using a translational approach \\ Relevance for dementia and schizophrenia}




\section{COLOFON}

(C) Copyright Inge Klinkenberg, Maastricht 2012

Universitaire Pers Maastricht

$\begin{array}{ll}\text { Cover illustration } & \text { Ramon Kool (www.mijnnaamisramon.nl) } \\ \text { Production } & \text { Datawyse/Universitaire Pers Maastricht } \\ \text { ISBN } & 9789461591883\end{array}$

Financial support for the publication of this dissertation was kindly provided by the Internationale Stichting Alzheimer Onderzoek and Novartis Pharma B.V.

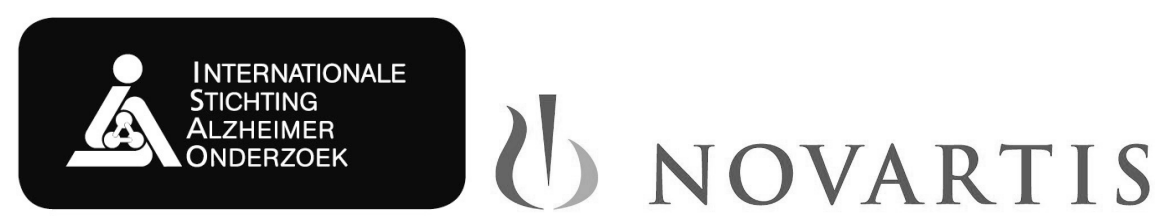




\section{Muscarinic $\mathrm{M}_{1}$ receptor modulation of cognition using a translational approach}

\section{Relevance for dementia and schizophrenia}

\section{PROEFSCHRIFT}

ter verkrijging van de graad van doctor aan de Universiteit Maastricht, op gezag van de Rector Magnificus, Prof. dr. L. L. G. Soete, volgens het besluit van het College van Decanen, in het openbaar te verdedigen op donderdag 13 december 2012 om 12.00 uur

door

Inge Klinkenberg

geboren op 18 december 1983 te Kerkrade

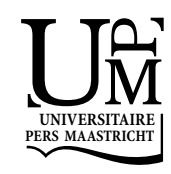




\section{PROMOTOR}

Prof. dr. W. J. Riedel

COPROMOTORES

Dr. A. Blokland

Dr. A. Sambeth

\section{BEOORDELINGSCOMMISSIE}

Prof. dr. J.G. Ramaekers (voorzitter)

Prof. dr. J. van Os

Dr. J. Prickaerts

Prof. dr. E.A. van der Zee (Rijksuniversiteit Groningen) 


\section{Contents}

$\begin{array}{lll}\text { Chapter } 1 & \text { General Introduction } & 7\end{array}$

Chapter 2 The validity of scopolamine as a pharmacological model for cognitive impairment: A review of animal behavioral studies

Chapter 3 A comparison of scopolamine and biperiden as a rodent model for cholinergic cognitive impairment

Chapter 4 The muscarinic $M_{1}$ antagonist biperiden induces verbal memory impairment in young, healthy participants: Implications for Alzheimer's disease

Chapter 5 Human electrophysiological correlates of learned irrelevance: Effects of the muscarinic $\mathrm{M}_{1}$ antagonist biperiden

Chapter 6 Cholinergic gating of hippocampal auditory evoked potentials in freemoving rats

Chapter 7 Cholinergic modulation of auditory processing and novelty detection 165 in human participants

Chapter 8 General Discussion

Summary

Abbreviations

Curriculum Vitae

219

Publications

Acknowledgements 

CHAPTER 1

Introduction 


\section{ACETYLCHOLINE AND COGNITION}

Cognitive (dys)function can be viewed as one of the main research themes within the field of psychology and neuroscience. Impairments in cognition usually occur as an epiphenomenon of brain diseases and/or neuropsychiatric disorders, yet these are not limited to one specific neurological affliction and can occur at any age. For instance, in the Netherlands approximately 156,726 people suffered from psychotic disorders, whereas about 210,366 people were afflicted with dementia in the year 2010. The annual cost for these disorders has been estimated to lie at 3972 million for psychosis, and 2958 million for dementia (Gustavsson et al., 2011). Neurological diseases are hence associated with significant reductions in quality of life for patients and their families, and place a heavy economical burden on society. In the clinical population, impairments are rarely restricted to only one or few cognitive domains (e.g., attention, memory, language, orientation, praxis, executive function, and problem solving: Sadock et al., 2009). Moreover, patient samples can be very heterogeneous in terms of etiology, treatment and disease history, cognitive deficits, clinical symptoms, disease progression, and socioeconomic factors (e.g., Cummings, 2000). This heterogeneity makes it difficult to correlate cognitive dysfunctions and/or clinical symptoms with specific neuropathological or neurochemical findings. Therefore, a lot of effort is dedicated to modeling cognitive deficits with pharmacological tools that temporarily and reversibly impact neurotransmission in healthy animals and young volunteers (e.g., Gilles \& Luthringer, 2007). These pharmacological models are essential for unraveling the neurobiological basis of cognition, and are used as methods to screen potential cognitionenhancing medications (Levin \& Buccafusco, 2006).

For instance, the non-selective cholinergic (i.e., muscarinic) antagonist scopolamine has been employed extensively to model age- and dementia-related impairments in cognitive functions, especially memory (see Chapter 2 ). The guiding principle for the use of scopolamine as a pharmacological method to investigate cholinergic impairment has been the cholinergic hypothesis of geriatric memory dysfunction, which was formulated by Bartus et al. (1982) 30 years ago: Stated in its most simple and direct terms, the cholinergic hypothesis asserts that significant, functional disturbances in cholinergic activity occur in the brains of aged and especially demented patients, these disturbances play an important role in the memory loss and related cognitive problems associated with old age and dementia, and proper enhancement or restoration of cholinergic function may significantly reduce the severity of the cognitive loss (Bartus et al., 1985, p. 332).

The specific role of acetylcholine in cognition - i.e. learning/memory and attention has been the subject of much debate during the last couple of decades, although initial evidence was promising. For instance, findings of reduced cholinergic enzyme activity in post-mortem brain tissue of Alzheimer patients (Bowen et al., 1976; Perry et al., 1977; Whitehouse et al., 1982), learning and memory impairments after cholinergic lesioning of basal forebrain neurons with neurotoxins in animals and after administration of the muscarinic antagonist scopolamine (for an extensive overview, see Chapter $\mathbf{2}$ and Baxter \& Murg, 2002) corroborated the assumptions of the cholinergic hypothesis. However, early neurotoxins used for this purpose were not fully selective for cholinergic neurons, and subsequent animal experiments using the more selective immunotoxin 192 IgG-saporin to lesion basal forebrain projections yielded attentional instead of learning/memory impairments (e.g., Baxter \& Gallagher, 1996; Baxter et al., 1997; Chiba et al., 1999; McGaughy et 
al., 2000; Sarter et al., 2003; Torres et al., 1994; Voytko, 1996). Moreover, behavioral paradigms which assess stimulus discrimination and/or (sustained) attention processes were shown to be relatively more sensitive to impairments induced by the muscarinic antagonist scopolamine compared to tasks which measure learning/memory functions (i.e., effects at relatively lower scopolamine doses; see Chapter 2). Hence, a dissociation has emerged between researchers emphasizing the role of acetylcholine in attention (Sarter et al., 2003; $2005 ; 2009)$ vs. those still adhering to views which emphasize the involvement of the cholinergic system in learning/memory functions (Hasselmo, 1999; 2006; Hasselmo et al., 2002; Hasselmo \& McGaughy, 2004). However, by generalizing the effects of cholinergic neurotransmission on cognitive functions to learning/memory vs. attention, these hypotheses fail to recognize that cholinergic projections can be found diffusely throughout the brain and hence acetylcholine might have differential effects dependent on receptor subtype and brain region targeted.

In addition, an exclusive role for acetylcholine in geriatric memory dysfunction is too restrictive. For example, cholinergic impairments have also been noted in Parkinson's disease (e.g., Calabresi et al., 2006), mood disorders (e.g., Drevets et al., 2008), and schizophrenia (e.g., Sarter et al., 2012). Despite the strong research emphasis on dopaminergic and glutaminergic neurotransmitter changes in schizophrenia, several lines of evidence also suggest a role for cholinergic (i.e., muscarinic) signaling (e.g., Brooks et al., 2011; Sarter et al., 2012; Tandon et al., 1991; 1999). For example, postmortem and in-vivo imaging studies have shown a reduction of muscarinic receptor density or binding in the caudate-putamen (Dean et al., 1996; but see Dean et al., 2000), the hippocampal formation (Crook et al., 2000; but see Scarr et al., 2007), prefrontal cortex (Crook et al., 2001; Scarr et al., 2008), superior temporal gyrus (Deng \& Huang, 2005), and cingulate cortex (Newell et al., 2007; Zavitsanou et al., 2004). Furthermore, cognitive impairments associated with schizophrenia have been suggested to be the most severe in the domains of memory and attention (amongst others; see Sadock et al., 2009). Thus, the question arises whether aberrant cholinergic signaling is a common neuropathological pathway underlying both dementia and schizophrenia. Conversely, administration of cholinergic (i.e., muscarinic) antagonists might hence serve as a model for cognitive impairments associated with aging, Alzheimer's disease, and schizophrenia.

Interestingly, findings of studies using muscarinic drugs are in line with a role for aberrant cholinergic signaling in schizophrenia. For instance, high doses of the non-selective muscarinic antagonists scopolamine and atropine have both been shown to induce an antimuscarinic psychosis consisting of visual hallucinations, delusions, hyperactive and stereotypical behavior, loss of attention and memory, disorganized thinking and confusion (Barak $\&$ Weiner, 2009). Whereas amphetamine-induced psychosis mainly mimics the positive symptoms of schizophrenia and is thought to reflect the acute stage of the disorder, antimuscarinic psychosis also includes some cognitive symptoms and is seen as a model for chronic schizophrenia (Barak \& Weiner, 2009). Moreover, administration of muscarinic $\left(\mathrm{M}_{1}\right)$ antagonists biperiden or procyclidine has been shown to increase positive symptomatology in schizophrenia patients (Johnstone et al., 1983; Tandon et al., 1990; 1992), yet to reduce negative symptoms (Tandon et al., 1992).

In sum, although Alzheimer's disease can be characterized as a neurodegenerative illness, and schizophrenia as a neurodevelopmental disorder, they appear to share a common denominator: cholinergic impairment. However, as noted previously, cholinergic neu- 
rons and projections are found throughout the central nervous system (e.g., Mesulam, 1990; Mesulam et al., 1983). Hence, for the purpose of modeling cholinergic impairments associated with Alzheimer's disease and/or schizophrenia, it might be preferable to use drugs which bind to cholinergic receptor subtypes in a relatively selective manner. In addition, non-selective cholinergic (i.e., muscarinic) antagonists such as scopolamine are capable of inducing a wide range of peripheral side-effects ${ }^{1}$ (Chapter 2). By using drugs which target cholinergic receptors more selectively, it is expected that correlating blockade of cholinergic neurotransmission with specific cognitive dysfunctions will be relatively more straightforward.

\section{ACETYLCHOLINE IN THE BRAIN AND BODY}

Acetylcholine exerts its effects on brain function via binding to and interacting with two main classes of cholinergic receptors; i.e., nicotinic and muscarinic. Nicotinic receptors are ionotropic receptors or ligand-gated ion channels, of which the actions can be characterized by a fast onset and a short duration of postsynaptic effects (Kandel et al., 2000). The second class of cholinergic receptors is made up by the muscarinic receptors, which are the main focus of the current dissertation. All muscarinic receptors are metabotropic or Gprotein-coupled receptors which actions have a slower onset and longer duration relative to those of nicotinic receptors (Caulfield, 1993). In Table 1 an overview is given of the signaling cascades, localization and disease relevance of muscarinic receptor subtypes. As is evident in this Table, the most predominant receptor subtype found in the brain is the muscarinic $M_{1}$ receptor, which is mainly expressed in the cerebral cortex, hippocampus, amygdala and striatum (Caulfield, 1993; Flynn et al., 1997). Interestingly, in the hippocampus - a site which is heavily implicated in learning and memory processes - the majority of muscarinic receptors are of the $M_{1}$ subtype (Volpicelli \& Levey, 2004). Furthermore, density of the $M_{1}$ receptor in the periphery is relatively sparse compared to muscarinic receptors $M_{2}-M_{5}$ (Caulfield, 1993). Thus, drugs which selectively block the effects of acetylcholine at muscarinic $M_{1}$ receptor sites might be preferable as a pharmacological model for cognitive deficits associated with aging, dementia, and schizophrenia.

\section{AIM OF THE DISSERTATION}

The main goal of the current thesis is to determine the role of the muscarinic $M_{1}$ receptor in cognition. Based on the predominance of the muscarinic $M_{1}$ receptor in the hippocampus (e.g., Volpicelli \& Levey, 2004), it is hypothesized that drugs targeting the muscarinic $M_{1}$ receptor will serve as a model for learning/memory rather than attentional impairment. Secondly, given the relatively low density of the muscarinic $M_{1}$ receptor in peripheral tissues, it is expected that drugs targeting this receptor subtype will display less severe sideeffects compared to non-selective muscarinic ligands. Finally, results will be interpreted in a psychopathological framework; i.e., they will be related to findings in patient groups which

\footnotetext{
${ }^{1}$ Since the current thesis focuses on the central nervous system, actions of cholinergic drugs at peripheral sites are interpreted as side-effects which might hamper interpretation of central effects on cognition and behavior.
} 
are known to exhibit cholinergic dysfunction, such as Alzheimer's disease and schizophrenia (Bartus et al., 1982; Sarter et al., 2012).

\section{METHODOLOGY}

The majority of the pharmacological studies described in the current dissertation are conducted with a placebo-controlled crossover design which, in the case of human experiments, is performed double-blind. We use several drugs to examine the effects of cholinergic manipulations on cognition and behavior, which generally fall into two categories: 1) muscarinic antagonists, i.e., scopolamine and biperiden, and 2) cholinesterase inhibitors, i.e., donepezil and rivastigmine. The cholinergic hypothesis postulated by Bartus et al. (1982) has provided the rationale for the use of the non-selective muscarinic antagonist scopolamine as a standard/reference drug for inducing age- and dementia-related cognitive deficits in healthy humans and animals (Ebert \& Kirch, 1998; Flood \& Cherkin, 1986). However, as will be described in further detail in Chapter 2, the tendency of scopolamine to bind non-selectively to muscarinic receptors hampers interpretation of systemic applications of the drug; i.e., widespread blockade of muscarinic receptors in the brain and body makes it difficult to dissociate central and peripheral drug effects from one-another.

Therefore, all studies described in this dissertation use the muscarinic $M_{1}$ antagonist biperiden (often in comparison to and/or in combination with scopolamine, donepezil or rivastigmine), to explore the role of the $M_{1}$ receptor subtype in cognition. It has about 10fold higher affinity for $M_{1}$ as compared to $M_{2}-M_{5}$ receptors (Bolden et al., 1992; Katayama et al., 1990). Although its selectivity for muscarinic receptors can be characterized as relative or functional rather than absolute (Eglen, 2006), it is nevertheless currently the most selective $M_{1}$ antagonist available for use in human participants. Moreover, muscarinic $M_{1}$ agonists are not yet approved for use in humans (Bradley et al., 2010). Therefore we chose to employ cholinesterase inhibitors donepezil and rivastigmine to examine their interactions with biperiden on cognitive function in rats and humans, respectively.

In addition, the studies described in this dissertation can be characterized as translational, as the cognitive effects of cholinergic manipulations are explored in both normal volunteers and healthy rats. Since animal models of cognitive dysfunction are used extensively as a tool for screening potential cognition-enhancing medications, it is pertinent that the usability of muscarinic drugs for this purpose is explored. Furthermore, we chose to test young, healthy participants instead of patients groups in order to be able to assess whether muscarinic drugs would be capable of inducing cognitive deficits comparable to those in aging, Alzheimer's disease and/or schizophrenia.

Lastly, we employed EEG paradigms in several of our experiments in order to enhance translatability of results; particularly, we chose to use a learned irrelevance (LIrr), pairedclick, and novelty oddball task. Schizophrenia patients have been shown to display deficits in these paradigms (e.g., Baldeweg et al., 2004; Boutros et al., 2004; Orosz et al., 2008), and we sought to determine to what extent aberrant cholinergic signaling might contribute to this phenomenon. Central to schizophrenia is the idea that individuals suffering from this disorder have difficulties inhibiting irrelevant input and/or display deficits in the gating of repetitive stimuli (Patterson et al., 2008). These processes can be measured with LIrr and paired-click paradigms, respectively. It is assumed that the lack in the ability to suppress 
redundant information causes it to gain access to conscious processing, ultimately leading to sensory overload and attentional dysfunction in schizophrenia patients. Like the pairedclick task, the novelty oddball task also makes use of the automatic processing of auditory stimuli in the absence of effortful attention (e.g., Javitt et al., 2008; Leiser et al., 2011; Lijffijt et al., 2009). It generates a so-called mismatch negativity (MMN) ERP potential which provides an index of context-dependent change detection and/or sensory memory (e.g., Toyomaki et al., 2008). Schizophrenia patients generally show deficits in MMN generation (e.g., Light \& Braff, 2005).

\section{OUTLINE OF THE DISSERTATION}

Chapter 2 attempts to answer the following question: what cognitive and physiological processes are affected by the non-selective muscarinic antagonist scopolamine? Papers are reviewed in which scopolamine is used as a standard/reference drug to induce cognitive impairment in animals. At the end of Chapter 2, muscarinic $M_{1}$ antagonists are put forward as a more selective way of inducing cholinergic-induced cognitive deficits.

Chapters $\mathbf{3}$ and $\mathbf{4}$ try to provide an answer to the question whether muscarinic $M_{1}$ antagonists indeed have relatively more specific effects on cognition (i.e., on learning/memory rather than other central and/or peripheral processes) in healthy rats and healthy volunteers. In Chapter 3, a battery of operant tests is used which assess sensorimotor responding (fixed ratio schedule of reinforcement; FR5), food motivation (progressive ratio schedule of reinforcement; PR10), attention and working memory (delayed nonmatching to position: DNMTP) in order to determine whether the muscarinic $\mathrm{M}_{1}$ antagonist biperiden induces relatively more selective effects on memory compared to the nonselective muscarinic antagonist scopolamine. Chapter $\mathbf{4}$ explores the effects of biperiden on verbal memory, psychomotor behavior and self-reports of side-effects in young, healthy participants, again to determine the specificity of biperiden as a cognition-impairing drug.

Chapters 5, 6 and 7 assess whether the muscarinic $M_{1}$ receptor is involved in several cognitive impairments and event-related potential (ERP) abnormalities seen in schizophrenia. In Chapter 5, we expect that biperiden will disrupt learned irrelevance (LIrr) and ERPs in healthy volunteers. Chapter 6 describes the interaction between muscarinic antagonists scopolamine and biperiden, and the cholinesterase inhibitor donepezil on sensory gating in the rat. We anticipate a disruption of sensory gating after both scopolamine and biperiden, and reversal by donepezil. However, in line with their respective binding affinities we hypothesize that scopolamine will affect auditory processing more severely than biperiden (i.e., beyond a deficit in sensory gating). Chapter 7 explores the effects of biperiden and rivastigmine on sensory gating and mismatch negativity in young, healthy participants. Again, we expect that biperiden will disrupt auditory processing, sensory gating and mismatch negativity (MMN), and that rivastigmine will reverse these effects. Finally, Chapter 8 gives an overview and general of the main findings of this dissertation; suggestions for future research are provided. 
Table 1. Muscarinic receptor subtypes: signaling, expression, and disease relevance (modified from: Caulfield, 1993; Flynn et al., 1997; Langmead et al., 2008).

\begin{tabular}{|c|c|c|c|c|c|}
\hline \multirow{2}{*}{ Characteristics } & \multicolumn{5}{|c|}{ Muscarinic receptor subtype } \\
\hline & $\mathrm{M}_{1}$ & $\mathbf{M}_{2}$ & $M_{3}$ & $M_{4}$ & $M_{5}$ \\
\hline \multirow[t]{2}{*}{ Signaling cascade } & $\begin{array}{l}\mathrm{G}_{\mathrm{q}} \\
\text { (excitatory) }\end{array}$ & $\begin{array}{l}\mathrm{G}_{\mathrm{i} / \mathrm{o}} \\
\text { (inhibitory) }\end{array}$ & $\begin{array}{l}\mathrm{G}_{\mathrm{q}} \\
\text { (excitatory) }\end{array}$ & $\begin{array}{l}\mathrm{G}_{\mathrm{i} / \mathrm{o}} \\
\text { (inhibitory) }\end{array}$ & $\begin{array}{l}\mathrm{G}_{\mathrm{q}} \\
\text { (excitatory) }\end{array}$ \\
\hline & $\begin{array}{l}\text { Post-synaptic, } \\
\text { presynaptic in } \\
\text { striatum }\end{array}$ & Presynaptic & $\begin{array}{l}\text { Pre- and postsy- } \\
\text { naptic }\end{array}$ & $\begin{array}{l}\text { Pre- and } \\
\text { postsynaptic }\end{array}$ & Postsynaptic \\
\hline $\begin{array}{l}\text { Central expres- } \\
\text { sion }\end{array}$ & $\begin{array}{l}\text { Cortex, hippo- } \\
\text { campus, } \\
\text { amygdala, } \\
\text { striatum }\end{array}$ & $\begin{array}{l}\text { Basal fore- } \\
\text { brain/septum, } \\
\text { cortex, striatum, } \\
\text { thalamus, } \\
\text { hypothalamus, } \\
\text { pons, cerebel- } \\
\text { lum }\end{array}$ & $\begin{array}{l}\text { Relatively low } \\
\text { abundance but } \\
\text { widely } \\
\text { distributed in } \\
\text { the brain (e.g., } \\
\text { cortex, hippo- } \\
\text { campus, thala- } \\
\text { mus) }\end{array}$ & $\begin{array}{l}\text { Striatum, also } \\
\text { low presence } \\
\text { in cortex and } \\
\text { hippocampus }\end{array}$ & $\begin{array}{l}\text { Low abun- } \\
\text { dance, particu- } \\
\text { larly, substantia } \\
\text { nigra }\end{array}$ \\
\hline $\begin{array}{l}\text { Peripheral ex- } \\
\text { pression }\end{array}$ & $\begin{array}{l}\text { Endothelial } \\
\text { cells in vascu- } \\
\text { lar tissue }\end{array}$ & $\begin{array}{l}\text { Smooth muscle } \\
\text { tissue at respira- } \\
\text { tory, vascular, } \\
\text { and gastrointes- } \\
\text { tinal sites, heart }\end{array}$ & $\begin{array}{l}\text { Salivary glands, } \\
\text { smooth muscle } \\
\text { tissue at pupil- } \\
\text { lary, respiratory, } \\
\text { vascular, and } \\
\text { gastrointestinal } \\
\text { sites }\end{array}$ & Spinal cord & $\begin{array}{l}\text { Little data, } \\
\text { likely low } \\
\text { expression but } \\
\text { widely distrib- } \\
\text { uted }\end{array}$ \\
\hline Disease relevance & $\begin{array}{l}\text { Alzheimer's } \\
\text { disease, } \\
\text { schizophrenia, } \\
\text { cognitive } \\
\text { dysfunction }\end{array}$ & $\begin{array}{l}\text { Alzheimer's } \\
\text { disease, cogni- } \\
\text { tive dysfunction, } \\
\text { pain }\end{array}$ & $\begin{array}{l}\text { Urinary inconti- } \\
\text { nence, chronic } \\
\text { obstructive } \\
\text { pulmonary } \\
\text { disorder, irrita- } \\
\text { ble bowel } \\
\text { syndrome }\end{array}$ & $\begin{array}{l}\text { Parkinson's } \\
\text { disease, } \\
\text { schizophrenia, } \\
\text { pain }\end{array}$ & $\begin{array}{l}\text { Drug depend- } \\
\text { ence, Parkin- } \\
\text { son's disease, } \\
\text { schizophrenia }\end{array}$ \\
\hline
\end{tabular}




\section{REFERENCES}

Baldeweg, T., Klugman, A., Gruzelier, J., \& Hirsch, S. R. (2004). Mismatch negativity potentials and cognitive impairment in schizophrenia. Schizophrenia Research, 69, 203-217.

Barak, S., \& Weiner, I. (2009). Towards an animal model of an antipsychotic drug-resistant cognitive impairment in schizophrenia: Scopolamine induces abnormally persistent latent inhibition, which can be reversed by cognitive enhancers but not by antipsychotic drugs. The International Journal of Neuropsychopharmacology, 12, 227-241.

Bartus, R. T., Dean, R. L., Beer, B., \& Lippa, A. S. (1982). The cholinergic hypothesis of geriatric memory dysfunction. Science, 217, 408-417.

Bartus, R. T., Dean, R. L., Pontecorvo, M. J., \& Flicker, C. (1985). The cholinergic hypothesis: a historical overview, current perspective, and future directions. Annals of the New York Academy of Sciences, 444, 332-358.

Baxter, M., \& Gallagher, M. (1996). Intact spatial learning in both young and aged rats following selective removal of hippocampal cholinergic input. Behavioral Neuroscience, 110, 460-467.

Baxter, M. G., Holland, P. C., \& Gallagher, M. (1997). Disruption of decrements in conditioned stimulus processing by selective removal of hippocampal cholinergic input. The Journal of Neuroscience, 17, 5230-5236.

Baxter, M. G., \& Murg, S. L. (2002). The basal forebrain cholinergic system and memory: Beware of dogma. In L. R. Squire \& D. L. Schacter (Eds.), Neuropsychology of memory (3rd ed., pp. 425-436). New York, NY: Guilford Press.

Bolden, C., Cusack, B., \& Richelson, E. (1992). Antagonism by antimuscarinic and neuroleptic compounds at the five cloned human muscarinic cholinergic receptors expressed in Chinese hamster ovary cells. The Journal of Pharmacology and Experimental Therapeutics, 260, 576-580.

Boutros, N. N., Korzyukov, O., Jansen, B., Feingold, A., \& Bell, M. (2004). Sensory gating deficits during the mid-latency phase of information processing in medicated schizophrenia patients. Psychiatry Research, 126, 203-215.

Bowen, D. M., Smith, C. B., White, P., \& Davison, A. N. (1976). Neurotransmitter-related enzymes and indices of hypoxia in senile dementia and other abiotrophies. Brain, 99, 459-496.

Bradley, S. R., Lameh, J., Ohrmund, L., Son, T., Bajpai, A., Nguyen, D., et al. (2010). AC-260584, an orally bioavailable $\mathrm{M}(1)$ muscarinic receptor allosteric agonist, improves cognitive performance in an animal model. Neuropharmacology, 58, 365-373.

Brooks, J. M., Sarter, M., \& Bruno, J. P. (2011). Transient inactivation of the neonatal ventral hippocampus permanently disrupts the mesolimbic regulation of prefrontal cholinergic transmission: Implications for schizophrenia. Neuropsychopharmacology, 36, 2477-2487.

Calabresi, P., Picconi, B., Parnetti, L., \& Di Filippo, M. (2006). A convergent model for cognitive dysfunctions in Parkinson's disease: the critical dopamine-acetylcholine synaptic balance. Lancet Neurology, 5, $974-$ 983.

Caulfield, M. P. (1993). Muscarinic receptors - characterization, coupling and function. Pharmacology \& Therapeutics, 58, 319-379.

Chiba, A. A., Bushnell, P. J., Oshiro, W. M., \& Gallagher, M. (1999). Selective removal of cholinergic neurons in the basal forebrain alters cued target detection. Neuroreport, 10, 3119-3123.

Crook, J. M., Tomaskovic-Crook, E., Copolov, D. L., \& Dean, B. (2001). Low muscarinic receptor binding in prefrontal cortex from subjects with schizophrenia: A study of Brodmann's areas 8, 9, 10, and 46 and the effects of neuroleptic drug treatment. American Journal of Psychiatry, 158, 918-925.

Crook, J. M., Tomaskovic-Crook, E., Copolov, D.L., \& Dean, B. (2000). Decreased muscarinic receptor binding in subjects with schizophrenia: A study of the human hippocampal formation. Biological Psychiatry, 48, 381-388.

Cummings, J. L. (2000). Cognitive and behavioral heterogeneity in Alzheimer's disease: seeking the neurobiological basis. Neurobiology of Aging, 21, 845-861.

Dean, B., Crook, J. M., Opeskin, K., Hill, C., Keks, N., \& Copolov, D. L. (1996). The density of muscarinic $M_{1}$ receptors is decreased in the caudate-putamen of subjects with schizophrenia. Molecular Psychiatry, 1, 54-58.

Dean, B., Crook, J. M., Pavey, G., Opeskin, K., \& Copolov, D. L. (2000). Muscarinic ${ }_{1}$ and $_{2}$ receptor mRNA in the human caudate-putamen: No change in m1 mRNA in schizophrenia. Molecular Psychiatry, 5, 203-207. 
Deng, C., \& Huang, X. (2005). Decreased density of muscarinic receptors in the superior temporal gyrus in schizophrenia. Journal of Neuroscience Research, 81, 883-890.

Drevets, W. C., Price, J. L., \& Furey, M. L. (2008). Brain structural and functional abnormalities in mood disorders: implications for neurocircuitry models of depression. Brain Structure and Function, 213, 93118.

Ebert, U., \& Kirch, W. (1998). Scopolamine model of dementia: electroencephalogram findings and cognitive performance. European Journal of Clinical Investigation, 28, 944-949.

Eglen, R. M. (2006). Muscarinic receptor subtypes in neuronal and non-neuronal cholinergic function. Autonomic and Autacoid Pharmacology, 26, 219-233.

Flood, J. F., \& Cherkin, A. (1986). Scopolamine effects on memory retention in mice: a model of dementia? Behavioral and Neural Biology, 45, 169-184.

Flynn, D. D., Reever, C. M., \& Ferrari-DiLeo, G. (1997). Pharmacological strategies to selectively label and localize muscarinic receptor subtypes. Drug Development Research, 40, 104-116.

Gilles, C., \& Luthringer, R. (2007). Pharmacological models in healthy volunteers: their use in the clinical development of psychotropic drugs. Journal of Psychopharmacology, 21, 272-282.

Gustavsson, A., Svensson, M., Jacobi, F., Allgulander, C., Alonso, J., Beghi, E., et al. (2011). Cost of disorders of the brain in Europe 2010. European Neuropsychopharmacology, 21, 718-779.

Hasselmo, M. E. (1999). Neuromodulation: Acetylcholine and memory consolidation. Trends in Cognitive Sciences, 3, 351-359.

Hasselmo, M. E. (2006). The role of acetylcholine in learning and memory. Current Opinion in Neurobiology, $16,710-715$.

Hasselmo, M. E., Bodelón, C., \& Wyble, B. P. (2002). A proposed function for hippocampal theta rhythm: Separate phases of encoding and retrieval enhance reversal of prior learning. Neural Computation, 14, 793-817.

Hasselmo, M. E., \& McGaughy, J. (2004). High acetylcholine levels set circuit dynamics for attention and encoding and low acetylcholine levels set dynamics for consolidation. Progress in Brain Research, 145, 207-231.

Javitt, D. C., Spencer, K. M., Thaker, G. K., Winterer, G., \& Hajós, M. (2008). Neurophysiological biomarkers for drug development in schizophrenia. Nature reviews Drug Discovery, 7, 68-83.

Johnstone, E. C., Crow, T. J., Ferrier, I. N., Frith, C. D., Owens, D. G. C., Bourne, R. C., et al. (1983). Adverse effects of anticholinergic medication on positive schizophrenic symptoms. Psychological Medicine, 13, 513-527.

Kandel, E. R., Schwartz, J. H., \& Jessell, T. M. (2000). Principles of neural science (4th ed.). New York, NY: McGraw-Hill.

Katayama, S., Ishizaki, F., Yamamura, Y., Khoriyama, T., \& Kito, S. (1990). Effects of anticholinergic antiparkinsonian drugs on binding of muscarinic receptor subtypes in rat brain. Research Communications in Chemical Pathology and Pharmacology, 69, 261-270.

Langmead, C. J., Watson, J., \& Reavill, C. (2008). Muscarinic acetylcholine receptors as CNS drug targets. Pharmacology \& Therapeutics, 117(2), 232-243.

Leiser, S. C., Dunlop, J., Bowlby, M. R., \& Devilbiss, D. M. (2011). Aligning strategies for using EEG as a surrogate biomarker: A review of preclinical and clinical research. Biochemical Pharmacology, 81, 1408-1421.

Levin, E. D., \& Buccafusco, J. J. (2006). Animal models of cognitive impairment. Boca Raton, FL: CRC Press.

Light, G. A., \& Braff, D. L. (2005). Mismatch negativity deficits are associated with poor functioning in schizophrenia patients. Archives of General Psychiatry, 62, 127-136.

Lijffijt, M., Lane, S. D., Meier, S. L., Boutros, N. N., Burroughs, S., Steinberg, J. L., et al. (2009). P50, N100 and P200 sensory gating: Relationships with behavioral inhibition, attention, and working memory. Psychophysiology, 46, 1059-1068.

McGaughy, J., Everitt, B. J., Robbins, T. W., \& Sarter, M. (2000). The role of cortical cholinergic afferent projections in cognition: impact of new selective immunotoxins. Behavioural Brain Research, 115, 251 263.

Mesulam, M. M. (1990). Human brain cholinergic pathways. Progress in Brain Research, 84, 231-241.

Mesulam, M. M., Mufson, E. J., Wainer, B. H., \& Levey, A. I. (1983). Central cholinergic pathways in the rat: an overview based on an alternative nomenclature (ch1-ch6). Neuroscience, 10, 1185-1201. 
Newell, K. A., Zavitsanou, K., Kum Jew, S., \& Huang, X. (2007). Alterations of muscarinic and GABA receptor binding in the posterior cingulate cortex in schizophrenia. Progress in Neuro-Psychopharmacology \& Biological Psychiatry, 31, 225-233.

Orosz, A., Feldon, J., Gal, G., Simon, A., \& Cattapan-Ludewig, K. (2008). Deficient associative learning in drugnaive first-episode schizophrenia: Results obtained using a new visual within-subjects learned irrelevance paradigm. Behavioural Brain Research, 193, 101-107.

Patterson, J. V., Hetrick, W. P., Boutros, N. N., Jin, Y., Sandman, C., Stern, H., et al. (2008). P50 sensory gating ratios in schizophrenics and controls: a review and data analysis. Psychiatry Research, 158, 226-247.

Perry, E. K., Perry, R. H., Blessed, G., \& Tomlinson, B. E. (1977). Necropsy evidence of central cholinergic deficits in senile dementia. Lancet, 1(8004), 189.

Sadock, B. J., Sadock, V. A., \& Ruiz, P. (2009). Comprehensive textbook of psychiatry (9th ed.). Philadelphia, PA: Lippincott Williams \& Wilkins.

Sarter, M., Bruno, J.P., \& Givens, B. (2003). Attentional functions of cortical cholinergic inputs: What does it mean for learning and memory? Neurobiology of Learning and Memory, 80, 245-256.

Sarter, M., Hasselmo, M. E., Bruno, J. P., \& Givens, B. (2005). Unraveling the attentional functions of cortical cholinergic inputs: interactions between signal-driven and cognitive modulation of signal detection. Brain Research Reviews, 48, 98-111.

Sarter, M., Lustig, C., \& Taylor, S. F. (2012). Cholinergic contributions to the cognitive symptoms of schizophrenia and the viability of cholinergic treatments. Neuropharmacology, 62, 1544-1553.

Sarter, M., Parikh, V., \& Howe, W. M. (2009). Phasic acetylcholine release and the volume transmission hypothesis: Time to move on. Nature Reviews Neuroscience, 10, 383-390.

Scarr, E., Cowie, T. F., Kanellakis, S., Sundram, S., Pantelis, C., \& Dean, B. (2008). Decreased cortical muscarinic receptors define a subgroup of subjects with schizophrenia. Molecular Psychiatry, 14, 1017-1023.

Scarr, E., Sundram, S., Keriakous, D., \& Dean, B. (2007). Altered hippocampal muscarinic M4, but not M1, receptor expression from subjects with schizophrenia. Biological Psychiatry, 61, 1161-1170.

Tandon, R., DeQuardo, J. R., Goodson, J., Mann, N. A., \& Greden, J. F. (1992). Effect of anticholinergics on positive and negative symptoms in schizophrenia. Psychopharmacology Bulletin, 28, 297-302.

Tandon, R., Mann, N. A., Eisner, W. H., \& Coppard, N. (1990). Effect of anticholinergic medication on positive and negative symptoms in medication-free schizophrenic patients. Psychiatry Research, 31, 235-241.

Tandon, R., Shipley, J. E., Greden, J. F., Mann, N. A., Eisner, W. H., \& Goodson, J. (1991). Muscarinic cholinergic hyperactivity in schizophrenia: Relationship to positive and negative symptoms. Schizophrenia Research, 4, 23-30.

Tandon, R., Taylor, S.F., DeQuardo, J.R., Eiser, A., Jibson, M.D., \& Goldman, M. (1999). The cholinergic system in schizophrenia reconsidered: Anticholinergic modulation of sleep and symptom profiles. Neuropsychopharmacology, 21, S189-S202.

Torres, E. M., Perry, T. A., Blokland, A., Wilkinson, L. S., Wiley, R. G., Lappi, D. A., et al. (1994). Behavioural, histochemical and biochemical consequences of selective immunolesions in discrete regions of the basal forebrain cholinergic system. Neuroscience, 63, 95-122.

Toyomaki, A., Kusumi, I., Matsuyama, T., Kako, Y., Ito, K., \& Koyama, T. (2008). Tone duration mismatch negativity deficits predict impairment of executive function in schizophrenia. Progress in NeuroPsychopharmacology \& Biological Psychiatry, 32, 95-99.

Volpicelli, L. A., \& Levey, A. I. (2004). Muscarinic acetylcholine receptor subtypes in cerebral cortex and hippocampus. Progress in Brain Research, 145, 59-66.

Voytko, M. L. (1996). Cognitive functions of the basal forebrain cholinergic system in monkeys: memory or attention. Behavioural Brain Research, 75, 13-25.

Whitehouse, P. J., Price, D. L., Struble, R. G., Clark, A. W., Coyle, J. T., \& Delon, M. R. (1982). Alzheimer's disease and senile dementia: loss of neurons in the basal forebrain. Science, 215, 1237-1239.

Zavitsanou, K., Katsifis, A., Mattner, F., \& Huang, X. (2004). Investigation of M1/M4 muscarinic receptors in the anterior cingulate cortex in schizophrenia, bipolar disorder, and major depression disorder. Neuropsychopharmacology, 29, 619-625. 
CHAPTER 2

\section{The validity of scopolamine as a pharmacological model for cognitive impairment:} A review of animal behavioral studies 


\section{INTRODUCTION}

\section{Short historic overview}

In ancient times people already knew that certain plant extracts possess the capability to influence the mental state of an individual (Schultes \& Hofmann, 1979). The extracts of several herbs and plants like Belladonna, Mandrake, Datura and Henbane were used to make "magic potions" which could induce delusional states of the mind. After ingestion, most individuals would lose all sense of reality and afterwards could not recall what occurred during the time of intoxication. Furthermore, Belladonna extract was used in the Middle Ages by women who wished to increase their attractiveness by pupil dilation. Much later it was discovered that these herbs and plants contain a relatively high concentration of tropan alkaloids such as atropine, hyoscyamine and scopolamine hydrobromide (hereafter abbreviated as scopolamine), which are the active ingredients responsible for inducing hallucinations.

Of these tropan alkaloids, the non-selective muscarinic antagonist scopolamine has frequently been employed in the clinic, mainly to inhibit the effects of parasympathic activation (Brown \& Taylor, 1996; see also Safer \& Allen, 1971). However, there exists a multitude of other clinical applications of this compound. For instance, the amnesic properties of scopolamine were already noticed at the beginning of this century (Gaus, 1906; Thompson \& Cotterill, 1909) and therefore the substance was employed for obstetrical analgesia. Moreover, in 1874 the use of belladonna to antagonize Parkinsonism tremor was reported. A fourth well-known application of scopolamine is the alleviation of motion sickness (Klöcker et al., 2001; Parrott, 1989). Besides being employed in a clinical setting, scopolamine has also been used to facilitate interrogation (Geis, 1961).

Traditionally, scopolamine has been used in the field of neuropsychopharmacology as a standard/reference drug for inducing age- and dementia-related cognitive deficits in healthy humans and animals (Ebert \& Kirch, 1998; Flood \& Cherkin, 1986). Interestingly, the clinical observation that scopolamine treatment as a premedication for anesthesia frequently gave rise to amnesia stimulated research on the effects of cholinergic blockade on human memory (see Hardy \& Wakely, 1962; Kopelman, 1986). The use of scopolamine as a pharmacological model of cholinergic amnesia became very popular after the cholinergic hypothesis of geriatric memory dysfunction was postulated (Bartus et al., 1982). This hypothesis assumed that the age-related decline in cognitive functions was predominantly related to a decrease in the integrity of cholinergic neurotransmission. Since scopolamineinduced amnesia was most likely caused by a blockade of cholinergic signaling, it was used to model cognitive deficits associated with aging and (Alzheimer's) dementia (Flood \& Cherkin, 1986). The first experimental studies that evaluated the effects of scopolamine on cognitive functions in man were published in the early seventies (e.g., Crow \& Grove-White, 1973; Safer \& Allen, 1971). Drachman and Leavitt (1974) were the first who claimed that, when given to healthy volunteers, scopolamine mimicked many of the cognitive dysfunctions that could be observed in aging and dementia.

The significance of scopolamine use in humans also gave rise to studies in the field of animal research. The first experiments that investigated the central effects of scopolamine in animals were reported in the 1950's (e.g., Boren \& Navarro, 1959; Hearst, 1959). Scopolamine was employed to assess the role of the cholinergic system in non-specific types of behavior such as the rate of responding in operant tasks. Muscarinic antagonists such as 
scopolamine were presumed to induce behavioral disinhibition ${ }^{2}$ (Carlton, 1963). Later studies have employed scopolamine as a golden standard drug to validate new test models of cognitive function (Ennaceur \& Meliani, 1992), and to investigate the role of the cholinergic system in cognition - for instance by testing its interaction with other drugs (Levin, 1988) and specific brain lesions (Chudasama et al., 2004). These experiments supported the notion that scopolamine induced impairments in a wide variety of cognitive-behavioral tasks (Chintoh et al., 2003; Estapé, 2002; Flood \& Cherkin, 1986; Hodges Jr. et al., 2009; Hughes et al., 2004; Ison \& Bowen, 2000; Nomura et al., 1994; Robinson et al., 2004; Sambeth et al., 2007). Another important objective in which scopolamine has often been used is the preclinical testing of new substances that are designed to treat cognitive dysfunction (Snyder et al., 2005). Thus, if a compound is effective in reversing scopolamine-induced cognitive deficits in animals, it might also improve cognitive function in healthy participants or people diagnosed with a neuropsychiatric disorder. One of the advantages of the scopolamine model is that it provides a simple and quick way for testing cognition-enhancing properties of new drugs. However, this type of approach in preclinical screening of novel substances is associated with limited predictive validity, as it tends to yield a high number of false positives (i.e., drugs that were found to counteract scopolamine-induced deficits in preclinical research often do not have the same efficacy in clinical studies: Sarter, 2006).

\section{The cholinergic hypothesis}

A more recent hypothesis regarding the role of acetylcholine in learning and memory processes has been put forward (Hasselmo, 1999, 2006; Hasselmo et al., 2002; Hasselmo \& McGaughy, 2004; Meeter et al., 2004). It has been suggested that acetylcholine plays an important role in hippocampal mode shifting between encoding and retrieval. Specifically, a network model has been proposed which features the entorhinal cortex, dentate gyrus, CA3, CA1 and the medial septum (Meeter et al., 2004). In this model, high acetylcholine would allow acquisition of new information to take place, while low acetylcholine would enable recall of previously stored memories (Hasselmo \& McGaughy, 2004). Hence, encoding should be impaired by decreases in acetylcholine and consolidation, and retrieval is likely to be affected by increases in acetylcholine. Support in favor of this hypothesis is the finding that scopolamine predominantly impairs acquisition processes and can even facilitate consolidation (e.g., Winters et al., 2006; 2007; 2008; Young et al., 1995). Moreover, in a delayed non-matching to sample task intraseptal infusion of the cholinergic agonist carbachol 30 min. prior to the sample was found to have no effect on performance. In contrast, infusion immediately or $90 \mathrm{~min}$. after the sample produced amnesia (Bunce et al., 2004).

However, the cholinergic hypothesis of memory function as originally put forward by Bartus et al. (1982) has undergone a revision after several lesion studies were performed which used the highly specific cholinergic toxin 192 IgG-saporin (Wiley et al., 1995). This immunotoxin is a combination of a ribosome inactivating protein (saporin, which is derived from the plant Saponaria officinalis) and a monoclonal antibody (192 igG) which acts on the low- affinity nerve growth factor (NGF) receptor p75 (Wiley et al., 1991). Saporin is a toxin

\footnotetext{
${ }^{2}$ At the time it was believed that the cholinergic system served to inhibit an activating system. Hence, reducing cholinergic neurotransmission by administration of a muscarinic antagonist would disinhibit this activating system and cause behavioral activation/disinhibition.
} 
which enzymatically shuts down ribosome protein synthesis, leading to cell death (Wrenn \& Wiley, 1998). The addition of 192 IgG to saporin enables the induction of selective cholinergic basal forebrain lesions in rats, as only the cholinergic neurons in this brain area express the p75 receptor (Wenk, 1997). However, animals that were lesioned with this toxin did not show clear learning and memory impairments and hence it appeared that the influence of acetylcholine was more subtle than assumed (e.g., Baxter \& Gallagher, 1996; Baxter et al., 1997; Chiba et al., 1999; McGaughy et al., 2000; Torres et al., 1994; Voytko, 1996). Furthermore, it was found that attention tests tended to be relatively more sensitive to treatment by scopolamine as compared to learning and memory tasks (Hodges Jr. et al., 2009; Humby et al., 1999; Jones et al., 1995; Jones \& Higgins, 1995; Mirza, 2000; Shannon \& Eberle, 2006). Indeed, scopolamine disrupted performance in these tasks at much lower doses than those which were effective in learning and memory tests. It was concluded that acetylcholine is mainly involved in attentional processes (Blokland, 1995; Everitt \& Robbins, 1997; Fibiger, 1991; Sarter \& Bruno, 1997).

Apart from the role of acetylcholine in cognition, this neurotransmitter has also been strongly implicated in optimization of the signal-to-noise ratio in the parietal and visual striate cortex (Murphy \& Sillito, 1991; Sato et al., 1987), a feature which is deemed essential for stimulus processing. For instance, in rats that were performing a sustained attention task, cholinergic deafferentiation was found to diminish the neuronal activation of detected cues and enhance neuronal activity to distractor stimuli in neurons in the posterior parietal cortex (Broussard et al., 2009). According to the authors, this implicated an important modulatory role of acetylcholine in the detection and processing of relevant stimuli and the inhibitory suppression of irrelevant cues under attentionally challenging conditions. Moreover, it has been reported that increasing acetylcholine levels with donepezil reduces the spatial spread of excitatory visual responses in human visual cortex, which was suggested to be caused by a facilitation of thalamocortical synaptic transmission and/or suppression of intracortical connections (Silver et al., 2008). These effects were interpreted by the authors to be consistent with a role of acetylcholine in reducing excitatory receptive field size of cortical neurons in animals. Furthermore, it was reported that attending to the particular receptive field of a $\mathrm{V} 1$ neuron caused an increase in firing rate, which was enhanced by low doses of acetylcholine and modulated by the muscarinic antagonist scopolamine, but not by the nicotinic antagonist mecamylamine (Herrerro et al., 2008). These results thus demonstrated an important role for muscarinic but not nicotinic receptor mechanisms in cholinergic attentional modulation.

These recent notions concerning the function of acetylcholine have, of course, direct consequences for interpreting effects of scopolamine on cognition. Scopolamine is a relatively specific antagonist of muscarinic receptors, i.e. not nicotinic at low doses (Schmeller et al., 1995; Weiner, 1980), and its effects should most likely be interpreted within a cholinergic framework. In conclusion, acetylcholine seems to be primarily involved in attentional processes (Blokland, 1995; Everitt \& Robbins, 1997; Fibiger, 1991; Sarter \& Bruno, 1997) and plasticity of sensory neurons (Rasmusson, 2000). This constitutes a shift from the claims of the cholinergic hypothesis of learning and memory in the early eighties (Bartus et al., 1982; 1985) and from the relatively more restrictive hypothesis which was put forward more recently (Hasselmo, 1999; 2006; Hasselmo \& McGaughy, 2004; Parikh et al., 2007). 


\section{AIM AND SCOPE OF THIS REVIEW}

The current review provides a summary of the effects of scopolamine on animal behavior. First, the general properties of scopolamine and effects of this drug on non-behavioral measures will be discussed. Next, an overview will be given of behavioral studies which have assessed the effects of peripheral and central administration of scopolamine. Finally, the validity of scopolamine as a pharmacological model for inducing cognitive impairment will be debated and muscarinic $M_{1}$ antagonists will be introduced as a more selective and hence, more effective way of inducing cognitive deficits due to cholinergic blockade. Since scopolamine can be viewed as the golden standard for inducing cholinergic impairments, it was decided to put the focus of the review on this compound. Discussion of non-selective muscarinic drugs other than scopolamine is beyond the scope of this review (with the exception of selective muscarinic $M_{1}$ antagonists which will be put forward as an alternative for scopolamine). The specific characteristics of various drugs (e.g., blood brain barrier penetration, central versus peripheral effects, duration of action) may lead to differences in the effects of these ligands on cognition, which may therefore complicate interpretation of the outcome of different studies. In short, in the field of neuropsychopharmacology several additional non-selective muscarinic antagonists have been used besides scopolamine. For instance, atropine has also been frequently employed in behavioral studies, although less often than scopolamine. Atropine is less potent than scopolamine (about a factor 10, depending on assay), but in general effects on task performance are highly comparable between both compounds.

An additional restriction was made with respect to the type of experiments which were included in this review. Reference is made to studies which primary aim was to investigate the effects of scopolamine (or selective muscarinic $M_{1}$ antagonists) on cognition and behavior. Consequently, studies which have employed non-behavioral parameters (such as invitro and/or imaging experiments) will only be discussed very superficially. Moreover, no extensive review is given of experiments in which pharmacological reversal of scopolamineinduced impairment is investigated. Since a vast amount of studies on scopolamine has accumulated over the past 40 years, it would be impossible to refer to all of them. Nevertheless, it is our opinion that the most important and influential articles have been included in the present review.

\section{GENERAL PROPERTIES OF SCOPOLAMINE}

\section{Biochemical characteristics of scopolamine}

Scopolamine has generally been regarded as a non-selective muscarinic receptor antagonist (Bolden et al., 1992). The affinity of scopolamine to bind to the muscarinic receptor is about $1 \mathrm{nM}$ in the brain of rats (Lee \& El Fakahany, 1985). Furthermore, it has been demonstrated that scopolamine has a high selectivity for the muscarinic receptor (Hulme et al., 1978), although high doses of scopolamine can also block nicotinic receptors (Schmeller et al., 1995; Weiner, 1980). Currently, five different subtypes of muscarinic receptors have been characterized (Caulfield, 1993). This differentiation in muscarinic receptors was discovered after finding discrepancies in the binding characteristics of several ligands (e.g., scopolamine, pirenzepine: Messer et al., 1987). Pharmacological methods provided evi- 
dence for the existence of three receptor subtypes $\left(M_{1}, M_{2}\right.$ and $M_{3}$, see Waelbroeck et al., 1986), whereas the fourth and fifth muscarinic receptor subtypes were discovered only after molecular tools became available (Yasuda et al., 1992). All muscarinic receptors are Gprotein coupled receptors: $M_{1}, M_{3}$ and $M_{5}$ are linked to $G_{q}$ which activates phospholipase-C, whereas $M_{2}$ and $M_{4}$ are coupled to $G_{i / o}$ and can affect adenylyl cyclase or various ion channels (Conn et al., 2009). The $\mathrm{M}_{2}$ and $\mathrm{M}_{3}$ receptors are located presynaptically (Caulfield, 1993), where they act as autoreceptors to regulate neurotransmitter release (Bymaster et al., 2003). The orthosteric binding sites, to which acetylcholine and several muscarinic compounds bind, have been well characterized (Caulfield, 1993; Caulfield \& Birdsall, 1998). However, allosteric muscarinic receptor sites are not as extensively defined; these sites could be interesting targets for the development of more selective muscarinic compounds which can modulate the activation of orthosteric muscarinic receptors by acetylcholine (Wess, 2005).

Table 1. Distribution of the different muscarinic subtypes in the brain and body (adapted from: Caulfield, 1993). Of note, no distinction was made between findings from studies using mRNA and anti-body techniques.

\begin{tabular}{|c|c|c|c|c|c|}
\hline \multirow[b]{2}{*}{ Brain area } & \multicolumn{5}{|c|}{ Central distribution of muscarinic receptor subtypes } \\
\hline & $\mathbf{M}_{1}$ & $\mathbf{M}_{2}$ & $\mathbf{M}_{3}$ & $\mathbf{M}_{4}$ & $M_{5}$ \\
\hline Basal forebrain/ septum & & $X X$ & & & \\
\hline Cortex & $x X$ & & $\mathrm{x}$ & $x$ & \\
\hline Hippocampus & $x x$ & $\mathrm{x}$ & $x$ & $x$ & $x$ \\
\hline Amygdala & $x$ & & & & \\
\hline \multirow[t]{2}{*}{ Striatum } & $x$ & $\mathrm{x}$ & $\mathrm{x}$ & $x X$ & \\
\hline & \multicolumn{5}{|c|}{ Peripheral distribution of muscarinic receptor subtypes } \\
\hline Peripheral tissues & $\overline{M_{1}}$ & $\mathbf{M}_{2}$ & $M_{3}$ & $\mathbf{M}_{4}$ & $M_{5}$ \\
\hline Heart & & $x X$ & & & \\
\hline Lung & & $x$ & $x$ & $x X$ & \\
\hline lleum & & $x$ & $X X$ & & \\
\hline Exocrine Glands & $\mathrm{x}$ & & $x X$ & & \\
\hline
\end{tabular}

$X$ : low/modest mRNA expression or immunoprecipitation.

$\mathrm{XX}$ : high/strong mRNA expression or immunoprecipitation.

Molecular biological studies revealed that there are five different genes responsible for the expression of muscarinic receptors, denoted $M_{1}-M_{5}$ (Bonner et al., 1987; 1988). Furthermore, each receptor subtype likely has its own specific functional role reflected by differences in physiological distribution. In Table 1 an overview is given of the localization of muscarinic receptors in the brain and body. Localization and distribution of these subtypes was determined using mRNA techniques and receptor subtype-specific antibodies. It appears that $M_{1}$ (and $M_{5}$ ) receptors are predominantly located in the brain, although a high immunoprecipitation of $M_{1}$ receptors has also been observed in the vas deferens (Caulfield, 1993). On the other hand, the $M_{2}, M_{3}$ and $M_{4}$ receptors seem to be evenly distributed throughout the body and the brain. Since scopolamine has no preference for any muscarinic subtype (Bolden et al., 1992), it non-selectively blocks the effects of acetylcholine at muscarinic receptors and thus affects several physiological functions. However, it appears 
that the central effects of scopolamine might be mediated by the $M_{1}$ and (possibly) $M_{5}$ receptors because of their specific distribution (Caulfield, 1993).

\section{PERIPHERAL VS. CENTRAL EFFECTS OF SCOPOLAMINE}

Most studies have used systemic injections (IV, IM, IP, SC) to investigate the effects of scopolamine, as this is a relatively easy manner to apply the drug. Unfortunately, systemic administration makes it difficult to differentiate between central and peripheral effects of a compound. In the case of scopolamine, one way to deal with this problem is to include an experimental group that is given methylscopolamine at an equivalent dose (Harvey et al., 1983). Methylscopolamine, or scopolamine methylbromide, is a quaternary form of scopolamine that has the same receptor binding characteristics but does not readily cross the blood-brain barrier (Pradhan \& Roth, 1968). The substance has been used as a control condition for the peripheral side effects of scopolamine hydrobromide treatment (Evans, 1975). Thus, if scopolamine hydrobromide impairs cognitive performance at a given dose and an equivalent dose of methylscopolamine does not, it can be assumed that the effects of the former are mediated by a central mechanism. In animal studies the use of methylscopolamine has been questioned, as it has been found to have an influence on measures of cognitive performance (e.g., Andrews et al., 1994; Herremans et al., 1995; Pakarinen \& Moerschbaecher, 1993; van Haaren \& van Hest, 1989). This would suggest that methylscopolamine can also have central actions, especially when high doses are used. A microdialysis study showed that methylscopolamine indeed increased cortical acetylcholine release, although it should be mentioned that this effect occured at relatively higher doses (factor 2-4) than those which are commonly used for administration of scopolamine hydrobromide (Moore et al., 1992). Although there exist a lot of studies that show no central/cognitive effects of methylscopolamine, abovementioned data caution against simply assuming that this compound can be used a tool to dissociate central and peripheral effects of scopolamine hydrobromide.

\section{NON-BEHAVIORAL EFFECTS OF SCOPOLAMINE}

\section{Pupil diameter, salivation and smooth muscle function}

It is well-known that scopolamine dilates the pupil and impairs the lens accommodation (Leopold \& Comroe, 1948), an effect likely to be mediated by the muscarinic $M_{3}$ receptor (Shiraishi \& Takayanagi, 1993). In a study by Jones and Higgins (1995), a dose-dependent increase in pupil size was found after scopolamine injections $(0.01-0.1 \mathrm{mg} / \mathrm{kg}, \mathrm{SC})$, which was already observed at a dose of $0.01 \mathrm{mg} / \mathrm{kg}$. Interestingly, methylscopolamine was approximately twice more effective in dilating the pupil than scopolamine hydrobromide, suggesting that the peripheral effects of the former are relatively more pronounced than those of the latter. Scopolamine-induced mydriasis could lead to a disruption of performance in visual discrimination tasks. For instance, due to an increased sensitivity to light, visual stimuli of relatively high intensity might be experienced as aversive (Leaton \& Kreindler, 1972). Alternatively, effects of scopolamine on pupil diameter could also improve 
performance on visual discrimination tasks: stimuli might be more easily perceived if they are presented very briefly or at a low illuminance.

Moreover, scopolamine reduces salivation which is probably mediated by cholinergic blockade at muscarinic $M_{3}$ receptors, but $M_{1}$ and $M_{5}$ receptors could also play a minor role (Dai et al., 1991; Flynn et al., 1997; Shannon et al., 1994; Shida et al., 1993; Tobin et al., 2002). Because of this dry mouth effect of scopolamine solid food rewards are likely to become more difficult to consume. This could decrease the palatability of dry food, which could in turn interfere with performance on behavioral tasks that rely on this type of reinforcer in order to motivate the animals. Indeed, scopolamine was reported to already decrease dry food consumption at a dose of $0.01 \mathrm{mg} / \mathrm{kg}$, but it was suggested that using a liquid reward could counteract this side-effect (Hodges Jr. et al., 2009).

In the respiratory, vascular and gastrointestinal system, $M_{2}$ and $M_{3}$ receptors appear to mediate contraction of smooth muscle (Eglen et al., 1996). In what way non-selective effects of scopolamine on peripheral smooth muscle functions disrupt behavioral performance has not been directly assessed. Nevertheless, high doses of scopolamine might induce gastrointestinal distress (e.g., constipation) or give rise to changes in cerebral blood flow and glucose consumption due to vasodilation/vasoconstriction, which in turn could interfere with behavioral performance.

\section{ELECTROENCEPHALOGRAM}

A great deal of research has been dedicated to the neurobiological mechanisms underlying the cortical electroencephalogram (EEG). One of the pacemakers of the cortical EEG appears to be the cholinergic system (see Brimblecombe, 1974; Dringenberg \& Vanderwolf, 1998). Muscarinic agonists have been found to activate the EEG in rats (i.e., low voltage fast activity; LVFA). On the other hand, scopolamine decreased the LVFA after a relative high dose $(5 \mathrm{mg} / \mathrm{kg}, \mathrm{IP})$ in anesthetized rats (Dringenberg \& Vanderwolf, 1997). However, a decrease in LVFA in rats has also been observed after administration of relatively lower doses of scopolamine $(0.8 \mathrm{mg} / \mathrm{kg}$ IP: Riekkinen et al., 1990) or after injecting it iontophoretically (applied $5^{*} 10^{-8} \mathrm{~A}$ ) into the cortex (Spehlmann \& Norcross, 1982). These effects seemed to be mediated by the ascending cholinergic fibers from the basal forebrain (Vanderwolf, 1988) and indicated that scopolamine gives rise to a cortical deactivating state. In addition, it appeared that scopolamine can also induce disturbances in gamma oscillations (Rodriguez et al., 2004). The effects of scopolamine $(0.1,0.2,0.5,1 \mathrm{mg} / \mathrm{kg}, \mathrm{SC}$ ) on eventrelated potentials (ERPs) have also been assessed. For instance, scopolamine reduced the amplitude of auditory evoked potentials (i.e., P18 and N40 components) in a dosedependent manner (Campbell et al., 1995), which again suggested that it tends to lower EEG activity. These results were replicated by a more recent study (Sambeth et al., 2007).

It appears to be quite a challenging task to relate animal EEG measures to behavioral data. For instance, a study by Sambeth et al. (2007) reported an impairment of object recognition, an increase of the theta frequency in the EEG and a change in the N1 and N2 components of the AEP closer to baseline after scopolamine treatment $(0.1 \mathrm{mg} / \mathrm{kg}, I P)$. Both the acetylcholinesterase inhibitor donepezil $(3 \mathrm{mg} / \mathrm{kg}, \mathrm{PO})$ and nicotine $(0.1 \mathrm{mg} / \mathrm{kg}, \mathrm{IP})$ reversed the impairment in object recognition. However, combination treatment of scopolamine $(0.1 \mathrm{mg} / \mathrm{kg}, \mathrm{IP})$ with donepezil $(3 \mathrm{mg} / \mathrm{kg}, \mathrm{PO})$ increased theta even more, whereas 
nicotine $(0.1 \mathrm{mg} / \mathrm{kg}, \mathrm{IP})$ reversed the scopolamine-induced increment of theta to placebo level. The clear dissociation between effects of drug combination treatments on memory and EEG suggests that the relation between these two measures is not straightforward.

In human participants scopolamine has been reported to increase delta and theta activity whilst decreasing alpha and beta frequency bands (Ebert \& Kirch, 1998), indicative of a general slowing of EEG activity. Scopolamine $(0.25-0.75 \mathrm{mg}, \mathrm{IM})$ was also found to reduce the amplitude and increase the latency of flash-VEP P2-N3 ERPs with no effect on pattern-VEPs (Bajalan et al., 1986; Sannita et al., 1993). Moreover, scopolamine decreased P3 amplitude of auditory evoked potentials (Meador et al., 1995). A few studies have examined the relation between effects of scopolamine on EEG power and memory performance. For instance, Sloan et al. (1992) found no correlation between slowing of EEG power and decreased word recall on a verbal memory task after scopolamine. In contrast, Kikuchi et al. (1999) reported a negative correlation between memory score and absolute delta and alpha-1 power, whereas relative alpha-1 power was negatively correlated and relative alpha-2 power positively correlated with mnemonic performance after scopolamine administration. Overall, large alpha and small theta power seems indicative of good cognitive performance (Klimesch, 1999), which is in concurrence with scopolamine-induced slowing of EEG activity and concomitant disruption of performance.

In conclusion, in both animals and humans scopolamine appears to decrease the power of higher frequency bands - i.e., LVFA in animals, alpha and beta frequencies in humans (Dringenberg \& Vanderwolf, 1997; Ebert \& Kirch, 1998). Moreover, scopolamine reduced the amplitude of auditory evoked potentials in rats and humans (Campbell et al., 1995; Meador et al., 1995), although it should be mentioned that ERPs are not directly comparable between the two species (Sambeth et al., 2003; 2004). Scopolamine is also found to disrupt cognitive performance in rats as well as in humans (Kikuchi et al., 1999; Sambeth et al., 2007; Sloan et al., 1992).

\section{BEHAVIORAL EFFECTS OF SCOPOLAMINE}

In Table 2 an overview is given of the effects of systemic administration of scopolamine in various behavioral paradigms. Studies on the effects of scopolamine on behavior and cognition have been sorted in reverse chronological order per behavioral test paradigm. Doses were peripherally administered in rats, mice, rabbits, Mongolian gerbils, cats, pigeons or monkeys. Table 3 provides an overview of the effects of scopolamine in different behavioral tasks after central administration. Studies on the effect of scopolamine on behavior and cognition have been sorted in reverse chronological order per targeted brain region and behavioral paradigm.

The discussion of the behavioral effects of scopolamine will be divided into five parts. The first part will deal with the effects of scopolamine on locomotor behavior and motor learning. In the following three sections the effects of scopolamine on anxiety, sensory/stimulus discrimination and attention will be discussed. Of note, although drug effects on the latter two functions cannot always be dissociated from one another, discussion of effects of scopolamine on sensory/stimulus discrimination vs. attention will be separated on basis of the claims made in the respective reports. Furthermore, effects on sensory or stimulus discrimination tests are usually strictly related to presentation of the stimulus, 
whereas effects on attentional tasks can also be attributed to other (non-)cognitive factors. The fifth section will discuss the effects of scopolamine on learning and memory.

\section{Locomotor activity and motor learning}

Scopolamine has been generally found to increase locomotor activity already at systemic doses of $0.056 \mathrm{mg} / \mathrm{kg}$ and higher (Chintoh et al., 2003; Day et al., 1991; Gholamreza et al., 2002; Nomura et al., 1994; Pradhan \& Roth, 1968; Renfro et al., 1972; Sipos et al., 1999; Watanabe \& Shimizu, 1989). Cholinergic signaling in the hippocampus, striatum and/or frontal cortex appeared to be correlated positively with scopolamine-induced hyperactivity (Day et al., 1991) and central infusion of scopolamine $(1,10 \mu \mathrm{g}$ in $0.5 \mu \mathrm{L} / \mathrm{side}$ ) in the amygdala was found to increase locomotor activity (Nomura et al., 1994). In contrast, several experiments which used memory and/or operant tasks have reported a decrease in locomotor activity after systemic administration of scopolamine (Anisman \& Kokkinidis, 1975; Besheer et al., 2001; Hodges Jr. et al., 2009; Masuoka et al., 2006; Myhrer et al., 2004; Pradhan \& Roth, 1968) or no effect at all (Feigley, 1974; Humby et al., 1999). Thus, the role of scopolamine in locomotor behaviour - i.e., an increase or a decrease in activity, appears to be dependent on various experimental factors (such as strain, test, type of reinforcment, drug doses, etc.). For instance, a recent study showed that the effect of scopolamine on general activity in light-dark boxes was dependent on room novelty and gender of the rats (Hughes et al., 2004). For the scope of the current review it is sufficient to note that possible effects of scopolamine on locomotor activity should be taken into account when evaluating the role of scopolamine in cognition, especially in tests in which locomotor activity is closely related to the main dependent variable (see also Anisman, 1975).

A recent study examined the role of scopolamine on motor skills and motor learning (Thouvarecq et al., 2001). It was shown that methylscopolamine $(0.6,1.2 \mathrm{mg} / \mathrm{kg}, \mathrm{SC}$ ) impaired the motor skills of mice whereas the same dose of scopolamine hydrobromide (0.6, $1.2 \mathrm{mg} / \mathrm{kg}, \mathrm{SC}$ ) did not. Moreover, motor learning was found to be affected by scopolamine hydrobromide but not by methylscopolamine. It was reported that motor skills were independent of motor learning, as no correlation between the scores was found. In conclusion, the dissociation between motor skills and motor learning on the one hand, and the dissociation between the effects of scopolamine hydrobromide and methylscopolamine on the other, would strongly suggest that scopolamine hydrobromide mainly affects motor learning abilities rather than motor skills.

\section{Anxiety}

The effects of scopolamine on anxiety-related behaviors have been investigated in a limited number of papers (Hughes et al., 2004; Smythe et al., 1996). Of note, the distinction between tasks assessing locomotor activity (as discussed above) and those measuring anxiety can be rather small, since these paradigms often use similar experimental setups (such as the open field). Therefore, when interpreting effects of scopolamine on performance in these paradigms, one should keep in mind that an underlying effect on locomotor behavior could be present. Nevertheless, special changes to the apparatus allow for making inferences with respect to anxiety. For instance, by dividing an open field in a dark and a bright compartment it is possible to measure the time animals spend in each of these sections. In a study that assessed light-dark preferences, it was reported that scopolamine $(2 \mathrm{mg} / \mathrm{kg}, \mathrm{IP})$ 
lowered the number of transitions to the light side (Hughes et al., 2004). Furthermore, in the black-white box, scopolamine $(0.05,0.1 \mathrm{mg} / \mathrm{kg}, \mathrm{IP})$ was found to increase anxietyrelated behavior on both activity-dependent as well as activity-independent parameters (Smythe et al., 1996). Thus, possible behavioral activating effects of the substance could be excluded. Moreover, the doses used in this study were much lower than those used in studies that reported behavioral activation. In the same experiment, infusion of scopolamine in the hippocampus $(15,30 \mu \mathrm{g}$ in $3 \mu \mathrm{l} /$ side) increased anxiogenic behavior in the black-white box, while locomotor activity was unaffected. In conclusion, scopolamine generally has an anxiogenic effect on behavior which should be taken into account when interpreting effects of this ligand in other behavioral tasks.

\section{Stimulus discrimination}

The manner in which stimulus discrimination can be studied and drug effects can be assessed in animal models has been thoroughly described in the review by Heise and Milar (1984). In this paper, great attention was devoted to the different ways in which stimulus discrimination could be investigated in animals and also to possible confounding factors that could lead to erroneous conclusions. For instance, it was suggested that assessments of drug effects on stimulus discrimination can be made more sensitive by interposing a delay between stimulus presentation and response phase. Although this procedure has mainly been used to examine memory functions (see section on learning and memory below), it can also be employed for the evaluation of drug effects on stimulus discrimination, i.e., discrimination is expected to be the strongest at the zero-delay and gradually declines as a function of the length of the delay (Heise \& Milar, 1984). Moreover, signal detection theory-derived measures would provide a valuable tool for the evaluation of drug effects on stimulus discrimination. Although the abovementioned arguments strongly support the use of this method, only few animal studies have actually done so.

Several studies have indicated that scopolamine can have differential effects on discrimination performance, as it has been reported to influence accuracy, response latency and missed trials (Drinkenburg et al., 1995). For instance, a study by Bushnell et al. (1997) showed that scopolamine $(0.03,0.056,0.1 \mathrm{mg} / \mathrm{kg}, \mathrm{SC})$ decreased $\mathrm{p}(\mathrm{hit})$ - an effect which was dependent on stimulus intensity, increased $p$ (false alarm), number of omissions and reaction time. An additional problem with interpreting effects of scopolamine on discrimination performance is the fact that the dose at which performance was impaired varied a lot between studies: effects on discrimination accuracy have been reported for doses between 0.005 (Kirk et al., 1988) and $2.0 \mathrm{mg} / \mathrm{kg}$ (Robinson et al., 2004). It has been suggested that this could be due to differences in salience between stimuli (Andrews et al., 1992), since discrimination of relatively non-salient stimuli appears to be more easily disrupted by scopolamine (Evans, 1975). However, task difficulty cannot fully account for all discrepancies that exist between experiments. Of note, scopolamine appears to not only influence visual discrimination (probably due to its peripheral effects on pupil diameter and lens accommodation), but also auditory discrimination (Ison \& Bowen, 2000; Jones, \& Shannon, 2000; Sipos et al., 2001; van Haaren \& van Hest, 1989), yet not olfactory discrimination (Doty et al., 2003). The second finding suggests that scopolamine can also influence central sensory processes. Indeed, studies which used central infusion of scopolamine have implicated the (dorsal) hippocampus (Brito et al., 1983; Carli et al., 1995; 1999) and periform, 
dorsomedial prefrontal and ventromedial prefrontal cortex (Broersen et al., 1995; Herremans et al., 1997; Wilson, 2001) in discrimination processes.

In summary, stimulus discrimination is very sensitive to scopolamine treatment, especially when delayed response tasks and/or signal detection theory-derived measures are used to analyze performance. However, it should be noted that not all studies have reported a scopolamine-induced discrimination deficit (Harder et al., 1998). Effects of scopolamine on missed trials and increased response latencies tend to be relatively more consistent. In particular, doses as low as 0.005 and $0.025 \mathrm{mg} / \mathrm{kg}$ were able to decrease the sensitivity parameter (Herremans et al., 1995; Kirk et al., 1988). Furthermore, effects of scopolamine on visual discrimination could be (partly) caused by pupil dilation (Leopold \& Comroe, 1948), and hence may not be necessarily caused by central cholinergic blockade only.

\section{Attention}

Several studies have specifically evaluated the effects of scopolamine on tasks that were developed to study attentional processes in rodents. A relatively older study by Cheal (1981) assessed the role of acetylcholine in memory vs. behavioral disinhibition vs. stimulus selection in gerbils. By using an object recognition test, it was determined that scopolamine treatment $(0.1-10 \mathrm{mg} / \mathrm{kg}, \mathrm{SC})$ did not affect memory performance, response inhibition or stimulus selection. However, based on the duration that the gerbils inspected the objects it was concluded that scopolamine probably impaired the maintenance of attention.

In the 5-choice serial reaction time task scopolamine $(0.03,0.075,0.1 \mathrm{mg} / \mathrm{kg}, \mathrm{SC})$ was found to impair performance accuracy under normal conditions (i.e., standard light intensity and no interfering stimuli) only at the highest dose tested: Jones \& Higgins, 1995). However, these effects became more apparent when a burst of white noise was introduced during the inter-trial interval. It was suggested that these data underscored the notion that the cholinergic system is involved in selective attention. Similar to the aforementioned studies, scopolamine $(0.075$ and $0.1 \mathrm{mg} / \mathrm{kg})$ also increased the number of missed trials. Subsequently, a revised version of the 5-choice serial reaction time task was developed which supposedly could dissociate drug effects on attentional vs. motivational or motor processes (Higgs et al., 2000). It was found that scopolamine $(0.03,0.075,0.1 \mathrm{mg} / \mathrm{kg}, \mathrm{IP}) \mathrm{did}$ not affect accuracy performance in this modified version. On the other hand, at a dose of $0.075 \mathrm{mg} / \mathrm{kg}$ a clear increase in response latency and number of omissions was observed. A detailed analysis of signaled vs. non-signaled trials indicated that the effects of scopolamine could not solely be due to attentional dysfunctions. These findings (i.e., relatively reliable effects of scopolamine on general performance measures but no consistent effects on discrimination accuracy parameters) have been corroborated by other experiments using the 5-choice serial reaction time task (Callahan et al., 1993; Higgs et al., 2000; Hodges Jr. et al., 2009; McGaughy et al., 1994; Pattij et al., 2007; Shannon \& Eberle, 2006; Spinelli et al., 2006). A study by Davidson and Marocco (2000) using central infusion of scopolamine $(4,7$ $\mathrm{mg}$ in $1 \mathrm{~mL}$ Ringer solution) has implicated the intraparietal cortex in attentional shifting (i.e., covert orienting).

In summary, it appears that the effects of scopolamine on attention tasks are not unequivocal. Although different test paradigms have been utilized that presumably assess sustained attention, scopolamine did not consistently impair accuracy performance (Andrews et al., 1992; Doty et al., 2003; Leaton \& Kreindler, 1972). In addition, scopolamine 
consistently increased general non-cognitive performance measures, such as response latency and the number of missed trials (Andrews et al., 1992; Bushnell et al., 1997; Drinkenburg et al., 1995). Although the use of signal detection theory-derived measures would probably make attention task performance more sensitive to drug treatments, most studies have used standard parameters, such as percentage correct and number of omissions (Ksir \& Slifer, 1982). Nevertheless, the consensus appears to be that scopolamine mainly affects visuospatial sustained attention at doses of $0.02 \mathrm{mg} / \mathrm{kg}$ and higher (Callahan et al., 1993; Cheal, 1981; Hodges Jr. et al., 2009; Hoff et al., 2007; Humby et al., 1999; Leblond et al., 2002; Spinelli et al., 2006). In addition, a few experiments have reported effects of scopolamine on cross-modal (visual and auditory) divided attention (McGaughy et al., 1994) and covert orienting of visuospatial attention (Davidson \& Marrocco, 2000; Phillips et al., 2000).

\section{Learning and memory}

Several papers have given an overview of the effects of cholinergic drugs on learning and memory performance, but not specifically related to scopolamine (Blokland, 1995; Hagan \& Morris, 1988; Izquierdo, 1989; McDonald \& Overmier, 1998; McNamara \& Skelton, 1993; Smith, 1988; Spencer \& Lal, 1983). Since the amount of studies in which scopolamine was used to induce performance deficits is tremendous, only a short summary of the effects of scopolamine on learning and memory will be provided in this section. A more comprehensive review of the effects of anticholinergic drugs per behavioral task can be found in the papers of Hagan and Morris (1988), and Spencer and Lal (1983).

First of all, object recognition and spatial alternation tasks have been reasonably consistent in detecting drug effects in the sense that peripherally administered scopolamine generally tends to interfere with short-term memory (Baron et al., 1998; Lieben et al., 2005; Means et al., 1996; Sambeth et al., 2007). However, the effects of scopolamine in operant (delayed) alternation have been assumed to also be related with discrimination processes (Heise et al., 1976). Experiments using central infusion of scopolamine have implicated the infralimbic cortex (Wall et al., 2001), medial septal area (Givens \& Olton, 1995; Markowska et al., 1995), caudate nucleus (Prado-Alcala et al., 1978) and dorsal hippocampus as brain regions involved in spatial alternation (Brito et al., 1983). Infusion of scopolamine into the perirhinal cortex (Abe et al., 2004; Warburton et al., 2003; Winters et al., 2006; 2007) impairs object recognition.

In the radial maze, clear performance deficits were generally apparent after systemic scopolamine administration (Masuoka et al., 2006), although it must be noted that in some studies relative high doses of scopolamine $(\geq 0.5 \mathrm{mg} / \mathrm{kg}$ ) were used (Okaichi \& Jarrard, 1982). In general, doses of $0.1 \mathrm{mg} / \mathrm{kg}$ and higher are required to induce impairments in this task (Buresová \& Bures, 1982; Peele \& Baron, 1988b; Wirsching et al., 1984). Apart from the effects on acquisition, scopolamine especially disrupted performance when delay procedures were used, which suggests that scopolamine specifically impairs (spatial) working memory (Buresová \& Bures, 1982; Peele \& Baron, 1988b; Stevens, 1981). Moreover, when utilizing the radial maze procedure in which both working and reference memory can be assessed simultaneously, studies have provided support for a specific effect of scopolamine on working memory (Beatty \& Bierley, 1985; Hodges Jr. et al., 2009; Wirsching et al., 1984). However, the selective disruption of working memory after scopolamine has been questioned by other studies (Eckerman et al., 1980; Godding et al., 1982; Okaichi \& Jarrard, 
1982; Okaichi et al., 1989; Peele \& Baron, 1988a). Central infusion of scopolamine in the basal forebrain, dorsomedial thalamus nucleus, medial raphe nucleus (Mishima et al., 2000) and hippocampus (Kim \& Levin, 1996) has been found to disrupt radial maze performance. In the Morris water maze, systemic administration of scopolamine has been reported to be more effective in disrupting acquisition than impairing retention (Cozzolino et al., 1994).

Moreover, it was reported that the effects of scopolamine were dependent on age and pool wall brightness (Paylor \& Rudy, 1990) and pretraining (Saucier et al., 1996), which suggests that the effects of scopolamine in the Morris task may not only be related with spatial learning. Furthermore, some studies have reported that a dose of at least $0.1 \mathrm{mg} / \mathrm{kg}$ was needed to impair place learning (Buresová et al., 1986). In contrast, other experiments showed that higher doses (i.e., 0.8-1.0 mg/kg, IP) did not impair the acquisition of the Morris task (Decker et al., 1990; Riekkinen et al., 1990). Studies using central infusion of scopolamine have reported a role for the posterior cingulate (Riekkinen et al., 1995), septum (Elvander et al., 2004) and dorsal hippocampus (Blokland et al., 1992; Herrera-Morales et al., 2007) in Morris water maze performance.

The majority of studies using delayed (non-)matching procedures have indicated that systemical administration of scopolamine induces a delay-independent impairment at relatively low doses $(0.1 \mathrm{mg} / \mathrm{kg}$ and lower, see also Steckler et al., 1998), although other studies have challenged this finding (Estapé \& Steckler, 2002; Ruotsalainen et al., 1998; Santi \& Weise, 1995; Stanhope et al., 1995). Furthermore, in most experiments scopolamine also affected measures of responding, i.e., increased number of omissions, decrease in number of completed trials and increase in response latency (Estapé \& Steckler, 2002; Kirkby et al., 1995). Experiments using central administration of scopolamine have implicated the (dorso)medial prefrontal cortex (Broersen et al., 1994; Dunnett et al., 1990; Herremans et al., 1996), prelimbic cortex (Granon \& Poucet, 1995) and hippocampus (Dunnett et al., 1990; Robinson \& Mao, 1997) in delayed (non-)matching performance.

There exist a multitude of studies that have used scopolamine to assess the role of acetylcholine in anxiety-related memory (Anagnostaras et al., 1999; Roldán, 1997; Rudy \& Pugh, 1996; Spangler et al., 1989). For instance, in an active avoidance study by Flood and Cherkin (1986), relatively low doses of scopolamine $(0.01 \mathrm{mg} / \mathrm{kg} 1 \mathrm{~h}$ before training or 0.1 $\mathrm{mg} / \mathrm{kg}$ immediately after training, $\mathrm{SC}$ ) improved retention - probably due to a behavioral activating effect of scopolamine, whereas higher doses of scopolamine $(0.1 \mathrm{mg} / \mathrm{kg}$ 1h before training or $1.0 \mathrm{mg} / \mathrm{kg}$ immediately after training, $\mathrm{SC}$ ) disrupted performance. Moreover, these effects were dependent on time of administration: injection of scopolamine $1 \mathrm{~h}$ before the learning phase was relatively more effective in altering retention performance as compared to administration immediately after the learning phase (i.e., effects at lower doses). A study by Oliverio (1968) indicated an interaction effect between the amount of active avoidance pretraining and scopolamine treatment: a dose of $2 \mathrm{mg} / \mathrm{kg}$ (IP) ameliorated performance in naïve mice, whereas a similar dose disrupted performance in mice which were pretrained. Using central infusion of scopolamine $(10-20 \mu \mathrm{g})$, Hamilton and Grossman (1969) have reported a role for the septum in active avoidance in cats.

In several passive avoidance studies (Nomura et al., 1994; Quirarte et al., 1994; Rush, 1988), systemic administration of scopolamine just before training appeared relatively most effective in impairing retention measures (as compared to administration at least $1 \mathrm{~h}$ before training, after avoidance training or before avoidance testing). However, it seems that age of the animals is also a mediating factor in determining the sensitivity of passive 
avoidance performance to disruption by scopolamine; an article of Feigley (1974) reported effects of scopolamine in 20-28 day old rats at a dose of $0.5 \mathrm{mg} / \mathrm{kg}$ (IP) whereas in 70-84 day old animals, a dose of $4 \mathrm{mg} / \mathrm{kg}$ (IP) disrupted passive avoidance retention. Moreover, amount of pretraining influenced the effect of scopolamine on passive avoidance performance as well, as a dose of $0.5 \mathrm{mg} / \mathrm{kg}$ (IP) was found to impair retention in moderately trained rats whereas a similar dose had no effect on retention in over-trained animals (Pazzagli \& Pepeu, 1964).

Lastly, level of shock intensity also played a mediating role in the effect of scopolamine on passive avoidance retention; a study by Quirarte et al. (1994) showed that after a dose of $8 \mathrm{mg} / \mathrm{kg}$ (IP) using low foot shock conditions, no state-dependency was found, whilst the same dose did have a state-dependent effect when a high level of foot shock was employed. Thus, in avoidance tests effects of systemically administered scopolamine appear to be dependent on the type of avoidance task (i.e., passive vs. active avoidance), time of injection (Flood \& Cherkin, 1986; Quirarte et al., 1994), training experience (Oliverio, 1968; Pazzagli \& Pepeu, 1964), age of the animals (Feigley, 1974), level of shock intensity (Quirarte et al., 1994), and dose conditions (Flood \& Cherkin, 1986). Moreover, central administration of scopolamine in frontal cortex (Santucci \& Shaw, 2003), anterior but not posterior cingulate (Riekkinen et al., 1995), hippocampus (Wiener \& Messer, 1973), striatum (Diaz del Guante et al., 1991) and amygdala (Bianchin et al., 1999; Nomura et al., 1994) tends to disrupt passive avoidance retention.

Results of experiments in which the effects of scopolamine on fear conditioning were investigated tend to be quite variable, which could again be related to modest differences in test circumstances such as time of administration (Anagnostaras et al., 1999). Nevertheless, systemic injection of scopolamine was most often found to impair both context and cued conditioning (Anagnostaras et al., 1999; Rudy, 1996), an effect which might be mediated by the amygdala (Phillips \& LeDoux, 1992). However, no effects (Rudy \& Pugh, 1996), effects on only context (Anagnostaras et al., 1995) or cued conditioning (Young et al., 1995), and even a facilitation of cued conditioning have also been reported (Young et al., 1995). In contrast, central infusion of scopolamine in the (dorsal) hippocampus has been reported to impair contextual but not cued conditioning (Rogers \& Kesner, 2004; Wallenstein \& Vago, 2001). In summary, effects of scopolamine on tasks assessing learning and memory were observed at systemic doses higher than $0.03 \mathrm{mg} / \mathrm{kg}$ (dependent on the particular paradigm used). It appears that scopolamine is particularly effective in impairing acquisition/learning and short-term and working memory.

\section{DISCUSSION}

\section{Summary and interpretation of the behavioral effects of scopolamine}

A review of the literature on scopolamine (see Tables 2 and 3) clearly shows that this drug is capable of inducing various behavioral changes in several animal species (Bohdanecky et al., 1967; Cheal, 1981; Hamilton \& Grossman, 1969; Harvey et al., 1983; Pakarinen \& Moerschbaecher, 1993; Robinson et al., 2004; Santi \& Weise, 1995; Savage et al., 1996; Spinelli et al., 2006), and that scopolamine can cause very potent performance impairment on tests of learning and memory (Anagnostaras et al., 1999; Hodges Jr. et al., 2009; Means et al., 1996; Roldán, 1997; Sambeth et al., 2007; Spangler et al., 1989; Spinelli et al., 2006). This 
would corroborate the view that scopolamine is an amnesic drug that disrupts central cholinergic neurotransmission. Initially, much effort has been dedicated to examining whether scopolamine disrupts consolidation vs. retrieval, learning vs. memory, short-term vs. longterm memory, and working vs. reference memory. Since the most consistent effects are found in tests in which a delay interval was interposed between the sample and recognition/choice phase (Estapé \& Steckler, 2002; Givens \& Olton, 1995; Savage et al., 1996; Stanhope et al., 1995), it has been argued that scopolamine predominantly affects shortterm memory processes. However, it has become increasingly clear that tasks that assess stimulus discrimination and/or (sustained) attention are much more sensitive to pick up impairment after scopolamine treatment (i.e., effects at relatively lower doses, see Fig. 1), especially when signal detection-derived measures and/or delay procedures are used. These findings would suggest a role of acetylcholine in sensory processing and attention rather than short-term memory (Sarter et al., 2003). This conclusion is strengthened by the fact that cholinergic lesion studies have yielded comparable results - i.e., on discrimination/attention rather than learning/memory, see above (e.g., Baxter \& Gallagher, 1996; Baxter et al., 1997; Chiba et al., 1999; McGaughy et al., 2000; Torres et al., 1994; Voytko, 1996).

Unfortunately, due to the non-specific binding characteristics of scopolamine (Bolden et al., 1992), cognitive-behavioral effects of systemic administration are not very selective. In Figure 1 a schematic overview is made of effects of peripheral administration of scopolamine as a function of behavioral paradigm. As is shown, with increasingly higher doses scopolamine can also impair performance in behavioral tasks which assess non-mnemonic and/or non-attentional processes, such as anxiety (Hughes et al., 2004; Smythe et al., 1996). Furthermore, scopolamine can influence non-cognitive aspects of behavior: it has a rather robust effect on locomotor activity (decrease or increase), response rate (decrease), omissions (increase), and response latency (increase). Scopolamine is also known to affect peripheral, physiological processes such as pupil size (Leopold \& Comroe, 1948) and salivation (Dai et al., 1991; Flynn et al., 1997; Shannon et al., 1994; Shida et al., 1993; Tobin et al., 2002). These peripheral effects were found in dose ranges that also disrupt measures of cognitive behavior. Thus, use of (high doses of) scopolamine will affect additional cognitive and non-cognitive aspects of behavior that could directly interfere with performance in tasks assessing stimulus discrimination, attention or memory. As is the case for all drugs, effects of scopolamine on the abovementioned functions are found to be dose-dependent albeit that the dose response curves can differ between behavioral tasks (see Fig. 1).

Systemic administration of scopolamine thus tends to influence both peripheral and central mechanisms and therefore effects on these functions cannot always be dissociated from one another. Hence, systemic scopolamine injections can only have a limited contribution in understanding the role of the central cholinergic system in cognition. It is assumed that central infusion of compounds in animals offers information with respect to the function of a neurotransmitter in a specific brain region. Such an approach would enable an assessment of the influence of muscarinic receptors in different brain structures on cognitive performance. As receptor subtypes are not evenly distributed in the brain, central administration will also lead to differences in blockade between muscarinic receptor subtypes. Thus, studies that investigate the effects of intracerebral injections may provide a manner to dissociate effects of scopolamine on performance in (non-)cognitive tasks, especially those in which scopolamine is injected into more than one brain region (e.g., striatum 
and hippocampus). Furthermore, it has been suggested that specific projections of cholinergic cells in the nucleus basalis diagonal band complex might provide brain regions with some degree of selectivity in terms of cognition (Price \& Stern, 1983; van der Zee \& Luiten, 1999).

However, experiments that have used central administration of scopolamine do not provide a clear-cut picture of the role of the cholinergic system for each brain region (see Table 3): cognitive deficits seem diverse and only to some extent related to brain structure. For example, short-term memory impairments have been found after injections in several brain regions, such as the hippocampus (Brito et al., 1983; Dunnett et al., 1990; HerreraMorales et al., 2007; Mishima et al., 2000), septum (Givens \& Olton, 1995; Markowska et al., 1995), and amygdala (Ingles et al., 1993; Ohno et al., 1993). Moreover, centrally applied drugs are also capable of exerting widespread effects (e.g., Jolas et al., 1995).

Nevertheless, if a rough differentiation is made, it seems that the cortical regions are involved in attentional processes (Davidson \& Marrocco, 2000), short-term memory functions (Abe et al., 2004; Granon et al., 1995; Wall et al., 2001; Warburton et al., 2003; Winters et al., 2006), (conditional) discrimination (Broersen et al., 1995; Herremans et al., 1997; Wilson, 2001), and conditioned taste aversion (Gutiérrez et al., 2003; Naor \& Dudai, 1996; Ramírez-Lugo et al., 2003). The amygdala and septohippocampal system appear necessary for anxiety-related behavior (e.g., Smythe et al., 1998), and working and short-term memory (Brito et al., 1983; Dunnett et al., 1990; Givens \& Olton, 1995; Herrera-Morales et al., 2007; Ingles et al., 1993; Markowska et al., 1995; Mishima et al., 2000; Ohno et al., 1993), although one study did not support the latter conclusion (Robinson \& Mao, 1997). The striatal cholinergic system appears to modulate cognitive functions such as behavioral flexibility (Ragozzino et al., 2002), but also affects the execution of motor functions (Blokland, 1998; Chambers \& van Hartesveldt, 1984; Vrijmoed de Vries \& Cools, 1986).

These findings would implicate that the cognitive effects of systemic administration of scopolamine are not mediated by cholinergic blockade in a number of distinct brain areas but are rather caused by a non-selective, extensive inhibition of central cholinergic signaling. It was shown that in vivo administration of [3H]-scopolamine (IV) over a period of 240 min. with a plasma concentration of about $20 \mathrm{nM}$ could be traced in many brain regions of the rat (Frey et al., 1985). There was a good correlation between [3H]-scopolamine binding and receptor density, indicating that this ligand does not preferentially bind to a specific brain area. Thus, effects of systemic scopolamine treatment on cognitive function should be regarded as the end result of widespread blockade of muscarinic receptors throughout the brain. Moreover, studies using central administration of scopolamine have indicated that the dose range required to affect different behaviors was comparable among different brain structures (i.e., 5-15 $\mu \mathrm{g}$ ). In contrast, the effective dose range of systemically administered scopolamine appears to be greatly dependent on the particular behavioral task that is employed. In other words, experiments which have investigated the effect of central administration of scopolamine on cognition cannot easily explain the finding that this drug more potently affects performance in sensory/stimulus discrimination and attentional tasks rather than learning and memory paradigms.

In conclusion, the notion that scopolamine is an amnesic drug cannot be refuted, but as discussed in the present review, the mnemonic effects of scopolamine may not result from a specific effect on learning and memory processes. Thus, it is likely that effects on learning and memory performance which are observed after higher doses are mediated by 
1) primary effects on attention and sensory/stimulus discrimination, 2) non-specific effects on behavior (e.g., locomotor activity, anxiety), and 3) peripheral side-effects (e.g., pupil dilation, salivation). At the very least, a detailed account should be given in order to rule out side-effects as an underlying cause of memory impairments observed at higher doses. For each specific cognitive test, multi-parametric studies are needed to assess which dose (or dose range) of scopolamine induces cognitive deficits without causing behavioral side effects. In line with a paper in which a low dose of amphetamine was discussed (Grilly \& Loveland, 2001), scopolamine doses higher than $0.1 \mathrm{mg} / \mathrm{kg}$ should be considered as high doses in rats and mice.

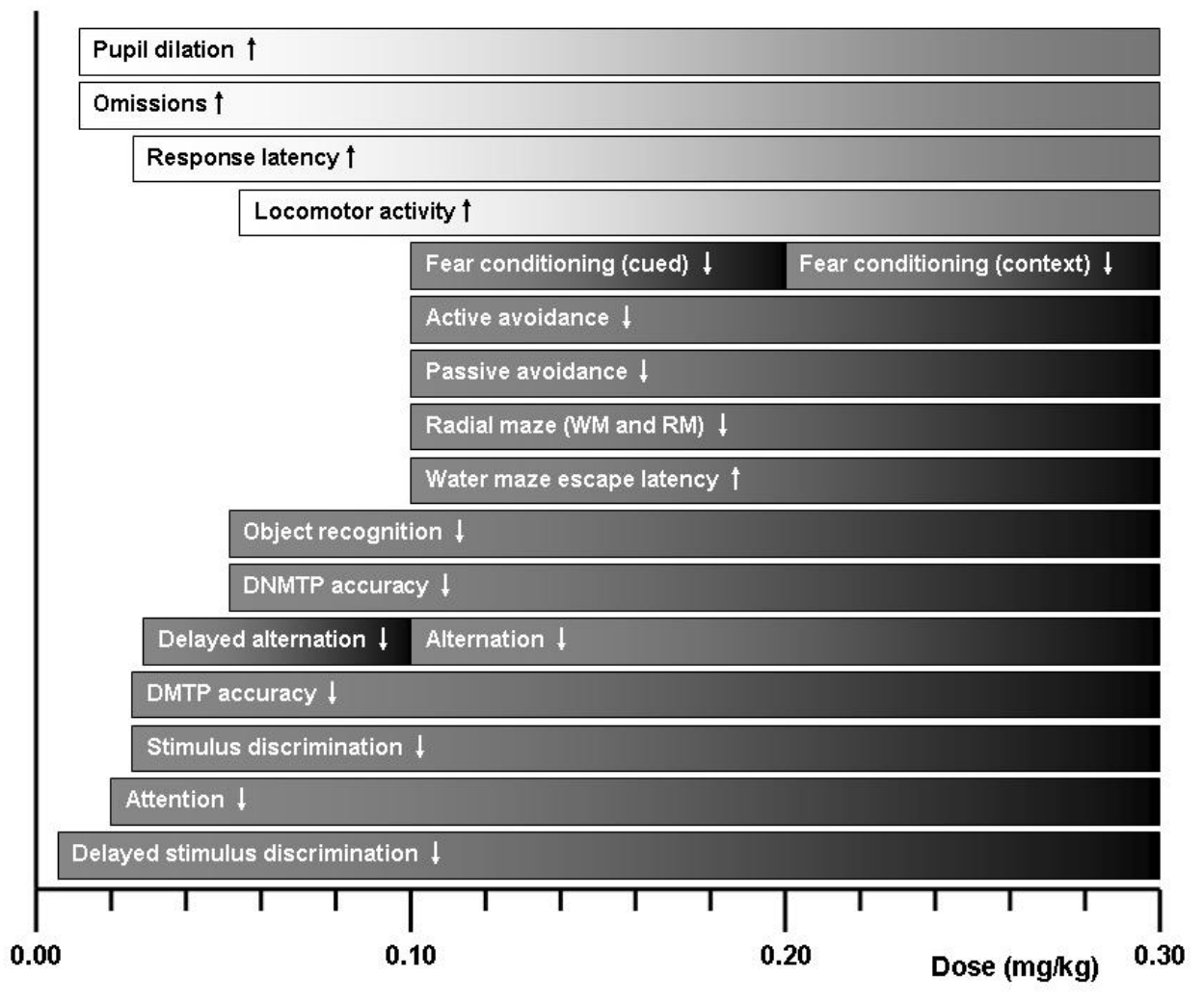

Figure 1. Schematic overview of the dose-response effects of scopolamine in several behavioral tasks. Doses were peripherally administered in rats and mice, as dose ranges used in monkeys cannot be directly compared with those in rodents. The left side of the box corresponds with the minimal dose at which effects have been reported in a particular behavioral task. The brighter boxes on top indicate the occurrence and onset of other (non-cognitive) effects of scopolamine. Table 2 provides an overview of studies which have assessed the effect of peripheral administration of scopolamine on behavior.

\section{SCOPOLAMINE AS A MODEL FOR COGNITIVE IMPAIRMENT}

The use of scopolamine in humans may be a useful tool to investigate the role of acetylcholine in cognition. However, animal studies have shown that this type of research, i.e., pe- 
ripheral administration of scopolamine, suffers important limitations because of the reasons that have been delineated in this paper. Scopolamine blocks acetylcholine at muscarinic receptors in a non-selective manner (Bolden et al., 1992); because of this widespread mode of action it may not be the optimal choice as a model of (muscarinic and/or cholinergic) cognitive impairment. On basis of the localization of different muscarinic receptors subtypes (see Table 1), it may be more useful to use ligands that block muscarinic receptors more selectively and thus are likely to affect cognitive function in a relatively more specific manner.

In this respect it might be interesting to explore the usability of selective muscarinic $M_{1}$ antagonists as a pharmacological model of cognitive deficits. As the $M_{1}$ receptor is predominantly located centrally and in brain regions such as cortex and hippocampus which are thought to be important for learning and memory (Caulfield, 1993), it is expected that $M_{1}$ antagonists will exert less peripheral side effects as compared to scopolamine and will impair cognition (especially memory) more selectively. This would supposedly make interpretation of the effects of selective $M_{1}$ antagonists on cognition relatively more straightforward. Moreover, muscarinic $M_{1}$ receptor agonists have been pursued as a treatment option for alleviation of cognitive impairments seen in disorders such as (Alzheimer's) dementia (Bodick et al., 1997) or schizophrenia (Shekhar et al., 2008): unfortunately, with limited success due to a lack of ligand selectivity to the $M_{1}$ receptor (Heinrich et al., 2009). Thus, selective $M_{1}$ antagonists might constitute a relatively more valid pharmacological model of cognitive impairment as compared to the non-selective muscarinic antagonist scopolamine.

\section{Muscarinic $M_{1}$ antagonists}

Several studies have used selective $M_{1}$ antagonists to assess the role of the muscarinic $M_{1}$ receptor in cognition and behavior. Deficits have been reported in passive avoidance tasks (Fornari et al., 2000; Kimura et al., 1999; Kramer-Soares et al., 2006; Roldán, 1997), contextual fear conditioning (Kramer-Soares et al., 2006) and object recognition (Myhrer et al., 2004; 2008) after administration of $M_{1}$ antagonists. To the best of our knowledge, only the muscarinic $M_{1}$ antagonist pirenzepine has been infused into distinct brain areas to determine its effects on cognition. When administered in the insular cortex, pirenzepine (100 $\mathrm{mM}$ in $1.0 \mu \mathrm{L} / \mathrm{side}$ ) was reported to affect acquisition of conditioned taste aversion, but did not affect retrieval (Ramírez-Lugo et al., 2003). Moreover, hippocampal or intracerebroventricular injection of pirenzepine $(0.32-34.55 \mu \mathrm{g})$ affected spontaneous alternation and caused performance deficits in the Morris water maze (Hagan et al., 1987; Herrera-Morales et al., 2007; Hunter \& Roberts, 1988), T-maze (Messer et al., 1987a; 1987b; 1990), radial maze (Mishima et al., 2000; Sala et al., 1991), spontaneous alternation (Ukai et al., 1995a, 1995b), delayed matching to position (Andrews et al., 1994; Aura et al., 1997) and the three-panel runway test (Ohno et al., 1994a; 1994b), indicative of an effect of this compound on memory functions. However, there are some indications that de $M_{1}$ receptor might be implicated in processes beyond memory, such as reversal learning (McCool et al., 2008; Tzavos et al., 2004) or anxiety (Wall et al., 2001).

In humans, the $M_{1}$ antagonist biperiden $(2 \mathrm{mg}$ ) impaired verbal episodic memory, locomotor behavior, motor learning and/or attentional processes without causing sedation (Wezenberg et al., 2005). Moreover, in human participants scopolamine was generally found to have a much more widespread effect on cognitive performance as compared to 
biperiden (Ebert et al., 1998; Wesnes, 1988). In these studies, scopolamine was also associated with relatively more side effects, such as sedation, accommodation disturbances and dry mouth. Of note, because of the highly conserved nature of the orthosteric binding site amongst muscarinic receptors, selectivity of muscarinic ligands for a particular receptor subtype might be limited and subject to improvement (Bolden et al., 1992; Heinrich et al., 2009). In other words, behavioral effects of "selective" muscarinic antagonists that target the orthosteric $M_{1}$ receptor site could also be caused by blockade of muscarinic receptors other than $\mathrm{M}_{1}$.

\section{Conclusions}

Scopolamine has widespread effects on physiological functioning and hence it also has a broad side-effect profile, which can be explained by the non-selective muscarinic binding characteristics of this ligand (Bolden et al., 1992). Moreover, the pharmacodynamic properties of scopolamine might give rise to non-selective effects of this drug on behavioral performance. In other words, this compound does not possess the appropriate pharmacological qualities in order to be able to affect just one aspect of cognition (such as mnemonic or attentional processes). Ideally, relating cognitive impairments to the impact of a model ligand on a particular receptor type should be relatively straightforward. Although scopolamine has a strong history as a model for cholinergic impairment, its pharmacological unspecificity renders it unfit for use as a golden standard drug. Thus, the validity of scopolamine as a drug of choice for inducing cognitive impairments should be questioned.

Ligands which antagonize the muscarinic $M_{1}$ receptor can regarded as a good alternative for scopolamine because of their ability to induce more selective cholinergic receptor blockade. Based on the relatively central distribution of the muscarinic $\mathrm{M}_{1}$ receptor (Caulfield, 1993), the relatively more specific cognitive effects of $M_{1}$ antagonists (Andrews et al., 1994; Aura et al., 1997; Hagan et al., 1987; Herrera-Morales et al., 2007; Hunter \& Roberts, 1988; Messer et al., 1987a; 1987b; 1990; Mishima et al., 2000; Ohno et al., 1994a; 1994b; Sala et al., 1991; Ukai et al., 1995a; 1995b), and the relatively more favorable side-effect profile of $\mathrm{M}_{1}$ antagonists (Ebert et al., 1998; Wesnes, 1988; Wezenberg et al., 2005), these compounds should be investigated in terms of their usability as a pharmacological model of cognitive impairment. However, at this point not enough effort has been put in determining the effects of $M_{1}$ antagonists on memory vs. attention vs. other cognitive and noncognitive processes (side-effects), partly because of a lack of highly selective muscarinic compounds (Bolden et al., 1992; Heinrich et al., 2009). More research is needed to develop $M_{1}$ ligands with a more selective binding profile (for instance by acting at allosteric sites for a particular muscarinic receptor type) and to assess whether $M_{1}$ antagonists can really be regarded as a valid pharmacological model for inducing cognitive (particularly mnemonic) deficits. 
THE VALIDITY OF SCOPOLAMINE AS A PHARMACOLOGICAL MODELFOR 37

COGNITIVE IMPAIRMENT

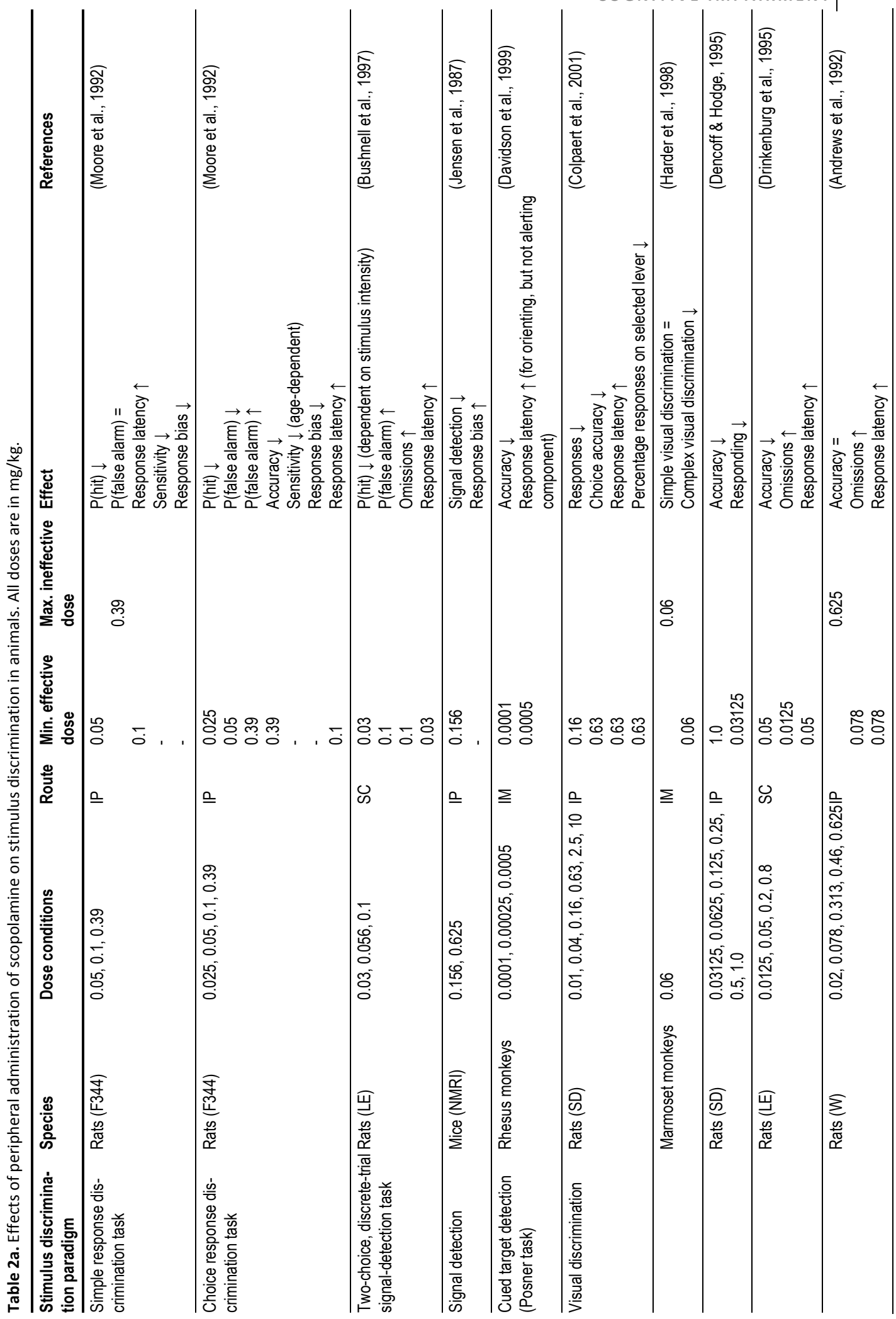




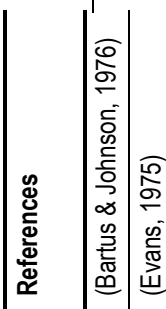

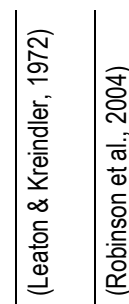

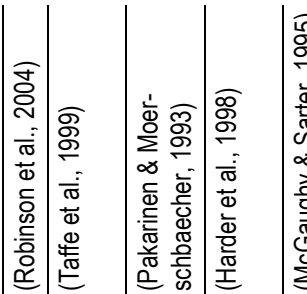

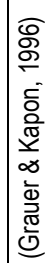

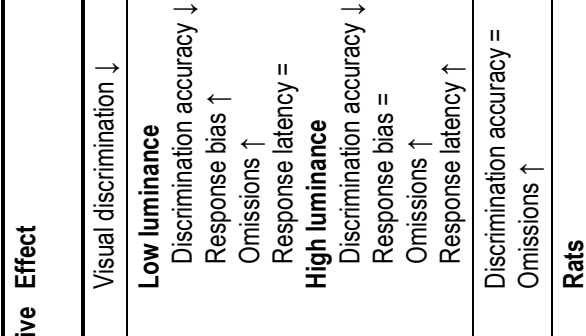

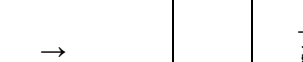

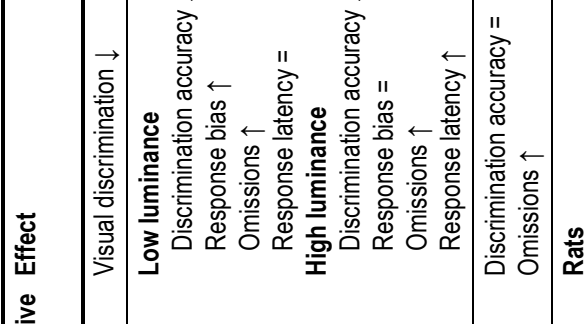

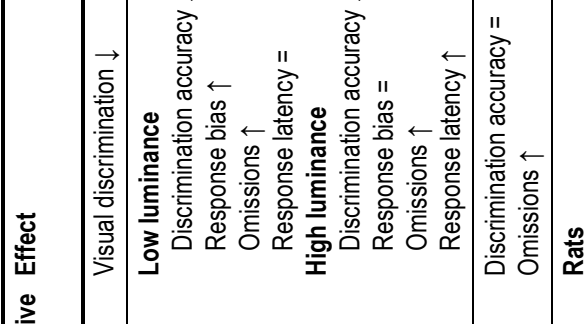

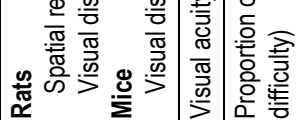

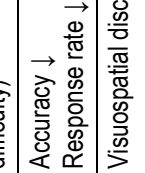

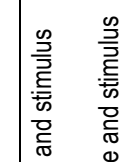

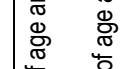

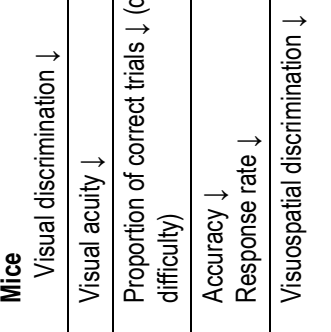

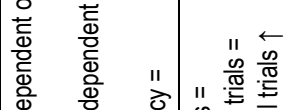

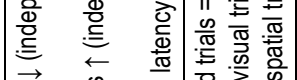

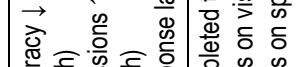

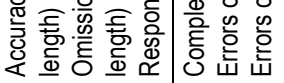

突

䒽

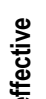

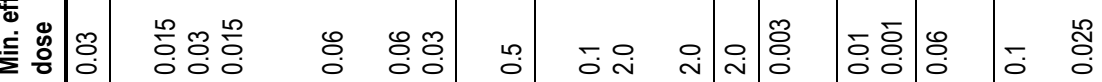

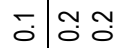

艺

\begin{tabular}{ll|l}
8 & 0 & 0 \\
0 & 0 & 0
\end{tabular}

으므

의 $\geqq \quad$

O

$\bar{\sigma}$
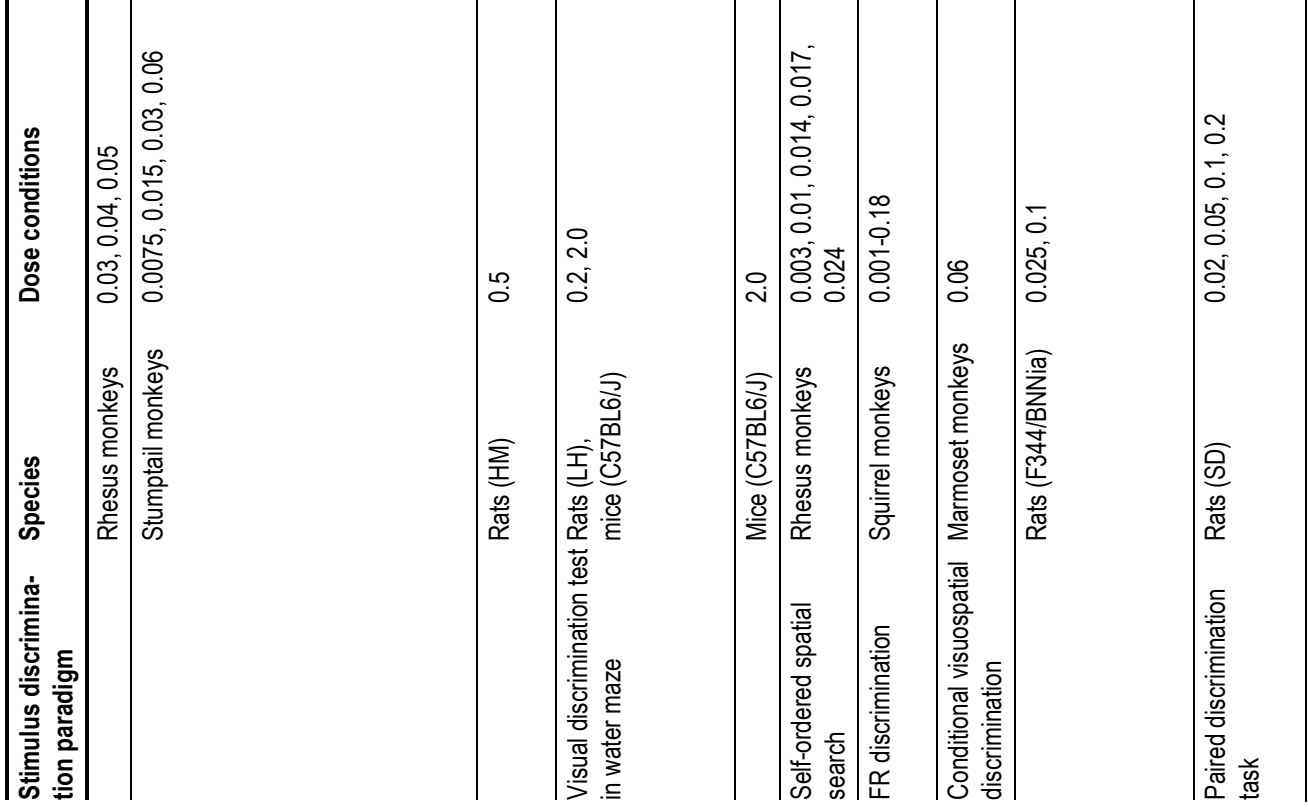


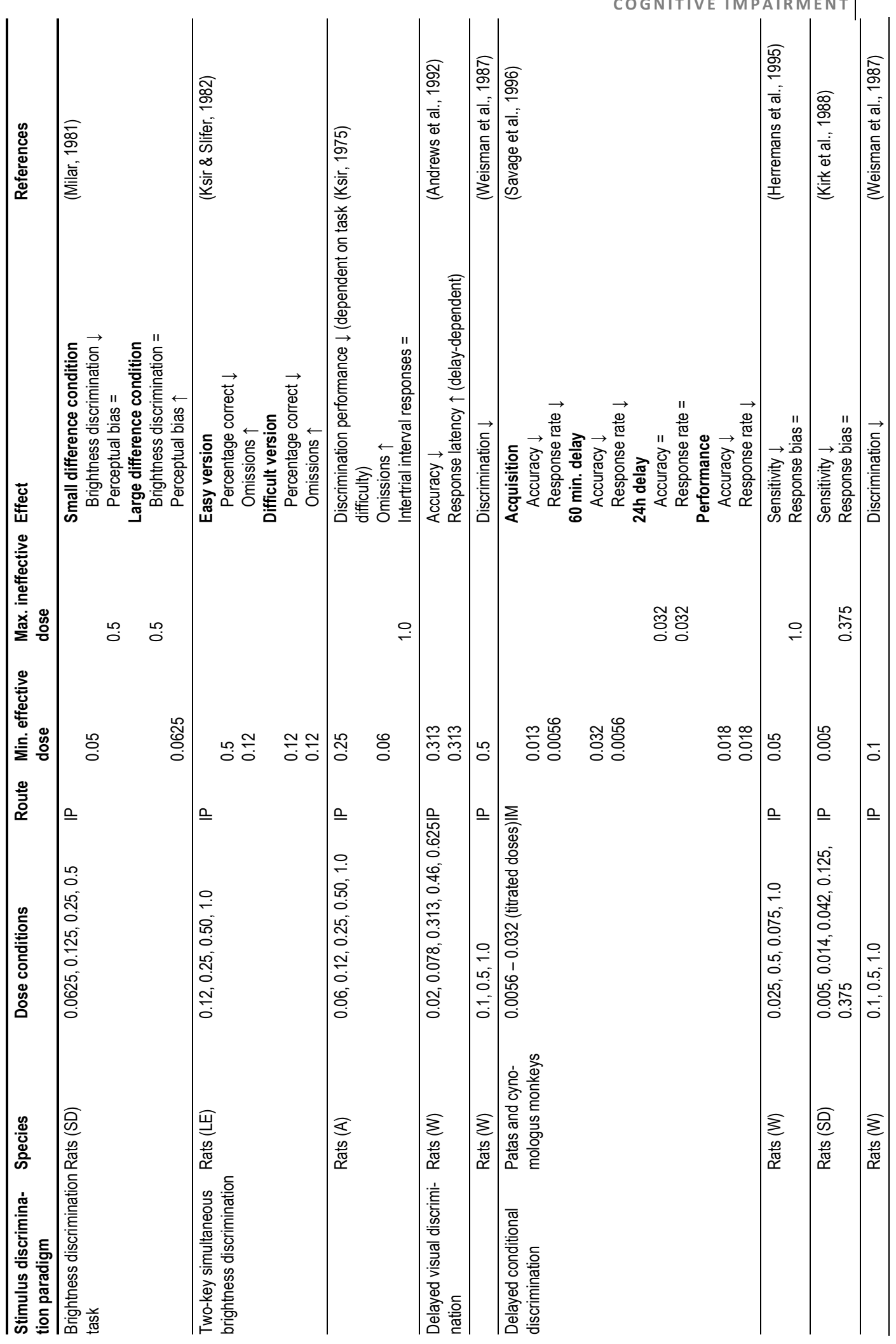




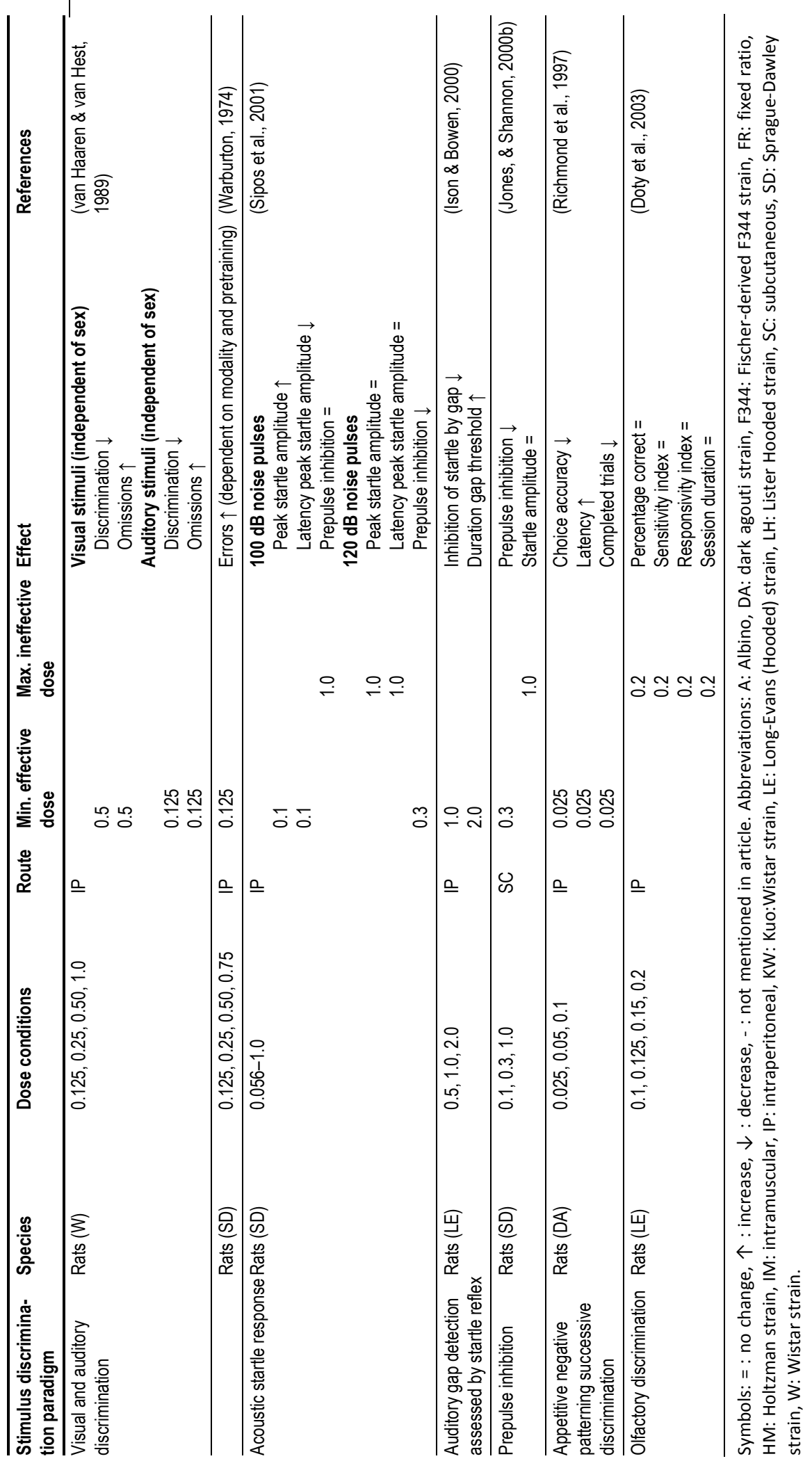




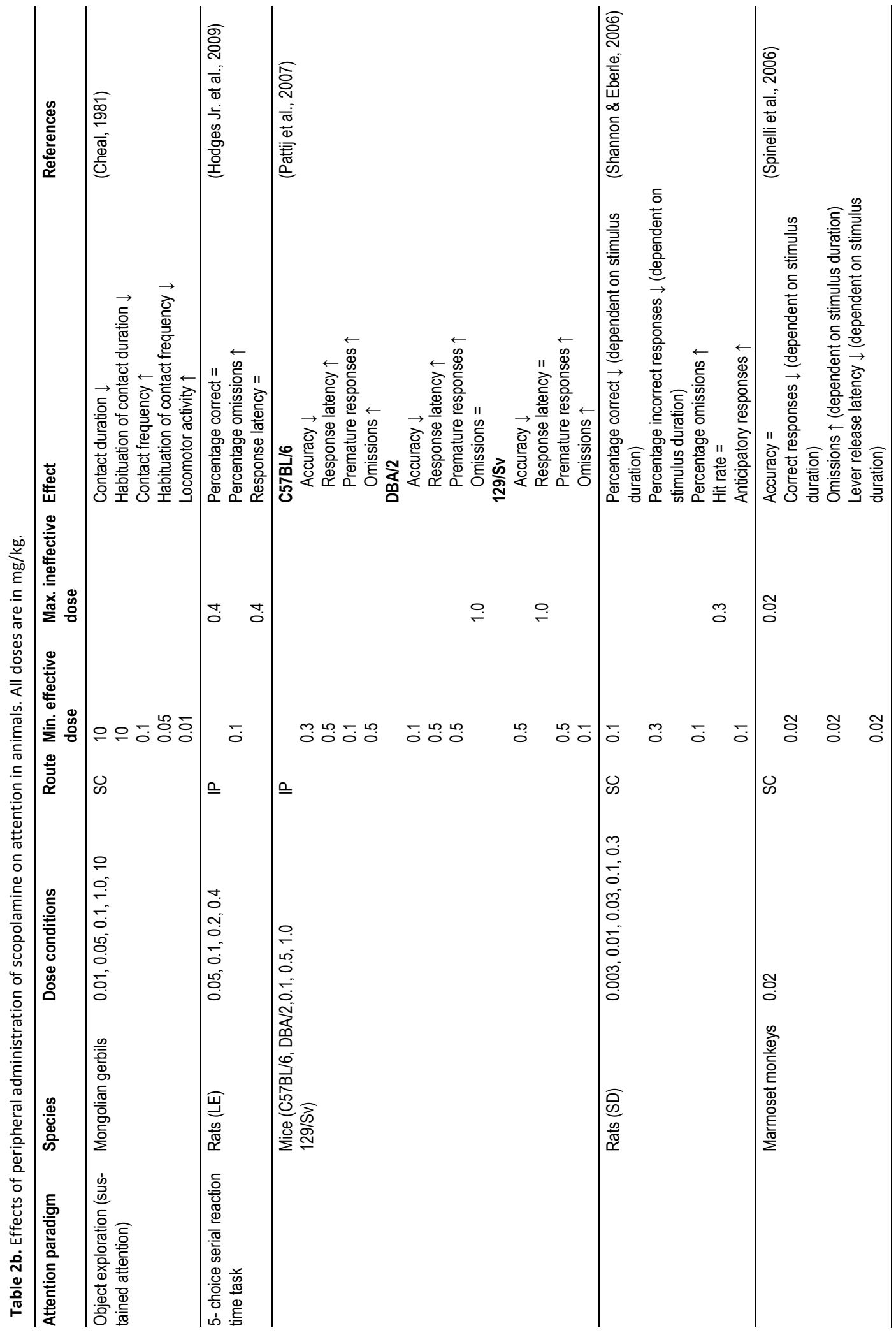




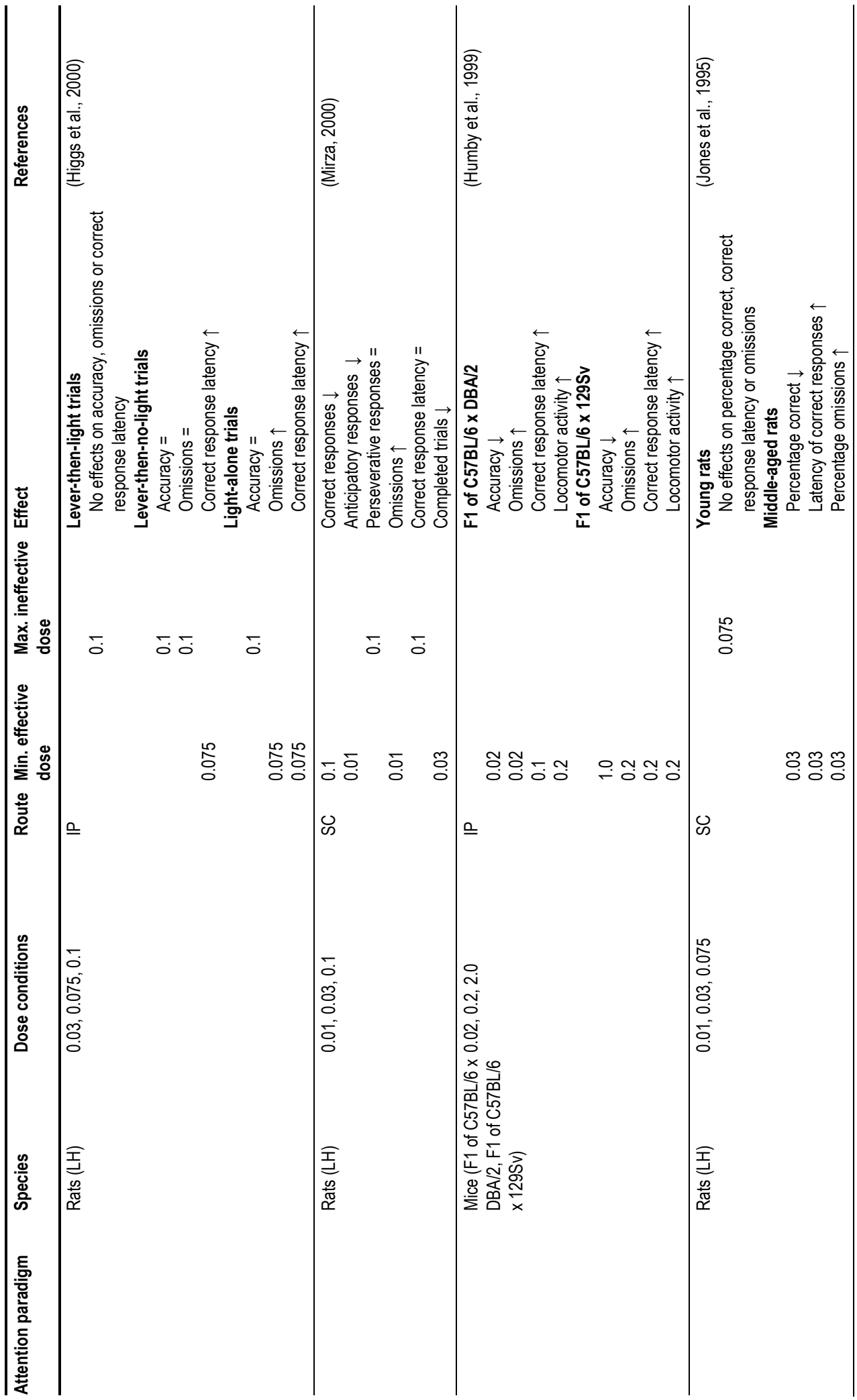




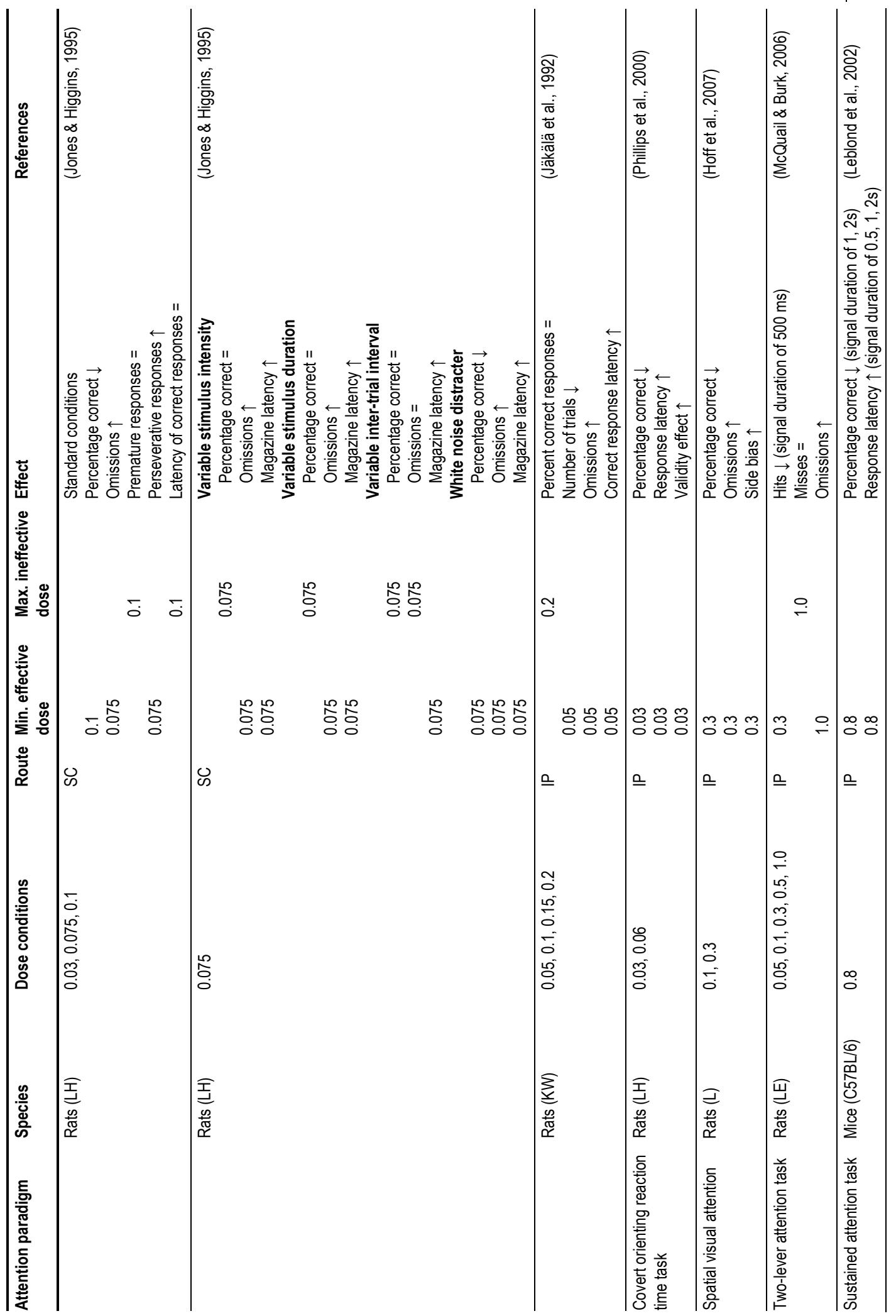




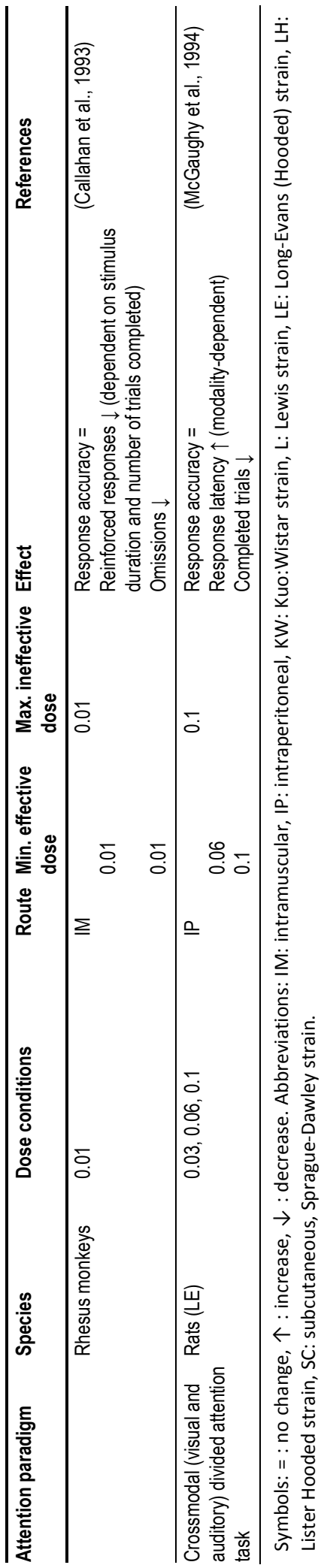




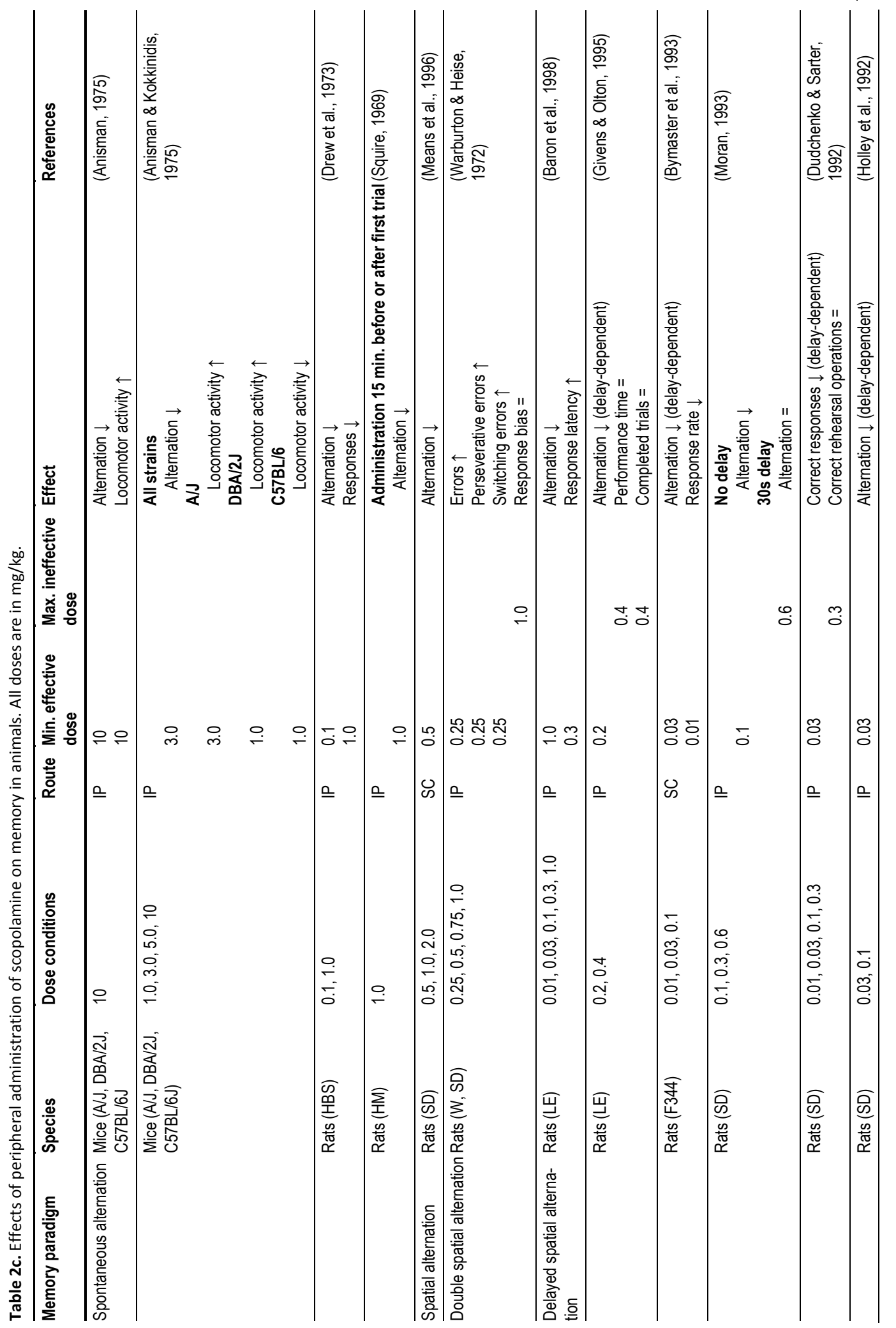




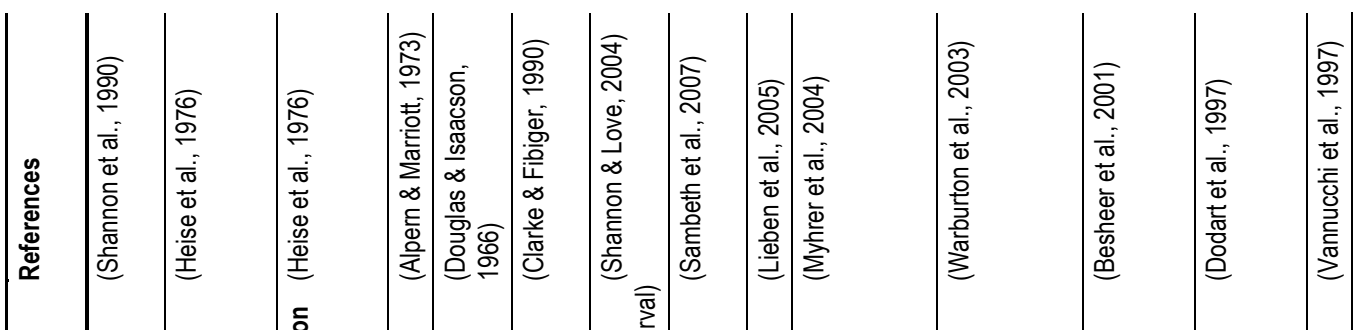

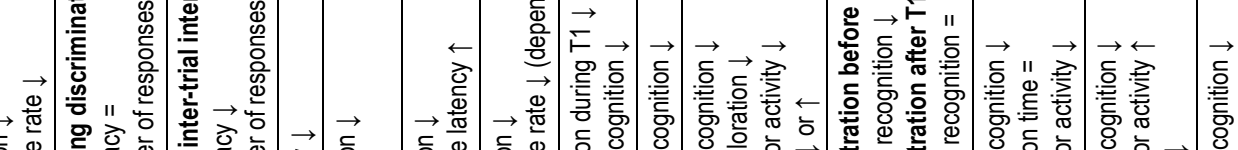

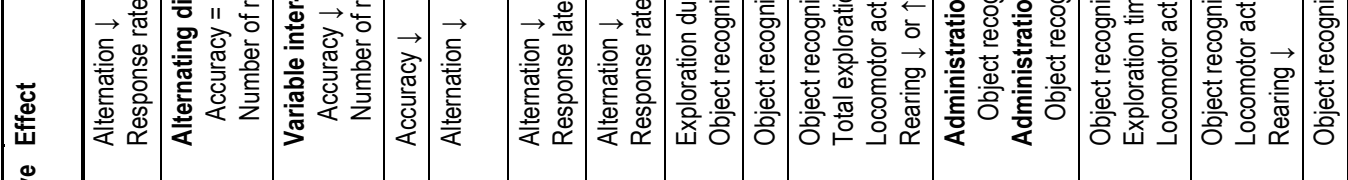

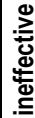

䒽路

这

豙兽

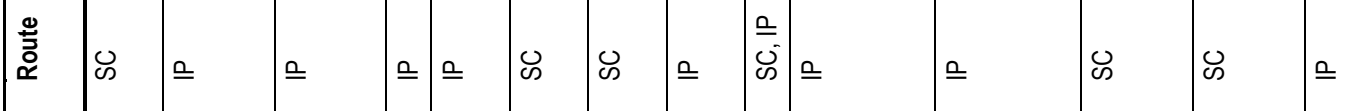

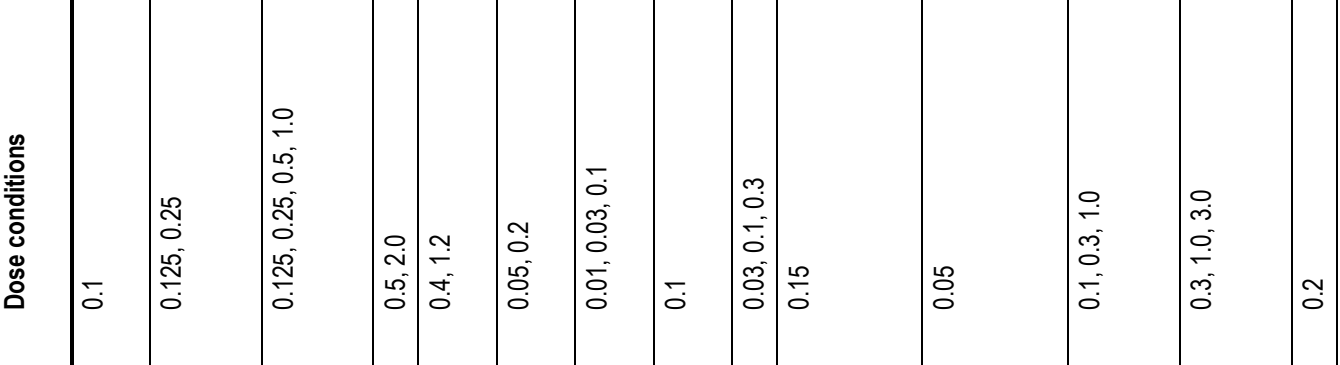

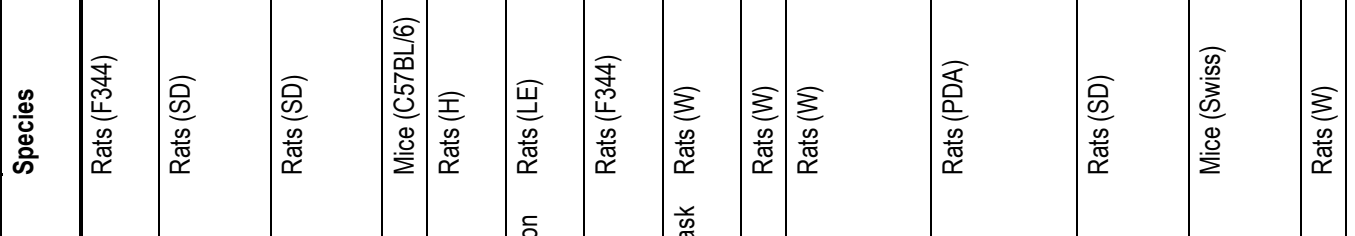




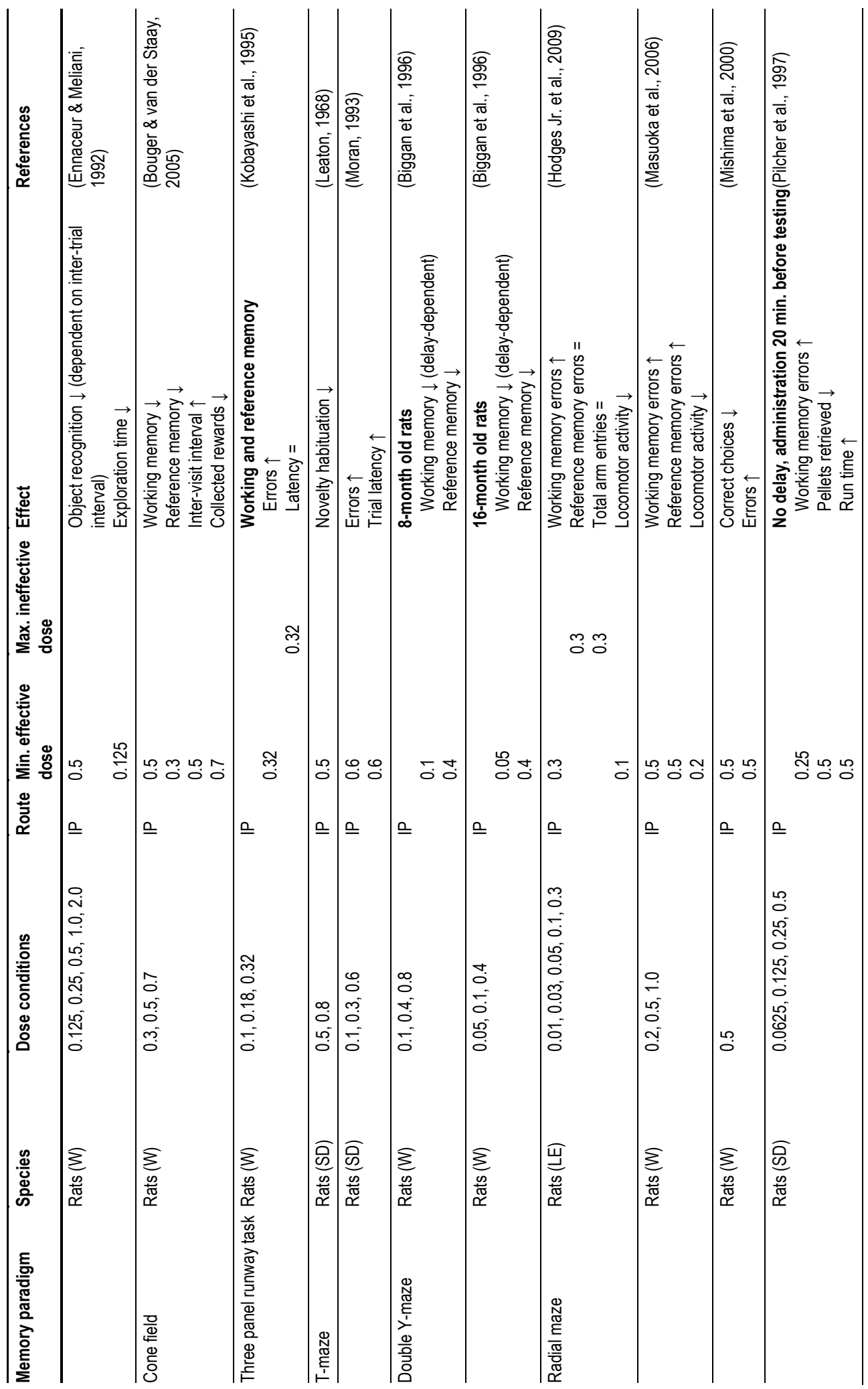




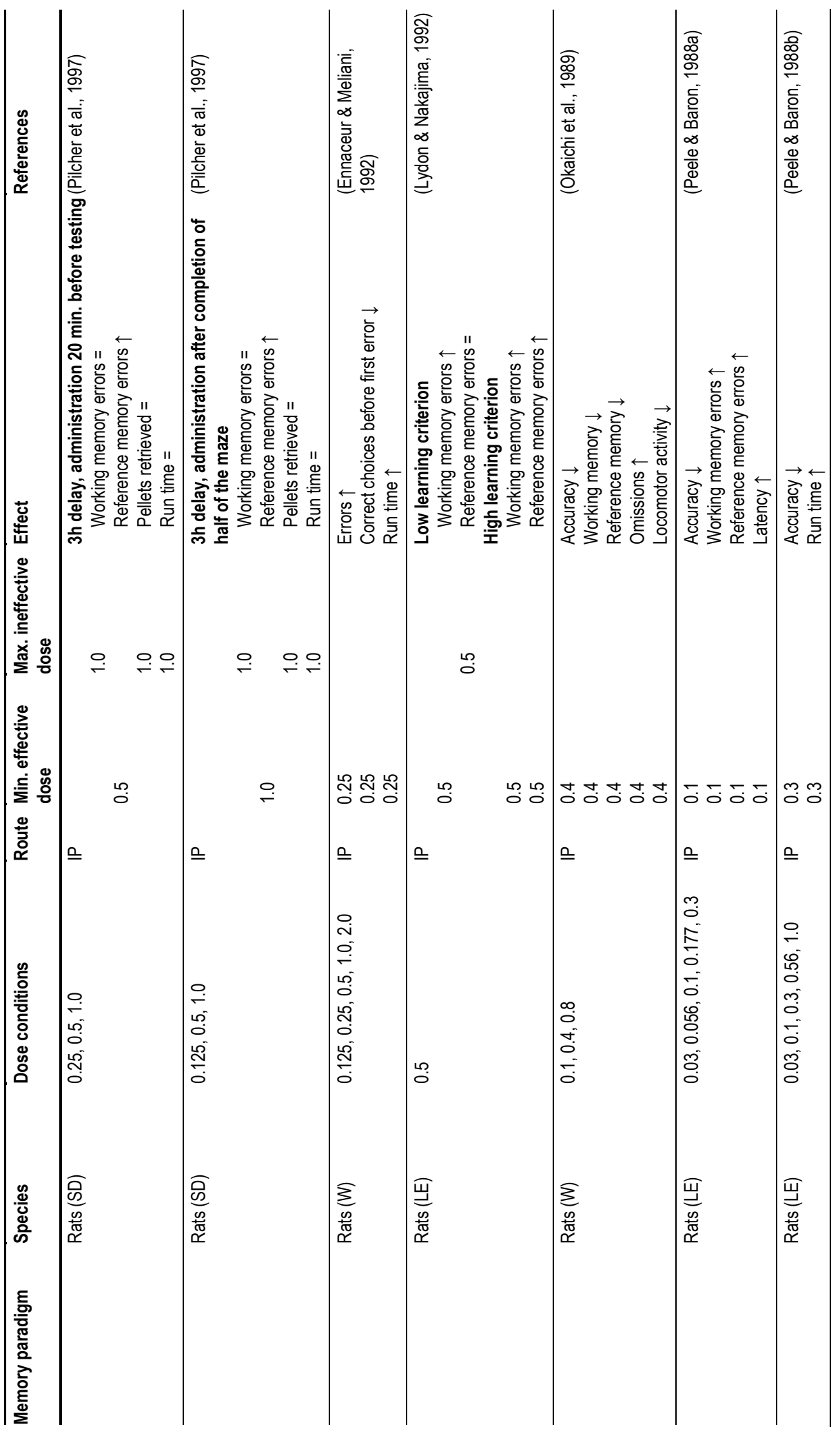




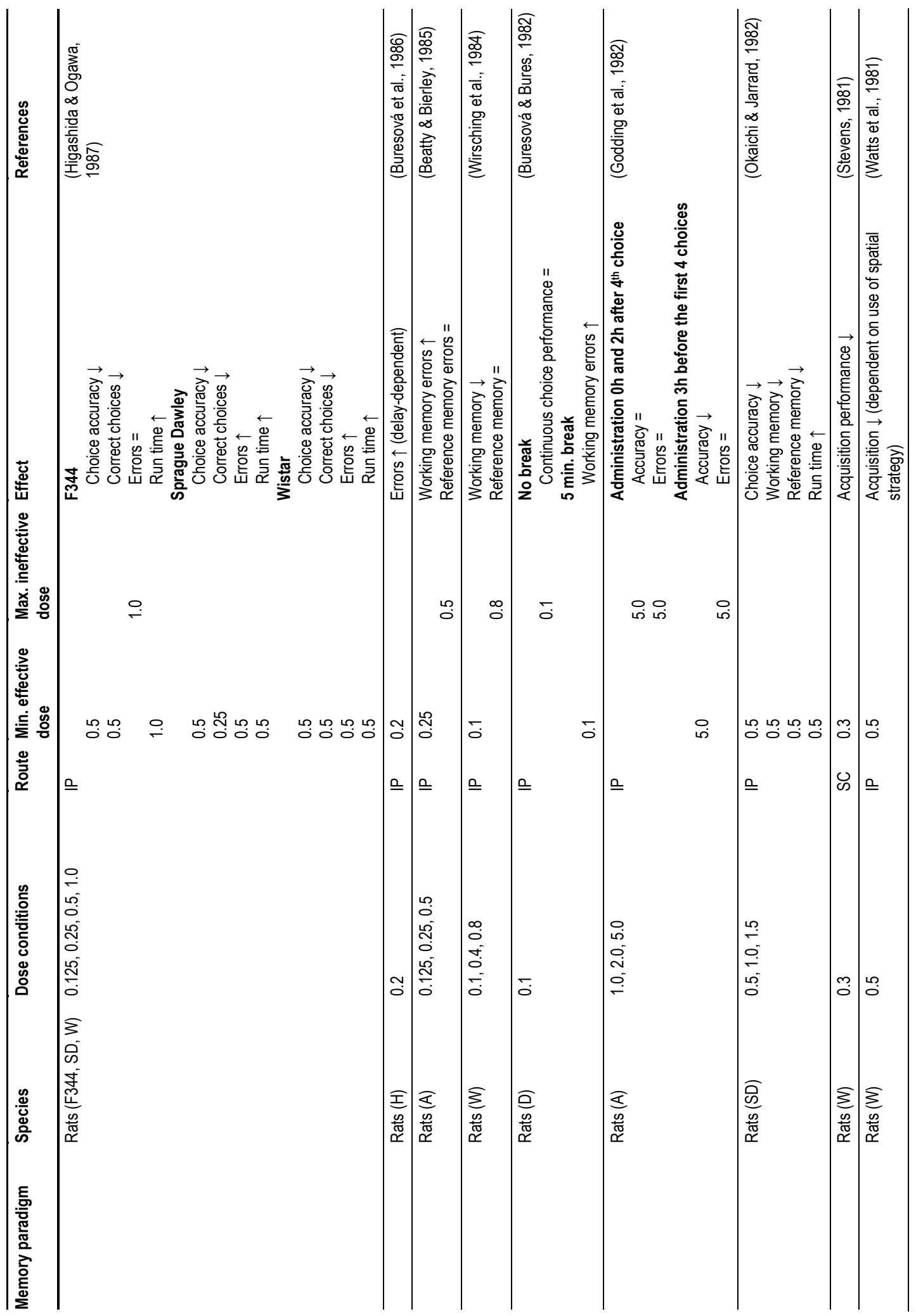




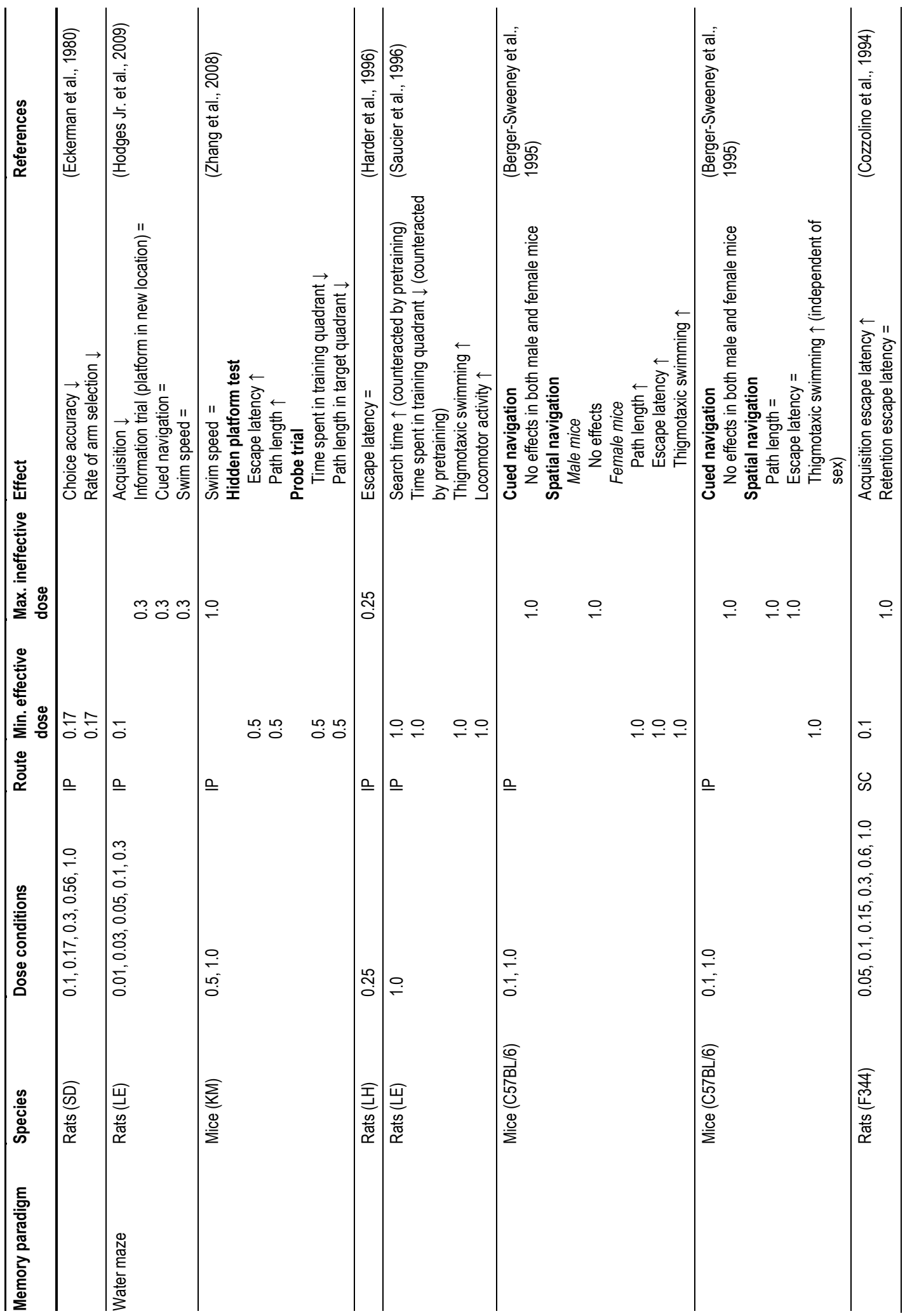




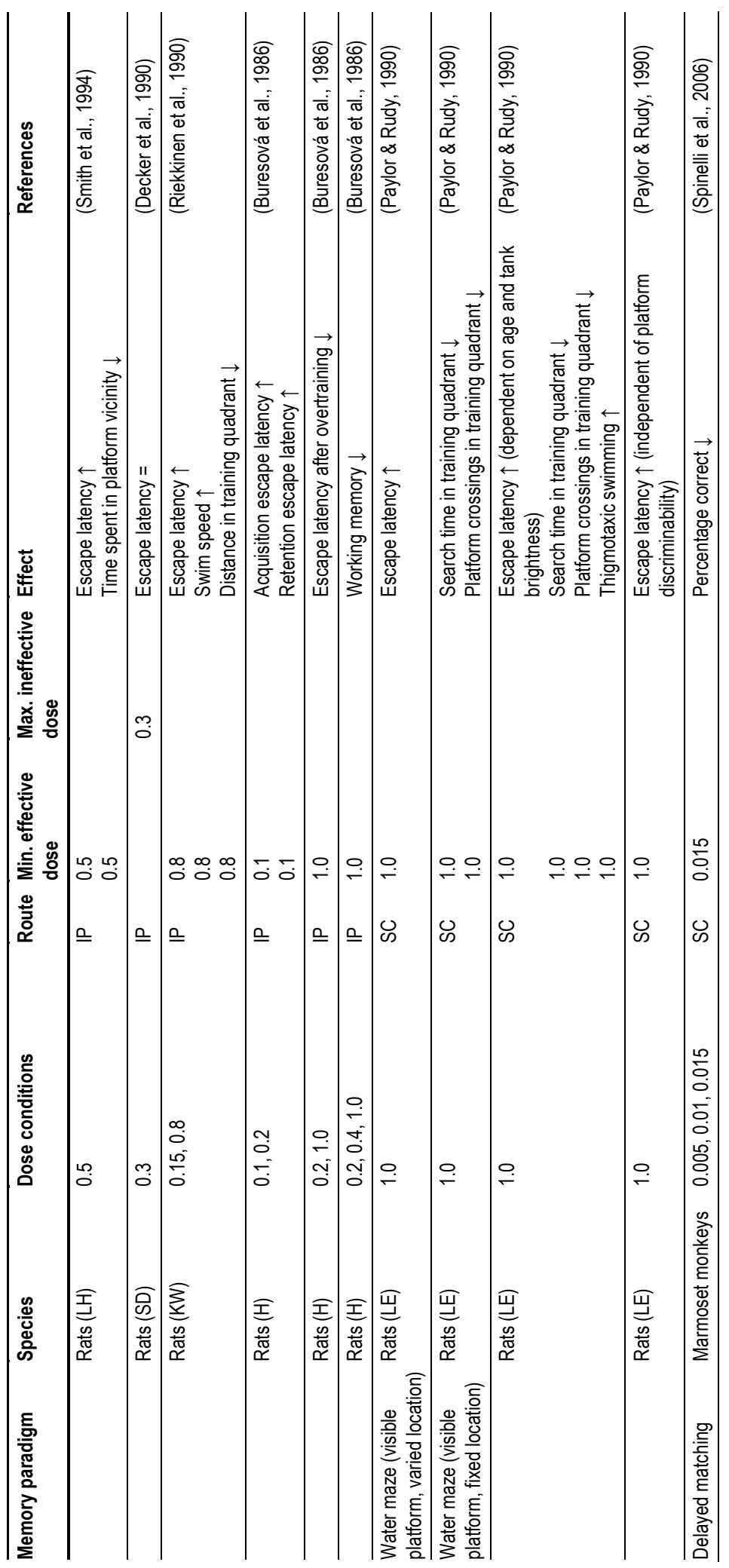




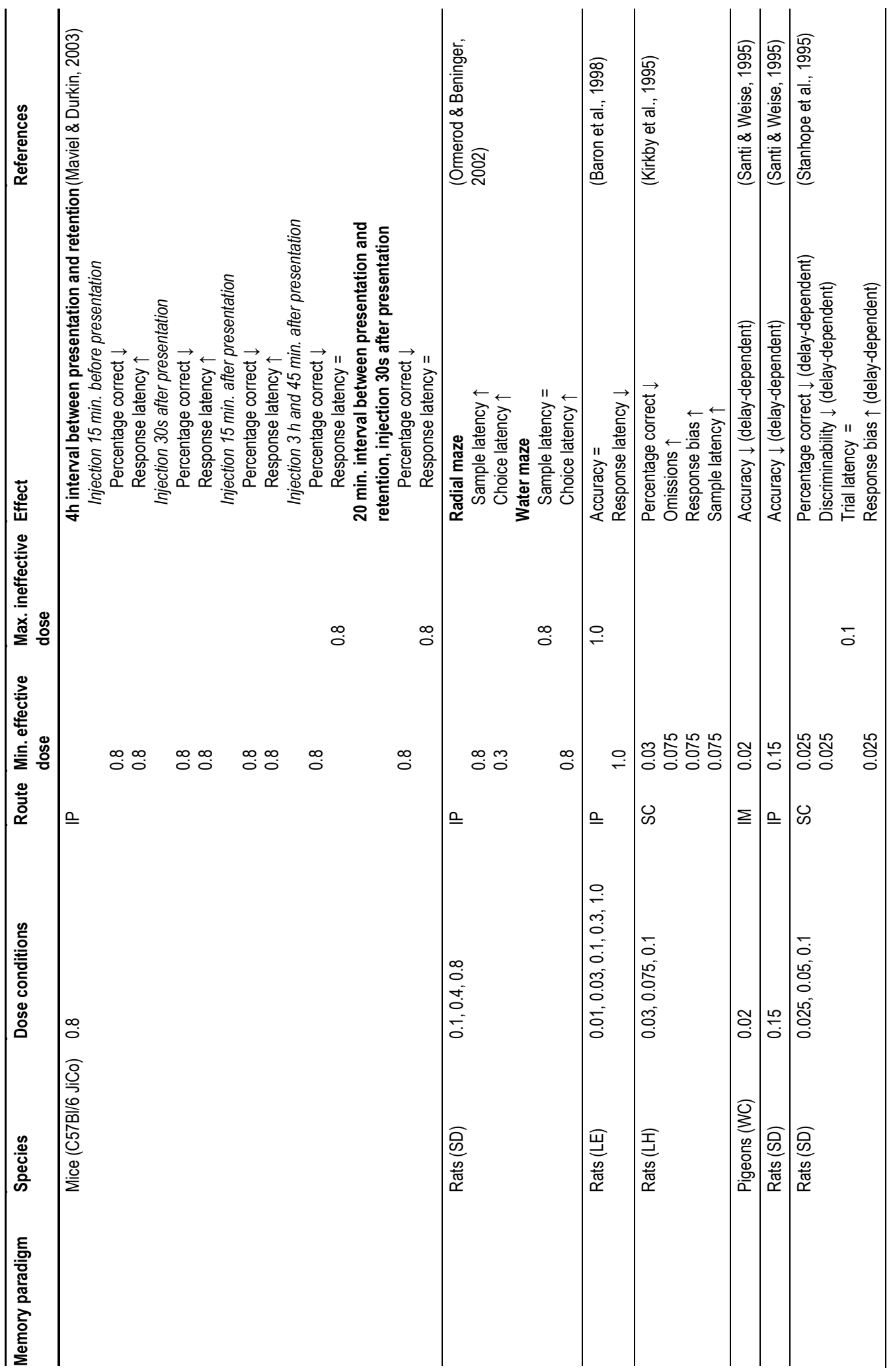




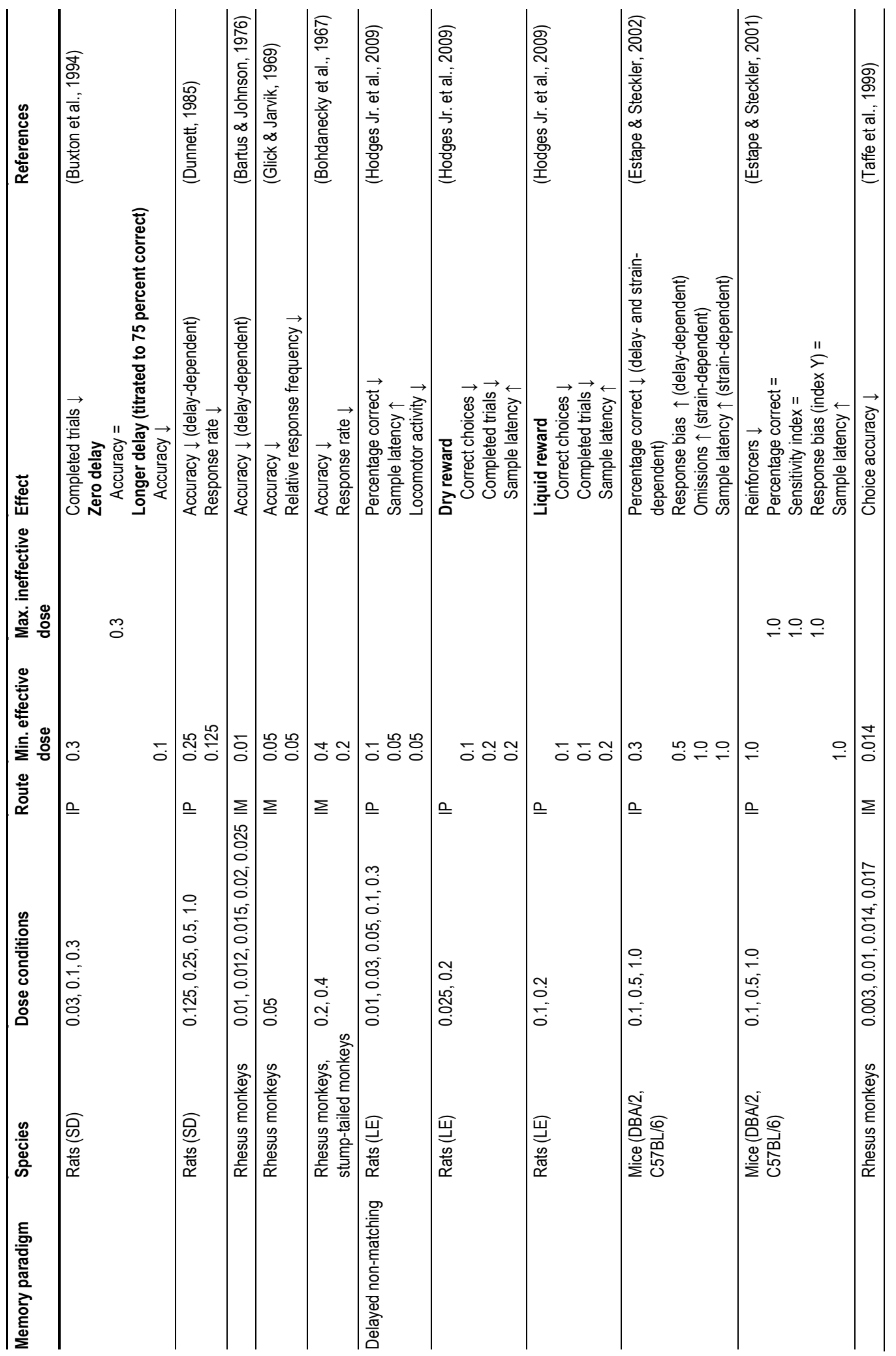




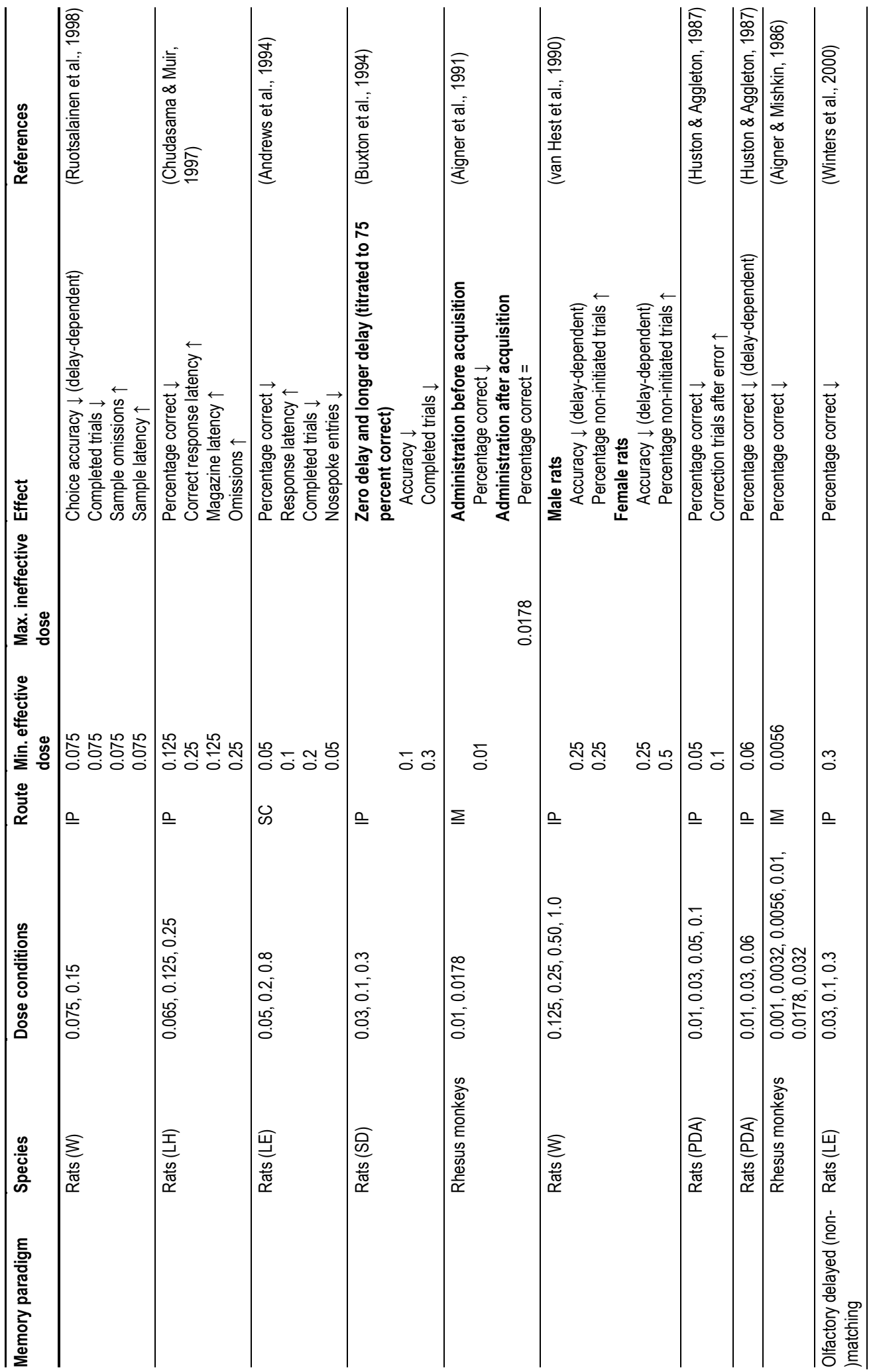




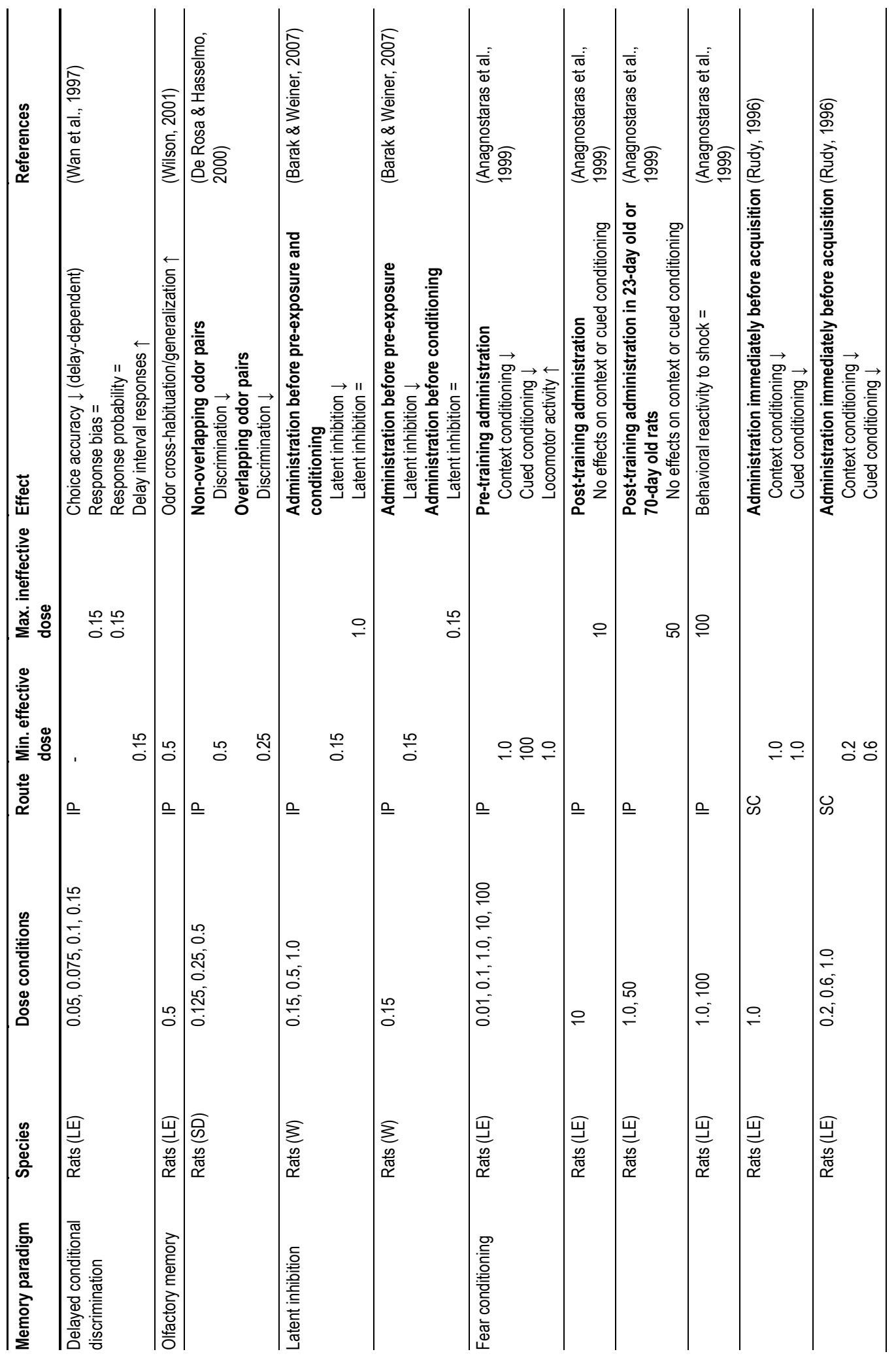




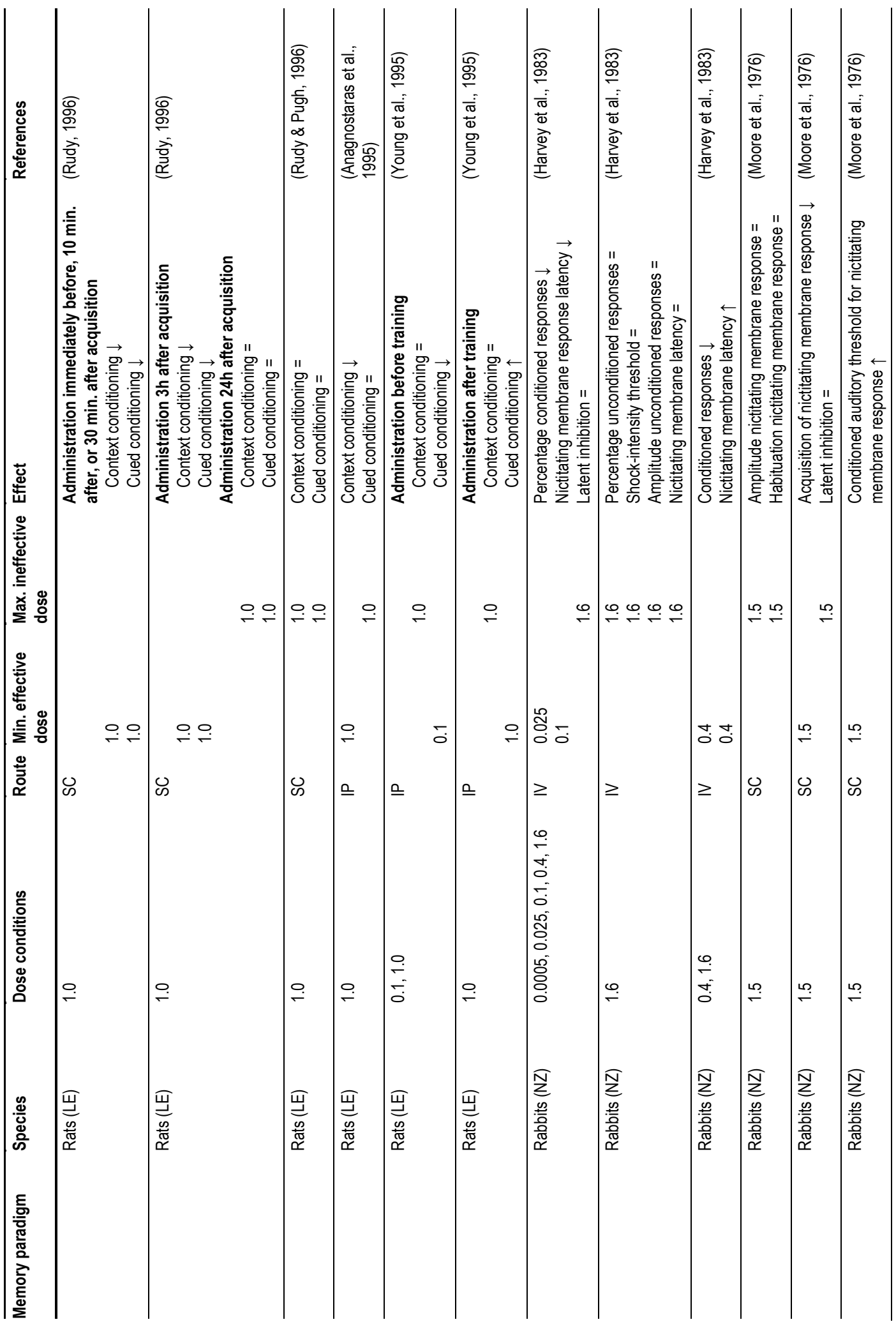




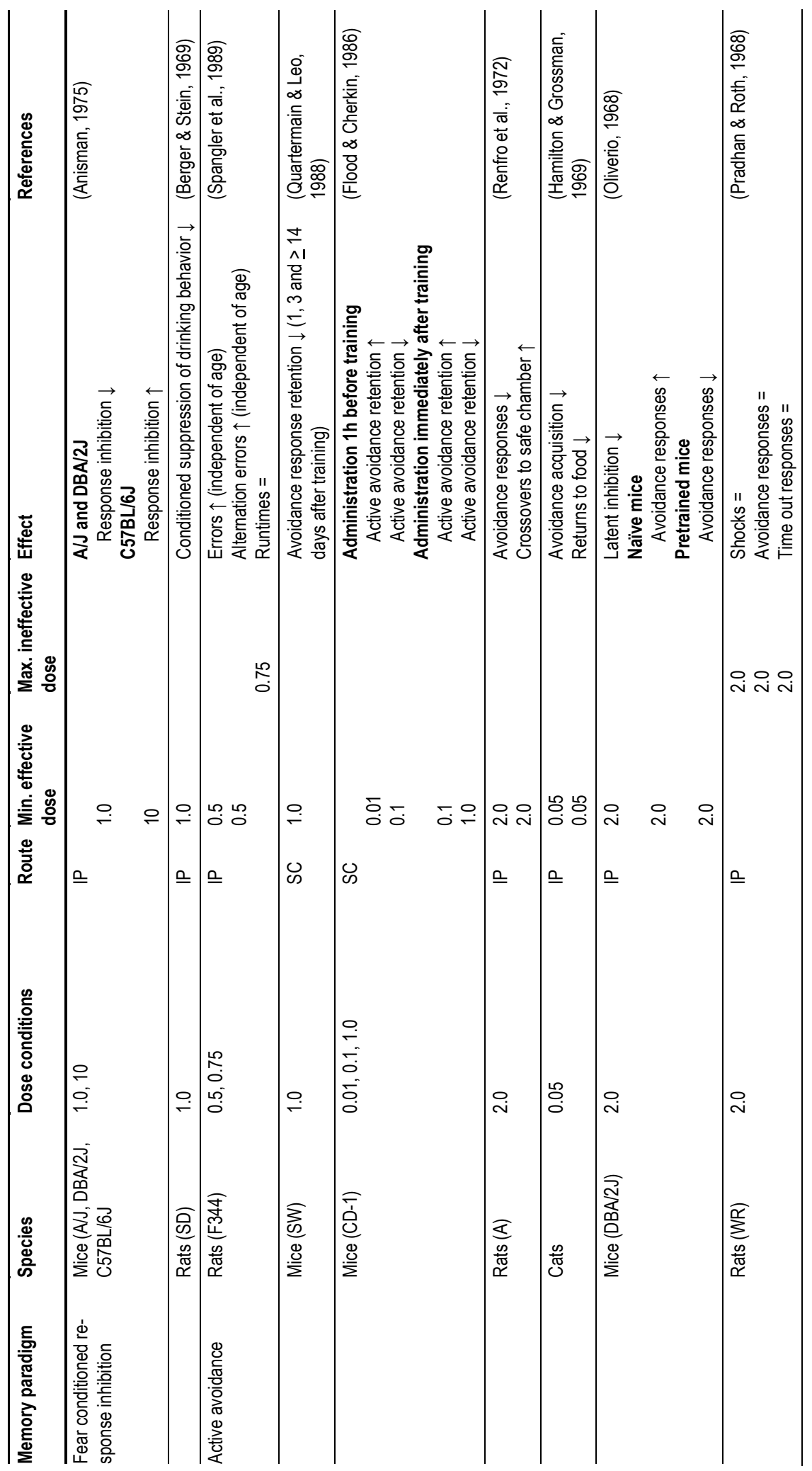




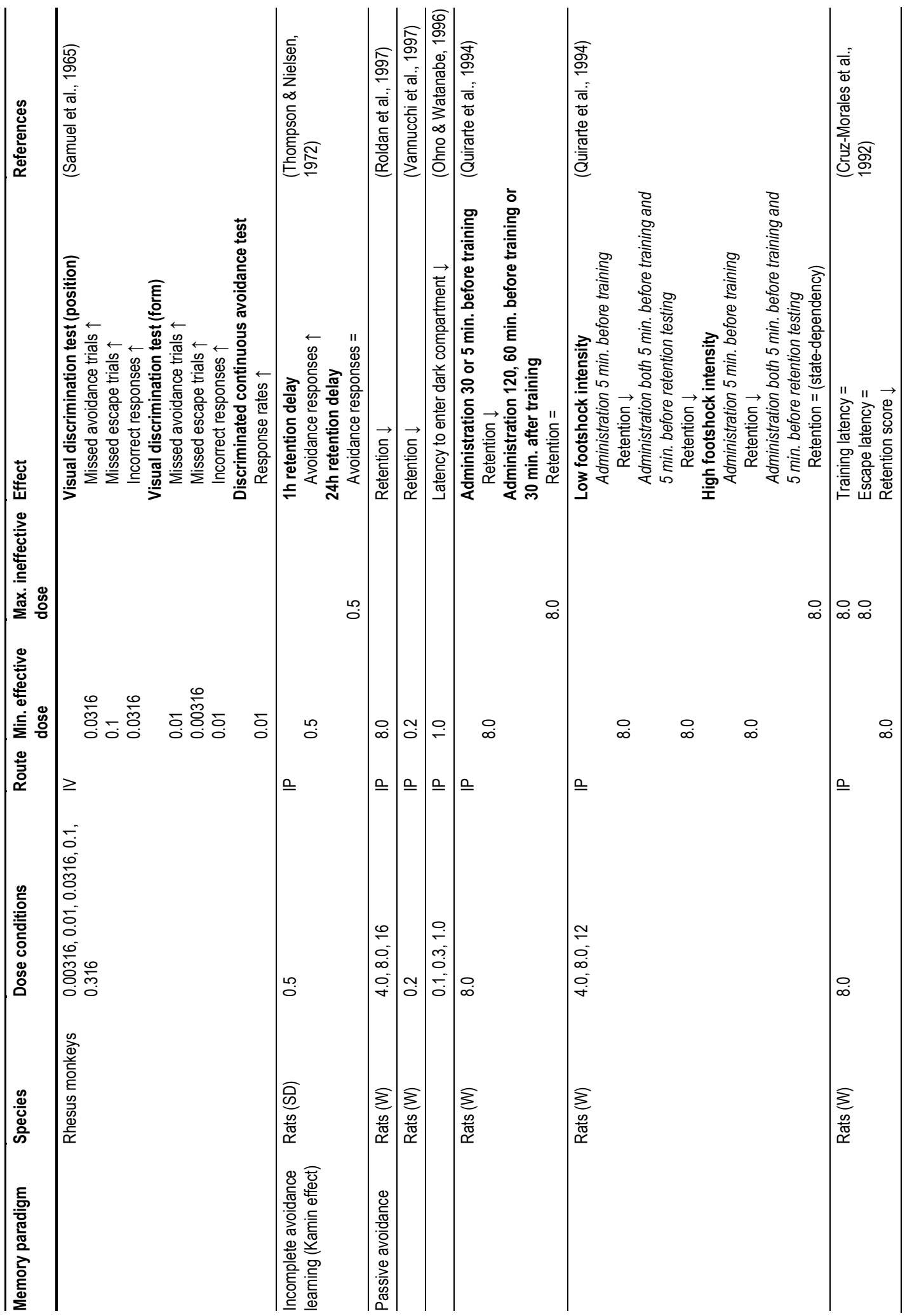




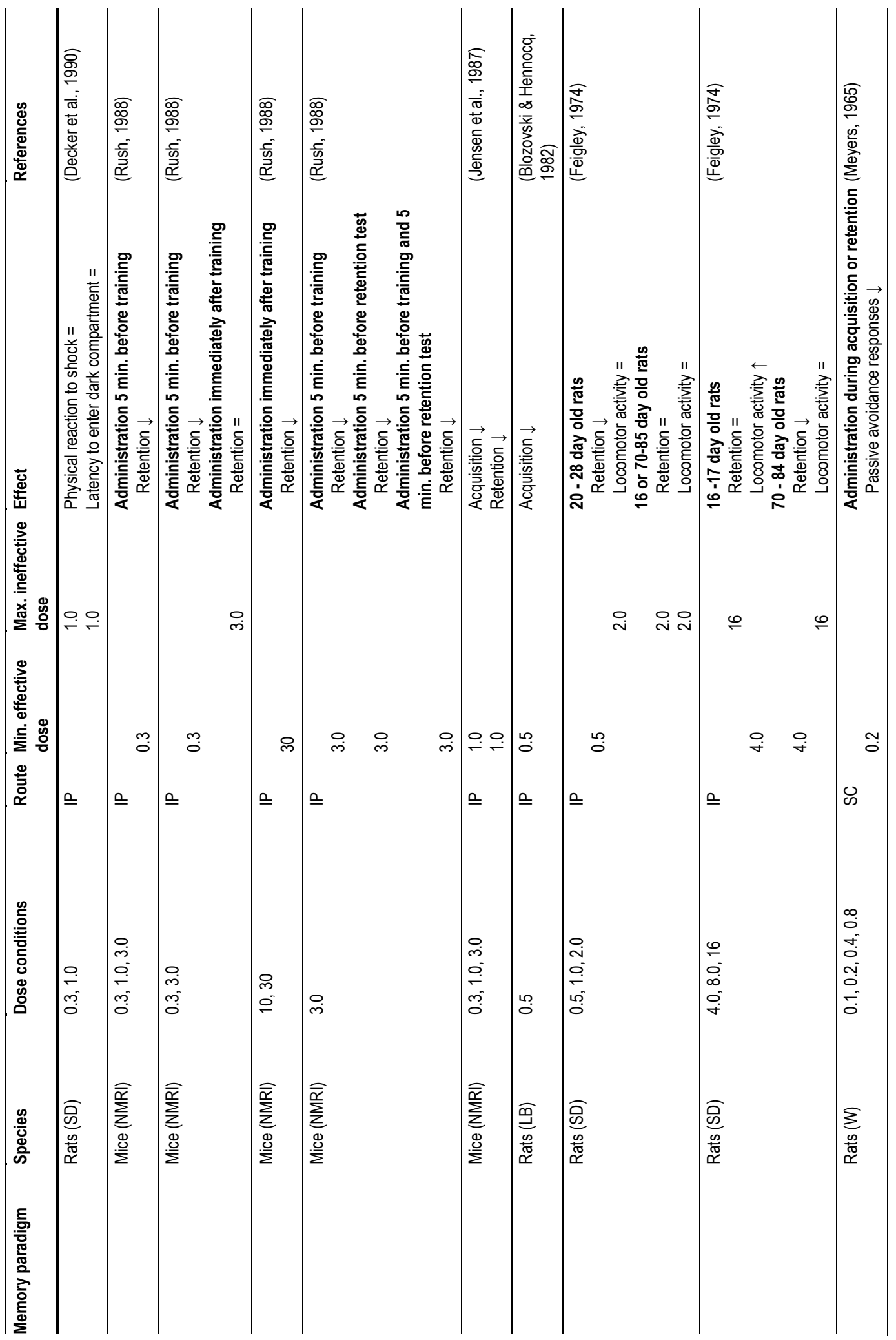




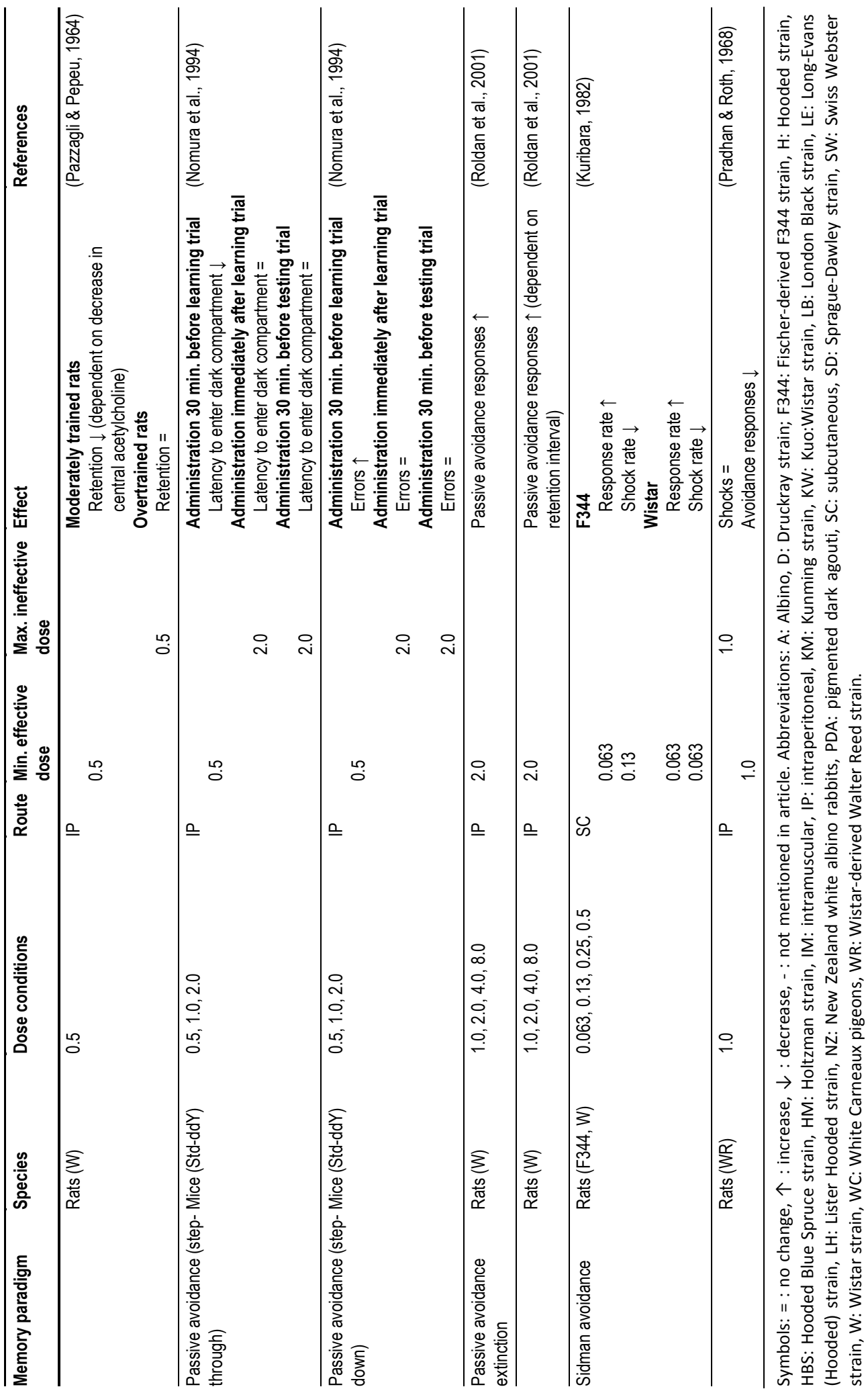




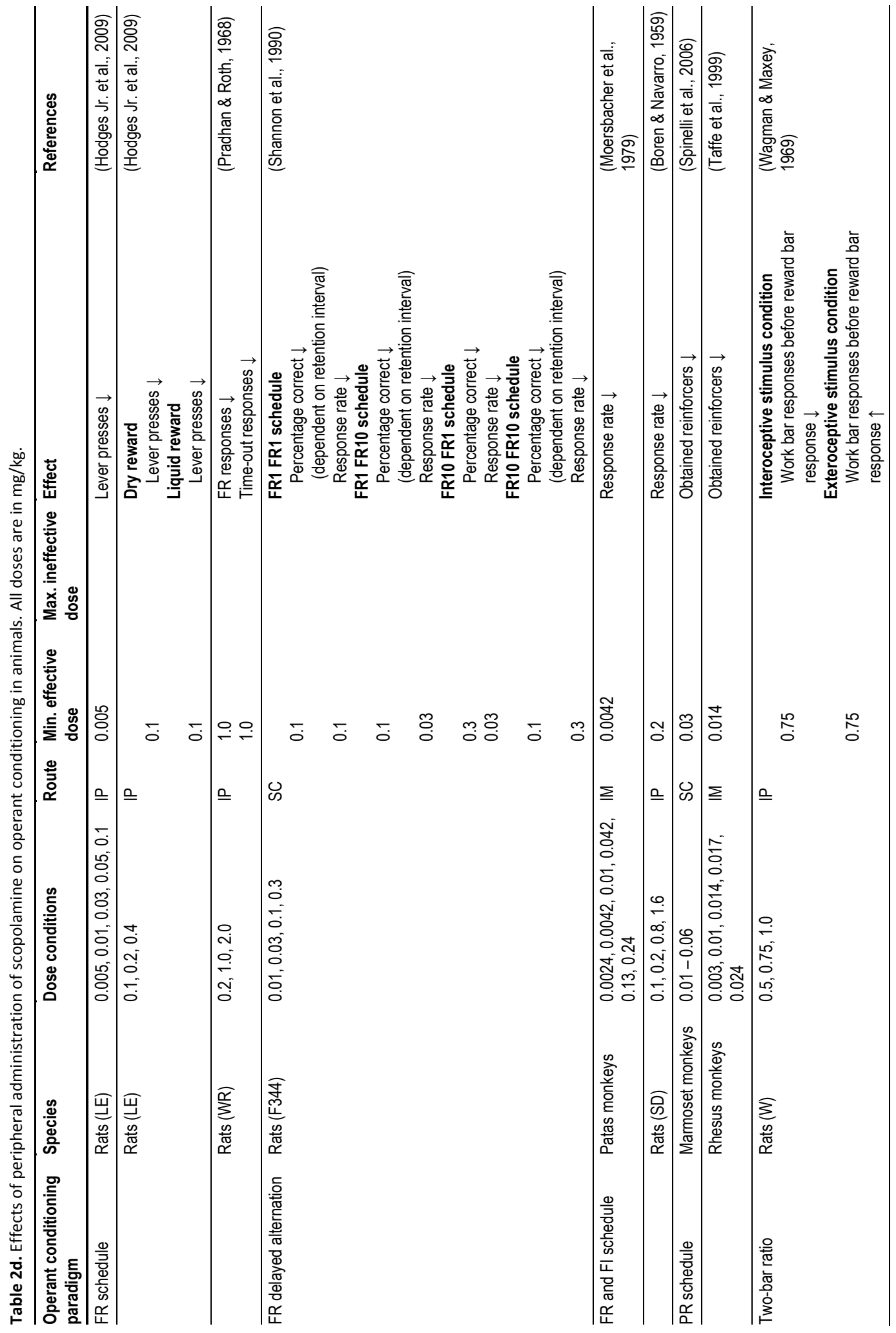




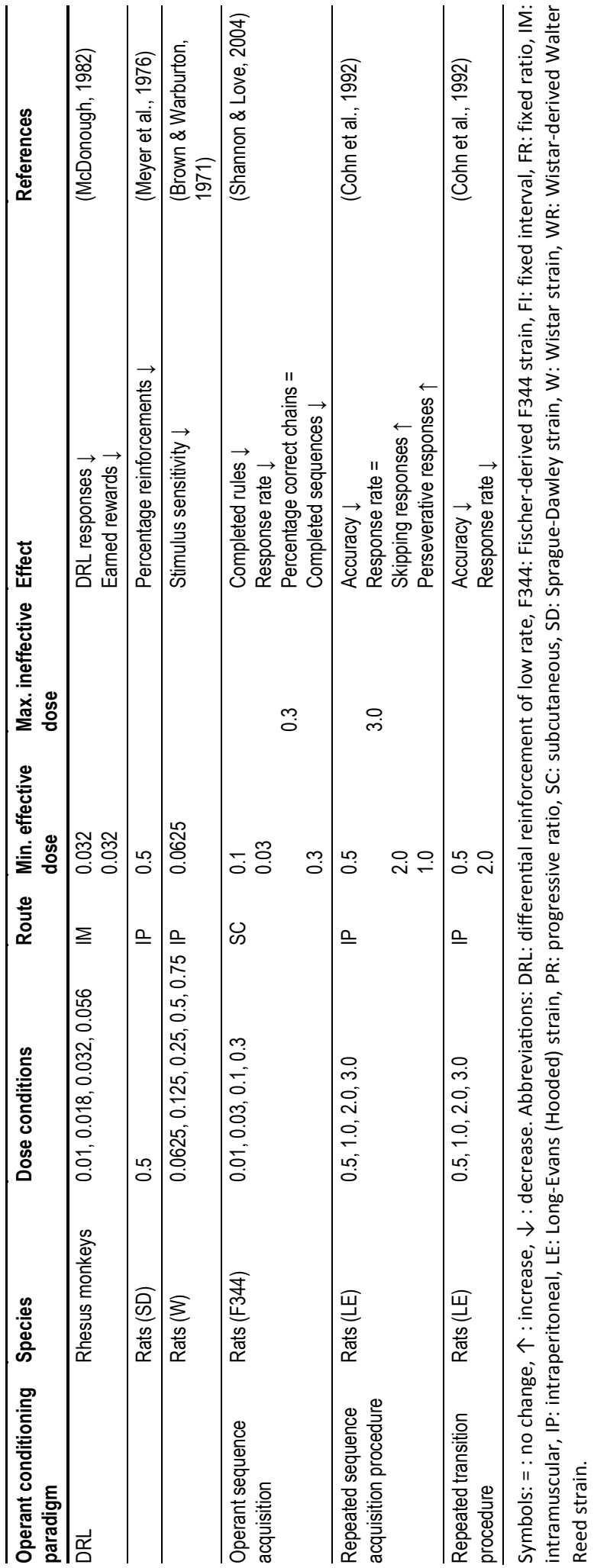




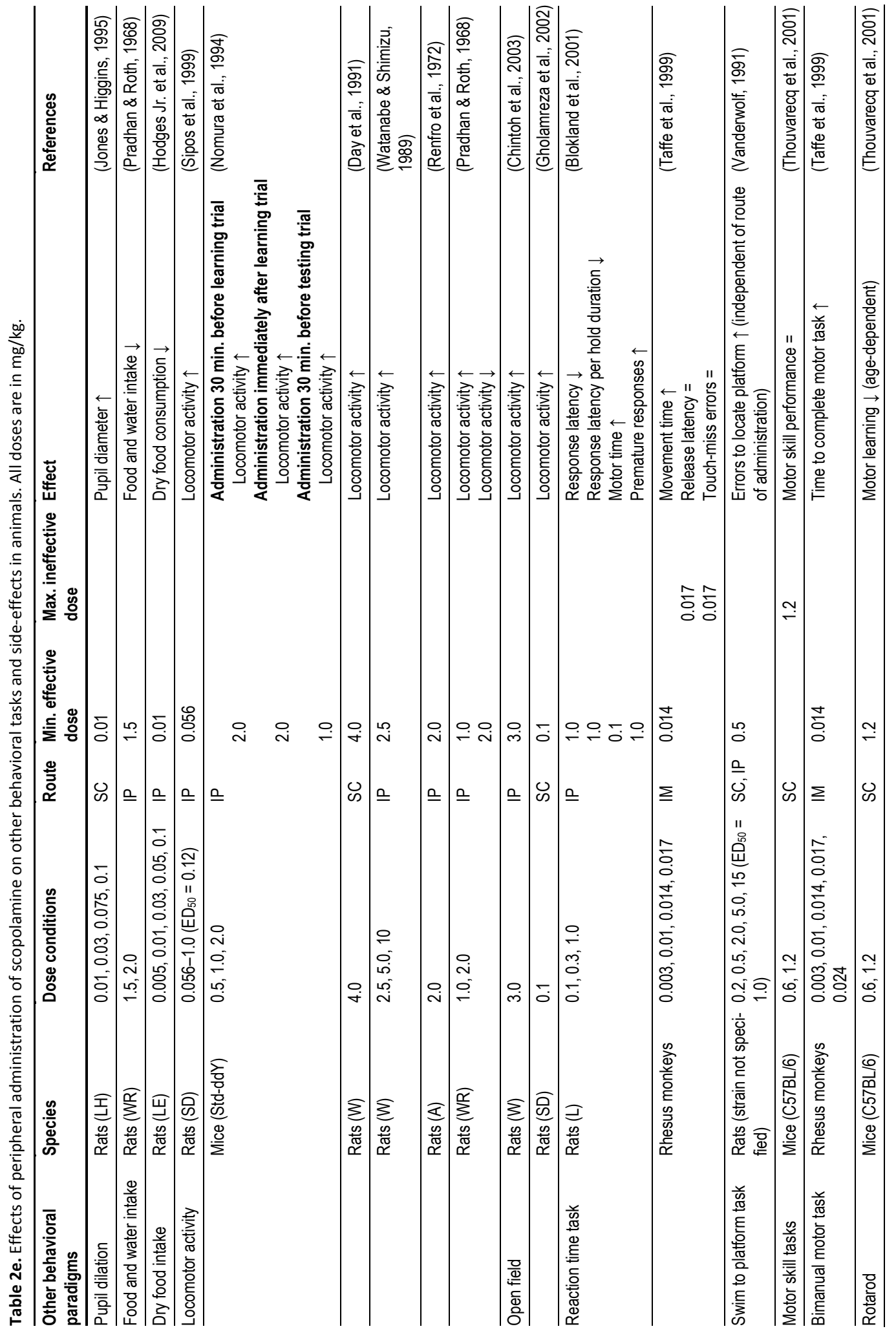




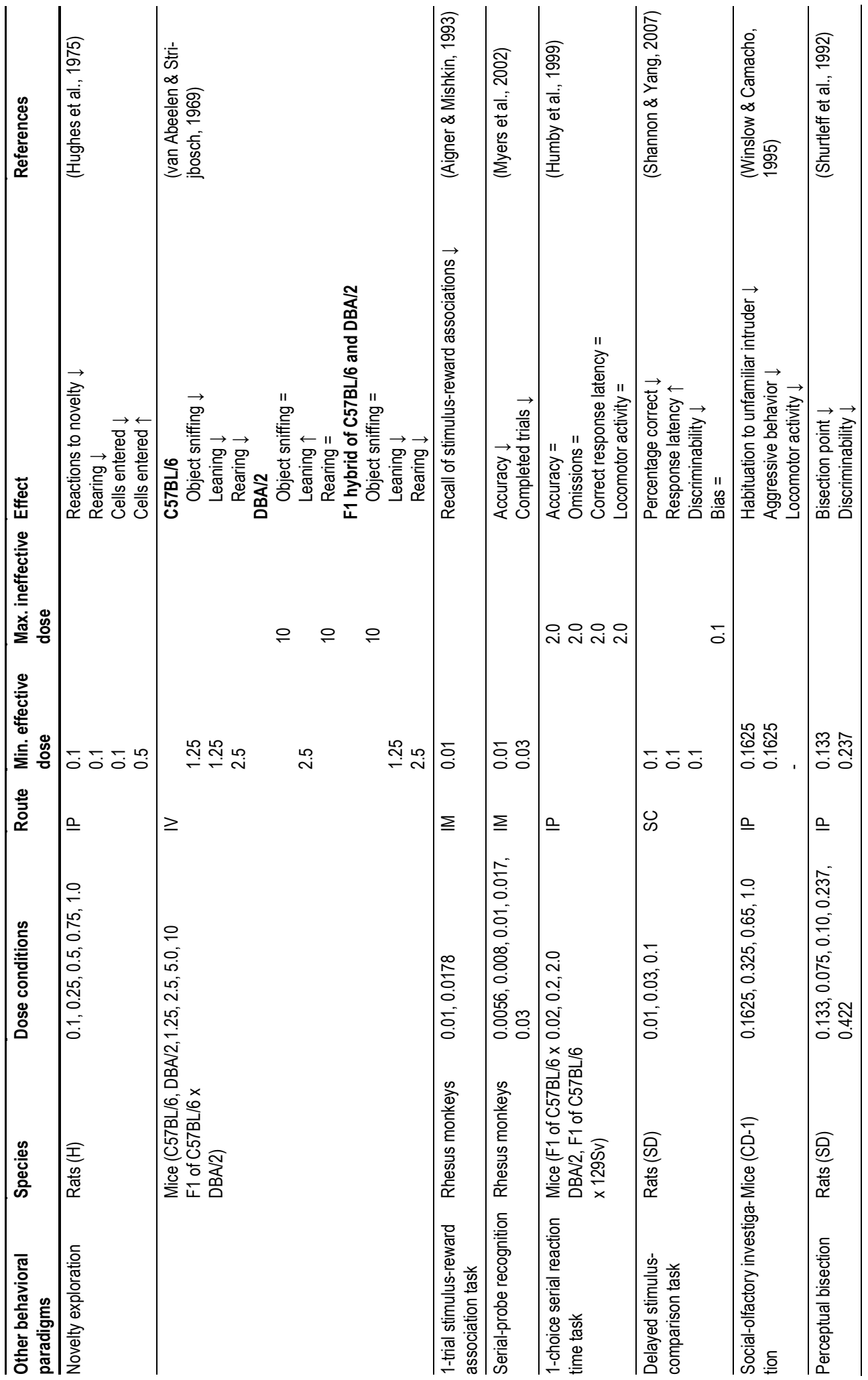




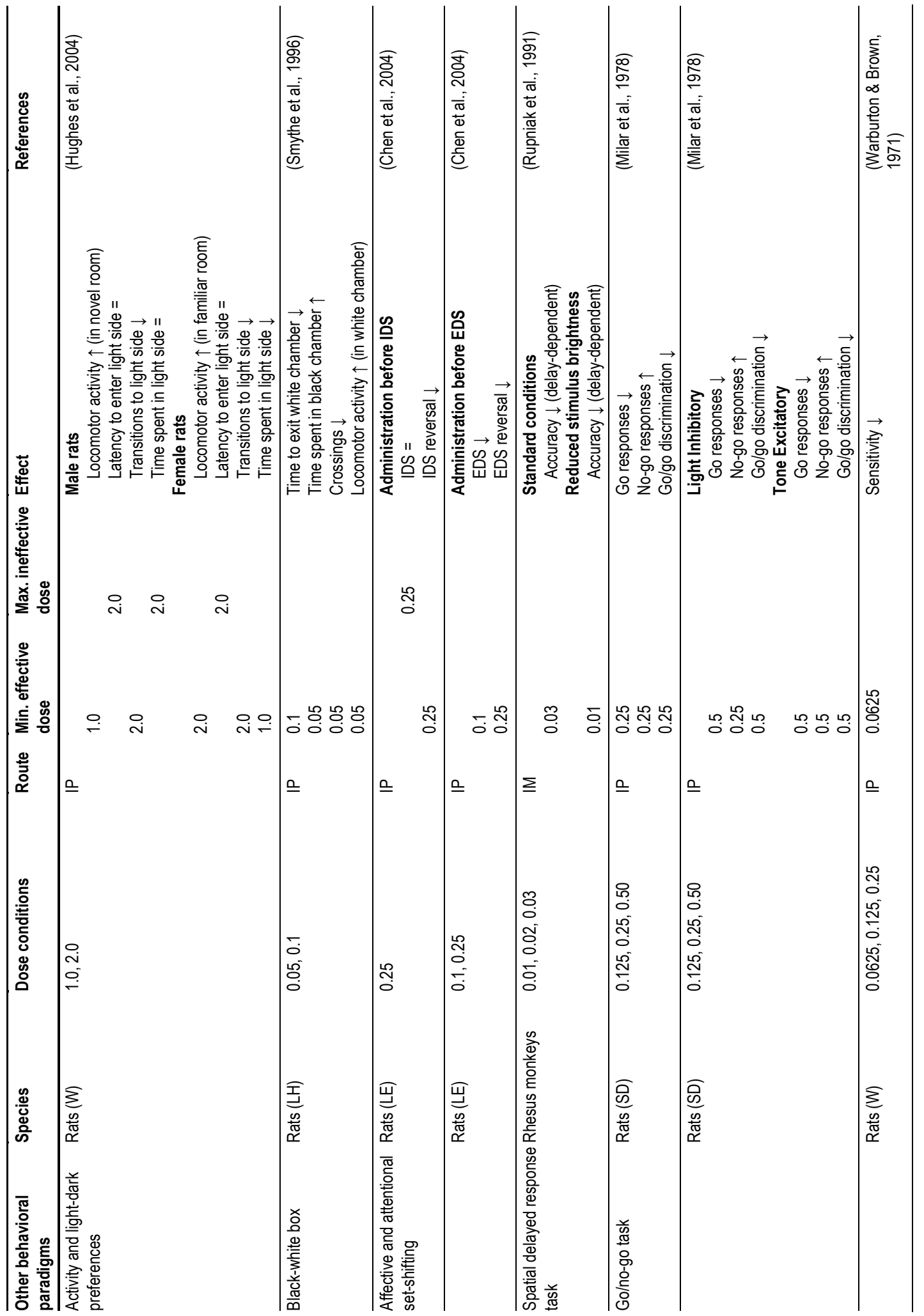




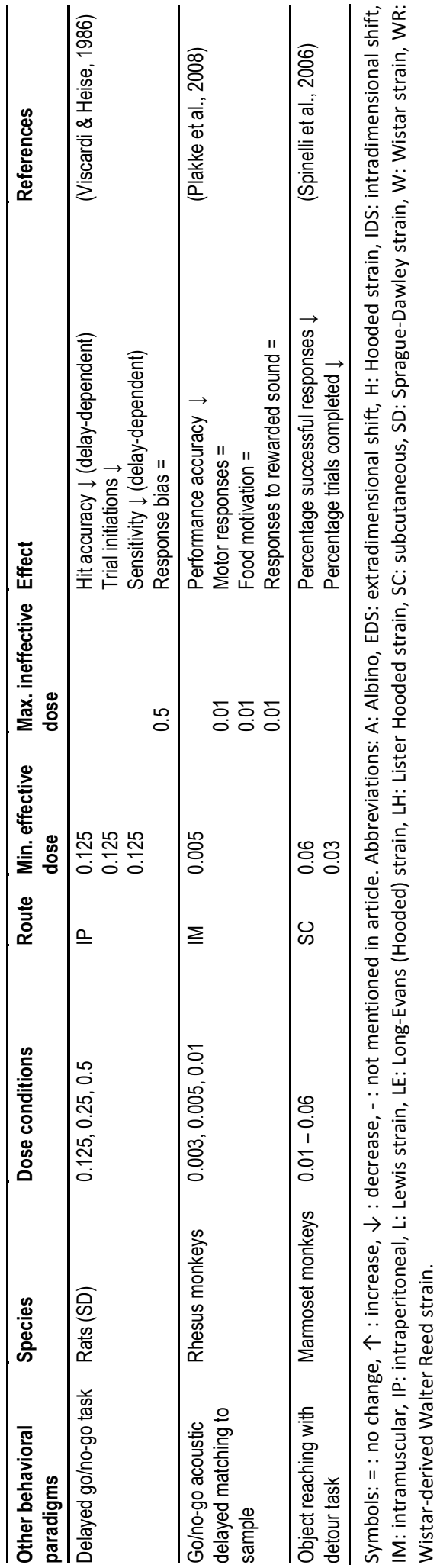




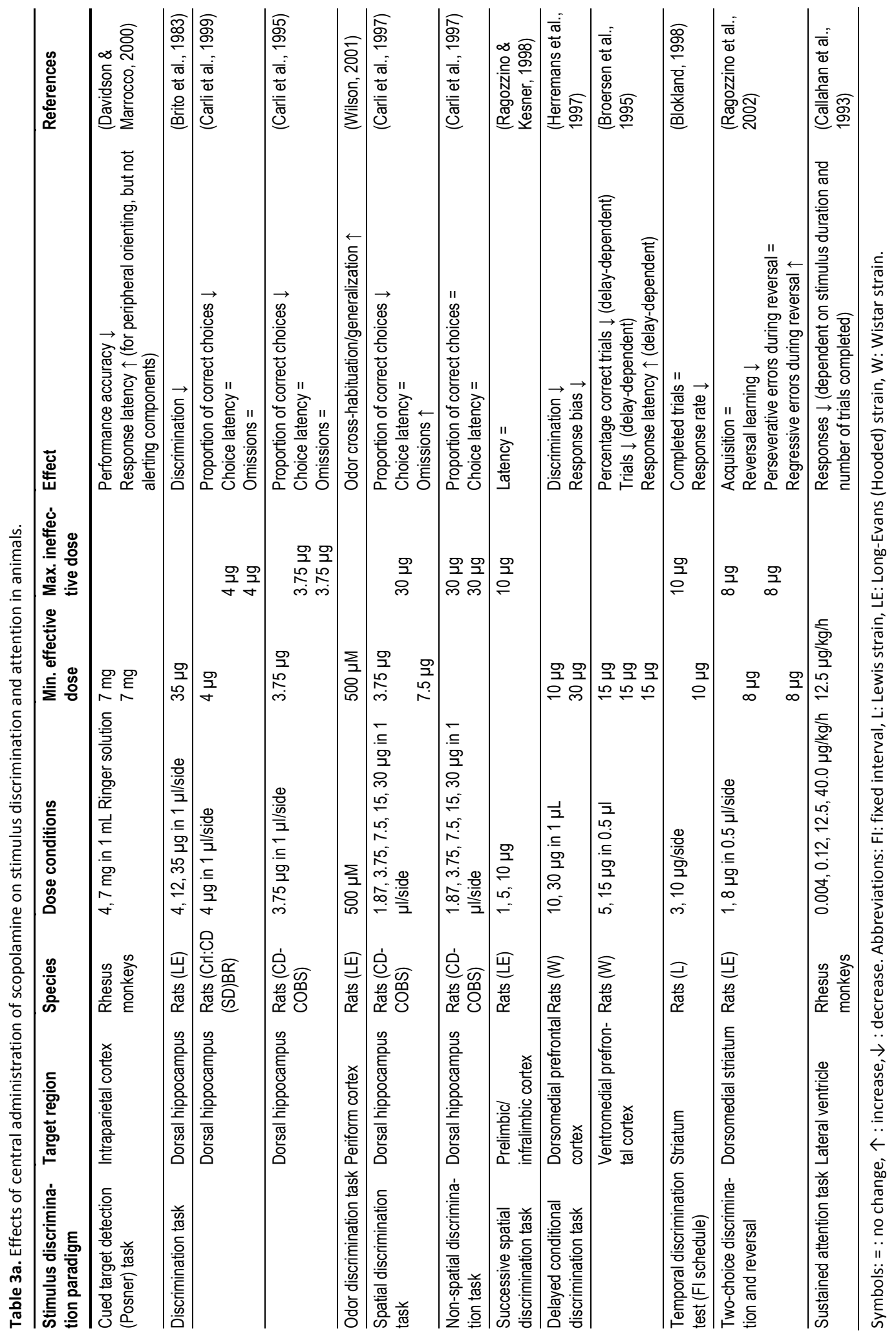




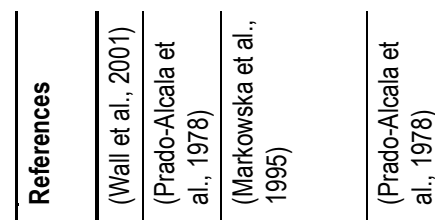

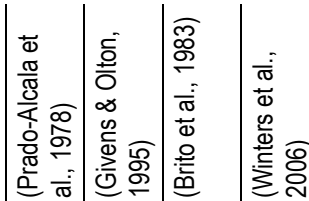

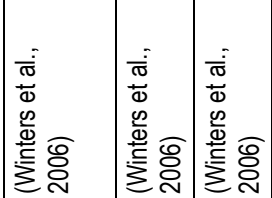
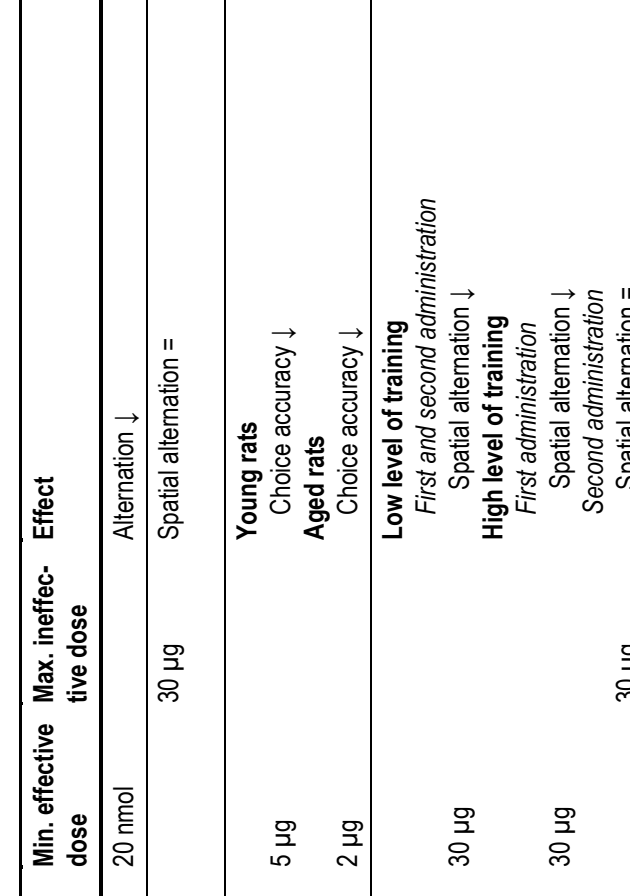

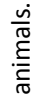

童

$\frac{0}{\frac{0}{0}}$

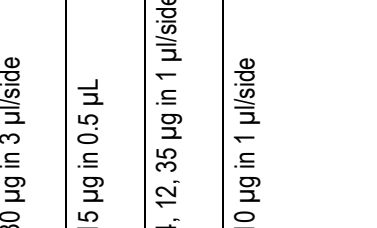
. 


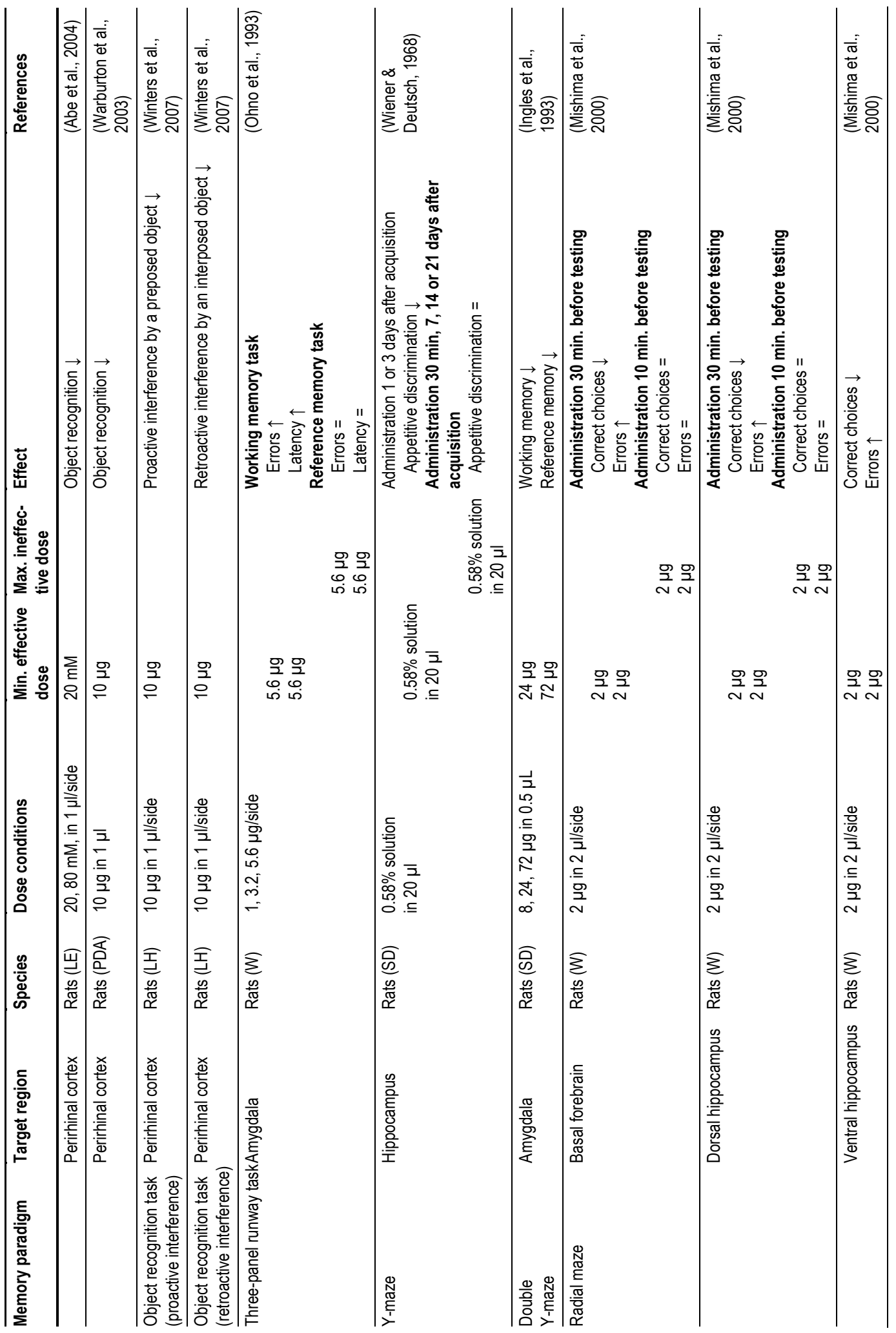




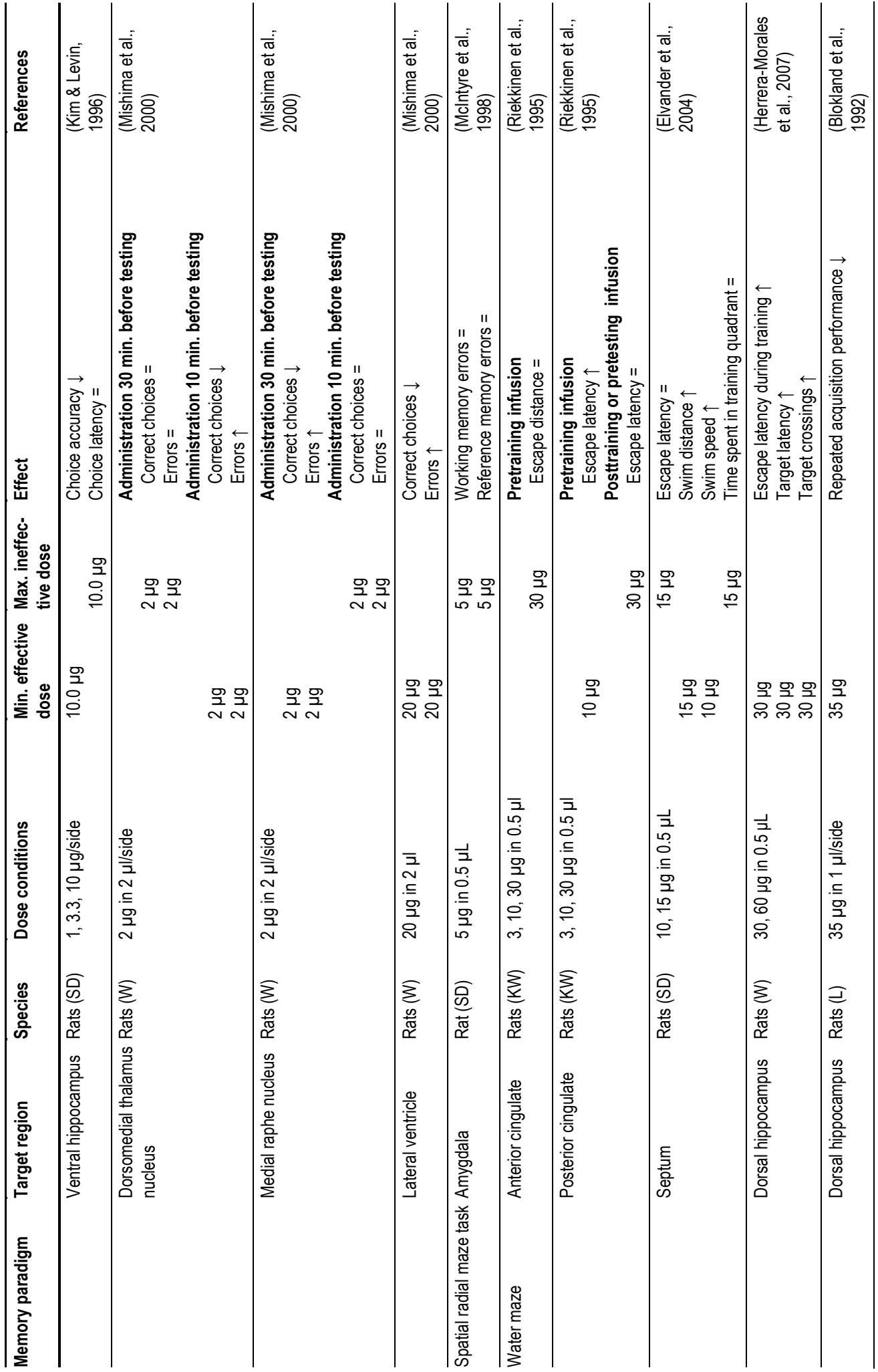




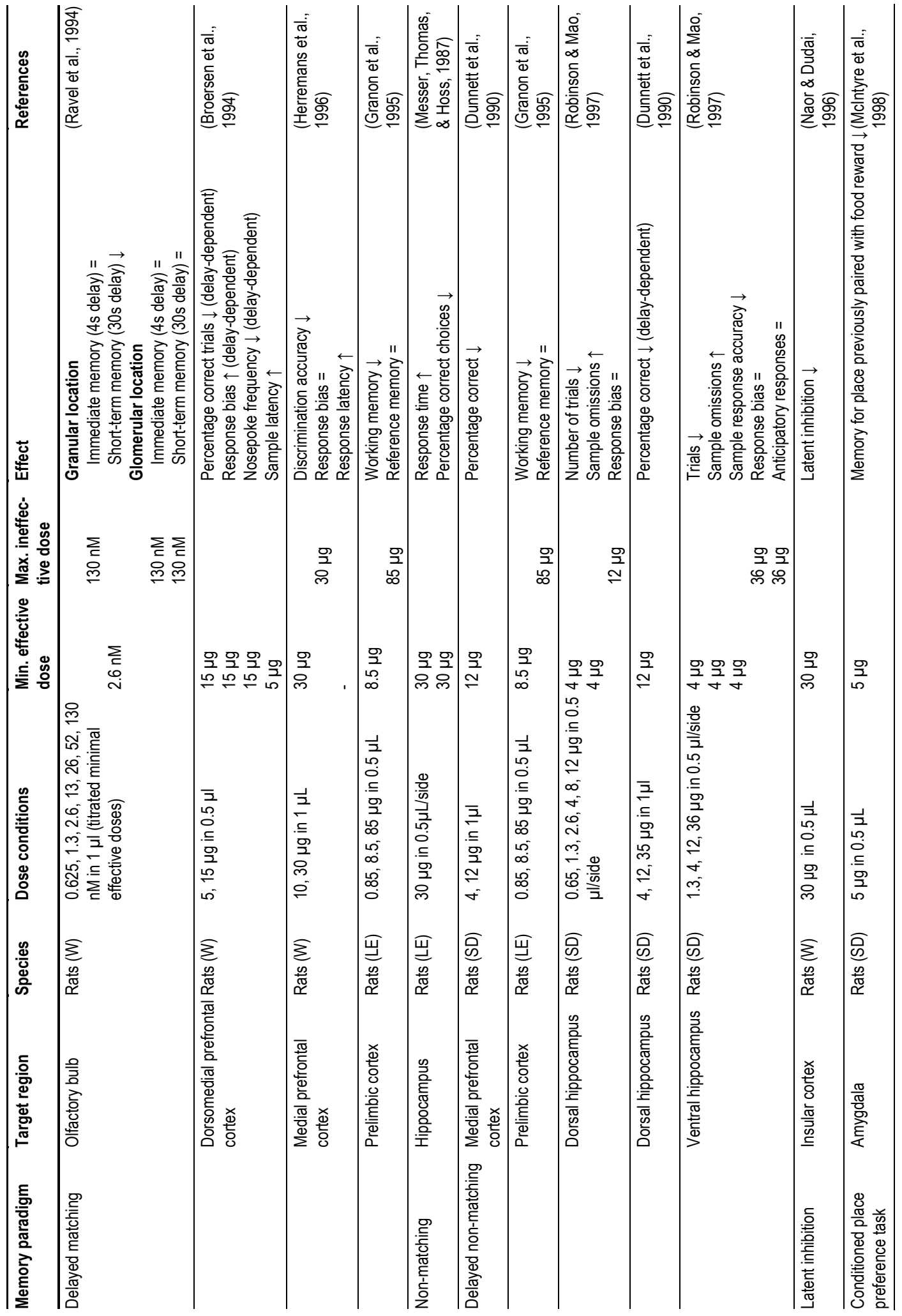




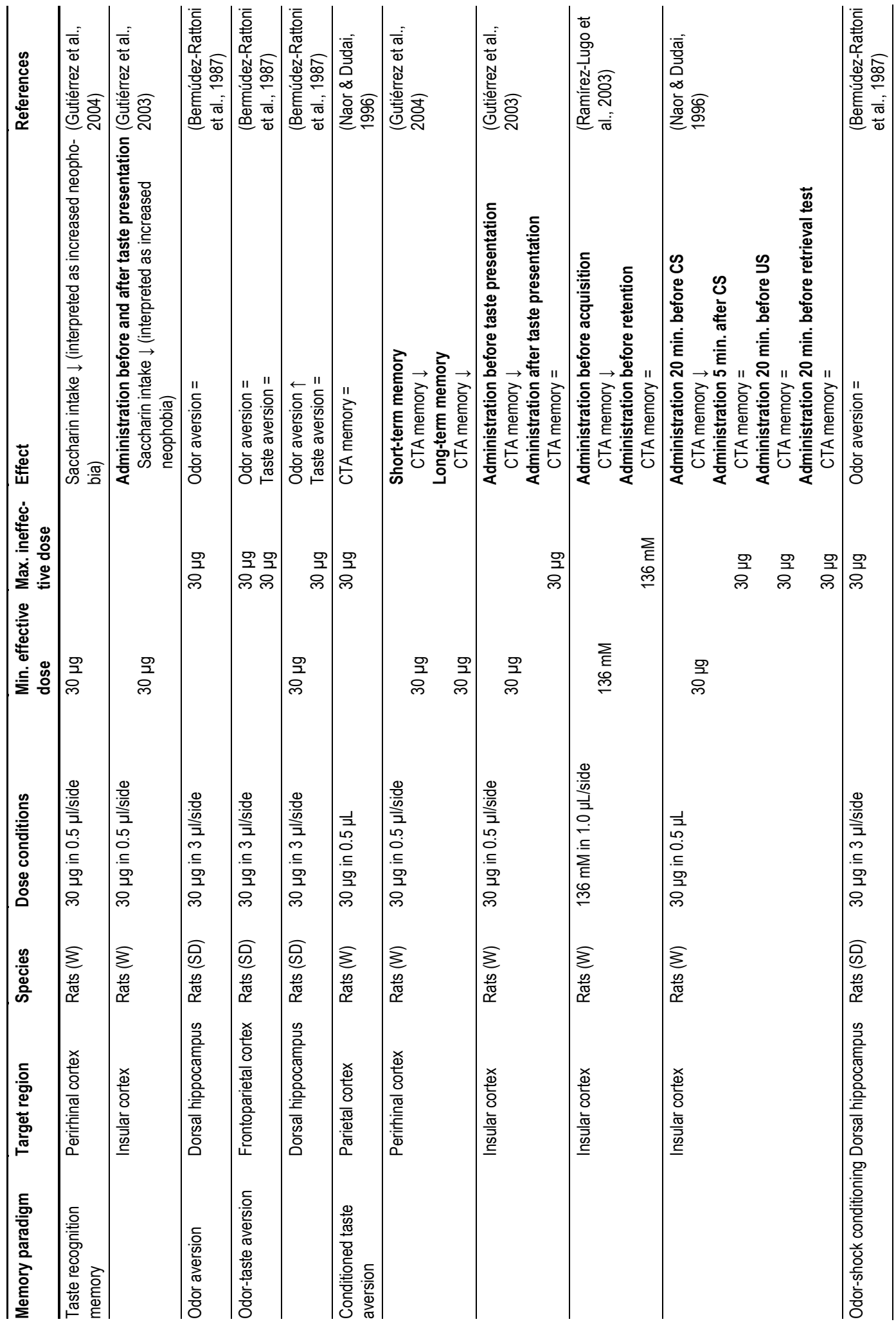




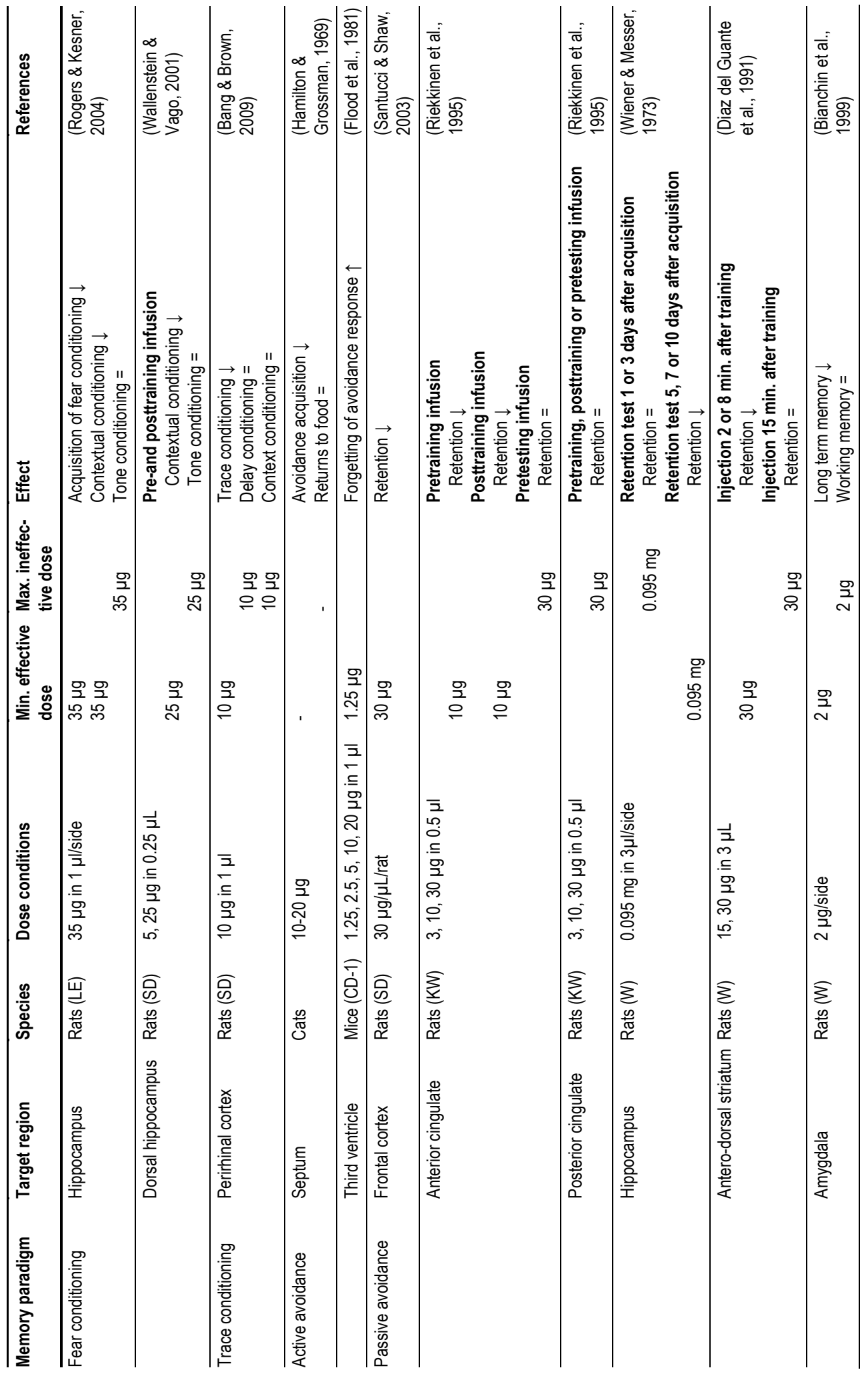




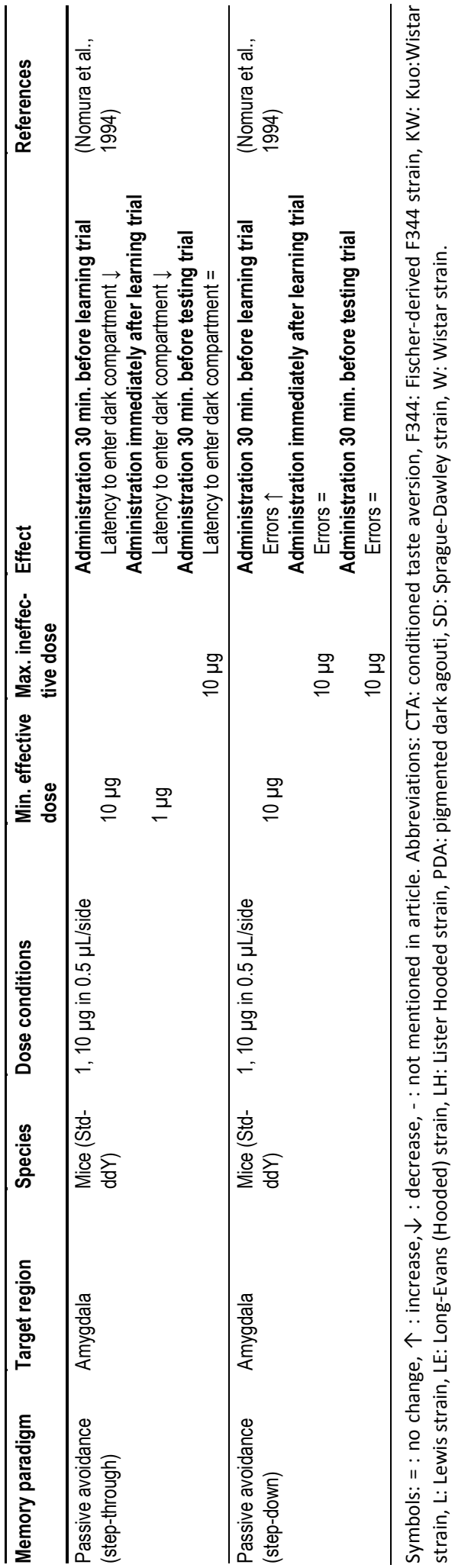




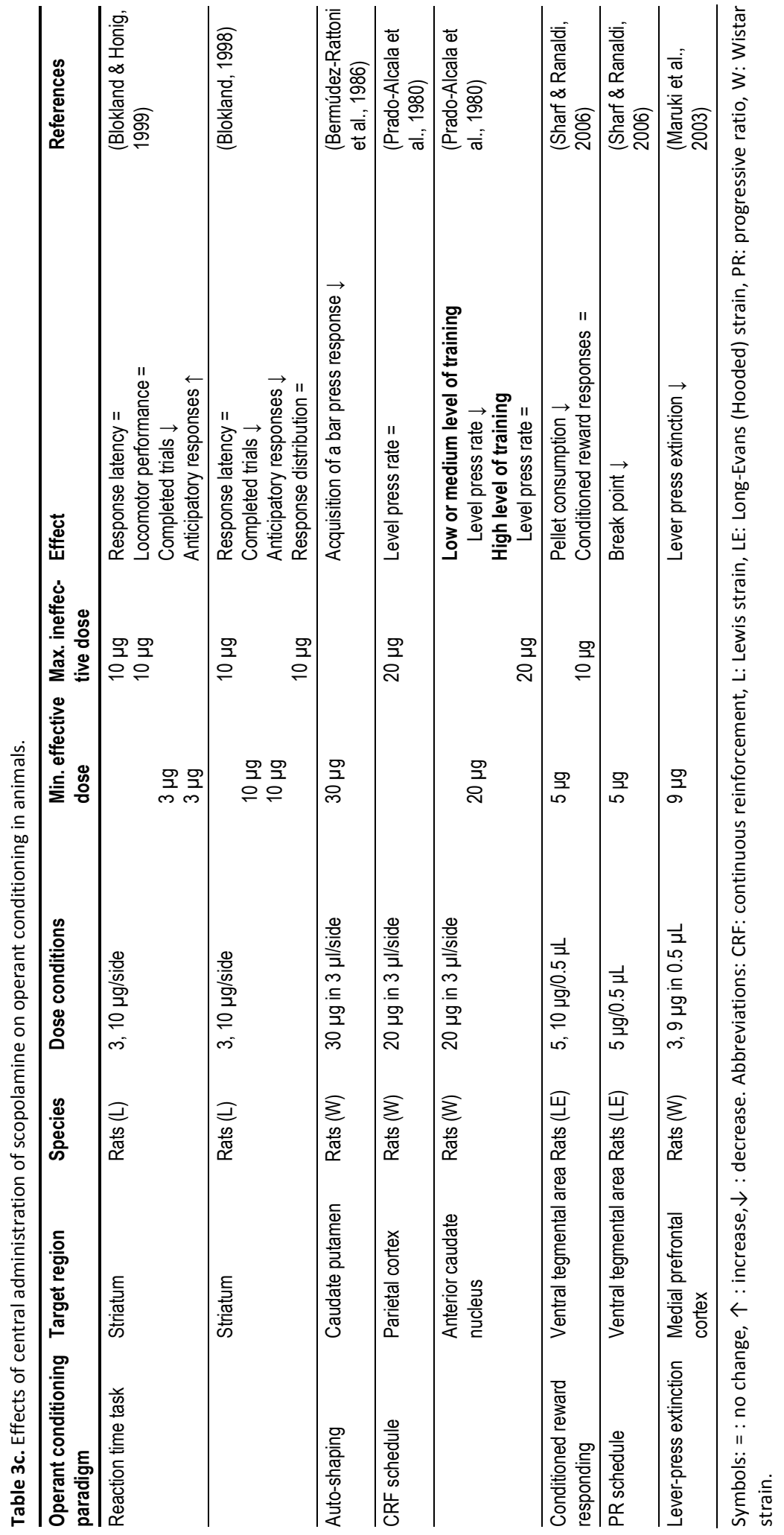




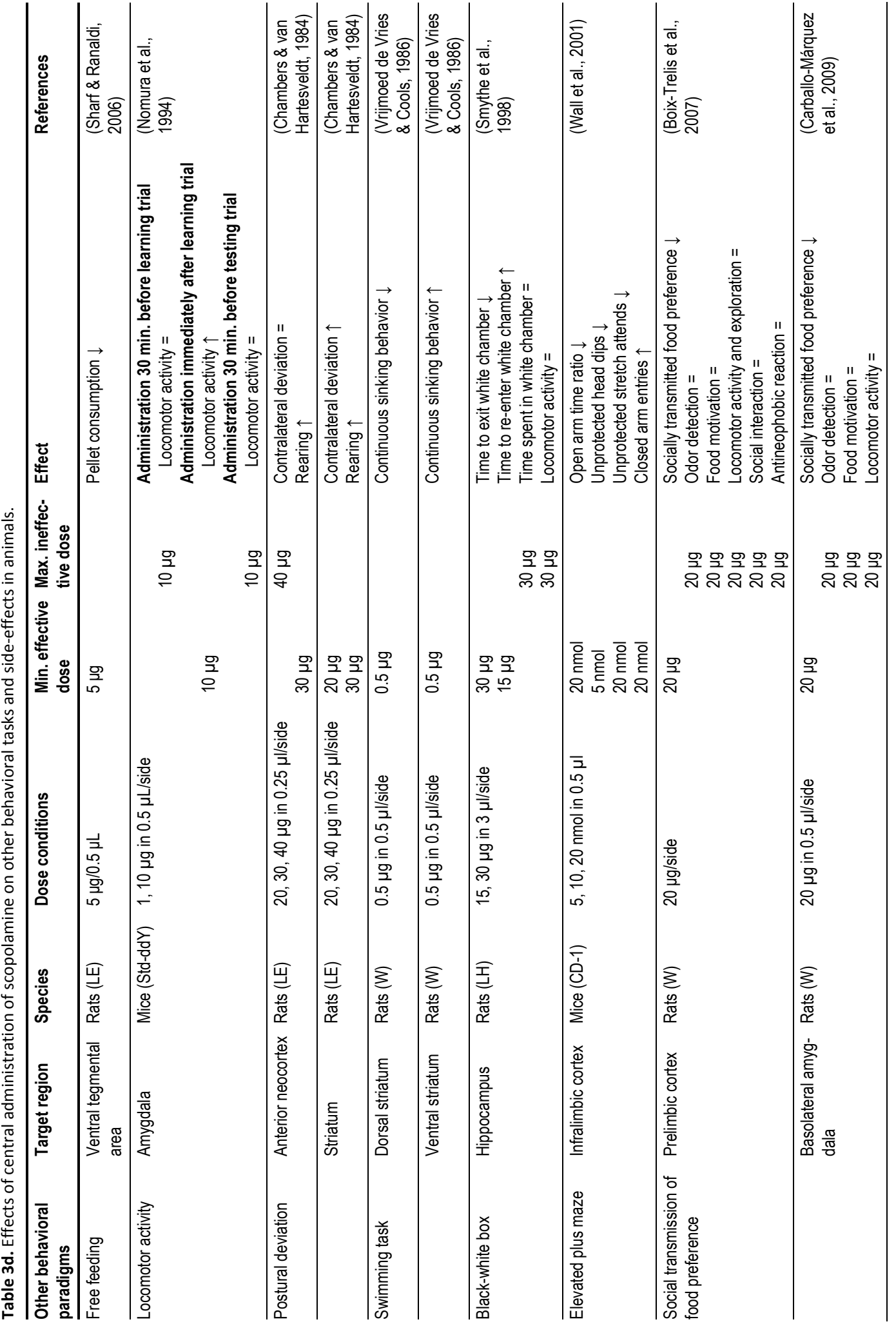


\begin{tabular}{ll|l} 
THE VALIDITY OF SCOPOLAMINE AS A PHARMACOLOGICAL MODEL FOR & 77
\end{tabular} COGNITIVE IMPAIRMENT

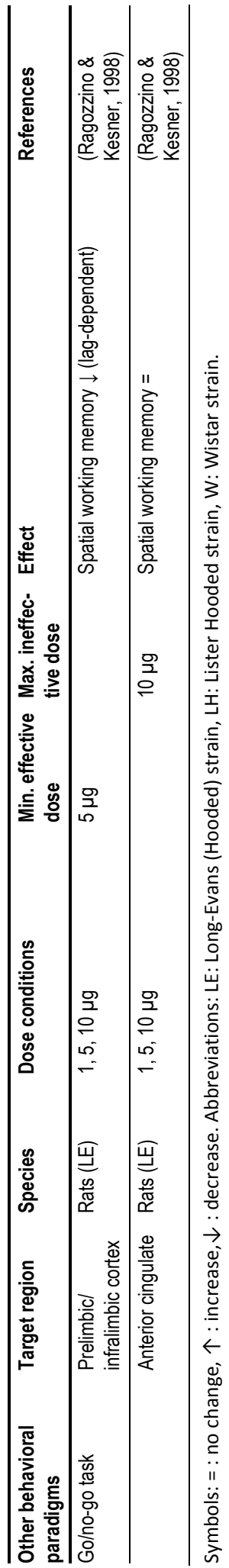




\section{REFERENCES}

Abe, H., Ishida, Y., \& Iwasaki, T. (2004). Perirhinal N-methyl-D-aspartate and muscarinic systems participate in object recognition in rats. Neuroscience Letters, 356, 191-194.

Aigner, T. G., \& Mishkin, M. (1986). The effects of physostigmine and scopolamine on recognition memory in monkeys. Behavioral and Neural Biology, 45, 81-87.

Aigner, T. G., \& Mishkin, M. (1993). Scopolamine impairs recall of one-trial stimulus-reward association in monkeys. Behavioural Brain Research, 54, 133-136.

Aigner, T. G., Walker, D. L., \& Mishkin, M. (1991). Comparison of the effects of scopolamine administered before and after acquisition in a test of visual recognition memory in monkeys [published erratum appears in Behav Neural Biol 1991 May;55(3):380]. Behavioral and Neural Biology, 55, 61-67.

Alpern, H. P., \& Marriott, J. G. (1973). Short-term memory: facilitation and disruption with cholinergic agents. Physiology \& Behavior, 11, 571-575.

Anagnostaras, S. G., Maren, S., \& Fanselow, M. S. (1995). Scopolamine selectively disrupts the acquisition of contextual fear conditioning in rats. Neurobiology of Learning and Memory, 64, 191-194.

Anagnostaras, S. G., Maren, S., Sage, J. R., Goodrich, S., \& Fanselow, M. S. (1999). Scopolamine and Pavlovian fear conditioning in rats: dose-effect analysis. Neuropsychopharmacology, 21, 731-744.

Andrews, J. S., Grützner, M., \& Stephens, D. N. (1992). Effects of cholinergic and non-cholinergic drugs on visual discrimination and delayed visual discrimination performance in rats. Psychopharmacology, 106, 523-530.

Andrews, J. S., Jansen, J. H. M., Linders, S., \& Princen, A. (1994). Effects of disrupting the cholinergic system on short-term spatial memory in rats. Psychopharmacology, 115, 485-494.

Anisman, H. (1975). Dissociation of disinhibitory effects of scopolamine: strain and task factors. Pharmacology, Biochemistry and Behavior, 3, 613-618.

Anisman, H., \& Kokkinidis, L. (1975). Effects of scopolamine, d-amphetamine and other drugs affecting catecholamines on spontaneous alternation and locomotor activity in mice. Psychopharmacologia, 45, 55-63.

Aura, J., Sirviö, J., \& Riekkinen, P. (1997). Methoctramine moderately improves memory but pirenzepine disrupts performance in delayed non-matching to position test. European Journal of Pharmacology, 333, 129-134.

Bajalan, A. A. A., Wright, C. E., \& Van der Vliet, V. J. (1986). Changes in the human visual evoked potential caused by the anticholinergic agent hyoscine hydrobromide: Comparison with results in Alzheimer's disease. Journal of Neurology, Neurosurgery, and Psychiatry, 49, 175-182.

Bang, S. J., \& Brown, T. H. (2009). Muscarinic receptors in perirhinal cortex control trace conditioning. The Journal of Neuroscience, 29, 4346-4350.

Barak, S., \& Weiner, I. (2007). Scopolamine induces disruption of latent inhibition which is prevented by antipsychotic drugs and an acetylcholinesterase inhibitor. Neuropsychopharmacology, 32, 989-999.

Baron, S. P., Wright, D., \& Wenger, G. R. (1998). Effects of drugs of abuse and scopolamine on memory in rats: delayed spatial alternation and matching to position. Psychopharmacology, 137, 7-14.

Bartus, R. T., Dean, R. L., Beer, B., \& Lippa, A. S. (1982). The cholinergic hypothesis of geriatric memory dysfunction. Science, 217, 408-417.

Bartus, R. T., Dean, R. L., Pontecorvo, M. J., \& Flicker, C. (1985). The cholinergic hypothesis: a historical overview, current perspective, and future directions. Annals of the New York Academy of Sciences, 444, 332-358.

Bartus, R. T., \& Johnson, H. R. (1976). Short-term memory in the rhesus monkey: disruption from the anticholinergic scopolamine. Pharmacology Biochemistry and Behavior, 5, 39-46.

Baxter, M., \& Gallagher, M. (1996). Intact spatial learning in both young and aged rats following selective removal of hippocampal cholinergic input. Behavioral Neuroscience, 110, 460-467.

Baxter, M. G., Holland, P. C., \& Gallagher, M. (1997). Disruption of decrements in conditioned stimulus processing by selective removal of hippocampal cholinergic input. The Journal of Neuroscience, 17, 5230-5236.

Beatty, W. W., \& Bierley, R. A. (1985). Scopolamine degrades spatial working memory but spares spatial reference memory: dissimilarity of anticholinergic effect and restriction of distal visual cues. Pharmacology, Biochemistry and Behavior, 23, 1-6. 
Berger-Sweeney, J., Arnold, A., Gabeau, D., \& Mills, J. (1995). Sex differences in learning and memory in mice: effects of sequence of testing and cholinergic blockade. Behavioral Neuroscience, 109, 859-873.

Berger, B. D., \& Stein, L. (1969). An analysis of the learning deficits produced by scopolamine. Psychopharmacologia, 14, 271-283.

Bermúdez-Rattoni, F., Coburn, K. L., Fernandez, J., Chavez, A. F., \& Garcia, J. (1987). Potentiation of odor by taste and odor aversions in rats are regulated by cholinergic activity of dorsal hippocampus. Pharmacology, Biochemistry and Behavior, 26, 553-559.

Bermúdez-Rattoni, F., Mujica Gonzalez, M., \& Prado Alcala, R. A. (1986). Is cholinergic activity of the striatum involved in the acquisition of positively-motivated behaviors? Pharmacology Biochemistry and Behavior, 24, 715-719.

Besheer, J., Short, K. R., \& Bevins, R. A. (2001). Dopaminergic and cholinergic antagonism in a novel-object detection task with rats. Behavioural Brain Research, 126, 211-217.

Bianchin, M., Mello e Souza, T., Medina, J. H., \& Izquierdo, I. (1999). The amygdala is involved in the modulation of long-term memory, but not in working or short-term memory. Neurobiology of Learning and Memory, 71, 127-131.

Biggan, S. L., Ingles, J. L., \& Beninger, R. J. (1996). Scopolamine differentially affects memory of 8- and 16month-old rats in the double Y-maze. Neurobiology of Aging, 17, 25-30.

Blokland, A. (1995). Acetylcholine: a neurotransmitter for learning and memory? Brain Research Reviews, 21, 285-300.

Blokland, A. (1998). Involvement of striatal cholinergic receptors in reaction time and fixed interval responding in rats. Brain Research Bulletin, 45, 21-25.

Blokland, A., \& Honig, W. (1999). Intra-striatal haloperidol and scopolamine injections: effects on choice reaction time performance in rats. European Neuropsychopharmacology, 9, 223-232.

Blokland, A., Honig, W., \& Raaijmakers, W. G. M. (1992). Effects of intra-hippocampal scopolamine injections in a repeated spatial acquisition task in the rat. Psychopharmacology, 109, 373-376.

Blokland, A., Scholtissen, B., Vermeeren, A., \& Ramaekers, J. (2001). Dissociable effects of histamine H1 antagonists on reaction time performance in rats. Pharmacology, Biochemistry and Behavior, 70, 427436.

Blozovski, D., \& Hennocq, N. (1982). Effects of antimuscarinic cholinergic drugs injected systemically or into the hippocampo-entorhinal area upon passive avoidance learning in young rats. Psychopharmacology, 76, 351-358.

Bodick, N. C., Offen, W. W., Levey, A. I., Cutler, N. R., Gauthier, S. G., Satlin, A., et al. (1997). Effects of xanomeline, a selective muscarinic receptor agonist, on cognitive function and behavioral symptoms in Alzheimer disease. Archives of Neurology, 54, 465-473.

Bohdanecky, Z., Jarvik, M. E., \& Carley, J. L. (1967). Differential impairment of delayed matching in monkeys by scopolamine and scopolamine methylbromide. Psychopharmacologia, 11, 293-299.

Boix-Trelis, N., Vale-Martínez, A., Guillazo-Blanch, G., \& Martí-Nicolovius, M. (2007). Muscarinic cholinergic receptor blockade in the rat prelimbic cortex impairs the social transmission of food preference. Neurobiology of Learning and Memory, 87, 659-668.

Bolden, C., Cusack, B., \& Richelson, E. (1992). Antagonism by antimuscarinic and neuroleptic compounds at the five cloned human muscarinic cholinergic receptors expressed in Chinese hamster ovary cells. The Journal of Pharmacology and Experimental Therapeutics, 260, 576-580.

Bonner, T. I., Buckley, N. J., Young, A. C., \& Brann, M. R. (1987). Identification of a family of muscarinic receptor genes. Science, 237, 527-532.

Bonner, T. I., Young, A. C., Bran, M. R., \& Buckley, N. J. (1988). Cloning and expression of the human and rat m5 muscarinic acetylcholine receptor genes. Neuron, 1, 403-410.

Boren, J. J., \& Navarro, A. P. (1959). The action of atropine, benactyzine, and scopolamine upon fixed-interval and fixed-ratio behavior. Journal of the Experimental Analysis of Behavior, 2, 107-115.

Bouger, P. C. M., \& van der Staay, F. J. (2005). Rats with scopolamine- or MK-801-induced spatial discrimination deficits in the cone field task: animal models for impaired spatial orientation performance. European Neuropsychopharmacology, 15, 331-346.

Brimblecombe, R. W. (1974). Drug actions on cholinergic systems. London, UK: The Macmillan Press Ltd.

Brito, G. N. O., Davis, B. J., Stopp, L. C., \& Stanton, M. E. (1983). Memory and the septo-hippocampal cholinergic system in the rat. Psychopharmacology, 81, 315-320. 
Broersen, L. M., Heinsbroek, R. P. W., de Bruin, J. P. C., Joosten, R. N. J., van Hest, A., \& Olivier, B. (1994). Effects of local application of dopaminergic drugs into the dorsal part of the medial prefrontal cortex of rats in a delayed matching to position task: comparison with local cholinergic blockade. Brain Research, 645, 113-122.

Broersen, L. M., Heinsbroek, R. P. W., de Bruin, J. P. C., Uylings, H. B. M., \& Olivier, B. (1995). The role of the medial prefrontal cortex of rats in short-term memory functioning: further support for involvement of cholinergic, rather than dopaminergic mechanisms. Brain Research, 674, 221-229.

Broussard, J. I., Karelina, K., Sarter, M., \& Givens, B. (2009). Cholinergic optimization of cue-evoked parietal activity during challenged attentional performance. European Journal of Neuroscience, 29, 1711-1722.

Brown, J. H., \& Taylor, P. (1996). Muscarinic receptor agonists and antagonists. In J. G. Hardman, A. Goodman Gilman \& L. E. Limbird (Eds.), The pharmacological basis of therapeutics (9th ed., pp. 141-160). New York, NY: McGraw-Hill.

Brown, K., \& Warburton, D. M. (1971). Attenuation of stimulus sensitivity by scopolamine. Psychonomic Science, 22, 297-298.

Bunce, J. G., Sabolek, H. R., \& Chrobak, J. J. (2004). Timing of administration mediates the memory effects of intraseptal carbachol infusion. Neuroscience, 127, 593-600.

Buresová, O., Bolhuis, J. J., \& Bures, J. (1986). Differential effects of cholinergic blockade on performance of rats in the water tank navigation task and in a radial water maze. Behavioral Neuroscience, 100, 476482.

Buresová, O., \& Bures, J. (1982). Radial maze as a tool for assessing the effect of drugs on the working memory of rats. Psychopharmacology, 77, 268-271.

Bushnell, P. J., Oshiro, W. M., \& Padnos, B. K. (1997). Detection of visual signals by rats: effects of chlordiazepoxide and cholinergic and adrenergic drugs on sustained attention. Psychopharmacology, 134, 230241.

Buxton, A., Callan, O. A., Blatt, E. J., Wong, E. H. F., \& Fontana, D. J. (1994). Cholinergic agents and delaydependent performance in the rat. Pharmacology, Biochemistry and Behavior, 49, 1067-1073.

Bymaster, F. P., Heath, I., Hendrix, J. C., \& Shannon, H. E. (1993). Comparative behavioral and neurochemical activities of cholinergic antagonists in rats. The Journal of Pharmacology and Experimental Therapeutics, 267, 16-24.

Bymaster, F. P., McKinzie, D. L., Felder, C. C., \& Wess, J. (2003). Use of M1-M5 muscarinic receptor knockout mice as novel tools to delineate the physiological roles of the muscarinic cholinergic system. Neurochemical Research, 28, 437-442.

Callahan, M. J., Kinsora, J. J., Harbaugh, R. E., Reeder, T. M., \& Davis, R. E. (1993). Continuous icv infusion of scopolamine impairs sustained attention of rhesus monkeys. Neurobiology of Aging, 14, 147-151.

Campbell, K. A., Kalmbacher, C. E., Specht, C. D., \& Gregg, T. R. (1995). Dependence of rat vertex auditory evoked potentials on central muscarinic receptor activation. Brain Research, 702, 110-116.

Carballo-Márquez, A., Vale-Martínez, A., Guillazo-Blanch, G., \& Martí-Nicolovius, M. (2009). Muscarinic transmission in the basolateral amygdala is necessary for the acquisition of socially transmitted food preferences in rats. Neurobiology of Learning and Memory, 91, 98-101.

Carli, M., Balducci, C., Millan, M. J., Bonalumi, P., \& Samanin, R. (1999). S 15535, a benzodioxopiperazine acting as presynaptic agonist and postsynaptic 5-HT1A receptor antagonist, prevents the impairment of spatial learning caused by intrahippocampal scopolamine. British Journal of Pharmacology, 128, 12071214.

Carli, M., Luschi, R., \& Samanin, R. (1995). (S)-WAY 100135, a 5-HT1A receptor antagonist, prevents the impairment of spatial learning caused by intrahippocampal scopolamine. European Journal of Pharmacology, 283, 133-139.

Carli, M., Luschi, R., \& Samanin, R. (1997). Dose-related impairment of spatial learning by intrahippocampal scopolamine: antagonism by odansetron, a 5-HT3 receptor antagonist. Behavioural Brain Research, 82, 185-194.

Carlton, P. L. (1963). Cholinergic mechanisms in the control of behavior by the brain. Psychological Review, 70, 19-39.

Caulfield, M. P. (1993). Muscarinic receptors - characterization, coupling and function. Pharmacology \& Therapeutics, 58, 319-379.

Caulfield, M. P., \& Birdsall, N. J. M. (1998). International union of pharmacology: XVII. Classification of muscarinic acetylcholine receptors. Pharmacological Reviews, 50, 279-290. 
Chambers, L. K., \& van Hartesveldt, C. (1984). Effects of intrastriatal and intracortical scopolamine on behavior in rats. Pharmacology, Biochemistry and Behavior, 21, 471-473.

Cheal, M. L. (1981). Scopolamine disrupts maintenance of attention rather than memory processes. Behavioral and Neural Biology, 33, 163-187.

Chen, K. C., Baxter, M. G., \& Rodefer, J. S. (2004). Central blockade of muscarinic cholinergic receptors disrupts affective and attentional set-shifting. European Journal of Neuroscience, 20, 1081-1088.

Chiba, A. A., Bushnell, P. J., Oshiro, W. M., \& Gallagher, M. (1999). Selective removal of cholinergic neurons in the basal forebrain alters cued target detection. Neuroreport, 10, 3119-3123.

Chintoh, A., Fulton, J., Koziel, N., Aziz, M., Sud, M., \& Yeomans, J. S. (2003). Role of cholinergic receptors in locomotion induced by scopolamine and oxotremorine-M. Pharmacology, Biochemistry and Behavior, 76, 53-61.

Chudasama, Y., Dalley, J. W., Nathwani, F., Bouger, P., \& Robbins, T. W. (2004). Cholinergic modulation of visual attention and working memory: dissociable effects of basal forebrain 192-lgG-saporin lesions and intraprefrontal infusions of scopolamine. Learning \& Memory, 11, 78-86.

Chudasama, Y., \& Muir, J. L. (1997). A behavioural analysis of the delayed non-matching to position task: the effects of scopolamine, lesions of the fornix and of the prelimbic region on mediating behaviours by rats. Psychopharmacology, 134, 73-82.

Clarke, P. B. S., \& Fibiger, H. C. (1990). Reinforced alternation performance is impaired by muscarinic but not by nicotinic receptor blockade in rats. Behavioural Brain Research, 36, 203-207.

Cohn, J., Ziriax, J. M., Cox, C., \& Cory-Slechta, D. A. (1992). Comparison of error patterns produced by scopolamine and MK-801 on repeated acquisition and transition baselines. Psychopharmacology, 107, 243254.

Colpaert, F. C., Koek, W., \& Bruins Slot, L. A. (2001). Evidence that mnesic states govern normal and disordered memory. Behavioural Pharmacology, 12, 575-589.

Conn, P. J., Jones, C. K., \& Lindsley, C. W. (2009). Subtype-selective allosteric modulators of muscarinic receptors for the treatment of CNS disorders. Cell, 30, 148-155.

Cozzolino, R., Guaraldi, D., Giuliani, A., Ghirardi, O., Ramacci, M. T., \& Angelucci, L. (1994). Effects of concomitant nicotinic and muscarinic blockade on spatial memory disturbances in rats are purely additive: evidence from the Morris water task. Physiology \& Behavior, 56, 111-114.

Crow, T. J., \& Grove-White, I. G. (1973). An analysis of the learning deficit following hyoscine administration to man. British Journal of Pharmacology, 49, 322-327.

Cruz-Morales, S. E., Duran-Arevalo, M., Diaz Del Guante, M. A., Quirarte, G., \& Prado-Alcala, R. A. (1992). A threshold for the protective effect of over-reinforced passive avoidance against scopolamine-induced amnesia. Behavioral and Neural Biology, 57, 256-259.

Dai, Y., Ambudkar, I. S., Horn, V. J., Yeh, C., Kousvelari, E. E., Wall, S. J., et al. (1991). Evidence that M3 muscarinic receptors in rat parotid gland couple to two second messenger systems. American Journal of Physiology, 261, C1063-C1073.

Davidson, M. C., Cutrell, E. B., \& Marrocci, R. T. (1999). Scopolamine slows the orienting of attention in primates to cued visual targets. Psychopharmacology, 142, 1-8.

Davidson, M. C., \& Marrocco, R. T. (2000). Local infusion of scopolamine into intraparietal cortex slows covert orienting in rhesus monkeys. Journal of Neurophysiology, 83, 1536-1549.

Day, J., Damsma, G., \& Fibiger, H. C. (1991). Cholinergic activity in the rat hippocampus, cortex and striatum correlates with locomotor activity: an in vivo microdialysis study. Pharmacology, Biochemistry and Behavior, 38, 723-729.

De Rosa, E., \& Hasselmo, M. E. (2000). Muscarinic cholinergic neuromodulation reduces proactive interference between stored odor memories during associative learning in rats. Behavioral Neuroscience, 114, 32-41.

Decker, M. W., Gill, T. M., \& McGaugh, J. L. (1990). Concurrent muscarinic and beta-adrenergic blockade in rats impairs place-learning in a water maze and retention of inhibitory avoidance. Brain Research, 513, 81-85.

Dencoff, J. E., \& Hodge, G. K. (1995). Scopolamine administration and NBM lesions differentially affect performance in an operant discrimination task. Psychobiology, 23, 290-301.

Diaz del Guante, M. A., Cruz-Morales, S. E., \& Prado-Alcala, R. A. (1991). Time-dependent effects of cholinergic blockade of the striatum on memory. Neuroscience Letters, 122, 79-82. 
Dodart, J. C., Mathis, C., \& Ungerer, A. (1997). Scopolamine-induced deficits in a two-trial object recgnition task in mice. NeuroReport, 8, 1173-1178.

Doty, R. L., Bagla, R., Misra, R., Mueller, E., \& Kerr, K. (2003). No influence of scopolamine hydrobromide on odor detection performance of rats. Chemical Senses, 28, 761-765.

Douglas, R. J., \& Isaacson, R. L. (1966). Spontaneous alternation and scopolamine. Psychonomic Science, 4, 283-284.

Drachman, D. A., \& Leavitt, J. (1974). Human memory and the cholinergic system: a relationship to aging? Archives in Neurology, 30, 113-121.

Drew, W. G., Miller, L. L., \& Baugh, E. L. (1973). Effects of Đ9-THC, LSD-25 and scopolamine on contineous, spontaneous alternation in the Y-maze. Psychopharmacologia, 32, 171-182.

Dringenberg, H. C., \& Vanderwolf, C. H. (1997). Neocortical activation: modulation by multiple pathways acting on central cholinergic and serotonergic systems. Experimental Brain Research, 116, 160-174.

Dringenberg, H. C., \& Vanderwolf, C. H. (1998). Involvement of direct and indirect pathways in electrocorticographic activation. Neuroscience and Biobehavioral Reviews, 22, 243-257.

Drinkenburg, W. H. I. M., Sondag, H. N. P. M., Coenders, C. J. H., Andrews, J. S., \& Vossen, J. M. H. (1995). Effects of selective antagonism or depletion of the cholinergic system on visual discrimination performance in rats. Behavioural Pharmacology, 6, 695-702.

Dudchenko, P., \& Sarter, M. (1992). Behavioral microanalysis of spatial delayed alternation performance: rehearsal through overt behavior, and effects of scopolamine and chlordiazepoxide. Psychopharmacology, 107, 263-270.

Dunnett, S. B. (1985). Comparative effects of cholinergic drugs and lesions of nucleus basalis or fimbriafornix on delayed matching in rats. Psychopharmacology, 87, 357-363.

Dunnett, S. B., Wareham, A. T., \& Torres, E. M. (1990). Cholinergic blockade in prefrontal cortex and hippocampus disrupts short-term memory in rats. NeuroReport, 1, 61-64.

Ebert, U., \& Kirch, W. (1998). Scopolamine model of dementia: electroencephalogram findings and cognitive performance. European Journal of Clinical Investigation, 28, 944-949.

Ebert, U., Siepmann, M., Oertel, R., Wesnes, K. A., \& Kirch, W. (1998). Pharmacokinetics and pharmacodynamics of scopolamine after subcutaneous administration. Journal of Clinical Pharmacology, 38, 720726.

Eckerman, D. A., Gordon, W. A., Edwards, J. D., MacPhail, R. C., \& Gage, M. I. (1980). Effects of scopolamine, pentobarbital, and amphetamine on radial arm maze performance in the rat. Pharmacology, Biochemistry and Behavior, 12, 595-602.

Eglen, R. M., Hedge, S. S., \& Watson, N. (1996). Muscarinic receptor subtypes and smooth muscle function. Pharmacological Reviews, 48, 531-565.

Elvander, E., Schött, P. A., Sandin, J., Bjelke, B., Kehr, J., Yoshitake, T., et al. (2004). Intraseptal muscarinic ligands and galanin: influence on hippocampal acetylcholine and cognition. Neuroscience, 126, 541-557.

Ennaceur, A., \& Meliani, K. (1992). Effects of physostigmine and scopolamine on rats' performances in object-recognition and radial-maze tests. Psychopharmacology, 109, 321-330.

Estapé, N., \& Steckler, T. (2002). Cholinergic blockade impairs performance in operant DNMTP in two inbred strains of mice. Pharmacology, Biochemistry and Behavior, 72, 319-334.

Estapé, N., \& Steckler, T. (2001). Effects of cholinergic manipulation on operant delayed non-matching to position performance in two inbred strains of mice. Behavioural Brain Research, 121, 39-55.

Evans, H. L. (1975). Scopolamine effects on visual discrimination: modifications related to stimulus control. Journal of Pharmacology and Experimental Therapeutics, 195, 105-113.

Everitt, B. J., \& Robbins, T. W. (1997). Central cholinergic systems and cognition. Annual Review of Psychology, 48, 649-684.

Feigley, D. A. (1974). Effects of scopolamine on activity and passive avoidance learning in rats of different ages. Journal of Comparative Physiological Psychology, 87, 26-36.

Fibiger, H. C. (1991). Cholinergic mechanisms in learning, memory and dementia: a review of recent evidence. Trends in Neurosciences, 14, 220-223.

Flood, J. F., \& Cherkin, A. (1986). Scopolamine effects on memory retention in mice: a model of dementia? Behavioral and Neural Biology, 45, 169-184.

Flood, J. F., Landry, D. W., \& Jarvik, M. E. (1981). Cholinergic receptor interactions and their effects on longterm memory processing. Brain Research, 215, 177-185. 
Flynn, D. D., Reever, C. M., \& Ferrari-DiLeo, G. (1997). Pharmacological strategies to selectively label and localize muscarinic receptor subtypes. Drug Development Research, 40, 104-116.

Fornari, R. V., Moreira, K. M., \& Oliviera, M. G. M. (2000). Effects of the selective M1 muscarinic receptor antagonist dicyclomine on emotional memory. Learning \& Memory, 7, 287-292.

Frey, K. A., Ehrenkaufer, R. L., \& Agranoff, B. W. (1985). Quantitative in vivo receptor binding. II. Autoradiographic imaging of muscarinic cholinergic receptors. The Journal of Neuroscience, 5, 2407-2414.

Gaus, C. J. (1906). Geburten in kunstlichem Dämmerschlaff. Archiv für Gynäkologie, 78, 579-631.

Geis, G. (1961). The status of interrogation drugs in the United States. Journal of Forensic Medicine, 8, 29-33.

Gholamreza, P., Pratt, J. A., \& Nima, D. (2002). Effects of low-dose scopolamine on locomotor activity: no dissociation between cognitive and non-cognitive effects. Neuroscience Research Communications, 31, 165-174.

Givens, B., \& Olton, D. S. (1995). Bidirectional modulation of scopolamine-induced working memory impairments by muscarinic activation of the medial septal area. Neurobiology of Learning Memory, 63, 269276.

Glick, S. D., \& Jarvik, M. E. (1969). Amphetamine, scopolamine and chlorpromazine interactions on delayed matching performance in monkeys. Psychopharmacologia, 16, 147-155.

Godding, P. R., Rush, J. R., \& Beatty, W. W. (1982). Scopolamine does not disrupt spatial working memory in rats. Pharmacology, Biochemistry and Behavior, 16, 919-923.

Granon, S., \& Poucet, B. (1995). Medial prefrontal lesions in the rat and spatial navigation: evidence for impaired planning. Behavioral Neuroscience, 109, 474-484.

Granon, S., Poucet, B., Thinus-Blanc, C., Changeux, J.-P., \& Vidal, C. (1995). Nicotinic and muscarinic receptors in the rat prefrontal cortex: Differential roles in working memory, response selection and effortful processing. Psychopharmacology, 119, 139-144.

Grauer, E., \& Kapon, J. (1996). Differential effects of anticholinergic drugs on paired discrimination performance. Pharmacology, Biochemistry and Behavior, 53, 463-467.

Grilly, D. M., \& Loveland, A. (2001). What is a "low dose" of d-amphetamine for inducing behavioral effects in laboratory rats? Psychopharmacology, 153, 155-169.

Gutiérrez, R., De la Cruz, V., Rodriguez-Ortiz, C. J., \& Bermudez-Rattoni, F. (2004). Perirhinal cortex muscarinic receptor blockade impairs taste recognition memory formation. Learning \& Memory, 11, 95-101.

Gutiérrez, R., Rodriguez-Ortiz, C. J., De La Cruz, V., Núnez-Jaramillo, L., \& Bermudez-Rattoni, F. (2003). Cholinergic dependence of taste memory formation: evidence of two distinct processes. Neurobiology of Learning and Memory, 80, 323-331.

Hagan, J. J., Jansen, J. H. M., \& Broekkamp, C. L. E. (1987). Blockade of spatial learning by the m1 muscarinic antagonist pirenzipine. Psychopharmacology, 93, 470-476.

Hagan, J. J., \& Morris, R. G. M. (1988). The cholinergic hypothesis of memory: a review of animal experiments. In L. L. Iversen, S. D. Iversen \& S. H. Snyder (Eds.), Handbook of psychopharmacology (Vol. 20, pp. 237-305). New York, NY: Plenum Press.

Hamilton, L. W., \& Grossman, S. P. (1969). Behavioral changes following disruption of central cholinergic pathways. Journal of Comparative and Physiological Psychology, 69, 76-82.

Harder, J. A., Baker, H. F., \& Ridley, R. M. (1998). The role of the central cholinergic projections in cognition: implications of the effects of scopolamine on discrimination learning by monkeys. Brain Research Bulletin, 45, 319-326.

Harder, J. A., Kelly, M. E., Cheng, C. H. K., \& Costall, B. (1996). Combined pCPA and muscarinic antagonist treatment produces a deficit in rat water maze acquisition. Pharmacology, Biochemistry and Behavior, 55, 61-65.

Hardy, T. K., \& Wakely, D. (1962). The amnesic properties of hyoscine and atropine in pre-anaesthetic medication. Anaesthesia, 17, 331-336.

Harvey, J. A., Gormezano, I., \& Cool-Hauser, V. A. (1983). Effects of scopolamine and methylscopolamine on classical conditioning of the rabbit nictitating membrane response. The Journal of Pharmacology and Experimental Therapeutics, 225, 42-49.

Hasselmo, M. E. (1999). Neuromodulation: Acetylcholine and memory consolidation. Trends in Cognitive Sciences, 3, 351-359.

Hasselmo, M. E. (2006). The role of acetylcholine in learning and memory. Current Opinion in Neurobiology, 16, 710-715. 
Hasselmo, M. E., Bodelón, C., \& Wyble, B. P. (2002). A proposed function for hippocampal theta rhythm: Separate phases of encoding and retrieval enhance reversal of prior learning. Neural Computation, 14, 793-817.

Hasselmo, M. E., \& McGaughy, J. (2004). High acetylcholine levels set circuit dynamics for attention and encoding and low acetylcholine levels set dynamics for consolidation. Progress in Brain Research, 145, 207-231.

Hearst, E. (1959). Effects of scopolamine on discriminated responding in the rat. The Journal of Pharmacology and Experimental Therapeutics, 126, 349-358.

Heinrich, J. N., Butera, J. A., Carrick, T., Kramer, A., Kowal, D., Lock, T., et al. (2009). Pharmacological comparison of muscarinic ligands: Historical versus more recent muscarinic M1-preferring receptor agonists. European Journal of Pharmacology, 605, 53-56.

Heise, G. A., Conner, R., \& Martin, R. A. (1976). Effects of scopolamine on variable intertrial interval spatial alternation and memory in the rat. Psychopharmacology, 49, 131-137.

Heise, G. A., \& Milar, K. S. (1984). Drugs and stimulus control. In L. L. Iversen, S. D. Iversen \& S. H. Snyder (Eds.), Drugs, neurotransmitters, and behavior (Vol. 18, pp. 129-190). New York, NY: Plenum Press.

Herremans, A. H. J., Hijzen, T. H., \& Olivier, B. (1997). Effects of cholinergic drug infusions into the dorsal part of the medial prefrontal cortex on delayed conditional discrimination performance in the rat. Behavioural Brain Research, 84, 291-299.

Herremans, A. H. J., Hijzen, T. H., Olivier, B., \& Slangen, J. L. (1995). Cholinergic drug effects on a delayed conditional discrimination task in the rat. Behavioral Neuroscience, 109, 426-435.

Herremans, A. H. J., Hijzen, T. H., Welborn, P. F. E., Olivier, B., \& Slangen, J. L. (1996). Effects of infusion of cholinergic drugs into the prefrontal cortex area on delayed matching to position performance in the rat. Brain Research, 711, 102-111.

Herrera-Morales, W., Mar, I., Serrano, B., \& Bermúdez-Rattoni, F. (2007). Activation of hippocampal postsynaptic muscarinic receptors is involved in long-term spatial memory formation. European Journal of Neuroscience, 25, 1581-1588.

Herrerro, J. L., Roberts, M. J., Delicato, L. S., Gieselmann, M. A., Dayan, P., \& Thiele, A. (2008). Acetylcholine contributes through muscarinic receptors to attentional modulation in V1. Nature, 454, 1110-1114.

Higashida, A., \& Ogawa, N. (1987). Differences in the acquisition process and the effect of scopolamine on radial maze performance in three strains of rats. Pharmacology, Biochemistry and Behavior, 27, 483489.

Higgs, S., Deacon, R. M. J., \& Rawlins, J. N. P. (2000). Effects of scopolamine on a novel choice serial reaction time task. European Journal of Neuroscience, 12, 1781-1788.

Hodges Jr., D. B., Lindner, M. D., Hogan, J. B., Jones, K. M., \& Markus, E. J. (2009). Scopolamine induced deficits in a battery of rat cognitive tests: Comparisons of sensitivity and specificity. Behavioural Pharmacology, 20, 237-251.

Hoff, E. I., van Oostenbrugge, R. J., Liedenbaum, M., Steinbusch, H. W., \& Blokland, A. (2007). Effects of righthemisphere cortical infarction and muscarinic acetylcholine receptor blockade on spatial visual attention performance in rats. Behavioural Brain Research, 178, 62-69.

Holley, L. A., Dudchenko, P., \& Sarter, M. (1992). Attenuation of muscarinic receptor blockade-induced impairment of spatial delayed alternation performance by the triazole MDL 26,479. Psychopharmacology, 109, 223-230.

Hughes, R. N., Blampied, N. M., \& Stewart, W. J. (1975). Scopolamine induced changes in activity and reactions to novelty. Pharmacology, Biochemistry and Behavior, 3, 731-734.

Hughes, R. N., Desmond, C. S., \& Fisher, L. C. (2004). Room novelty, sex, scopolamine and their interactions as determinants of general activity and rearing, and light-dark preferences in rats. Behavioural Processes, 67, 173-181.

Hulme, E. C., Birdsall, N. J., Burgen, A. S., \& Mehta, P. (1978). The binding of antagonists to brain muscarinic receptors. Molecular Pharmacology, 14, 737-750.

Humby, T., Laird, F. M., Davies, W., \& Wilkinson, L. S. (1999). Visuospatial attentional functioning in mice: interactions between cholinergic manipulations and genotype. European Journal of Neuroscience, 11, 2813-2823.

Hunter, A. J., \& Roberts, F. F. (1988). The effect of pirenzipine on spatial learning in the Morris water maze. Pharmacology, Biochemistry and Behavior, 30, 519-523. 
Huston, A. E., \& Aggleton, J. P. (1987). The effects of cholinergic drugs upon recognition memory in rats. The Quarterly Journal of Experimental Psychology, 39B, 297-314.

Ingles, J. L., Beninger, R. J., Jhamandas, K., \& Boegman, R. J. (1993). Scopolamine injected into the rat amygdala impairs working memory in the double Y-maze. Brain Research Bulletin, 32, 339-344.

Ison, J. R., \& Bowen, G. P. (2000). Scopolamine reduces sensitivity to auditory gaps in the rat, suggesting a cholinergic contribution to temporal acuity. Hearing Research, 145, 169-176.

Izquierdo, I. (1989). Mechanism of action of scopolamine as an amnestic. Trends in Pharmacological Sciences, 10, 175-177.

Jäkälä, P., Sirviö, J., Jolkkonen, J., Riekkinen, P., Jr., Acsady, L., \& Riekkinen, P. (1992). The effects of pchlorophenylalanine-induced serotonin synthesis inhibition and muscarinic blockade on the performance of rats in a 5- choice serial reaction time task. Behavioural Brain Research, 51, 29-40.

Jensen, L. H., Stephens, D. N., Sarter, M., \& Petersen, E. N. (1987). Bidirectional effects of beta-carbolines and benzodiazepines on cognitive processes. Brain Research Bulletin, 19, 359-364.

Jolas, T., Schreiber, R., Laporte, A. M., Chastanet, M., De Vry, J., Glaser, T., et al. (1995). Are postsynaptic 5HT1A receptors involved in the anxiolytic effects of 5-HT1A receptor agonists and in their inhibitory effects on the firing of serotonergic neurons in the rat? The Journal of Pharmacology and Experimental Therapeutics, 272, 920-929.

Jones, C. K., \& Shannon, H.E. (2000). Effects of scopolamine in comparison with apomorphine and phencyclidine on prepulse inhibition in rats. European Journal of Pharmacology, 391, 105-112.

Jones, D. N. C., Barnes, J. C., Kirkby, D. L., \& Higgins, G. A. (1995). Age-associated impairments in a test of attention: evidence for involvement of cholinergic systems. The Journal of Neuroscience, 15, 7282-7292.

Jones, D. N. C., \& Higgins, G. A. (1995). Effect of scopolamine on visual attention in rats. Psychopharmacology, 120, 142-149.

Kikuchi, M., Wada, Y., Nanbu, Y., Nakajima, A., Tachibana, H., Takeda, T., et al. (1999). EEG changes following scopolamine administration in healthy subjects. Neuropsychobiology, 39, 219-226.

Kim, J. S., \& Levin, E. D. (1996). Nicotinic, muscarinic and dopaminergic actions in the ventral hippocampus and the nucleus accumbens: effects on spatial working memory in rats. Brain Research, 725, 231-240.

Kimura, Y., Ohue, M., Kitaura, T., \& Kihira, K. (1999). Amnesic effects of the anticholinergic drugs, trihexyphenidyl and biperiden: differences in binding properties to the brain muscarinic receptor. Brain Research, 834, 6-12.

Kirk, R. C., White, K. G., \& McNaughton, N. (1988). Low dose of scopolamine affects discriminability but not rate of forgetting in delayed conditional discrimination. Psychopharmacology, 96, 541-546.

Kirkby, D. L., Jones, D. N. C., \& Higgins, G. A. (1995). Influence of prefeeding and scopolamine upon performance in a delayed matching-to-position task. Behavioural Brain Research, 67, 221-227.

Klimesch, W. (1999). EEG alpha and theta oscillations reflect cognitive and memory performance: A review and analysis. Brain Research Reviews, 29, 169-195.

Klöcker, N., Hanschke, W., Toussaint, S., \& Verse, T. (2001). Scopolamine nasal spray in motion sickness: A randomised, controled, and crossover study for the comparison of two scopolamine nasal sprays with oral dimenhydrinate and placebo. European Journal of Pharmaceutical Sciences, 13, 227-232.

Kobayashi, M., Ohno, M., Yamamoto, T., \& Watanabe, S. (1995). Concurrent blockade of -adrenergic and muscarinic receptors disrupts working memory but not reference memory in rats. Physiology \& Behavior, 58, 307-314.

Kopelman, M. D. (1986). The cholinergic neurotransmitter system in human learning and memory: a review. The Quarterly Journal of Experimental Psychology, 38A, 535-573.

Kramer-Soares, J. C., Vecchio-Fornari, R., \& Menezes-Oliviera, M. G. (2006). Role of muscarinic M1 receptors in inhibitory avoidance and contextual fear conditioning. Neurobiology of Learning and Memory, 86, 188-196.

Ksir, C. (1975). Scopolamine and amphetamine effects on discrimination: interaction with stimulus control. Psychopharmacologia, 43, 37-41.

Ksir, C., \& Slifer, B. (1982). Drug effects on discrimination performance at two levels of stimulus control. Psychopharmacology, 76, 286-290.

Kuribara, H. (1982). Strain differences to the effects of central acting drugs on Sidman avoidance response in Wistar and Fischer 344 rats. Pharmacology, Biochemistry and Behavior, 17, 425-429.

Leaton, R. N. (1968). Effects of scopolamine on exploratory motivated behavior. Journal of Comparative Physiological Psychology, 66, 524-527. 
Leaton, R. N., \& Kreindler, M. (1972). Effects of physostigmine and scopolamine on operant brightness discrimination in the rat. Physiology \& Behavior, 9, 121-123.

Leblond, L., Beaufort, C., Delerue, F., \& Durkin, T. (2002). Differential roles for nicotinic and muscarinic cholinergic receptors in sustained visuo-spatial attention? A study using a 5-arm maze protocol in mice. Behavioural Brain Research, 128, 91-102.

Lee, J. H., \& El Fakahany, E. E. (1985). Heterogeneity of binding of muscarinic receptor antagonists in rat brain homogenates. Journal of Pharmacology and Experimental Therapeutics, 233, 707-714.

Leopold, I. H., \& Comroe, J. H. (1948). Effect of intramuscular administration of morphine, atropine, scopolamine and neostigmine on the human eye. Archives of Ophthalmology, 46, 361-364.

Levin, E. D. (1988). Scopolamine interactions with D1 and D2 antagonists on radial-arm maze performance in rats. Behavioral and Neural Biology, 50, 240-245.

Lieben, C. K., Blokland, A., Sik, A., Sung, E., van Nieuwenhuizen, P., \& Schreiber, R. (2005). The selective 5$\mathrm{HT}(6)$ receptor antagonist Ro4368554 restores memory performance in cholinergic and serotonergic models of memory deficiency in the rat. Neuropsychopharmacology, 30, 2169-2179.

Lydon, R. G., \& Nakajima, S. (1992). Differential effects of scopolamine on working and reference memory depend upon level of training. Pharmacology, Biochemistry and Behavior, 43, 645-650.

Markowska, A. L., Olton, D. S., \& Givens, B. (1995). Cholinergic manipulations in the medial septal area: agerelated effects on working memory and hippocampal electrophysiology. The Journal of Neuroscience, 15, 2063-2073.

Maruki, K., Izaki, Y., Akema, T., \& Nomura, M. (2003). Effects of acetylcholine antagonist injection into the prefrontal cortex on the progress of lever-press extinction in rats. Neuroscience Letters, 351, 95-98.

Masuoka, T., Fujii, Y., \& Kamei, C. (2006). Effect of scopolamine on the hippocampal theta rhythm during an eight-arm radial maze task in rats. European Journal of Psychopharmacology, 539, 76-80.

Maviel, T., \& Durkin, T. P. (2003). Role of central cholinergic receptor sub-types in spatial working memory: a five-arm maze task in mice provides evidence for a functional role of nicotinic receptors in mediating trace access processes. Neuroscience, 120, 1049-1059.

McCool, M. F., Patel, S., Talati, R., \& Ragozzino, M. E. (2008). Differential involvement of M1-type and M4type muscarinic cholinergic receptors in the dorsomedial striatum in task switching. Neurobiology of Learning and Memory, 89, 114-124.

McDonald, M. P., \& Overmier, J. B. (1998). Present imperfect: a critical review of animal models of the mnemonic impairments in Alzheimer's disease. Neuroscience and Biobehavioral Reviews, 22, 99-120.

McDonough, J. H., Jr. (1982). Effects of anticholinergic drugs on DRL performance of rhesus monkeys. Pharmacology, Biochemistry and Behavior, 17, 85-90.

McGaughy, J., Everitt, B. J., Robbins, T. W., \& Sarter, M. (2000). The role of cortical cholinergic afferent projections in cognition: impact of new selective immunotoxins. Behavioural Brain Research, 115, 251263.

McGaughy, J., \& Sarter, M. (1995). Effects of chlordiazepoxide and scopolamine, but not aging, on the detection and identification of conditional visual stimuli. Journal of Gerontology, 50A, B90-B96.

McGaughy, J., Turchi, J., \& Sarter, M. (1994). Crossmodal divided attention in rats: effects of chlordiazepoxide and scopolamine. Psychopharmacology, 115, 213-220.

McIntyre, C. K., Ragozzino, M. E., \& Gold, P. E. (1998). Intra-amygdala infusions of scopolamine impair performance on a conditioned place preference task but not a spatial radial maze task. Behavioural Brain Research, 95, 219-226.

McNamara, R. K., \& Skelton, R. W. (1993). The neuropharmacological and neurochemical basis of place learning in the Morris water maze. Brain Research Reviews, 18, 33-49.

McQuail, J. A., \& Burk, J. A. (2006). Evaluation of muscarinic and nicotinic receptor antagonists on attention and working memory. Pharmacology, Biochemistry and Behavior, 85, 796-803.

Meador, K. J., Loring, D. W., Hendrix, N., Nichols, M. E., Oberzan, R., \& Moore, E. E. (1995). Synergistic anticholinergic and antiserotonergic effects in humans. Journal of Clinical and Experimental Neuropsychology, 17, 611-621.

Means, L. W., Holsten, R. D., Long, M., \& High, K. M. (1996). Scopolamine- and morphine-induced deficits in water maze alternation: failure to attenuate with glucose. Neurobiology of Learning and Memory, 66, 167-175.

Meeter, M., Murre, J. M., \& Talamini, L. M. (2004). Mode shifting between storage and recall based on novelty detection in oscillating hippocampal circuits. Hippocampus, 14, 722-741. 
Messer, W. S., Bohnett, M., \& Stibbe, J. (1990). Evidence for a preferential involvement of M1 muscarinic receptors in representational memory. Neuroscience Letters, 116, 184-189.

Messer, W. S., Thomas, G. J., \& Hoss, W. (1987a). Selectivity of pirenzepine in the central nervous system. II differential effects of pirenzepine and scopolamine on performance of a representational memory task. Brain Research, 407, 37-45.

Messer, W. S., Thomas, G. J., Price, M., \& Hoss, W. (1987b). Selectivity of pirenzepine in the central nervous system. III differential effects of multiple pirenzepine and scopolamine administrations on muscarinic receptors as measured autoradiographically. Brain Research, 407, 46-54.

Meyer, M. E., Severson, G. A., \& Thompson, R. W. (1976). Scopolamine, methylscopolamine, and response conditioned inhibition in rats. Physiological Psychology, 4, 43-44.

Meyers, B. (1965). Some effects of scopolamine on a passive avoidance response in rats. Psychopharmacologia, 8, 111-119.

Milar, K. S. (1981). Cholinergic drug effects on visual discriminations: a signal detection analysis. Psychopharmacology, 74, 383-388.

Milar, S. K., Halgren, C. R., \& Heise, G. A. (1978). A reappraisal of scopolamine effects on inhibition. Pharmacology, Biochemistry and Behavior, 9, 307-313.

Mirza, N. R., \& Stolerman, I.P. (2000). The role of nicotinic and muscarinic acetylcholine receptors in attention. Psychopharmacology, 148, 243-250.

Mishima, K., Iwasaki, K., Tsukikawa, H., Matsumoto, Y., Egashira, N., Abe, K., et al. (2000). The scopolamineinduced impairment of spatial cognition parallels the acetylcholine release in the ventral hippocampus in rats. Japanese Journal of Pharmacology, 84, 163-173.

Moersbacher, J. M., Thompson, D. M., \& Thomas, J. R. (1979). Effects of methamphetamine and scopolamine on variability of response location. Journal of the Experimental Analysis of Behavior, 32, 255-263.

Moore, H., Dudchenko, P., Bruno, J. P., \& Sarter, M. (1992). Toward modeling age-related changes of attentional abilities in rats: simple and choice reaction time tasks and vigilance. Neurobiology of Aging, 13, 759-772.

Moore, H., Dudchenko, P., Comer, K. S., Bruno, J. P., \& Sarter, M. (1992). Central versus peripheral effects of muscarinic antagonists: the limitations of quarternary ammonium derivatives. Psychopharmacology, 108, 241-243.

Moore, J. W., Goodell, N. A., \& Solomon, P. R. (1976). Central cholinergic blockade by scopolamine and habituation, classical conditioning, and latent inhibition of the rabbit's nictitating membrane response. Physiological Psychology, 4, 395-499.

Moran, P. M. (1993). Differential effects of scopolamine and mecamylamine on working and reference memory in the rat. Pharmacology, Biochemistry and Behavior, 45, 533-538.

Murphy, P. C., \& Sillito, A. M. (1991). Cholinergic enhancement of direction selectively in the visual cortex of the cat. Neuroscience, 40, 13-20.

Myers, T. M., Galbicka, G., Sipos, M. L., Varadi, S., Oubre, J. L., \& Clark, M. G. (2002). Effects of anticholinergics on serial-probe recognition accuracy of rhesus macaques (Macaca mulatta). Pharmacology, Biochemistry and Behavior, 73, 829-834.

Myhrer, T., Enger, S., \& Aas, P. (2004). Cognitive side effects in rats caused by pharmacological agents used to prevent soman-induced lethality. European Journal of Pharmacology, 483, 271-279.

Myhrer, T., Enger, S., \& Aas, P. (2008). Antiparkinson drugs used as prophylactics for nerve agents: Studies of cognitive side effects in rats. Pharmacology, Biochemistry and Behavior, 89, 633-638.

Naor, C., \& Dudai, Y. (1996). Transient impairment of cholinergic function in the rat insular cortex disrupts the encoding of taste in conditioned taste aversion. Behavioural Brain Research, 79, 61-67.

Nomura, Y., Nishiyama, N., Saito, H., \& Matsuki, N. (1994). Role of cholinergic neurotransmission in the amygdala on performances of passive avoidance learning in mice. Biological \& Pharmaceutical Bulletin, $17,490-494$.

Ohno, M., Kikusui, M., Yoshimatsu, A., Yamamoto, T., \& Watanabe, S. (1994a). Somatostatin alleviates impairment of working memory induced by hippocampal muscarinic M1 receptor blockade in rats. European Journal of Pharmacology, 271, 557-560.

Ohno, M., \& Watanabe, S. (1996). Interactive processing between glutamatergic and cholinergic systems involved in inhibitory avoidance learning of rats. European Journal of Pharmacology, 312, 145-147.

Ohno, M., Yamamoto, T., \& Watanabe, S. (1993). Amygdaloid NMDA and muscarinic receptors involved in working memory performance of rats. Physiology and Behavior, 54, 993-997. 
Ohno, M., Yamamoto, T., \& Watanabe, S. (1994b). Blockade of hippocampal M1 muscarinic receptors impairs working memory performance of rats. Brain Research, 650, 260-266.

Okaichi, H., \& Jarrard, L. E. (1982). Scopolamine impairs performance of a place and cue task in rats. Behavioral and Neural Biolology, 35, 319-325.

Okaichi, H., Oshima, Y., \& Jarrard, L. E. (1989). Scopolamine impairs both working and reference memory in rats: a replication and extension. Pharmacology, Biochemistry and Behavior, 34, 599-602.

Oliverio, A. (1968). Effects of scopolamine on avoidance conditioning and habituation of mice. Psychopharmacologia, 12, 214-226.

Ormerod, B. K., \& Beninger, R. J. (2002). Water maze versus radial maze: differential performance of rats in a spatial delayed match-to-position task and response to scopolamine. Behavioural Brain Research, 128, 139-152.

Pakarinen, E. D., \& Moerschbaecher, J. M. (1993). Comparison of the effects of scopolamine and methylscopolamine on the performance of a fixed-ratio discrimination in squirrel monkeys. Pharmacology, Biochemistry and Behavior, 44, 815-819.

Parikh, V., Kozak, R., Martinez, V., \& Sarter, M. (2007). Prefrontal acetylcholine release controls cue detection on multiple timescales. Neuron, 56, 141-154.

Parrott, A. C. (1989). Transdermal scopolamine: A review of its effects upon motion sickness, psychological performance, and physiological functioning. Aviation, Space and Environmental Medicine, 60, 1-9.

Pattij, T., Janssen, M. C. W., Loos, M., Smit, A. B., Schoffelmeer, A. N. M., \& van Gaalen, M. M. (2007). Strain specificity and cholinergic modulation of visuospatial attention in three inbred mouse strains. Genes, Brain and Behavior, 6, 579-587.

Paylor, R., \& Rudy, J. W. (1990). Cholinergic receptor blockade can impair the rat's performance on both place learning and cued versions of the Morris water task: the role of age and pool wall brightness. Behavioural Brain Research, 36, 79-90.

Pazzagli, A., \& Pepeu, G. (1964). Amnesic properties of scopolamine and brain acetylcholine in the rat. Neuropharmacology, 4, 291-299.

Peele, D. B., \& Baron, S. P. (1988a). Effects of scopolamine on repeated acquisition of radial-arm maze performance by rats. Journal of Experimental Analysis of Behavior, 49, 275-290.

Peele, D. B., \& Baron, S. P. (1988b). Effects of selection delays on radial maze performance: acquisition and effects of scopolamine. Pharmacology, Biochemistry and Behavior, 29, 143-150.

Phillips, J. M., McAlonan, K., Robb, W. G., \& Brown, V. J. (2000). Cholinergic neurotransmission influences covert orientation of visuospatial attention in the rat. Psychopharmacology, 150, 112-116.

Phillips, R. G., \& LeDoux, J. E. (1992). Differential contribution of amygdala and hippocampus to cued and contextual fear conditioning. Behavioral Neuroscience, 106, 274-285.

Pilcher, J. J., Sessions, G. R., \& McBride, S. A. (1997). Scopolamine impairs spatial working memory in the radial maze: an anlysis by error type and arm choice. Pharmacology, Biochemistry and Behavior, 58, 449-459.

Plakke, B., Ng, C., \& Poremba, A. (2008). Scopolamine impairs auditory delayed matching-to-sample performance in monkeys. Neuroscience Letters, 438, 126-130.

Pradhan, S. N., \& Roth, T. (1968). Comparative behavioral effects of several anti-cholinergic agents in rats. Psychopharmacologia, 12, 358-366.

Prado-Alcala, R. A., Bermudez-Rattoni, F., Velazquez-Martinez, D. N., \& Bacha, G. (1978). Cholinergic blockade of the caudate nucleus and spatial alternation performance in rats: overtraining induced protection against behavioral deficits. Life Sciences, 23, 889-896.

Prado-Alcala, R. A., Kaufmann, P., \& Moscona, R. (1980). Scopolamine and $\mathrm{KCl}$ injections into the caudate nucleus. Overtraining- induced protection against deficits of learning. Pharmacology, Biochemistry and Behavior, 12, 249-253.

Price, J. L., \& Stern, R. (1983). Individual cells in the nucleus basalis--diagonal band complex have restricted axonal projections to the cerebral cortex in the rat. Brain Research, 269, 352-356.

Quartermain, D., \& Leo, P. (1988). Strength of scopolamine-induced amnesia as a function of time between training and testing. Behavioral and Neural Biology, 50, 300-310.

Quirarte, G. L., Cruz-Morales, S. E., Cepeda, A., Garcia-Montanez, M., Roldan-Roldan, G., \& Prado-Alcala, R. A. (1994). Effects of central muscarinic blockade on passive avoidance: anterograde amnesia, state dependency, or both? Behavioral and Neural Biology, 62, 15-20. 
Ragozzino, M. E., Jih, J., \& Tzavos, A. (2002). Involvement of the dorsomedial striatum in behavioral flexibility: Role of muscarinic cholinergic receptors. Brain Research, 953, 205-214.

Ragozzino, M. E., \& Kesner, R. P. (1998). The effects of muscarinic cholinergic receptor blockade in the rat anterior cingulate and prelimbic/infralimbic cortices on spatial working memory. Neurobiology of Learning and Memory, 69, 241-257.

Ramírez-Lugo, L., Miranda, M. I., Escobar, M. L., Espinosa, E., \& Bermúdez-Rattoni, F. (2003). The role of cortical cholinergic pre- and post-synaptic receptors in taste memory formation. Neurobiology of Learning and Memory, 79, 184-193.

Rasmusson, D. D. (2000). The role of acetylcholine in cortical synaptic plasticity. Behavioural Brain Research, $115,205-218$.

Ravel, N., Elaagouby, A., \& Gervais, R. (1994). Scopolamine injection into the olfactory bulb impairs shortterm olfactory memory in rats. Behavioral Neuroscience, 108, 317-324.

Renfro, C. T., Freedman, P. E., \& Rosen, A. J. (1972). The concurrent effects of scopolamine on spontaneous motor activity and the acquisition of an active avoidance response. Neuropharmacology, 11, 337-346.

Richmond, M. A., Nichols, B. P., Deacon, R. M. J., \& Rawlins, J. N. P. (1997). Effects of scopolamine and hippocampal lesions on negative patterning discrimination performance in rats. Behavioral Neuroscience, $111,1217-1227$.

Riekkinen, P., Jr., Kuitunen, J., \& Riekkinen, M. (1995). Effects of scopolamine infusions into the anterior and posterior cingulate on passive avoidance and water maze navigation. Brain Research, 685, 46-54.

Riekkinen, P., Jr., Sirvio, J., Valjakka, A., Pitkanen, A., Partanen, J., \& Riekkinen, P. (1990). The effects of concurrent manipulations of cholinergic and noradrenergic systems on neocortical EEG and spatial learning. Behavioral and Neural Biology, 54, 204-210.

Robinson, J. K., \& Mao, J. B. (1997). Differential effects on delayed non-matching-to-position in rats of microinjections of muscarinic receptor antagonist scopolamine or NMDA receptor antagonist MK-801 into the dorsal or ventral extent of the hippocampus. Brain Research, 765, 51-60.

Robinson, L., Harbaran, D., \& Riedel, G. (2004). Visual acuity in the water maze: sensitivity to muscarinic receptor blockade in rats and mice. Behavioural Brain Research, 151, 277-286.

Rodriguez, R., Kallenbach, U., Singer, W., \& Munk, M. H. (2004). Short- and long-term effects of cholinergic modulation on gamma oscillations and response synchronization in the visual cortex. The Journal of Neuroscience, 24, 10369-10378.

Rogers, J. L., \& Kesner, R. P. (2004). Cholinergic modulation of the hippocampus during encoding and retrieval of tone/shock-induced fear conditioning. Learning \& Memory, 11, 102-107.

Roldán, G., Bolaňos-Badillo, E., González-Sánchez, H., Quirarte, G.L., \& Prado-Alcalá, R.A. (1997). Selective M1 muscarinic receptor antagonists disrupt memory consolidation of inhibitory avoidance in rats. Neuroscience Letters, 230, 93-96.

Roldán, G., Cobos-Zapiain, G., Quirarte, G. L., \& Prado-Alcala, R. A. (2001). Dose- and time-dependent scopolamine-induced recovery of an inhibitory avoidance response after its extinction in rats. Behavioural Brain Research, 121, 173-179.

Rudy, J. W. (1996). Scopolamine administered before and after training impairs both contextual and auditory-cue fear conditioning. Neurobiology of Learning and Memory, 65, 73-81.

Rudy, J. W., \& Pugh, C. R. (1996). Postconditioning scopolamine administration selectively influences generalized auditory-cue fear conditioning. Psychobiology, 24, 294-299.

Ruotsalainen, S., Miettinen, R., Macdonald, E., Riekkinen, M., \& Sirviö, J. (1998). The role of the dorsal rapheserotonergic system and cholinergic receptors in the modulation of working memory. Neuroscience and Biobehavioral Reviews, 22, 21-31.

Rupniak, N. M. J., Samson, N. A., Tye, S. J., Field, M. J., \& Iversen, S. D. (1991). Evidence against a specific effect of cholinergic drugs on spatial memory in primates. Behavioural Brain Research, 43, 1-6.

Rush, D. K. (1988). Scopolamine amnesia of passive avoidance: a deficit of information acquisition. Behavioral and Neural Biology, 50, 255-274.

Safer, D. J., \& Allen, R. P. (1971). The central effects of scopolamine in man. Biological Psychiatry, 3, 347-355.

Sala, M., Braida, D., Calcaterra, P., Leone, M. P., Comotti, F. A., Gianola, S., et al. (1991). Effect of centrally administered atropine and pirenzepine on radial arm maze performance in the rat. European Journal of Pharmacology, 194, 45-49.

Sambeth, A., Maes, J. H., Quian Quiroga, R., \& Coenen, A. M. (2004). Effects of stimulus repetitions on the event-related potential of humans and rats. International Journal of Psychophysiology, 53, 197-205. 
Sambeth, A., Maes, J. H., Van Luijtelaar, G., Molenkamp, I. B., Jongsma, M. L., \& Van Rijn, C. M. (2003). Auditory event-related potentials in humans and rats: effects of task manipulation. Psychophysiology, 40, 60-68.

Sambeth, A., Riedel, W., Smits, L., \& Blokland, A. (2007). Cholinergic drugs affect novel object recognition in rats: Relation with hippocampal EEG? European Journal of Pharmacology, 572, 151-159.

Samuel, G. K., Kodama, J. K., \& Mennear. (1965). Effects of scopolamine and atropine and their quarternized salts on avoidance behavior in the monkey. Psychopharmacologia, 8, 295-301.

Sannita, W. G., Balestra, V., DiBon, G., Marotta, V., \& Rosadini, G. (1993). Human flash-VEP and quantitative EEG are independently affected by acute scopolamine. Electroencephalography and Clinical Neurophysiology, 86, 275-282.

Santi, A., \& Weise, L. (1995). The effects of scopolamine on memory for time in rats and pigeons. Pharmacology, Biochemistry and Behavior, 51, 271-277.

Santucci, A. C., \& Shaw, C. (2003). Peripheral 8-OH-DPAT and scopolamine infused into the frontal cortex produce passive avoidance retention impairments in rats. Neurobiology of Learning and Memory, 79, 136-141.

Sarter, M. (2006). Preclinical research into cognition enhancers. Trends in Pharmacological Sciences, 27, 602608.

Sarter, M., \& Bruno, J. P. (1997). Cognitive functions of cortical acetylcholine: toward a unifying hypothesis. Brain Research Reviews, 23, 28-46.

Sarter, M., Bruno, J.P., \& Givens, B. (2003). Attentional functions of cortical cholinergic inputs: What does it mean for learning and memory? Neurobiology of Learning and Memory, 80, 245-256.

Sato, H., Hata, Y., Musui, H., \& Tsumoto, T. (1987). A functional role of cholinergic innervation to neurons in the cat visual cortex. Journal of Neurophysiology, 58, 765-780.

Saucier, D., Hargreaves, E. L., Boon, F., Vanderwolf, C. H., \& Cain, D. P. (1996). Detailed behavioral analysis of water maze acquisition under systemic NMDA or muscarinic antagonism: nonspatial pretraining eliminates spatial learning deficits. Behavioral Neuroscience, 110, 103-116.

Savage, U. C., Faust, W. B., Lambert, P., \& Moerschbaecher, J. M. (1996). Effects of scopolamine on learning and memory in monkeys. Psychopharmacology, 123, 9-14.

Schmeller, T., Sporer, F., Sauerwein, M., \& Wink, M. (1995). Binding of tropane alkaloids to nicotinic and muscarinic acetylcholine receptors. Pharmazie, 50, 493-495.

Schultes, R. E., \& Hofmann, A. (1979). Plants of the gods. New York, NY: McGraw-Hill company.

Shannon, H. E., Bemis, K. G., \& Hart, J. C. (1990). Assessment of working memory in rats using spatial alternation behavior with variable retention intervals: effects of fixed-ratio size and scopolamine. Psychopharmacology, 100, 491-497.

Shannon, H. E., Bemis, K. G., Hendrix, J. C., \& Ward, J. S. (1990). Interactions between scopolamine and muscarinic cholinergic agonists or cholinesterase inhibitors on spatial alternation performance in rats. The Journal of Pharmacology and Experimental Therapeutics, 255, 1071-1077.

Shannon, H. E., Bymaster, F. P., Calligaro, D. O., Greenwood, B., Mitch, C. H., Sawyer, B. D., et al. (1994). Xanomeline: A novel muscarinic receptor agonist with functional selectivity for M1 receptors. The Journal of Pharmacology and Experimental Therapeutics, 269, 271-281.

Shannon, H. E., \& Eberle, E. L. (2006). Effects of biasing the location of stimulus presentation, and the muscarinic cholinergic receptor antagonist scopolamine, on performance of a 5-choice serial reaction time attention task in rats. Behavioural Pharmacology, 17, 71-85.

Shannon, H. E., \& Love, P. L. (2004). Within-session repeated acquisition behavior in rats as a potential model of executive function. European Journal of Pharmacology, 498, 125-134.

Shannon, H. E., \& Yang, L. (2007). A non-spatial, stimulus-comparison working memory task in rats and disruption by scopolamine. Neuroscience, 145, 955-962.

Sharf, R., \& Ranaldi, R. (2006). Blockade of muscarinic acetylcholine receptors in the ventral tegmental area disrupts food-related learning in rats. Psychopharmacology, 184, 87-94.

Shekhar, A., Potter, W. Z., Lightfoot, J., Lienemann, J., Dubé, S., Mallinckrodt, C., et al. (2008). Selective muscarinic receptor agonist xanomeline as a novel treatment approach for schizophrenia. American Journal of Psychiatry, 165, 1033-1039.

Shida, T., Tokunaga, A., Kondo, E., Ueda, Y., Ohno, K., Saika, T., et al. (1993). Expression of muscarinic and nicotinic receptor mRNA in the salivary gland of rats: A study by in situ hybridization histochemistry. Molecular Brain Research, 17, 335-339. 
Shiraishi, K., \& Takayanagi, I. (1993). Subtype of muscarinic receptors mediating relaxation and contraction in the rat iris dilator smooth muscle. General Pharmacology, 24, 139-142.

Shurtleff, D., Raslear, T. G., Genovese, R. F., \& Simmons, L. (1992). Perceptual bisection in rats: the effects of physostigmine, scopolamine and pirenzipine. Physiology \& Behavior, 51, 381-390.

Silver, M. A., Shenhav, A., \& D’Esposito, M. (2008). Cholinergic enhancement reduces spatial spread of visual responses in human early visual cortex. Neuron, 60, 904-914.

Sipos, M. L., Burchnell, V., \& Galbicka, G. (1999). Dose-response curves and time-course effects of selected anticholinergics on locomotor activity in rats. Psychopharmacology, 147, 250-256.

Sipos, M. L., Burchnell, V., \& Galbicka, G. (2001). Effects of selected anticholinergics on acoustic startle response in rats. Journal of Applied Toxicology, 21, S95-S101.

Sloan, E. P., Fenton, G. W., \& Standage, K. P. (1992). Anticholinergic drug effects on quantitative electroencephalogram, visual evoked potential, and verbal memory. Biological Psychiatry, 31, 600-606.

Smith, C. P. S., Hunter, A. J., \& Bennett, G. W. (1994). Effects of (R)- $\alpha$-methylhistamine and scopolamine on spatial learning in the rat assessed using a water maze. Psychopharmacology, 114, 651-656.

Smith, G. (1988). Animal models of Alzheimer's disease: experimental cholinergic denervation. Brain Research Reviews, 13, 103-118.

Smythe, J. W., Bhatnagar, S., Murphy, D., Timothy, C., \& Costall, B. (1998). The effects of intrahippocampal scopolamine infusions on anxiety in rats as measured by the black-white box test. Brain Research Bulletin, 45, 89-93.

Smythe, J. W., Murphy, D., Bhatnagar, S., Timothy, C., \& Costall, B. (1996). Muscarinic antagonists are anxiogenic in rats tested in the black-white box. Pharmacology, Biochemistry and Behavior, 54, 57-63.

Snyder, P. J., Bednar, M. M., Cromer, J. R., \& Maruff, P. (2005). Reversal of scopolamine-induced deficits with a single dose of donepezil, an acetylcholinesterase inhibitor. Alzheimer's \& Dementia, 1, 126-135.

Spangler, E. L., Chachich, M. E., Curtis, N. J., \& Ingram, D. K. (1989). Age-related impairment in complex maze learning in rats: relationship to neophobia and cholinergic antagonism. Neurobiology of Aging, 10, 133141.

Spehlmann, R., \& Norcross, K. (1982). Cholinergic mechanisms in the production of focal cortical slow waves. Experientia, 38, 109-111.

Spencer, D. G., Jr., \& Lal, H. (1983). Effects of anticholinergic drugs on learning and memory. Drug Development Research, 3, 489-502.

Spinelli, S., Ballard, T., Feldon, J., Higgins, G. A., \& Pryce, C. R. (2006). Enhancing effects of nicotine and impairing effects of scopolamine on distinct aspects of performance in computerized attention and working memory tasks in marmoset monkeys. Neuropharmacology, 51, 238-250.

Squire, L. R. (1969). Effects of pretrial and posttrial administration of cholinergic drugs on spontaneous alternation. Journal of Comparative and Physiological Psychology, 69, 69-75.

Stanhope, K. J., McLenachan, A. P., \& Dourish, C. T. (1995). Dissociation between cognitive and motor/motivational deficits in the delayed matching to position test: effects of scopolamine, 8-OH-DPAT and EAA antagonists. Psychopharmacology, 122, 268-280.

Steckler, T., Sahgal, A., Aggleton, J. P., \& Drinkenburg, W. H. (1998). Recognition memory in rats--III. Neurochemical substrates. Progress in Neurobiology, 54, 333-348.

Stevens, R. (1981). Scopolamine impairs spatial maze performance in rats. Physiology \& Behavior, 27, 385386.

Taffe, M. A., Weed, M. R., \& Gold, L. H. (1999). Scopolamine alters rhesus monkey performance on a novel neuropsychological test battery. Cognitive Brain Research, 8, 203-212.

Thompson, H. T., \& Cotterill, D. (1909). Note on the use of of scopolamine-morphine combination as an anaesthetic adjunct. Edinburgh Medical Journal, 3, 548-554.

Thompson, R. W., \& Nielsen, C. (1972). The effect of scopolamine on the Kamin effect: a test of parasympathetic overreaction hypothesis. Psychonomic Science, 28, 140-142.

Thouvarecq, R., Protais, P., Jouen, F., \& Caston, J. (2001). Influence of cholinergic system on motor learning during aging in mice. Behavioural Brain Research, 118, 209-218.

Tobin, G., Giglio, D., \& Götrick, B. (2002). Studies of muscarinic receptor subtypes in salivary gland function in anaesthetized rats. Autonomic Neuroscience: Basic and Clinical, 100, 1-9.

Torres, E. M., Perry, T. A., Blokland, A., Wilkinson, L. S., Wiley, R. G., Lappi, D. A., et al. (1994). Behavioural, histochemical and biochemical consequences of selective immunolesions in discrete regions of the basal forebrain cholinergic system. Neuroscience, 63, 95-122. 
Tzavos, A., Jih, J., \& Ragozzino, M. E. (2004). Differential effects of M1 muscarinic receptor blockade and nicotinic receptor blockade in the dorsomedial striatum on response reversal learning. Behavioural Brain Research, 154, 245-253.

Ukai, M., Shinkai, N., \& Kameyama, T. (1995a). Cholinergic receptor agonists inhibit pirenzepine-induced dysfunction of spontaneous alternation performance in the mouse. General Pharmacology, 26, 15291532.

Ukai, M., Shinkai, N., \& Kameyama, T. (1995b). k-opiod receptor agonists improve pirenzipine-induced disturbance of spontaneous alternation performance in the mouse. European Journal of Pharmacology, 281, 173-178.

van Abeelen, J. H. F., \& Strijbosch, H. (1969). Genotype-dependent effects of scopolamine and eserine on exploratory behaviour in mice. Psychopharmacologia, 16, 81-88.

van der Zee, E. A., \& Luiten, P. G. (1999). Muscarinic acetylcholine receptors in the hippocampus, neocortex and amygdala: a review of immunocytochemical localization in relation to learning and memory. Progress in Neurobiology, 58, 409-471.

van Haaren, F., \& van Hest, A. (1989). The effects of scopolamine and methylscopolamine on visual and auditory discriminations in male and female Wistar rats. Pharmacology, Biochemistry and Behavior, 32, 707-710.

van Hest, A., Stroet, J., van Haaren, F., \& Feenstra, M. (1990). Scopolamine differentially disrupts the behavior of male and female Wistar rats in a delayed nonmatching to position procedure. Pharmacology, Biochemistry and Behavior, 35, 903-909.

Vanderwolf, C. H. (1988). Cerebral activity and behavior: control by central cholinergic and serotonergic systems. International Review of Neurobiology, 30, 225-340.

Vanderwolf, C. H. (1991). Anti-muscarinic drug effects in a swim-to-platform test: dose-response relations. Behavioural Brain Research, 44, 217-219.

Vannucchi, M. G., Scali, C., Kopf, S. R., Pepeu, G., \& Casamenti.F. (1997). Selective muscarinic antagonists differentially affect in vivo acetylcholine release and memory performance of young and aged rats. Neuroscience, 79, 837-846.

Viscardi, A. P., \& Heise, G. A. (1986). Effects of scopolamine on components of delayed response performance in the rat. Pharmacology, Biochemistry and Behavior, 25, 633-639.

Voytko, M. L. (1996). Cognitive functions of the basal forebrain cholinergic system in monkeys: memory or attention. Behavioural Brain Research, 75, 13-25.

Vrijmoed de Vries, M. C., \& Cools, A. R. (1986). Differential effects of striatal injections of dopaminergic, cholinergic and GABAergic drugs upon swimming behavior of rats. Brain Research, 364, 77-90.

Waelbroeck, M., Gillard, M., Robberecht, P., \& Christophe, J. (1986). Kinetic studies of [3H]-Nmethylscopolamine binding to muscarinic receptors in the rat central nervous system: evidence for the existence of three classes of binding sites. Molecular Pharmacology, 30, 305-314.

Wagman, W. D., \& Maxey, G. C. (1969). The effects of scopolamine hydrobromide and methyl scopolamine hydrobromide upon the discrimination of interoceptive and exteroceptive stimuli. Psychopharmacologia, 15, 280-288.

Wall, P. M., Flinn, J., \& Messier, C. (2001). Infralimbic muscarinic M1 receptors modulate anxiety-like behaviour and spontaneous working memory in mice. Psychopharmacology, 155, 58-68.

Wallenstein, G. V., \& Vago, D. R. (2001). Intrahippocampal scopolamine impairs both acquisition and consolidation of contextual fear conditioning. Neurobiology of Learning and Memory, 75, 245-252.

Wan, R. Q., Pang, K., \& Olton, D. S. (1997). Nonhippocampal muscarinic receptors are required for nonspatial working memory. Pharmacology, Biochemistry and Behavior, 58, 361-367.

Warburton, D. M. (1974). The effects of scopolamine on a two-cue discrimination. Quarterly Journal of Experimental Psychology, 26, 395-404.

Warburton, D. M., \& Brown, K. (1971). Attenuation of stimulus sensitivity induced by scopolamine. Nature, 230, 126-127.

Warburton, D. M., \& Heise, G. A. (1972). Effects of scopolamine on spatial double alternation in rats. Journal of Comparative and Physiological Psychology, 81, 523-532.

Warburton, E. C., Koder, T., Kwangwook, C., Massey, P. V., Duguid, G., Barker, G. R. I., et al. (2003). Cholinergic neurotransmission is essential for perirhinal cortical plasticity and recognition memory. Neuron, 38 , 987-996. 
Watanabe, H., \& Shimizu, H. (1989). Effect of anticholinergic drugs on striatal acetylcholine release and motor activity in freely moving rats studied by brain microdialysis. Japanese Journal Pharmacology, 51, 75-82.

Watts, J., Stevens, R., \& Robinson, C. (1981). Effects of scopolamine on radial maze performance in rats. Physiology \& Behavior, 26, 845-851.

Weiner, N. (1980). Atropine, scopolamine, and related muscarinic drugs. In L. S. Goodman \& A. Gilman (Eds.), The pharmacological basis of therapeutics (6th ed., pp. 120-137). New York, NY: Macmillen.

Weisman, R. G., Bruce, R., \& Beninger, R. J. (1987). Simple and conditional discriminations in rats: the effects of delays and scopolamine. Learning and Motivation, 18, 274-287.

Wenk, G. L. (1997). The nucleus basalis magnocellularis cholinergic system: One hundred years of progress. Neurobiology of Learning and Memory, 67, 85-95.

Wesnes, K. (1988). An investigation of the range of cognitive impairments induced by scopolamine $0.6 \mathrm{mg}$ s.c. Human Psychopharmacology, 3, 27-41.

Wess, J. (2005). Allosteric binding sites on muscarinic acetylcholine receptors. Molecular Pharmacology, 68, 1506-1509.

Wezenberg, E., Verkes, R. J., Sabbe, B. G., Ruigt, G. S., \& Hulstijn, W. (2005). Modulation of memory and visuospatial processes by biperiden and rivastigmine in elderly healthy subjects. Psychopharmacology, 181, 582-594.

Wiener, N., \& Deutsch, J. A. (1968). Temporal aspects of anticholinergic- and anticholinesterase-induced amnesia for an appetitive habit. Journal of Comparative and Physiological Psychology, 66, 613-617.

Wiener, N. I., \& Messer, J. (1973). Scopolamine-induced impairment of long-term retention in rats. Behavioral Biology, 9, 227-234.

Wiley, R. G., Berbos, T. G., Deckwerth, T. L., Johnson, E. M., Jr., \& Lappi, D. A. (1995). Destruction of the cholinergic basal forebrain using immunotoxin to rat NGF receptor: modeling the cholinergic degeneration of Alzheimer's disease. Journal of the Neurological Sciences, 128, 157-166.

Wiley, R. G., Oeltmann, T. N., \& Lappi, D. A. (1991). Immunolesioning: Selective destruction of neurons using immunotoxin to rat NGF receptor. Brain Research, 562, 149-153.

Wilson, D. A. (2001). Scopolamine enhances generalization between odor representations in rat olfactory cortex. Learning \& Memory, 8, 279-285.

Winslow, J. T., \& Camacho, F. (1995). Cholinergic modulation of a decrement in social investigation following repeated contacts between mice. Psychopharmacology, 121, 164-172.

Winters, B., Matheson, W. R., McGregor, I. S., \& Brown, R. (2000). An automated two-choice test of olfactory working memory in the rat: effect of scopolamine. Psychobiology, 28, 21-31.

Winters, B. D., Bartko, S. J., Saksida, L. M., \& Bussey, T. J. (2007). Scopolamine infused into perirhinal cortex improves object recognition memory by blocking the acquisition of interfering object information. Learning \& Memory, 14, 590-596.

Winters, B. D., Saksida, L. M., \& Bussey, T. J. (2006). Paradoxical facilitation of object recognition memory after infusion of scopolamine into perirhinal cortex: Implications for cholinergic system function. The Journal of Neuroscience, 26, 9520-9529.

Winters, B. D., Saksida, L. M., \& Bussey, T. J. (2008). Object recognition memory: Neurobiological mechanisms of encoding, consolidation and retrieval. Neuroscience and Biobehavioral Reviews, 32, 1055-1070.

Wirsching, B. A., Beninger, R. J., Jhamandas, K., Boegman, R. J., \& El-Defrawy, S. R. (1984). Differential effects of scopolamine on working and reference memory of rats in the radial maze. Pharmacology, Biochemistry and Behavior, 20, 659-662.

Wrenn, C. C., \& Wiley, R. G. (1998). The behavioral functions of the cholinergic basal forebrain: Lessons from 192 IgG-saporin. International Journal of Developmental Neuroscience, 16, 595-602.

Yasuda, R. P., Ciesla, W., Flores, L. R., Wall, S. J., Li, M., Satkus, S. A., et al. (1992). Development of antisera selective for $\mathrm{m} 4$ and $\mathrm{m} 5$ muscarinic cholinergic receptors: Distribution of $\mathrm{m} 4$ and $\mathrm{m} 5$ receptors in rat brain. Molecular Pharmacology, 43, 149-157.

Young, S. L., Bohenek, D. L., \& Fanselow, M. S. (1995). Scopolamine impairs acquisition and facilitates consolidation of fear conditioning: differential effects for tone vs context conditioning. Neurobiology of Learning and Memory, 63, 174-180.

Zhang, W., Song, M., Cui, Y., Wang, H., Zhu, L., Niu, Y., et al. (2008). Differential neuropsychopharmacological influences of naturally occuring tropane alkaloids anisodamine versus scopolamine. Neuroscience Letters, 443, 241-245. 

CHAPTER 3

\section{A comparison of scopolamine and biperiden as a rodent model for cholinergic cognitive impairment}




\section{INTRODUCTION}

The muscarinic antagonist scopolamine hydrobromide is used as the gold standard for inducing deficits in human and animal models of memory dysfunction. Justification for this purpose has been provided by the cholinergic hypothesis of geriatric memory dysfunction proposed in the early eighties by Bartus et al. (1982). The scopolamine model is still used extensively for preclinical testing of new substances designed to treat cognitive impairment (e.g., Barak \& Weiner, 2009; Buccafusco et al., 2008; Cunha et al., 2008; Loiseau et al., 2008; Vaisman \& Pelled, 2009). However, its use in cognition research is surrounded by controversy (see Chapter 2 and Hodges Jr. et al., 2009). Scopolamine is non-selective in terms of binding affinity and, depending on its dose, has the capability to block cholinergic neurotransmission at all muscarinic receptor subtypes $M_{1}-M_{5}$ (Bolden et al., 1992; Bymaster et al., 2003). As muscarinic receptors are found throughout the brain and body (Caulfield, 1993), scopolamine is able to induce widespread effects.

Systemic injections of scopolamine are capable of disrupting several autonomic nervous system functions. At doses of $0.01 \mathrm{mg} / \mathrm{kg}$ and higher, scopolamine can reduce salivation (dry mouth side-effect: Dai et al., 1991; Hodges Jr. et al., 2009; Shiraishi \& Takayanagi, 1993), which may lower responding in tasks which employ solid food rewards in order to motivate the animals. Although this problem can be dealt with by using liquid reinforcers (Hodges Jr. et al., 2009), the majority of studies still favor dry food pellets (see Chapter 2). Further, most behavioral tasks also have a strong non-cognitive component which can be influenced by scopolamine treatment (e.g., increases in locomotor activity, response latency, and omissions at doses lower than $0.03 \mathrm{mg} / \mathrm{kg}$, see Chapter 2 and Bushnell et al., 1997; Mirza, 2000; Phillips et al., 2000; Sipos et al., 1999). Performance on behavioral tasks assessing sensory/stimulus discrimination and/or attentional processes appears to be most susceptible to scopolamine treatment (Hodges Jr. et al., 2009). Only if doses higher than 0.1 $\mathrm{mg} / \mathrm{kg}$ are administered systemically, robust performance deficits on a variety of learning and memory tasks are reported (see Chapter 2). Therefore it has been argued that acetylcholine is predominantly involved in mediating discriminatory and attentional processes (Blokland, 1995; Everitt \& Robbins, 1997; Fibiger, 1991; Sarter \& Bruno, 1997) rather than learning and memory functions (Bartus et al., 1982). In sum, the validity of scopolamine as a tool for inducing cognitive dysfunction is questionable.

Of note, systemic administration makes it difficult to dissociate central and peripheral effects. One way to address this issue is to include an experimental group that is given methylscopolamine, a quaternary form of scopolamine that has the same receptor binding characteristics but supposedly does not cross the blood-brain barrier when given at an equivalent dose (Evans, 1975; Harvey et al., 1983; Pradhan \& Roth, 1968). However, several animal studies have shown that methylscopolamine can influence measures of cognitive performance (e.g., Andrews et al., 1994; Herremans et al., 1995; Moore et al., 1992; Pakarinen \& Moerschbaecher, 1993; van Haaren \& van Hest, 1989). In addition, methylscopolamine cannot control for the widespread blockade of central muscarinic receptors after systemic administration of scopolamine (Frey et al., 1985).

Several of the muscarinic receptor subtypes $M_{1}-M_{5}$ might underlie the cognitive effects of scopolamine. Muscarinic $M_{2}$ presynaptic autoreceptors have an inhibitory effect on acetylcholine efflux (Bymaster et al., 2003). Hence, $M_{2}$ antagonists might act as cognitive enhancers by elevating central cholinergic tone, but behavioral data are mixed (Carey et al., 
2001; Daniel \& Dohanich, 2001; Messer \& Miller, 1988; Quirion et al., 1995). The role of $\mathrm{M}_{3}$ receptors in cognition is as of yet quite obscure (Bymaster et al., 2003), although one study showed a potential role of $\mathrm{M}_{3}$ receptors in cognition (Poulin et al., 2010). Information on the involvement of $M_{4}$ presynaptic autoreceptors and $M_{5}$ postsynaptic in cognitive function is also relatively limited (Wess, 2004); there are some indications that the $M_{5}$ receptor is implicated in central cerebral blood flow and memory processes (Araya et al., 2006).

Evidence for a role in mnemonic processes in both rodents and humans is strongest for the postsynaptic muscarinic $\mathrm{M}_{1}$ receptor (e.g., Conn et al., 2009; Fornari et al., 2000; Kimura et al., 1999; Kramer-Soares et al., 2006; Roldán, 1997; Wezenberg et al., 2005). This receptor is predominantly located in brain regions thought to be important for learning and memory such as cortex and hippocampus; presence of the $M_{1}$ receptor in the periphery is relatively limited (Caulfield, 1993; Volpicelli \& Levey, 2004). Hence, $M_{1}$ antagonists are considered an interesting option with regards to finding novel pharmacological alternatives to induce cognitive impairment which are not so much hampered by issues of nonselectivity or peripheral side-effects (Conn et al., 2009).

This is the first study to compare the effects of scopolamine versus the relatively more selective muscarinic $M_{1}$ antagonist biperiden (Bolden et al., 1992) on various facets of behavior. Specifically, we wanted to dissociate behavioral effects of these two drugs on a battery of four operant tasks: fixed ratio (FR5) and progressive ratio (PR10) schedules of reinforcement (assessing sensorimotor responding and food motivation, respectively) versus performance on an attention task and a delayed non-matching to position task (DNMTP; assessing short-term memory). On basis of the direct comparison between both drugs we wanted to determine whether biperiden would be preferable over scopolamine as a cholinergic memory deficit model.

\section{METHODS}

\section{Subjects}

All experimental procedures were approved by the local ethical committee for animal experiments at Maastricht University and met governmental guidelines. Twenty male 3month old Wistar rats (Harlan, NL) served as subjects in this study. To ensure consistency, the same animals were used in all behavioral tasks. They were housed in pairs in standard type III Makrolon ${ }^{\mathrm{TM}}$ cages on sawdust bedding in an air-conditioned room $\left(21^{\circ} \mathrm{C}, 45-55 \%\right.$ humidity) under a reversed light/dark cycle (lights on from 7 PM to 7 AM). Rats were housed in the room in which they were tested. All testing was performed between 12 and 6 PM. Rats had free access to water, but were subjected to a food deprivation regime from Monday through Friday, in order to reduce their weight to about $90 \%$ of their free feeding weight. Food was given ad libitum from Friday afternoon to Sunday afternoon. Food was taken away at Sunday afternoon which caused a sufficient appetite at the morning session on Monday.

\section{Apparatus}

Rats were trained and tested in 10 identical Skinner boxes $(40 \times 30 \times 33 \mathrm{~cm})$. The ceiling of these conditioning chambers contained a light that illuminated the conditioning chamber 
during experiments. The left and right sidewalls served as control panels. A recess $(5 \times 5$ $\mathrm{cm}$ ), built into the left side panel $2.5 \mathrm{~cm}$ above the grid floor, contained a food tray with a hinged panel into which a pellet dispenser delivered $45-\mathrm{mg}$ food pellets (Bioserve TestDiet AIN-76A rodent tablets, Frenchtown, NJ, USA). Two retractable stainless steel levers $(4 \mathrm{~cm}$ wide) projected $2 \mathrm{~cm}$ into the conditioning chamber and were located $6 \mathrm{~cm}$ from both sides of the recess, $12 \mathrm{~cm}$ above the grid floor. The conditioning chambers were enclosed in sound-attenuating housing. Background noise was produced by a radio and an exhaust fan. A personal computer controlled the experimental equipment and collected the data.

\section{Fixed ratio (5) task}

Rats first underwent five magazine training sessions and were then subjected five times to continuous reinforcement (CRF). Next the rats were trained on a fixed ratio schedule of reinforcement, in which they had to press a lever for five times (FR5) in order to obtain a 45 mg food reward. Reinforcement was continuous; i.e., each set of five lever presses was rewarded. A session was terminated after 60 trials or 30 min., whichever came first. Rats were trained once a day, Monday to Friday, and were given eight FR5 sessions before drug testing started. The measure used to evaluate performance on the FR5 schedule was interresponse time (i.e., time between consecutive lever presses which was averaged for each animal).

\section{Progressive ratio (10) task}

After finishing drug testing in the FR5 task, rats immediately started training on a progressive ratio (PR10) schedule of reinforcement (Hodos, 1961). PR tasks are generally used to asses the reinforcing efficacy of a particular type of reward. The rats had to progressively increase the response requirement (steps of 10 lever presses) to obtain a food reward. For the first food pellet they were required to press 10 times, for the next reinforcement they had to press the lever 20 times, and so on. A session was terminated if a rat did not press the lever for $3 \mathrm{~min}$. or after 1050 lever presses, whichever came first. Rats were trained once a day, Monday to Friday, and were given eight PR10 sessions before drug testing started. The measure used to evaluate performance in the PR10 task was breakpoint (i.e., number of lever presses made during a session).

\section{Attention task}

After the PR10 task, the rats were subjected to one CRF session before they started training in the attention task. During this task, a light stimulus was presented either on the left side or on the right side of the food reward tray. The duration of the light stimulus varied randomly between 3, 1 and $0.3 \mathrm{~s}$. One second after the light stimulus was extinguished, the two levers were inserted simultaneously. When the rat hit the lever on the side of the prior light stimulus (correct response), the rat was rewarded with a food pellet followed by an intertrial interval of 5-10s. When the rat hit the lever on the opposite side of the previous light stimulus (incorrect response), the rat was not rewarded and a time-out period of $5 \mathrm{~s}$ was followed by an inter-trial interval. When the rat did not hit a lever within 3 s (omission), the rat was not rewarded and both levers were retracted followed by a time-out period of $5 \mathrm{~s}$ and an inter-trial interval. A session was terminated after 80 trials or 40 min., whichever came first. A more detailed description of this task is provided by Hoff et al. (2007). Rats 
were trained once a day, Monday to Friday, and were given eight attention task sessions before drug testing started. The derived behavioral measures were percentage correct, percentage omissions, response time (averaged across all stimulus durations) and two signal detection theory derived measures:

1) Sensitivity index (SI): a signal detection measure for discriminability which was calculated as follows:

$$
S I=\frac{h-f}{2(h+f)-(h+f)^{2}}
$$

where

$$
h=\frac{\text { correct left }}{\text { correct left }+ \text { incorrect right }}
$$

and

$$
f=\frac{\text { incorrect left }}{\text { incorrect left }+ \text { correct right }}
$$

A value of zero reflects no discrimination whereas a value of 1 reflects perfect discrimination.

2) Index Y: a signal detection derived variable for evaluating a response bias. This parameter is calculated as follows:

$$
\text { Index } Y=\frac{\text { percentage correct left }- \text { percentage correct right }}{\text { percentage correct left }+ \text { percentage correct right }}
$$

A more detailed description of $\mathrm{SI}$, index $\mathrm{Y}$ and other signal detection measures can be found elsewhere (Steckler, 2001).

\section{Delayed non-matching to position}

After the rats had finished drug testing on the attention task, they immediately started training in a non-matching to position task (NMTP), to which subsequently delays were added. This paradigm consisted of two stages: a sample and a choice phase. In the sample phase, one of the two levers was inserted into the operant chamber. After the rat had pressed the sample lever, it was retracted and the rat was required to poke its nose against the hinged panel which gave access to the pellet magazine (positioned equidistantly between the two levers). This was done in order to prevent the rats from using a behavioral strategy (i.e. mediating behavior, Herremans \& Hijzen, 1997) to perform the DNMTP task (e.g., after pressing a lever they can move to the other side and wait for the lever to come out). More than one panel press or keeping the nose in the food tray was without consequence. 
After the rat had pushed the panel at least once and had pulled its nose out of the food hopper, both levers were inserted (the choice phase) and the rat was required to press the lever opposite to the one in the sample phase. It was physically not possible for an animal to keep its nose in the pellet magazine and press the levers, as the food hopper and response levers were placed too far apart. A non-matching lever press was continuously reinforced with a food reward. There was a 5 s time-out period (and no food reward) when the lever pressed in the choice phase was the same one as in the sample phase (i.e., when the response was incorrect). The inter-trial interval was always $8 \mathrm{~s}$ (also in subsequent testing in the DNMPT task). A session was terminated after 80 trials or 60 min., whichever came first. No limited hold period was used for the sample or choice phase, which means that no omission errors were recorded. A more elaborate description of the NMTP training can be found elsewhere (Blokland et al., 2004; Prickaerts et al., 1999).

Rats were trained once a day, Monday to Friday and received five NMTP training sessions and a single forced choice NMTP session (in which the task was continued only after a correct response was given) before delay intervals were being introduced in between the sample and choice phase. The duration of the delays was gradually increased over successive training sessions over a period of about two and a half weeks. In order to speed up DNMTP training rats now received two daily sessions. The delay interval was randomly chosen from the following five alternatives: $0,2,4,8$ or 16s. The animals were able to keep their nose in the food hopper during the delays or press the food panel repeatedly without any consequence, but could not press the levers as these were retracted during the delay. In previous studies, we have not observed the animals developing a mediating strategy while performing the DNMTP task (e.g., Blokland et al., 2004), as they were required to press the panel of the food well before the choice phase was presented. The measures used to evaluate performance in the DNMTP were percentage correct, response time (averaged across all delays), $\mathrm{SI}$ and index $\mathrm{Y}$ (see section Attention task for more information on these parameters).

\section{Drug treatment}

Dose range and pretreatment time were chosen based on previous scopolamine and biperiden data (e.g., Hodges Jr. et al., 2009; Jones, \& Shannon, 2000). Dose conditions were determined according to their position on a logarithmic scale. For example, biperiden doses were 1,3 and $10 \mathrm{mg} / \mathrm{kg}$. When converted to logarithms, these values are approximately equally spaced: $0.0,0.5$ and 1.0 , respectively. Doses were titrated on basis of behavioral effects found in our essay. Scopolamine hydrobromide trihydrate $99 \%$ (obtained from Acros Organics) was dissolved in isotonic saline in doses $0,0.1,0.3$ and $1 \mathrm{mg} / \mathrm{kg}$ (mg salt per $\mathrm{kg}$ body weight), whereas biperiden lactate (Akineton ${ }^{\circledR} 5 \mathrm{mg} / \mathrm{mL}$, obtained from Laboratorio Farmaceutico S.I.T.) was dissolved in Milli-Q purified water in doses $0,1,3$ and $10 \mathrm{mg} / \mathrm{kg}$ (mg salt per kg body weight). We used quite high doses of scopolamine and biperiden (1 and $10 \mathrm{mg} / \mathrm{kg}$, respectively) as an upper limit at which - certainly in case of scopolamine serious behavioral side-effects were expected. All drug solutions were prepared freshly each day prior to testing. Scopolamine and biperiden were both injected in a volume of 2 $\mathrm{ml} / \mathrm{kg}$ (IP) with a pretreatment time of $30 \mathrm{~min}$. Each drug dose was tested once per rat per test. On each testing day, only one scopolamine and one biperiden dose was given, with half of the rats receiving scopolamine and the other half receiving biperiden. The order of doses was semi-randomized over testing days. 


\section{Repeated testing}

Repeated testing of drugs in the same group of animals offers several advantages over between-group studies (e.g., better statistical power). However, this particular type of design can be associated with tolerance, drug sensitivity and carry-over effects. To ensure sufficient wash-out of the drug, testing days were always separated by at least one drugfree day on which the animals received FR5, PR10, attention task or DNMTP training. Frequency of administration and dose level were kept as low as possible (i.e., no higher doses were tested than those yielding a significant behavioral effect). This procedure minimized the number of injections each rat received. In order to further minimize group differences due to receptor changes, the drug that was given (scopolamine or biperiden) alternated between groups for the different behavioral tasks; i.e., ten rats received only scopolamine doses and the other ten only received biperiden doses during testing of one paradigm. When testing of the next behavioral test started this order was reversed: rats which had previously received scopolamine, now received biperiden and vice versa.

Statistical analysis

Data were analyzed by parametric analysis of variance (mixed-model ANOVA; SPSS 15.0) with Dose as within-subject variable and Drug as between-subject variable. In case an interaction with Drug and/or a main effect of Drug was found, a repeated measures ANOVA was performed for each Drug separately, with Dose as within-subject variable (and possibly Stimulus Duration or Delay). Hence, drug effects of scopolamine and biperiden were compared with their own vehicle condition: i.e., scopolamine with saline and biperiden with Milli-Q. For the analysis of the attention task and the DNMTP, Stimulus Duration and Delay were added as additional within-subject variables, respectively. In case a significant Dose $x$ Stimulus Duration or Dose $x$ Delay interaction was reported, several repeated measure ANOVAs were run separately for Stimulus Duration or Delay, respectively. One exception was the measure response time; here, data was averaged for each animal and collapsed across Stimulus Duration or Delay. Differences from vehicle conditions were always examined with a Least Significant Difference (LSD) post-hoc test. Due to some mechanical issues, occasionally data of nine rats were used for analysis.

\section{RESULTS}

\section{Fixed ratio (5) task}

Three rats failed to complete 60 trials within $30 \mathrm{~min}$. after a dose of $1 \mathrm{mg} / \mathrm{kg}$ scopolamine. Figure 1 shows the effects of scopolamine and biperiden on inter-response time in a FR5 schedule of reinforcement. In the mixed model ANOVA, the within-subject effect of Dose on inter-response time varied per level of Drug (Dose $x$ Drug interaction effect; $F(3,48)=$ 10.77, $P<0.001)$. Therefore two separate repeated measure ANOVAs for the different levels of Drug were performed. For the group treated with scopolamine, inter-response time in the FR5 task was increased (main effect of Dose; $F(3,24)=12.82, P<0.001$; see Fig. 1a). Post-hoc analysis showed that the $0.3 \mathrm{mg} / \mathrm{kg}(P<0.05)$ and $1 \mathrm{mg} / \mathrm{kg}(P<0.01)$ doses slowed responding. In the group treated with biperiden, there was an increase in FR5 interresponse time (main effect of Dose; $F(3,24)=7.80, P<0.01$; see Fig. $1 \mathrm{~b}$ ). Post-hoc analysis indicated only an effect of the high $10 \mathrm{mg} / \mathrm{kg}$ dose $(P<0.01)$. 
a

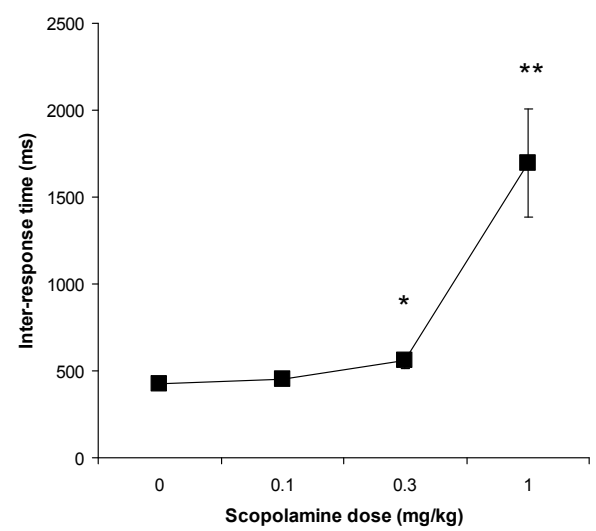

b

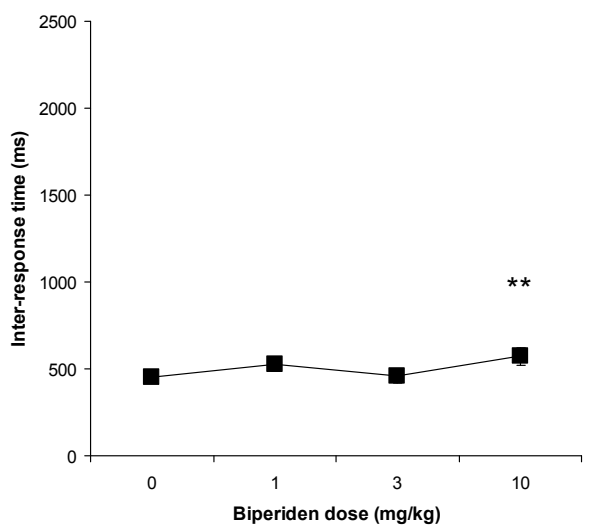

Figure 1. The effects of scopolamine $(0.1,0.3,1 \mathrm{mg} / \mathrm{kg}, \mathrm{IP})$ and biperiden $(1,3,10 \mathrm{mg} / \mathrm{kg}$, IP) on a FR5 schedule of reinforcement. (a) Inter-response time. Scopolamine slowed sensorimotor responding at a dose of 0.3 and $1 \mathrm{mg} / \mathrm{kg}$. (b) Inter-response time. Biperiden slowed sensorimotor responding at a dose of $10 \mathrm{mg} / \mathrm{kg}$. Data represent mean (+SEM). Asterisks indicate differences from vehicle condition ( $\left.{ }^{*}: P<0.05,{ }^{* *}: P<0.01\right)$.

\section{Progressive ratio (10) task}

Figure 2 shows the effects of scopolamine and biperiden on breakpoint and inter-response time on a PR10 schedule of reinforcement. In the mixed model ANOVA, the within-subject effect of Dose on breakpoint did not vary per level of Drug (no Dose $x$ Drug interaction effect; $F(2,36)=0.77$, n.s.). Further, breakpoint was differentially affected by Dose (main effect of Dose; $F(2,36)=5.57, P<0.01$ ). The between-subject analysis of Drug showed that scopolamine and biperiden differentially affected breakpoint (main effect of Drug; $F(1,18)=$ 5.93, $P<0.05$ ). Therefore, two separate repeated measure ANOVAs for the different levels of Drug were performed. For the group treated with scopolamine, breakpoint in the PR10 task was reduced (main effect of Dose; $F(2,18)=3.91, P<0.05$; see Fig. 2a). Post-hoc analysis showed an effect of the $1 \mathrm{mg} / \mathrm{kg}$ dose $(P<0.05)$. For the group treated with biperiden, no change in breakpoint (no main effect of Dose; $F(2,18)=2.10$, n.s.; see Fig. $2 b$ ) was found.

In the mixed model ANOVA, the within-subject effect of Dose on inter-response time did not vary per level of Drug (no Dose $x$ Drug interaction effect; $F(2,36)=0.38$, n.s.; see Fig. $2 \mathrm{c}$ and Fig. 2d). The within-subject analysis of Dose was not significant (no main effect of Dose; $F(2,36)=3.04$, n.s.), which means that the different dose conditions also did not change inter-response time. The between-subject analysis of Drug showed that scopolamine and biperiden did not differentially affect inter-response time (no main effect of Drug; $F(1,18)=0.32$, n.s. $)$. 
a

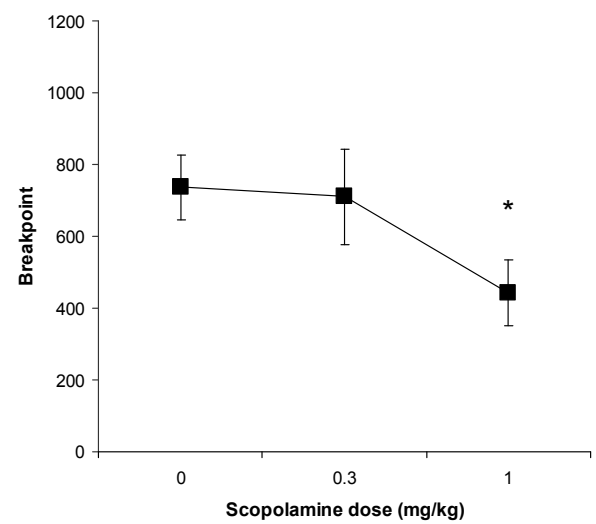

C

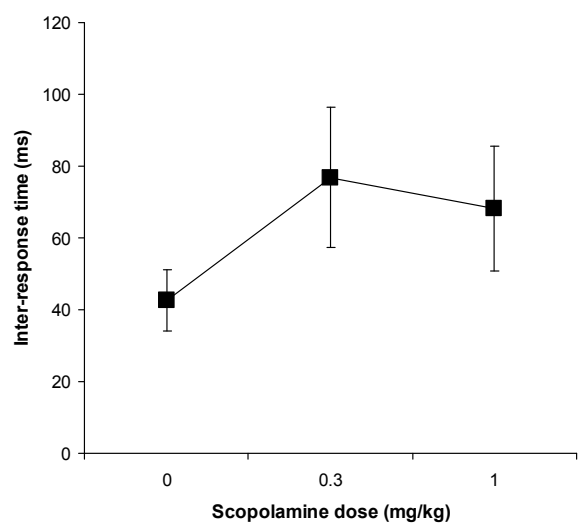

b

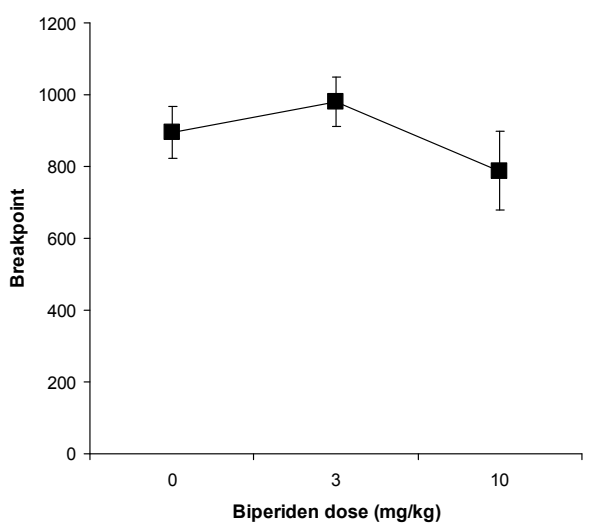

d

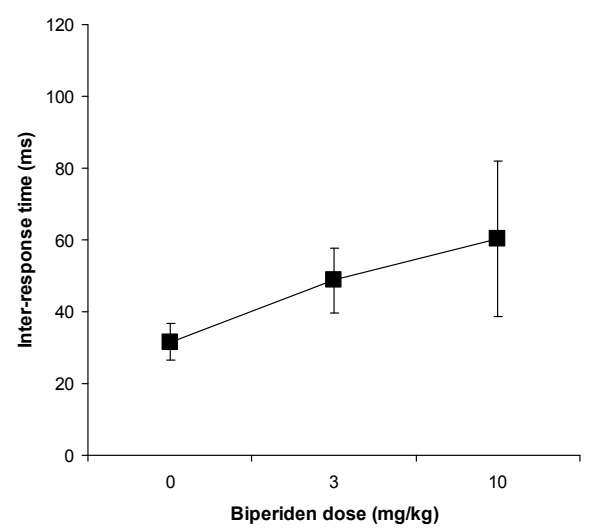

Figure 2. The effects of scopolamine $(0.3,1 \mathrm{mg} / \mathrm{kg}, \mathrm{IP})$ and biperiden $(3,10 \mathrm{mg} / \mathrm{kg}$, IP) on a PR10 schedule of reinforcement. (a) Breakpoint. Scopolamine decreased food motivation at a dose of $1 \mathrm{mg} / \mathrm{kg}$. (b) Breakpoint. Biperiden did not have an effect on food motivation. (c) Inter-response time. Scopolamine slowed sensorimotor responding at a dose of $1 \mathrm{mg} / \mathrm{kg}$. (d) Inter-response time. Biperiden did not have an effect on sensorimotor responding. Data represent mean (+SEM). Asterisks indicate differences from vehicle condition ( ${ }^{*}$ : $P<0.05)$.

\section{Attention task}

Figures $3 a$ and $3 b$ show the effects of scopolamine and biperiden on percentage correct in the attention task. In the mixed model ANOVA, the within-subject effect of Dose on percentage correct did not vary per level of Drug and Stimulus Duration (no Dose $x$ Drug $x$ Stimulus Duration interaction effect; $F(4,68)=0.75$, n.s.). However, the within-subject effect of Dose on percentage correct did vary per level of Drug (Dose $x$ Drug interaction effect; $F(2,34)=7.96, P<0.01)$. The within-subject effect of Stimulus Duration on percentage correct was also different per level of Drug (Stimulus Duration $\mathrm{x}$ Drug interaction effect; $F(2,34)=3.82, P<0.05)$. Therefore separate repeated measures ANOVAs for the two levels of Drug were performed. In the group treated with scopolamine, the within-subject effect of Stimulus Duration on percentage correct was not different per level of Dose (no Stimulus 
Duration $x$ Dose interaction effect; $F(4,36)=0.83$, n.s.; see Fig. 3a). There was a reduction in percentage correct responses with shorter stimulus durations (main effect of Stimulus Duration; $F(2,18)=40.06, P<0.001)$. Scopolamine decreased percentage correct responses in the attention task (main effect of Dose; $F(2,18)=20.55, P<0.001$ ). Post-hoc analysis showed that at a dose of $0.3 \mathrm{mg} / \mathrm{kg}$ scopolamine lowered percentage correct score as compared to the vehicle condition $(P<0.01)$. In the group treated with biperiden, the withinsubject effect of Stimulus Duration on percentage correct was not different per level of Dose (no Stimulus Duration $x$ Dose interaction effect; $F(4,32)=0.36$, n.s.; see Fig. $3 b$ ). Moreover, shorter stimulus durations reduced percentage correct (main effect of Stimulus Duration; $F(2,16)=149.29, P<0.001$ ). Biperiden treatment did not affect the measure percentage correct (no main effect of Dose; $F(2,16)=2.69$, n.s.).

Figures $3 c$ and $3 d$ show the effects of scopolamine and biperiden on percentage omissions in the attention task. In the mixed model ANOVA, the within-subject effect of Dose on percentage omissions did not vary per level of Drug and Stimulus Duration (no Dose $x$ Drug $x$ Stimulus Duration interaction effect; $F(4,68)=0.98$, n.s.). The within-subject effect of Stimulus Duration on percentage omissions was also not different per level of Drug (no Stimulus Duration $x$ Drug interaction effect; $F(2,34)=1.16$, n.s.). In contrast, the withinsubject effect of Dose on percentage omissions did vary per level of Drug (Dose $x$ Drug interaction effect; $F(2,34)=6.98, P<0.01)$. Therefore, separate repeated measures ANOVAs for the two levels of Drug were performed. In the group treated with scopolamine, the within-subject effect of Stimulus Duration on percentage omissions was not different per level of Dose (no Stimulus Duration $x$ Dose interaction effect; $F(4,36)=0.95$, n.s.; see Fig. 3c). There was no change in percentage omissions with shorter stimulus durations (no main effect of Stimulus Duration; $F(2,18)=1.70$, n.s.). Scopolamine enhanced percentage omissions in the attention task (main effect of Dose; $F(2,18)=15.66, P<0.001$ ). Post-hoc analysis showed that at a dose of $0.3 \mathrm{mg} / \mathrm{kg}$ scopolamine augmented percentage omissions as compared to the vehicle condition $(P<0.01)$. In the group treated with biperiden, the within-subject effect of Stimulus Duration on percentage omissions was not different per level of Dose (no Stimulus Duration $x$ Dose interaction effect; $F(4,32)=0.61$, n.s.; see Fig. $3 d$ ). Moreover, shorter stimulus durations had no effect on percentage omissions (no main effect of Stimulus Duration; $F(2,16)=0.01$, n.s.). Biperiden treatment did not affect the measure percentage omissions (no main effect of Dose; $F(2,16)=3.31$, n.s.).

Figures $3 e$ and $3 f$ show the effects of scopolamine and biperiden on response time in the attention task. The within-subject effect of Dose on response time was found to vary per level of Drug (Dose $x$ Drug interaction effect; $F(2,34)=5.59, P<0.01$ ). Therefore, separate repeated measures ANOVAs for the two levels of Drug were performed. In the group treated with scopolamine, response time was slowed (main effect of Dose; $F(2,18)=27.74$, $P<0.001$; see Fig. 3e). Post-hoc analysis showed an effect of the $0.3 \mathrm{mg} / \mathrm{kg}$ dose $(P<$ $0.001)$. In the biperiden group, response time was also significantly changed (main effect of Dose; $F(2,16)=4.28, P<0.05$; see Fig. 3f). However, post-hoc analysis revealed no differences between vehicle and dose conditions. 
a

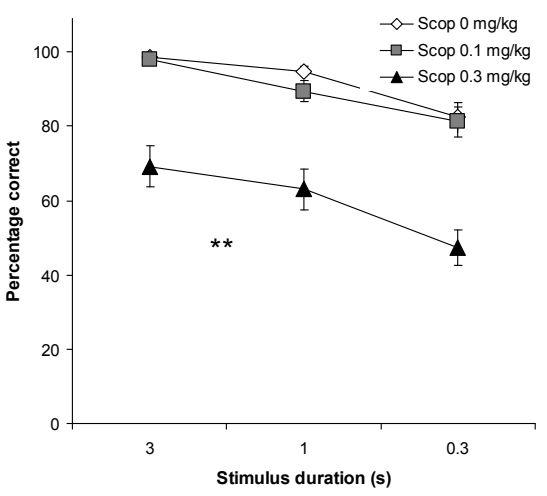

C

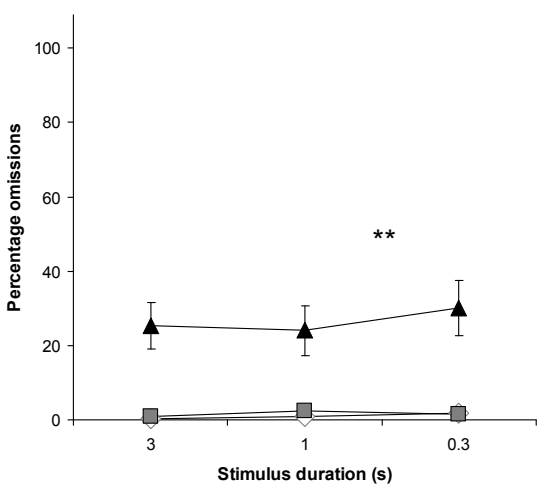

e

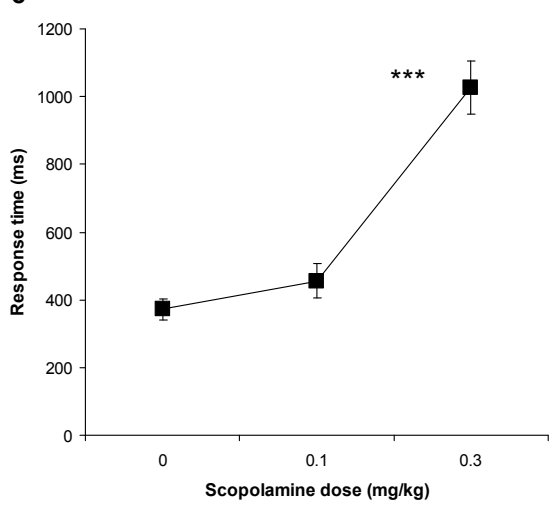

b

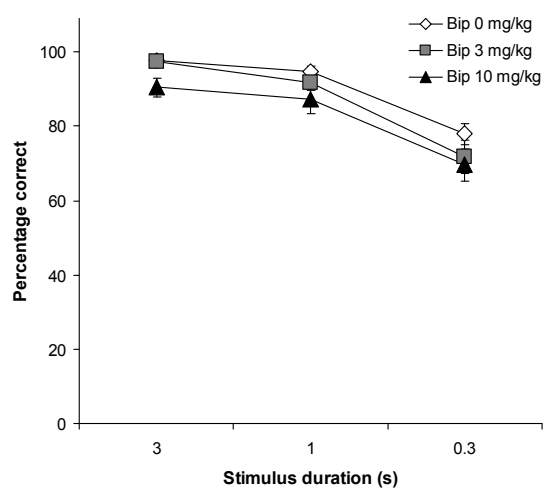

d

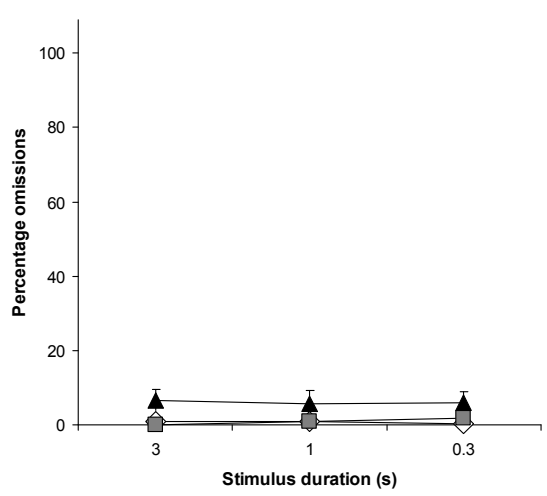

f

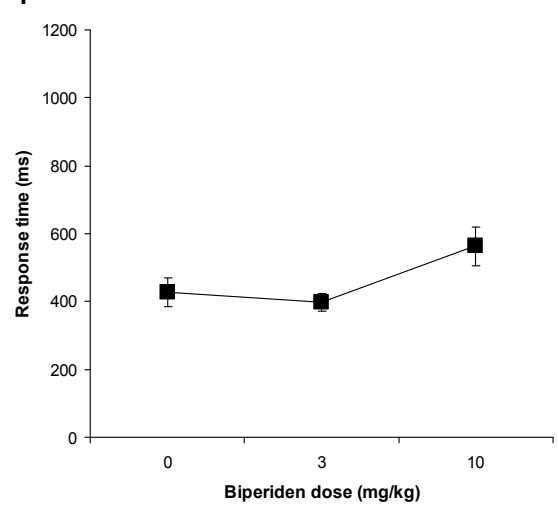

Figure 3. The effects of scopolamine $(0.1,0.3 \mathrm{mg} / \mathrm{kg}, \mathrm{IP})$ and biperiden $(3,10 \mathrm{mg} / \mathrm{kg}$, IP) on performance measures in the attention task. (a) Percentage correct responses. Scopolamine decreased accuracy independent of stimulus duration at a dose of $0.3 \mathrm{mg} / \mathrm{kg}$. (b) Percentage correct responses. Biperiden did not have an effect on accuracy (c) Percentage omissions. Scopolamine increased response omissions independent of stimulus duration at a dose of $0.3 \mathrm{mg} / \mathrm{kg}$. (d) Percentage omissions. Biperiden did not have an effect on response omissions. (e) Response time. Scopolamine slowed sensorimotor responding at a dose of 0.3 $\mathrm{mg} / \mathrm{kg}$. (f) Response time. Biperiden did not have an effect on sensorimotor responding. Data represent mean (+SEM). Asterisks indicate differences from vehicle condition $(* *: P<0.01, * * *: P<0.001)$. 
Figures $4 \mathrm{a}$ and $4 \mathrm{~b}$ show the effects of scopolamine and biperiden on sensitivity index (SI) in the attention task. In the mixed model ANOVA, the within-subject effect of Dose on SI did not vary per level of Drug and Stimulus Duration (no Dose $x$ Drug $\times$ Stimulus Duration interaction effect; $F(4,68)=1.34$, n.s.). However, the within-subject effect of Dose on SI did vary per level of Drug (Dose $x$ Drug interaction effect; $F(2,34)=6.30, P<0.01$ ). The withinsubject effect of Stimulus Duration on SI was also different per level of Drug (Stimulus Duration $\times$ Drug interaction effect; $F(2,34)=4.63, P<0.05)$. Therefore, separate repeated measures ANOVAs for the two levels of Drug were performed. In the group treated with scopolamine, the within-subject effect of Stimulus Duration on SI varied per level of Dose (Stimulus Duration $x$ Dose interaction effect; $F(4,36)=2.82, P<0.05$; see Fig. 4a). Hence, separate repeated measures ANOVAs were performed per level of Stimulus Duration. Posthoc analyses showed that scopolamine reduced $\mathrm{SI}$ at all stimulus duration conditions. In the group treated with biperiden, the within-subject effect of Stimulus Duration on SI was not different per level of Dose (no Stimulus Duration x Dose interaction effect; $F(4,32)=0.12$, n.s.; see Fig. 4b). Shorter stimulus durations reduced SI (main effect of Stimulus Duration; $F(2,16)=151.65, P<0.001$ ). Biperiden treatment did not affect the measure SI (no main effect of Dose; $F(2,16)=1.15$, n.s.).

Figures $4 c$ and $4 d$ show the effects of scopolamine and biperiden on index $Y$ in the attention task. In the mixed model ANOVA, the within-subject effect of Dose on response bias did not vary per level of Drug and Stimulus Duration (no Dose $x$ Drug $\times$ Stimulus Duration interaction effect; $F(4,68)=0.68$, n.s.). The within-subject effect of Stimulus Duration on index $Y$ was also not different per level of Drug (no Stimulus Duration $x$ Drug interaction effect; $F(2,34)=0.11$, n.s.). The within-subject effect of Dose on response bias did not vary per level of Drug (no Dose $x$ Drug interaction effect; $F(2,34)=1.53$, n.s.). Index $Y$ was differentially affected by Dose (main effect of Dose; $F(2,34)=4.00, P<0.05$ ). Post-hoc analysis showed that the highest dose conditions of scopolamine and biperiden augmented index $Y$ as compared to the vehicle condition $(P<0.05)$. However, the between-subject analysis of Drug showed that scopolamine and biperiden did not differentially affect index $Y$ (no main effect of Drug; $F(1,17)=3.13$, n.s.). Because we sought to determine which Drug was responsible for the main effect of Dose in the mixed-model analysis, we did separate repeated measures ANOVAs per level of Drug. In the group treated with scopolamine, the within-subject effect of Stimulus Duration on index $Y$ was not different per level of Dose (no Stimulus Duration $x$ Dose interaction effect; $F(4,36)=0.32$, n.s.; see Fig. 4c). There was a change in index $Y$ with shorter stimulus durations (main effect of Stimulus Duration; $F(2,18)$ $=12.40, P<0.001$ ). Scopolamine did not affect the index $Y$ measure (no main effect of Dose; $F(2,18)=3.35$, n.s.). In the group treated with biperiden, the within-subject effect of Stimulus Duration on index $Y$ was not different per level of Dose (no Stimulus Duration $x$ Dose interaction effect; $F(4,32)=1.79$, n.s.; see Fig. $4 d$ ). Shorter stimulus durations reduced index $Y$ (main effect of Stimulus Duration; $F(2,16)=15.22, P<0.001$ ). Biperiden treatment did not affect index $Y$ (no main effect of Dose; $F(2,16)=1.48$, n.s.). 
a

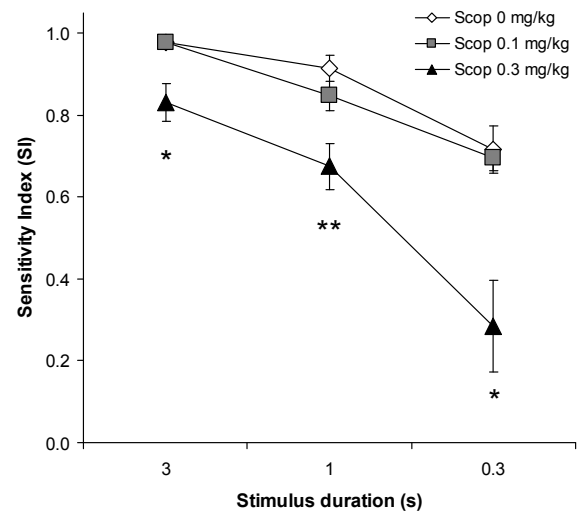

C

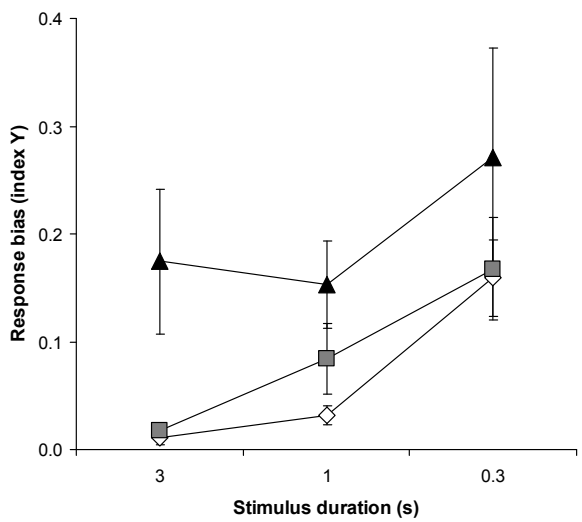

b

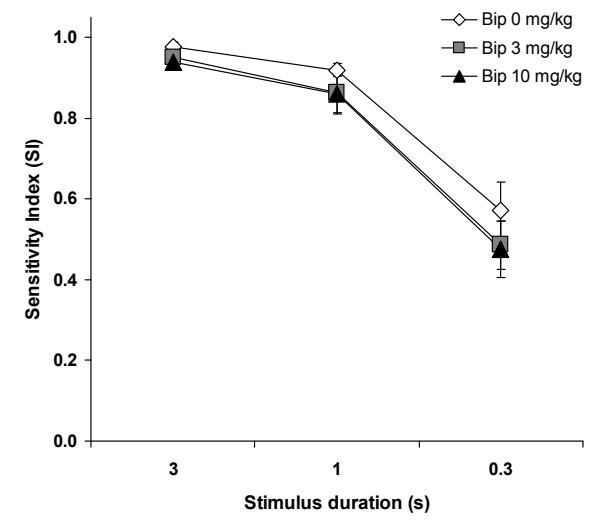

d

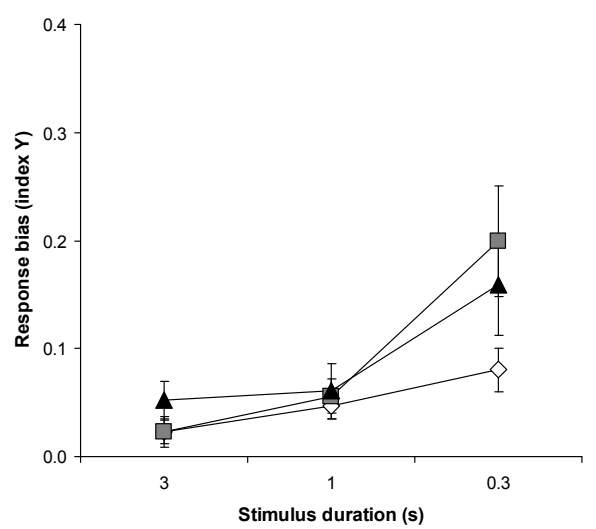

Figure 4. The effects of scopolamine $(0.1,0.3 \mathrm{mg} / \mathrm{kg}, \mathrm{IP})$ and biperiden $(3,10 \mathrm{mg} / \mathrm{kg}$, IP) on signal detection theory measures in the attention task. (a) Sensitivity Index (SI). Scopolamine decreased discriminability dependent of stimulus duration at a dose of $0.3 \mathrm{mg} / \mathrm{kg}$. (b) Sensitivity Index (SI). Biperiden did not have an effect on discriminability. (c) Index Y. Scopolamine did not have an effect on response bias. (d) Index Y. Biperiden did not have an effect on response bias. Data represent mean (+SEM). Asterisks indicate differences from vehicle condition $(*: P<0.05, * *: P<0.01)$.

\section{Delayed non-matching to position}

Figures $5 \mathrm{a}$ and $5 \mathrm{~b}$ show the effects of scopolamine and biperiden on percentage correct in the DNMTP task. In the mixed model ANOVA on percentage correct, the Dose effect varied per level of Delay and Drug (Dose $x$ Delay $x$ Drug interaction effect; $F(8,144)=3.69, P<$ 0.01). Therefore, separate repeated measures ANOVAs for the two levels of Drug were performed. In the group treated with scopolamine, the within-subject effect of Delay on percentage correct was different per level of Dose (Delay $x$ Dose interaction effect; $F(8,72)$ $=3.84, P<0.01$; see Fig. 5a). Hence, additional repeated measures ANOVAs were performed per level of Delay. Scopolamine affected percentage correct at the 0-, 2-, 4- and 8-s delay conditions (main effect of Dose; $F s(2,18)>9.23$, Ps $<0.01$ ). Post-hoc analyses showed that a dose of $0.3 \mathrm{mg} / \mathrm{kg}$ was different from the vehicle condition. In addition, a dose of 0.1 $\mathrm{mg} / \mathrm{kg}$ also affected accuracy performance at the 8-s delay condition. Scopolamine had no 
effect on percentage correct at 16-s delay condition (no main effect of Dose; $F(2,18)=0.31$, n.s.).

In the group treated with biperiden, the within-subject effect of Delay on percentage correct was different per level of Dose (Delay $\times$ Dose interaction effect; $F(8,72)=2.30, P<$ 0.05 ; see Fig. $5 b)$. Hence, separate repeated measures ANOVAs were performed per level of Delay. Biperiden did not affect percentage correct at the 0 - and 16-s delay condition (no main effect of Dose; $F s(2,18)<2.95$, n.s.). However, biperiden impaired percentage correct in trials with a 2-, 4-, and 8-s delay (main effect of Dose; Fs $(2,18)>5.84, P s<0.05$ ); Separate post-hoc analyses demonstrated that the $3 \mathrm{mg} / \mathrm{kg}$ dose decreased percentage correct as compared to the vehicle condition.

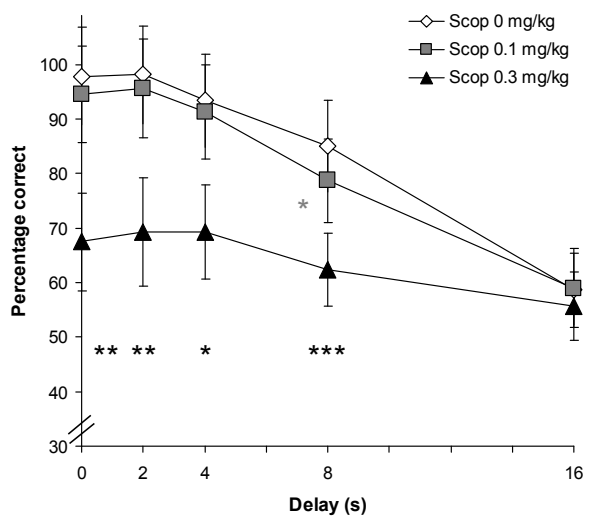

C

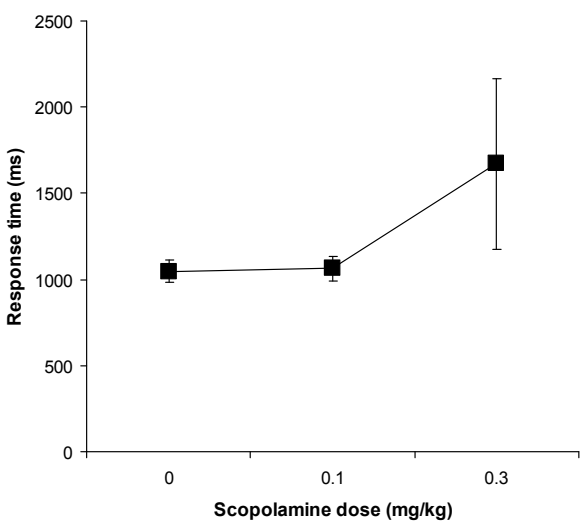

b

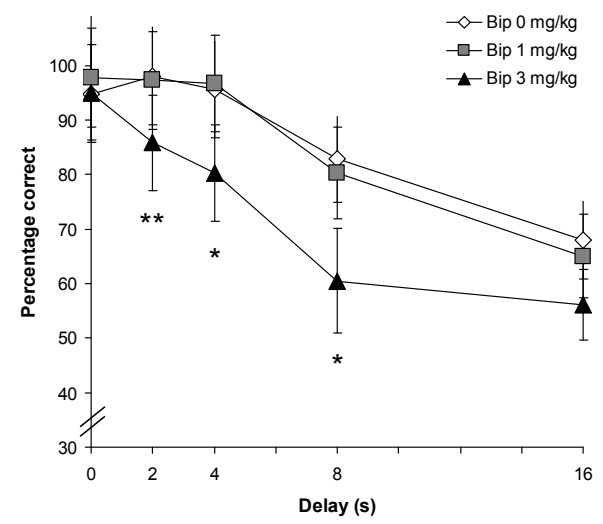

d

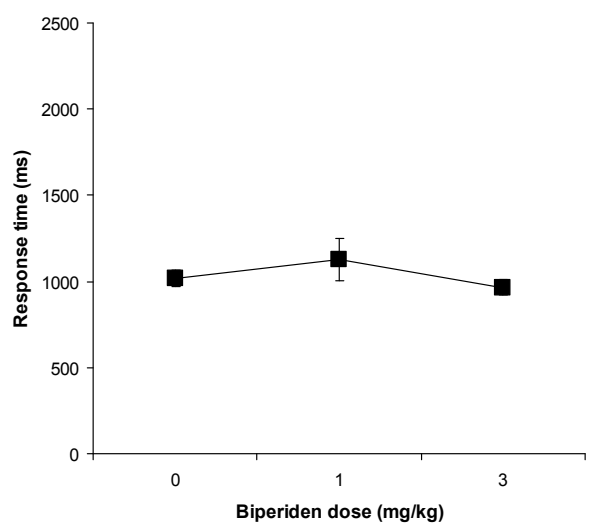

Figure 5. The effects of scopolamine $(0.1,0.3 \mathrm{mg} / \mathrm{kg}, \mathrm{IP})$ and biperiden $(1,3 \mathrm{mg} / \mathrm{kg}, \mathrm{IP})$ on performance measures in the DNMTP task. (a) Percentage correct responses. Scopolamine decreased accuracy delaydependently at a dose of 0.1 and $0.3 \mathrm{mg} / \mathrm{kg}$. (b) Percentage correct responses. Biperiden decreased delaydependently accuracy at a dose of $3 \mathrm{mg} / \mathrm{kg}$. (c) Response time. Scopolamine had no effect on sensorimotor responding. (d) Response time. Biperiden had no effect on sensorimotor responding. Data represent mean (+SEM). Asterisks indicate differences from vehicle condition $\left({ }^{*}: P<0.05,{ }^{* *}: P<0.01, * * *: P<0.001\right)$. 
Figures $5 c$ and $5 d$ show the effects of scopolamine and biperiden on response time in the DNMTP task. The within-subject effect of Dose on response time did not vary per level of Drug (no Dose $x$ Drug interaction effect; $F(2,36)=2.06$, n.s.). There was no effect of Dose (no main effect of Dose; $F(2,36)=1.06$, n.s.); scopolamine and biperiden did not differentially affect response time (no main effect of Drug; $F(1,18)=1.44$, n.s.).

a

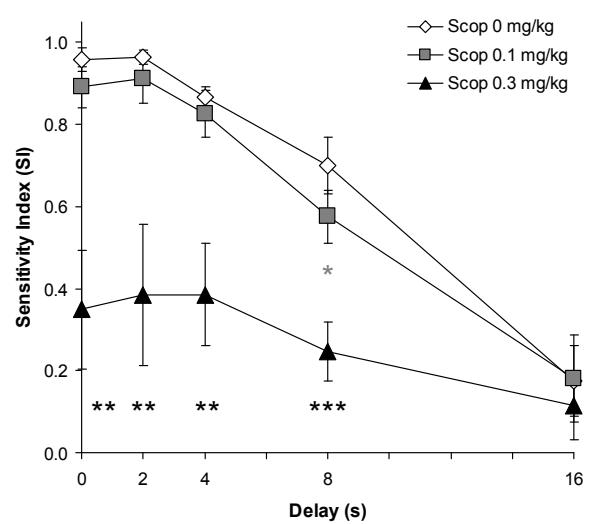

C

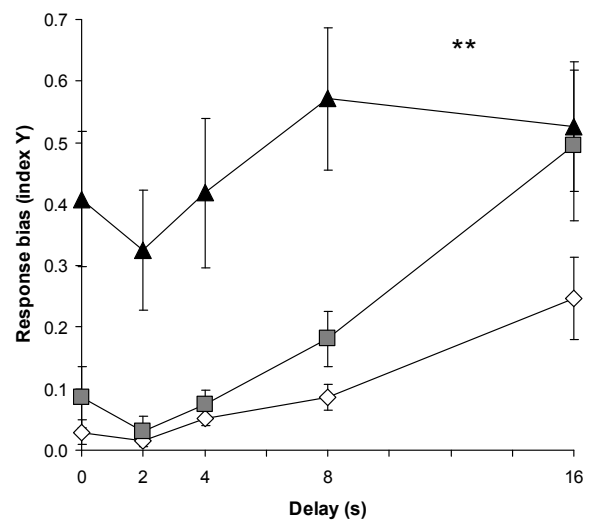

b

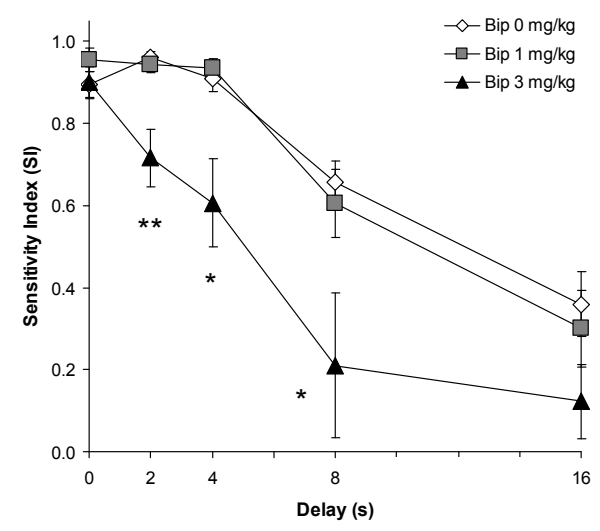

d

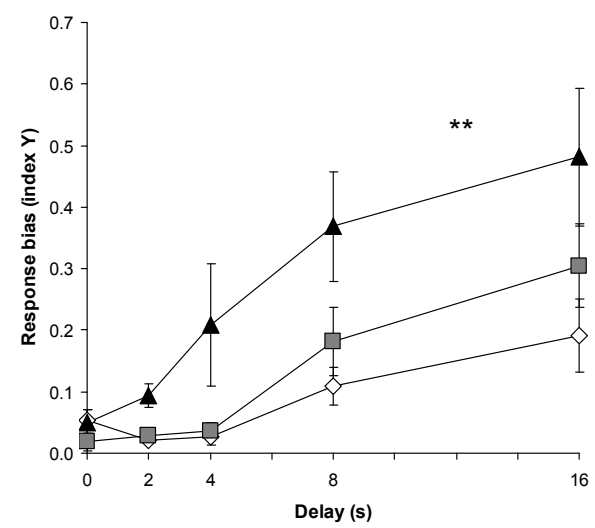

Figure 6. The effects of scopolamine $(0.1,0.3 \mathrm{mg} / \mathrm{kg}, \mathrm{IP})$ and biperiden $(1,3 \mathrm{mg} / \mathrm{kg}$, IP) on signal detection theory measures in the DNMTP task. (a) Sensitivity Index (SI). Scopolamine decreased discriminability delaydependently at a dose of 0.1 and $0.3 \mathrm{mg} / \mathrm{kg}$. (b) Sensitivity Index (SI). Biperiden decreased discriminability delay-dependently at a dose of $3 \mathrm{mg} / \mathrm{kg}$. (c) Index Y. Scopolamine decreased response bias delayindependently at a dose of $0.3 \mathrm{mg} / \mathrm{kg}$. (d) Index Y. Biperiden decreased response bias delay-independently at a dose of $3 \mathrm{mg} / \mathrm{kg}$. Data represent mean (+SEM). Asterisks indicate differences from vehicle condition $(*: P<$ $0.05, * *: P<0.01, * * *: P<0.001)$.

Figures $6 \mathrm{a}$ and $6 \mathrm{~b}$ show the effects of scopolamine and biperiden on $\mathrm{SI}$ in the DNMTP task. In the mixed model ANOVA on $\mathrm{SI}$, the Dose effect varied per level of Delay and Drug (Dose $\mathrm{x}$ Delay $x$ Drug interaction effect; $F(8,144)=3.68, P<0.01)$. Therefore, separate repeated measures ANOVAs for the two levels of Drug were performed. In the group treated with scopolamine, the within-subject effect of Delay on SI was different per level of Dose (Delay $x$ Dose interaction effect; $F(8,72)=3.84, P<0.01$; see Fig. 6a). Hence, additional repeated 
measures ANOVAs were performed per level of Delay. In the 0-, 2-, 4- and 8-s delay trials a main effect of Dose was found $(F s(2,18)>9.23, P s<0.01)$ Separate post-hoc analyses showed that at a dose of $0.3 \mathrm{mg} / \mathrm{kg}$ scopolamine reduced $\mathrm{SI}$ as compared to the vehicle condition. In addition a dose of $0.1 \mathrm{mg} / \mathrm{kg}$ also affected performance at the 8-s delay condition. Scopolamine had no effect on SI in trials which used a 16-s delay (no main effect of Dose; $F(2,18)=0.31$, n.s. $)$.

In the group treated with biperiden, the within-subject effect of Delay on SI was different per level of Dose (Delay $x$ Dose interaction effect; $F(8,72)=2.30, P<0.05$; see Fig. $6 b$ ). Hence, separate repeated measures ANOVAs were performed per level of Delay. In trials with a 0- or 16-s delay biperiden did not affect SI (no main effect of Dose; Fs $(2,18)<2.95$, n.s.). Biperiden did influence $\mathrm{SI}$ in trials with a 2-, 4- and 8-s delay (main effect of Dose; Fs $(2,18)>5.84, P s<0.05)$; post-hoc analysis revealed that the $3 \mathrm{mg} / \mathrm{kg}$ dose decreased $\mathrm{SI}$ as compared to the vehicle condition $(P<0.01)$.

Figures $6 c$ and $6 d$ show the effects of scopolamine and biperiden on index $Y$ in the DNMTP task. In the mixed model ANOVA, the within-subject effect of Dose on response bias did not vary per level of Drug and Delay (no Dose $\times$ Drug $\times$ Delay interaction effect; $F(8,136)=1.13$, n.s.). The within-subject effect of Delay on index $Y$ was also not different per level of Drug (no Delay $x$ Drug interaction effect; $F(4,68)=0.43$, n.s.). Moreover, the within-subject effect of Dose on response bias did not vary per level of Drug (no Dose $x$ Drug interaction effect; $F(2,34)=3.06$, n.s.). The within-subject effect of Dose on index $Y$ was also not different per level of Delay (no Dose $x$ Delay interaction effect; $F(8,136)=1.78$, n.s.). Index $Y$ was differentially affected by Dose (main effect of Dose; $F(2,34)=22.24, P<$ 0.001). The between-subject analysis of Drug showed that scopolamine and biperiden differentially affected index $Y$ (main effect of Drug; $F(1,17)=4.49, P<0.05$ ). Therefore, separate repeated measures ANOVAs for the two levels of Drug were performed. In the group treated with SCOP, the within-subject effect of Delay on response bias was not different per level of Dose (no Delay $x$ Dose interaction effect; $F(8,64)=1.67$, n.s.; see Fig. $6 c$ ). Index $Y$ increased with longer delays (main effect of Delay; $F(4,32)=12.28, P<0.001$ ). Scopolamine enhanced response bias in the DNMTP task (main effect of Dose; $F(2,16)=11.62$, $P<0.01$ ). Post-hoc analysis showed that at a dose of $0.3 \mathrm{mg} / \mathrm{kg}$ scopolamine augmented index $Y$ as compared to the vehicle condition $(P<0.01)$. In the group treated with biperiden, the within-subject effect of Delay on index $Y$ was not different per level of Dose (no Delay $x$ Dose interaction effect; $F(8,72)=1.29$, n.s.; see Fig. $6 d$ ). Moreover, with longer delays response bias was increased (main effect of Delay; $F(4,36)=18.92, P<0.001$ ). Biperiden was shown to increase response bias in the DNMTP task (main effect of Dose; $F(2,18)=12.55, P<0.001)$. Post-hoc analysis showed that at a dose of $3 \mathrm{mg} / \mathrm{kg}$ biperiden augmented index $Y$ as compared to the vehicle condition $(P<0.01)$.

\section{DISCUSSION}

The main objective of the current study was to compare the effects of the non-selective muscarinic antagonist scopolamine and the $M_{1}$ antagonist biperiden after systemic injections on different aspects of operant behavior: sensorimotor responding (FR5), food motivation (PR10), attention and short-term memory (DNMTP). The direct comparison of both drugs allowed evaluation with respect to the usability of biperiden, as opposed to scopola- 
mine, as a suitable model of cholinergic memory dysfunction. Since biperiden is relatively selective for $M_{1}$ receptors which can be found predominantly in brain areas involved in learning and memory (Caulfield, 1993; Volpicelli \& Levey, 2004), we expected also a more selective effect of biperiden on cognition and behavioral performance. In Table 1 an overview is given of the effects of both drugs on the various behavioral measures. A wide range of behavioral impairments were found after scopolamine; cognitive and peripheral effects were not dissociable on basis of dose conditions. Moreover, performance deficits in the short-term memory task were of a non-mnemonic nature. In contrast, biperiden more selectively impaired DNMTP performance at a dose of $3 \mathrm{mg} / \mathrm{kg}$, at which no peripheral effects were found; sensorimotor responding was slowed after the $10 \mathrm{mg} / \mathrm{kg}$ dose.

Of note, some caution should be taken with respect to the selectivity of muscarinic (ant)agonists. Due to the highly conserved nature of the orthosteric binding site amongst muscarinic receptors, drugs that target these can be characterized as possessing relative rather than absolute receptor subtype selectivity. These issues should be borne in mind when trying to attribute effects of these drugs to specific muscarinic receptor subtypes. For instance, biperiden has about 10-fold higher affinity for $M_{1}$ as compared to $M_{2}-M_{5}$ receptors (see Bolden et al., 1992; Katayama et al., 1990). The pharmacokinetic characteristics of biperiden are quite favorable; cerebellar levels after a dose of $3.2 \mathrm{mg} / \mathrm{kg}$ (IV) have been reported to be about 10 times higher than plasma levels (see Nakashima et al., 1993; Syvälahti et al., 1988; Yokogawa et al., 1990; 1992). Regardless, biperiden is currently the drug of choice for making a direct comparison with SCOP, particularly as it is approved for use in humans and therefore suitable for translational research. Some other drugs that target the muscarinic $M_{1}$ receptor cannot be used in systemic injections because they do not cross the blood-brain barrier (e.g., pirenzepine: Guthrie et al., 2000).

Table 1. An overview of the effects of scopolamine and biperiden on sensorimotor responding, food motivation, attention and short-term memory. Doses are given in $\mathrm{mg} / \mathrm{kg}, \mathrm{IP}$.

\begin{tabular}{lll}
\hline & Drug & \\
\cline { 2 - 3 } Paradigm & Scopolamine & Biperiden \\
\hline FR5 & Inter-response time $\uparrow(0.3,1)$ & Inter-response time $\uparrow(10)$ \\
PR10 & Breakpoint $\downarrow(1)$ & Breakpoint $=$ \\
& Inter-response time $=$ & Inter-response time $=$ \\
& & \\
AT & Percentage correct $\downarrow(0.3, \mathrm{DI})$ & Percentage correct $=$ \\
& Percentage omissions $\uparrow(0.3, \mathrm{DI})$ & Percentage omissions $=$ \\
& SI $\downarrow(0.3, \mathrm{DD})$ & SI $=$ \\
& Index $Y=$ & Index $\mathrm{Y}=$ \\
& Response time $\uparrow(0.3)$ & Response time $=$ \\
& & \\
& Percentage correct $\downarrow(0.1,0.3, \mathrm{DD})$ & Percentage correct $\downarrow$ (3, DD) \\
DNMTP & SI $\downarrow(0.1,0.3, \mathrm{DD})$ & SI $\downarrow(3, \mathrm{DD})$ \\
& Index $\uparrow \uparrow(0.3, \mathrm{DI})$ & Index $\mathrm{Y} \uparrow(3, \mathrm{DI})$ \\
& Response time $=$ & Response time $=$
\end{tabular}

Symbols: $=$ : no change; $\uparrow:$ increase; $\downarrow$ : decrease

Abbreviations: FR5: fixed ratio 5, PR10: progressive ratio 10, AT: attention task, DNMTP: delayed nonmatching to position, DD: delay-dependent effect, DI: delay-independent effect, SI: Sensitivity Index. 


\section{Sensorimotor responding}

Both scopolamine and biperiden were found to slow sensorimotor responding on a FR5 schedule of reinforcement, although at a different dose $(0.3$ and $1 \mathrm{mg} / \mathrm{kg}$ for scopolamine and $10 \mathrm{mg} / \mathrm{kg}$ for biperiden, see Fig.1). Although both scopolamine and biperiden increased inter-response time in the FR5 task it should be noted that the effects of biperiden were smaller as compared to scopolamine. Biperiden, at a dose of $10 \mathrm{mg} / \mathrm{kg}$, slowed FR5 responses by $26 \%$ as compared to the vehicle condition. Scopolamine, at a dose of 0.3 and 1 $\mathrm{mg} / \mathrm{kg}$, increased inter-response time by about $32 \%$ and $298 \%$, respectively. In FR tasks, scopolamine has generally been found to decrease lever presses independent of reward type (dry vs. wet, Hodges Jr. et al., 2009), which has been ascribed to central muscarinic blockade. However, the minimal effective dose reported in these studies does show quite some variability (0.005-1.0 mg/kg IP, Hodges Jr. et al., 2009; Pradhan \& Roth, 1968). In a brightness discrimination task, biperiden $(0.25-2 \mathrm{mg} / \mathrm{kg}, \mathrm{SC})$ was found to reduce the rate of reinforcement (Liu, 1996). Furthermore, intracerebroventricular infusion of the $\mathrm{M}_{1}$ antagonist pirenzepine $(10,30 \mu \mathrm{g}$ in $2.5 \mu \mathrm{L}$ ) increased the sample latency in a DNMTP task (Aura et al., 1997), although a reduction in response latency has also been reported (Andrews et al., 1994).

These results suggest that the effect of systemic administration of scopolamine and biperiden on sensorimotor responding is at least partially mediated by the $M_{1}$ receptor. However, from the present data it cannot be deduced whether this change in sensorimotor responding is caused by central or peripheral $M_{1}$ blockade, or both. For instance, in the periphery $M_{1}$ receptors have been found in abundance in rat sympathetic ganglia such as the superior cervical ganglion (Caulfield \& Birdsall, 1998). However, the effects of scopolamine and biperiden on sensorimotor responding could also result from an interaction between $\mathrm{M}_{1}$ and striatal dopaminergic signaling (De Klippel et al., 1993; Gerber et al., 2001).

\section{Food motivation}

Scopolamine (1 $\mathrm{mg} / \mathrm{kg}$ ) was found to decrease food motivation and slow sensorimotor responding on a PR10 schedule, whereas biperiden $(3,10 \mathrm{mg} / \mathrm{kg})$ did not have an effect on these measures (see Fig. 2). This is in accordance with studies on monkeys performing a PR schedule where scopolamine reduced the number of obtained reinforcements (Spinelli et al., 2006; Taffe et al., 1999). Food and water intake in rats was found to be diminished after scopolamine administration (Hodges Jr. et al., 2009; Pradhan \& Roth, 1968). To the best of our knowledge, neither biperiden, nor any other $M_{1}$ antagonists have been tested in paradigms assessing food motivation and/or free feeding behavior. Although it is possible that a higher dose of biperiden would have yielded a reduction in motivation, our dose range is comparable to those used in other behavioral studies (Jones, \& Shannon, 2000; Kimura et al., 1999; Liu, 1996; Myers et al., 2002; Myhrer et al., 2008; Roldán, 1997; Sipos et al., 1999; 2001).

Again, it cannot be decisively determined whether the decrement in motivation for food after administration of scopolamine is a central or a peripheral effect. Scopolamine has been known to induce dry mouth (Hodges Jr. et al., 2009), which might affect the palatability and thus the hedonic impact of dry food rewards. Of note, when using a liquid reward a central but not peripheral effect of scopolamine has been found in FR5 and DNMTP paradigms (Hodges Jr. et al., 2009). Nevertheless, a decrease in "liking" dry food 
rewards after systemic administration of scopolamine could interfere with behavioral performance. Particularly the $M_{3}$ (Dai et al., 1991; Shida et al., 1993) but also the $M_{1}$ and $M_{5}$ receptor have been implicated in rat salivary responses (Flynn et al., 1997; Shannon et al., 1994; Tobin et al., 2002). Thus, according to the literature biperiden is capable of interfering with salivation to some extent. However, the current data suggests that any reductions in salivation after biperiden doses of $10 \mathrm{mg} / \mathrm{kg}$ and lower are not sufficient to interfere with food motivation. These findings are in contrast with those of scopolamine, which is likely to more fully block muscarinic receptor subtypes in rat salivary glands and to profoundly affect food motivation. A central effect of scopolamine might also interfere with incentivedriven behaviors (such as PR performance). Centrally infused scopolamine in rat nucleus accumbens has been found to reduce sucrose consumption $(1 \mu \mathrm{g} / \mathrm{side}$ or $10 \mu \mathrm{g} / \mathrm{side})$ and breakpoint $(5.0 \mu \mathrm{g} / \mathrm{side}$ ) in a PR paradigm (Pratt \& Kelley, 2004). Furthermore, muscarinic receptors appear to be implicated in reward-driven motivational behaviors via excitatory interactions with dopamine in the nucleus accumbens and ventral tegmental area (Forster et al., 2001; Yeomans \& Baptista, 1997).

\section{Attention}

At a dose of $0.3 \mathrm{mg} / \mathrm{kg}$, scopolamine decreased percentage correct, increased percentage omissions and response time independent of the duration of the stimulus (see Fig. 3). Discriminability (SI) was also reduced after the $0.3 \mathrm{mg} / \mathrm{kg}$ dose; however the effect of scopolamine was dependent on stimulus duration (see Fig. 4). Response bias (index Y) was unaffected after scopolamine $(0.1,0.3 \mathrm{mg} / \mathrm{kg})$ or biperiden $(3,10 \mathrm{mg} / \mathrm{kg})$. Biperiden also did not affect any of the other measures in the attention task. In attentional paradigms such as the 5-choice serial reaction time task, scopolamine has been reported to disrupt visuospatial sustained attention at doses of $0.02 \mathrm{mg} / \mathrm{kg}$ and higher (Callahan et al., 1993; Cheal, 1981; Hodges Jr. et al., 2009; Hoff et al., 2007; Humby et al., 1999; Leblond et al., 2002; Spinelli et al., 2006); however, behavioral effects of scopolamine on attentional accuracy are not reported consistently (Andrews et al., 1992; Doty et al., 2003; Leaton \& Kreindler, 1972). Moreover, scopolamine has been shown to influence general non-cognitive performance measures, such as response latency and number of missed trials (Andrews et al., 1992; Bushnell et al., 1997; Drinkenburg et al., 1995). As scopolamine also disrupted performance in the FR5 and PR10 tasks, its effect on attention could (partially) be caused by deficits in sensorimotor responding and/or food motivation. Moreover, it is unlikely that $M_{1}$ receptor blockade underlies the attentional impairment, as biperiden had no effect on this task. To the best of our knowledge, effects of $M_{1}$ antagonists have not been assessed in attentional paradigms before. Further studies are required in order to provide more support for the lack of a role of $\mathrm{M}_{1}$ and potentially other muscarinic receptors in attention.

\section{Short-term memory}

Similar to its effects on the attention task, scopolamine impaired various performance measures in the DNMTP task (see Fig. 5 and 6). Scopolamine decreased percentage correct and discriminability (SI) in a delay-dependent manner, and increased response bias (index Y) delay-independently at a dose of $0.3 \mathrm{mg} / \mathrm{kg}$. Scopolamine already affected DNMTP performance at the shortest delay(s), whereas it failed to disrupt performance in trials with the longest delay. The latter is likely due to a floor effect; i.e., accuracy of the animals in the 16- 
$s$ delay trials was already at around chance level ( $50 \%$ correct) even in the vehicle condition, and therefore further impairment due to cholinergic blockade could not be induced. The different delay intervals between sample and choice phase are presumed to produce a temporal performance gradient with longer retention intervals yielding poorer DNMTP performance as short-term memory functions are taxed in a progressively increasing manner. Thus, the disruption of DNMTP performance at the zero delay indicates an effect of scopolamine on other (non-)cognitive processes rather than just short-term memory. As the current study demonstrates, the effects of scopolamine $(0.3 \mathrm{mg} / \mathrm{kg})$ on sensorimotor responding, food motivation and/or attention could (at least partially) underlie deficits in DNMTP performance.

The majority of studies using delayed (non-)matching procedures have reported a delay-independent impairment after relatively low doses which again suggests that scopolamine does not specifically affect short-term memory functions (e.g., 0.05, 0.075 and $0.1 \mathrm{mg} / \mathrm{kg} \mathrm{IP}$, Herremans et al., 1995; $0.1 \mathrm{mg} / \mathrm{kg} \mathrm{IP}$, Hodges Jr. et al., 2009), although some articles have challenged this finding (Estapé \& Steckler, 2002; Ruotsalainen et al., 1998; Santi \& Weise, 1995; Stanhope et al., 1995). Furthermore, in most studies using systemic injections scopolamine also affected measures of responding; it increased number of omissions, decreased number of completed trials and increased response latency (Estapé \& Steckler, 2002; Kirkby et al., 1995). Central administration of scopolamine in the medial prefrontal cortex (Dunnett et al., 1990; Herremans et al., 1996; 1997), prelimbic cortex (Granon \& Poucet, 1995) and hippocampus (Robinson \& Mao, 1997) has been shown to yield a delay-independent reduction of DNMTP response accuracy (but see Broersen et al., 1994; 1995; Dunnett et al., 1990; Granon et al., 1995), and increases in number of omissions (Robinson \& Mao, 1997).

It is likely that DNMTP deficits produced by scopolamine can be partially attributed to $M_{1}$ blockade, which is in line with the results reported by Bymaster et al. (1993). Biperiden $(3 \mathrm{mg} / \mathrm{kg}$ ) was found to decrease percentage correct and discriminability (SI) in a delaydependent manner, and increase response bias (index $\mathrm{Y}$ ) delay-independently. Biperiden did not influence response time at the doses used in the DNMTP $(1,3 \mathrm{mg} / \mathrm{kg}$, IP) which is in line with our findings in the FR5 task. As is shown in Figures 5 and 6, biperiden did not affect DNMTP performance at the zero delay. However, as the delay interval increased, biperiden increasingly impaired accuracy performance as compared to the vehicle condition. Thus, the disruption of DNMTP performance at longer delays but not the shortest delay indicates a genuine effect of biperiden on short-term memory functions rather than other (non-)cognitive processes. These effects are unlikely to be caused by deficits in sensorimotor responding, food motivation or attention, as biperiden (at a dose of $3 \mathrm{mg} / \mathrm{kg}$ ) did not affect performance on the FR5 or PR10 schedule of reinforcement or in the attention task. Of note, the lack of an effect of biperiden at the 16-s delay is again likely due to a floor effect. Taken together, these findings suggest a role for the $M_{1}$ receptor in mediating shortterm memory functions. This would implicate selective $M_{1}$ antagonists such as biperiden as a promising alternative instead of the gold standard drug scopolamine as a tool for inducing cholinergic mnemonic impairments in animals.

Effects of systemic administration of biperiden on DNMTP performance have not been assessed previously; however, $M_{1}$ antagonists have been found to affect performance in a variety of other behavioral tasks which measure (short-term) memory. For instance, deficits have been reported in passive avoidance tasks (Fornari et al., 2000; Kimura et al., 1999; 
Kramer-Soares et al., 2006; Roldán, 1997), contextual fear conditioning (Kramer-Soares et al., 2006; but see Sheffler et al., 2009), spatial alternation (Bymaster et al., 1993) and object recognition (Myhrer et al., 2004; 2008) after systemic injections. Furthermore, $\mathrm{M}_{1}$ agonists have been shown to improve DNMTP performance in animals which were cognitively impaired after cholinergic lesioning (McDonald et al., 1998), scopolamine administration or aging (Bartholomeo et al., 2000), which suggests that enhanced $M_{1}$ signaling can be sufficient in order to reverse memory deficits. Infusion of the muscarinic $M_{1}$ antagonist pirenzepine ( $35 \mu \mathrm{g}$ in $0.5 \mu \mathrm{L} / \mathrm{side}$ ) in the dorsal hippocampus impaired accuracy performance on a DNMTP task (Messer et al., 1987; 1990); this implicates the importance of $M_{1}$ receptor signaling in the hippocampus for accurate DNMTP responding.

Of note, there are some indications that the $M_{1}$ receptor might also be involved in reversal learning (McCool et al., 2008; Tzavos et al., 2004) and anxiety (Wall et al., 2001). In addition, muscarinic $\left(\mathrm{M}_{1}\right)$ blockade in non-hippocampal brain regions might also be responsible for short-term memory effects; for instance, intact performance on non-matching tasks seems to also require the prefrontal, entorhinal and perirhinal cortices (Otto \& Eichenbaum, 1992) Thus, our study does not exclude the involvement of muscarinic receptor subtypes other than $M_{1}$ and brain regions other than the septo-hippocampal system in memory functions, nor the engagement of the $M_{1}$ receptor in other cognitive processes besides memory (e.g., Araya et al., 2006; Carey et al., 2001; Daniel \& Dohanich, 2001; McCool et al., 2008; Messer \& Miller, 1988; Poulin et al., 2010; Power et al., 2003; Quirion et al., 1995; Tzavos et al., 2004; Wall et al., 2001; Wess, 2004).

In fact, the manner in which $M_{1}$ receptors affect memory processes is still under investigation; one possibility is the modulation of glutamatergic neurotransmission and/or synaptic plasticity (see Caulfield, 1993; Hasselmo, 1999; 2006). Muscarinic $\mathrm{M}_{1}$ receptors couple to Gq-proteins which activate several signaling cascades via phospholipase (PL)C (Caulfield, 1993; Jones, 1993; Liu et al., 2006), which can ultimately influence $\mathrm{Ca}^{2+}$ and $\mathrm{K}^{+}$currents (Liu et al., 2006), raise cyclic AMP levels (Jones, 1993), and can stimulate other receptor systems such as glutamatergic N-methyl-D-aspartate (NMDA) receptor currents produced by hippocampal CA1 pyramidal neurons (Calabresi et al., 1998; Ma et al., 2009; Marino et al., 1998). Moreover, $M_{1}$ receptors and NR1a NMDA receptor subunits were found to be colocalized at glutamatergic synapses, suggestive of a direct interaction between the two receptor systems. A link between $\mathrm{M}_{1}$ receptor signaling and long-term potentiation (LTP), a mechanism which is thought to underlie learning and memory processes, has also been put forward (Boddeke et al., 1992; Burgard \& Sarvey, 1990; Calabresi et al., 1999; Doralp \& Leung, 2008; Kamsler et al., 2010; Ovsepian et al., 2004; Shinoe et al., 2005). For instance, it has been shown that muscarinic agonists and antagonists which act preferentially on the $\mathrm{M}_{1}$ receptor are able to facilitate or prevent the induction of LTP in rat dentate gyrus (Burgard \& Sarvey, 1990), CA1 (Boddeke et al., 1992; Doralp \& Leung, 2008; Ovsepian et al., 2004) and striatum (Calabresi et al., 1999), respectively.

Future studies on the role of muscarinic receptors should focus on determining whether there exists some degree of dissociation between muscarinic receptor subtypes in terms of their involvement in memory (or other cognitive functions) as is reflected by their differential distribution in the brain (e.g., Rouse \& Levey, 1996). It is likely that particular muscarinic subtypes are particularly important for a restricted (set of) cognitive subdomain(s); e.g., hippocampal $\mathrm{M}_{1}$ receptors are important for working but not reference memory (Ohno et al., 1994). Furthermore, it is imperative that the manner in which $M_{1}$ recep- 
tors influence memory processes is more extensively investigated. Information on the exact signaling cascade(s) downstream of the muscarinic $M_{1}$ receptor that are responsible for its effects on memory could lead to interesting implications for the development of novel treatments for disorders in which memory is impaired, such as Alzheimer's disease or schizophrenia. Lastly, additional behavioral validation is required to firmly establish the usability of $\mathrm{M}_{1}$ antagonists instead of the gold standard scopolamine for producing cholinergic amnesia in healthy animals and human participants. 


\section{REFERENCES}

Andrews, J. S., Grützner, M., \& Stephens, D. N. (1992). Effects of cholinergic and non-cholinergic drugs on visual discrimination and delayed visual discrimination performance in rats. Psychopharmacology, 106, 523-530.

Andrews, J. S., Jansen, J. H. M., Linders, S., \& Princen, A. (1994). Effects of disrupting the cholinergic system on short-term spatial memory in rats. Psychopharmacology, 115, 485-494.

Araya, R., Noguchi, T., Yuhki, M., Kitamura, N., Higuchi, M., Saido, T. C., et al. (2006). Loss of M5 muscarinic acetylcholine receptors leads to cerebrovascular and neuronal abnormalities and cognitive deficits in mice. Neurobiology of Disease, 24, 334-344.

Aura, J., Sirviö, J., \& Riekkinen, P. (1997). Methoctramine moderately improves memory but pirenzepine disrupts performance in delayed non-matching to position test. European Journal of Pharmacology, 333, 129-134.

Barak, S., \& Weiner, I. (2009). Towards an animal model of an antipsychotic drug-resistant cognitive impairment in schizophrenia: Scopolamine induces abnormally persistent latent inhibition, which can be reversed by cognitive enhancers but not by antipsychotic drugs. The International Journal of Neuropsychopharmacology, 12, 227-241.

Bartholomeo, A. C., Morris, H., Buccafusco, J. J., Kille, N., Rosenzweig-Lipson, S., Husbands, M. G., et al. (2000). The preclinical pharmacological profile of WAY-132983, a potent M1 preferring agonist. The Journal of Pharmacology and Experimental Therapeutics, 292, 584-596.

Bartus, R. T., Dean, R. L., Beer, B., \& Lippa, A. S. (1982). The cholinergic hypothesis of geriatric memory dysfunction. Science, 217, 408-417.

Blokland, A. (1995). Acetylcholine: a neurotransmitter for learning and memory? Brain Research Reviews, 21, 285-300.

Blokland, A., Şik, A., \& Van Der Staay, F. J. (2004). Delayed non-matching to position performance in aged hybrid Fischer 344 x Brown Norway rats: a longitudinal study. Brain Research Bulletin, 64, 39-46.

Boddeke, E. W. G. M., Enz, A., \& Shapiro, G. (1992). SDZ ENS 163, a selective muscarinic $M_{1}$ receptor agonist, facilitates the induction of long-term potentiation in rat hippocampal slices. European Journal of Pharmacology, 222, 21-25.

Bolden, C., Cusack, B., \& Richelson, E. (1992). Antagonism by antimuscarinic and neuroleptic compounds at the five cloned human muscarinic cholinergic receptors expressed in Chinese hamster ovary cells. The Journal of Pharmacology and Experimental Therapeutics, 260, 576-580.

Broersen, L. M., Heinsbroek, R. P. W., de Bruin, J. P. C., Joosten, R. N. J., van Hest, A., \& Olivier, B. (1994). Effects of local application of dopaminergic drugs into the dorsal part of the medial prefrontal cortex of rats in a delayed matching to position task: comparison with local cholinergic blockade. Brain Research, 645, 113-122.

Broersen, L. M., Heinsbroek, R. P. W., de Bruin, J. P. C., Uylings, H. B. M., \& Olivier, B. (1995). The role of the medial prefrontal cortex of rats in short-term memory functioning: further support for involvement of cholinergic, rather than dopaminergic mechanisms. Brain Research, 674, 221-229.

Buccafusco, J. J., Terry, A. V., Webster, S. J., Martin, D., Hohnadel, E. J., Bouchard, K. A., et al. (2008). The scopolamine-reversal paradigm in rats and monkeys: The importance of computer-assisted operantconditioning memory tasks for screening drug candidates. Psychopharmacology, 199, 481-494.

Burgard, E. C., \& Sarvey, J. M. (1990). Muscarinic receptor activation facilitates the induction of long-term potentiation (LTP) in the rat dentate gyrus. Neuroscience Letters, 116, 34-39.

Bushnell, P. J., Oshiro, W. M., \& Padnos, B. K. (1997). Detection of visual signals by rats: effects of chlordiazepoxide and cholinergic and adrenergic drugs on sustained attention. Psychopharmacology, 134, 230241.

Bymaster, F. P., Heath, I., Hendrix, J. C., \& Shannon, H. E. (1993). Comparative behavioral and neurochemical activities of cholinergic antagonists in rats. The Journal of Pharmacology and Experimental Therapeutics, 267, 16-24.

Bymaster, F. P., McKinzie, D. L., Felder, C. C., \& Wess, J. (2003). Use of M1-M5 muscarinic receptor knockout mice as novel tools to delineate the physiological roles of the muscarinic cholinergic system. Neurochemical Research, 28, 437-442.

Calabresi, P., Centonze, D., Gubbellini, P., \& Bernardi, G. (1999). Activation of M1-like muscarinic receptors is required for the induction of corticostriatal LTP. Neuropharmacology, 38, 323-326. 
Calabresi, P., Centonze, D., Gubellini, P., Pisani, A., \& Bernardi, G. (1998). Endogenous ACh enhances striatal NMDA-responses via M1-like muscarinic receptors and PKC activation. European Journal of Neuroscience, 10, 2887-2895.

Callahan, M. J., Kinsora, J. J., Harbaugh, R. E., Reeder, T. M., \& Davis, R. E. (1993). Continuous icv infusion of scopolamine impairs sustained attention of rhesus monkeys. Neurobiology of Aging, 14, 147-151.

Carey, G. J., Billard, W., Binch, H., Cohen-Williams, M., Crosby, G., Grzelak, M., et al. (2001). SCH 57790, a selective muscarinic $\mathrm{M} 2$ receptor antagonist, releases acetylcholine and produces cognitive enhancement in laboratory animals. European Journal of Pharmacology, 431, 189-200.

Caulfield, M. P. (1993). Muscarinic receptors - characterization, coupling and function. Pharmacology \& Therapeutics, 58, 319-379.

Caulfield, M. P., \& Birdsall, N. J. M. (1998). International union of pharmacology: XVII. Classification of muscarinic acetylcholine receptors. Pharmacological Reviews, 50, 279-290.

Cheal, M. L. (1981). Scopolamine disrupts maintenance of attention rather than memory processes. Behavioral and Neural Biology, 33, 163-187.

Conn, P. J., Jones, C. K., \& Lindsley, C. W. (2009). Subtype-selective allosteric modulators of muscarinic receptors for the treatment of CNS disorders. Cell, 30, 148-155.

Cunha, G. M. A., Canas, P. M., Melo, C. S., Hockemeyer, J., \& Müller, C. E. (2008). Adenosine A2A receptor blockade prevents memory dysfunction caused by $\beta$-amyloid peptides but not by scopolamine or MK801. Experimental Neurology, 210, 776-781.

Dai, Y., Ambudkar, I. S., Horn, V. J., Yeh, C., Kousvelari, E. E., Wall, S. J., et al. (1991). Evidence that M3 muscarinic receptors in rat parotid gland couple to two second messenger systems. American Journal of Physiology, 261, C1063-C1073.

Daniel, J. M., \& Dohanich, G. P. (2001). Acetylcholine mediates the estrogen-induced increase in NMDA receptor binding in CA1 of the hippocampus and the associated improvement in working memory. The Journal of Neuroscience, 21, 6949-6956.

De Klippel, N., Sarre, S., Ebinger, G., \& Michotte, Y. (1993). Effect of M1- and M2-muscarinic drugs on striatal dopamine release and metabolism: $\mathrm{An}$ in vivo microdialysis study comparing normal and 6hydroxydopamine-lesioned rats. Brain Research, 630, 57-64.

Doralp, S., \& Leung, L. S. (2008). Cholinergic modulation of hippocampal CA1 basal-dendritic long-term potentiation. Neurobiology of Learning and Memory, 90, 382-388.

Doty, R. L., Bagla, R., Misra, R., Mueller, E., \& Kerr, K. (2003). No influence of scopolamine hydrobromide on odor detection performance of rats. Chemical Senses, 28, 761-765.

Drinkenburg, W. H. I. M., Sondag, H. N. P. M., Coenders, C. J. H., Andrews, J. S., \& Vossen, J. M. H. (1995). Effects of selective antagonism or depletion of the cholinergic system on visual discrimination performance in rats. Behavioural Pharmacology, 6, 695-702.

Dunnett, S. B., Wareham, A. T., \& Torres, E. M. (1990). Cholinergic blockade in prefrontal cortex and hippocampus disrupts short-term memory in rats. NeuroReport, 1, 61-64.

Estapé, N., \& Steckler, T. (2002). Cholinergic blockade impairs performance in operant DNMTP in two inbred strains of mice. Pharmacology, Biochemistry and Behavior, 72, 319-334.

Evans, H. L. (1975). Scopolamine effects on visual discrimination: modifications related to stimulus control. Journal of Pharmacology and Experimental Therapeutics, 195, 105-113.

Everitt, B. J., \& Robbins, T. W. (1997). Central cholinergic systems and cognition. Annual Review of Psychology, 48, 649-684.

Fibiger, H. C. (1991). Cholinergic mechanisms in learning, memory and dementia: a review of recent evidence. Trends in Neurosciences, 14, 220-223.

Flynn, D. D., Reever, C. M., \& Ferrari-DiLeo, G. (1997). Pharmacological strategies to selectively label and localize muscarinic receptor subtypes. Drug Development Research, 40, 104-116.

Fornari, R. V., Moreira, K. M., \& Oliviera, M. G. M. (2000). Effects of the selective M1 muscarinic receptor antagonist dicyclomine on emotional memory. Learning \& Memory, 7, 287-292.

Forster, G. L., Yeomans, J. S., Takeuchi, J., \& Blaha, C. D. (2001). M5 muscarinic receptors are required for prolonged accumbal dopamine release after electrical stimulation of the pons in mice. The Journal of Neuroscience, 21, 1-6.

Frey, K. A., Ehrenkaufer, R. L., \& Agranoff, B. W. (1985). Quantitative in vivo receptor binding. II. Autoradiographic imaging of muscarinic cholinergic receptors. The Journal of Neuroscience, 5, 2407-2414. 
Gerber, D. J., Sotnikova, T. D., Gainetdinov, R. R., Huang, S. Y., Caron, M. G., \& Tonegawa, S. (2001). Hyperactivity, elevated dopaminergic transmission and response to amphetamine in M1 muscarinic acetylcholine receptor-deficient mice. Proceedings of the National Academy of Sciences, 98, 15312-15317.

Granon, S., \& Poucet, B. (1995). Medial prefrontal lesions in the rat and spatial navigation: evidence for impaired planning. Behavioral Neuroscience, 109, 474-484.

Granon, S., Poucet, B., Thinus-Blanc, C., Changeux, J.-P., \& Vidal, C. (1995). Nicotinic and muscarinic receptors in the rat prefrontal cortex: Differential roles in working memory, response selection and effortful processing. Psychopharmacology, 119, 139-144.

Guthrie, S. K., Manzey, L., Scott, D., Giordani, B., \& Tandon, R. (2000). Comparison of central and peripheral pharmacologic effects of biperiden and trihexyphenidyl in human volunteers. Journal of Clinical Psychopharmacology, 20, 77-83.

Harvey, J. A., Gormezano, I., \& Cool-Hauser, V. A. (1983). Effects of scopolamine and methylscopolamine on classical conditioning of the rabbit nictitating membrane response. The Journal of Pharmacology and Experimental Therapeutics, 225, 42-49.

Hasselmo, M. E. (1999). Neuromodulation: Acetylcholine and memory consolidation. Trends in Cognitive Sciences, 3, 351-359.

Hasselmo, M. E. (2006). The role of acetylcholine in learning and memory. Current Opinion in Neurobiology, $16,710-715$.

Herremans, A. H., \& Hijzen, T. H. (1997). The delayed-conditional-discrimination task improves measurement of working memory in rats. Neuroscience and Biobehavioral Reviews, 21, 371-379.

Herremans, A. H. J., Hijzen, T. H., \& Olivier, B. (1997). Effects of cholinergic drug infusions into the dorsal part of the medial prefrontal cortex on delayed conditional discrimination performance in the rat. Behavioural Brain Research, 84, 291-299.

Herremans, A. H. J., Hijzen, T. H., Olivier, B., \& Slangen, J. L. (1995). Cholinergic drug effects on a delayed conditional discrimination task in the rat. Behavioral Neuroscience, 109, 426-435.

Herremans, A. H. J., Hijzen, T. H., Welborn, P. F. E., Olivier, B., \& Slangen, J. L. (1996). Effects of infusion of cholinergic drugs into the prefrontal cortex area on delayed matching to position performance in the rat. Brain Research, 711, 102-111.

Hodges Jr., D. B., Lindner, M. D., Hogan, J. B., Jones, K. M., \& Markus, E. J. (2009). Scopolamine induced deficits in a battery of rat cognitive tests: Comparisons of sensitivity and specificity. Behavioural Pharmacology, 20, 237-251.

Hodos, W. (1961). Progressive ratio as a measure of reward strength. Science, 134, 943-944.

Hoff, E. I., van Oostenbrugge, R. J., Liedenbaum, M., Steinbusch, H. W., \& Blokland, A. (2007). Effects of righthemisphere cortical infarction and muscarinic acetylcholine receptor blockade on spatial visual attention performance in rats. Behavioural Brain Research, 178, 62-69.

Humby, T., Laird, F. M., Davies, W., \& Wilkinson, L. S. (1999). Visuospatial attentional functioning in mice: interactions between cholinergic manipulations and genotype. European Journal of Neuroscience, 11, 2813-2823.

Jones, C. K., \& Shannon, H.E. (2000). Muscarinic cholinergic modulation of prepulse inhibition of the acoustic startle reflex. The Journal of Pharmacology and Experimental Therapeutics, 294, 1017-1023.

Jones, S. V. P. (1993). Muscarinic receptor subtypes: Modulation of ion channels. Life Sciences, 52, 457-464.

Kamsler, A., McHugh, T. J., Gerber, D., Huang, S. Y., \& Tonegawa, S. (2010). Presynaptic m1 muscarinic receptors are necessary for mGluR long-term depression in the hippocampus. Proceedings of the National Academy of Sciences USA, 107, 1618-1623.

Katayama, S., Ishizaki, F., Yamamura, Y., Khoriyama, T., \& Kito, S. (1990). Effects of anticholinergic antiparkinsonian drugs on binding of muscarinic receptor subtypes in rat brain. Research Communications in Chemical Pathology and Pharmacology, 69, 261-270.

Kimura, Y., Ohue, M., Kitaura, T., \& Kihira, K. (1999). Amnesic effects of the anticholinergic drugs, trihexyphenidyl and biperiden: differences in binding properties to the brain muscarinic receptor. Brain Research, 834, 6-12.

Kirkby, D. L., Jones, D. N. C., \& Higgins, G. A. (1995). Influence of prefeeding and scopolamine upon performance in a delayed matching-to-position task. Behavioural Brain Research, 67, 221-227.

Kramer-Soares, J. C., Vecchio-Fornari, R., \& Menezes-Oliviera, M. G. (2006). Role of muscarinic $M_{1}$ receptors in inhibitory avoidance and contextual fear conditioning. Neurobiology of Learning and Memory, 86, 188-196. 
Leaton, R. N., \& Kreindler, M. (1972). Effects of physostigmine and scopolamine on operant brightness discrimination in the rat. Physiology \& Behavior, 9, 121-123.

Leblond, L., Beaufort, C., Delerue, F., \& Durkin, T. (2002). Differential roles for nicotinic and muscarinic cholinergic receptors in sustained visuo-spatial attention? A study using a 5-arm maze protocol in mice. Behavioural Brain Research, 128, 91-102.

Liu, L., Zhao, R., Bai, Y., Stanish, L. F., Evans, J. E., Sanderson, M. J., et al. (2006). M1 muscarinic receptors inhibit L-type $\mathrm{Ca}^{2+}$ current and $\mathrm{M}$-current by divergent signal transduction cascades. The Journal of $\mathrm{Neu}$ roscience, 26, 11588-11598.

Liu, W. (1996). Effects of antimuscarinic antiparkinsonian drugs on brightness discrimination performance in rats. Pharmacology, Biochemistry and Behavior, 54, 425-430.

Loiseau, F., Dekeyne, A., \& Millan, M. J. (2008). Pro-cognitive effects of 5HT6 receptor antagonists in the social recognition procedure in rats: Implication of the frontal cortex. Psychopharmacology, 196, 93104.

Ma, L., Seager, M. A., Wittmann, M., Jacobson, M., Bickel, D., Burno, M., et al. (2009). Selective activation of the $\mathrm{M}_{1}$ muscarinic acetylcholine receptor achieved by allosteric potentiation. Proceedings of the $\mathrm{Na}$ tional Academy of Sciences, 106, 15950-15955.

Marino, M. J., Rouse, S. T., Levey, A. I., Potter, L. T., \& Conn, P. J. (1998). Activation of the genetically defined $\mathrm{m} 1$ muscarinic receptor potentiates $\mathrm{N}$-methyl-D-aspartate (NMDA) receptor currents in hippocampal pyramidal cells. Proceedings of the National Academy of Sciences USA, 95, 11465-11470.

McCool, M. F., Patel, S., Talati, R., \& Ragozzino, M. E. (2008). Differential involvement of M1-type and M4type muscarinic cholinergic receptors in the dorsomedial striatum in task switching. Neurobiology of Learning and Memory, 89, 114-124.

McDonald, M. P., Willard, L. B., Wenk, G. L., \& Crawly, J. N. (1998). Coadministration of galanin antagonist M40 with a muscarinic M1 agonist improves delayed nonmatching to position choice accuracy in rats with cholinergic lesions. The Journal of Neuroscience, 18, 5078-5085.

Messer, W. S., Bohnett, M., \& Stibbe, J. (1990). Evidence for a preferential involvement of $M_{1}$ muscarinic receptors in representational memory. Neuroscience Letters, 116, 184-189.

Messer, W. S., \& Miller, M. D. (1988). Intrahippocampal injections of gallamine impair learning of a memory task. Neuroscience Letters, 89, 367-372.

Messer, W. S., Thomas, G. J., \& Hoss, W. (1987). Selectivity of pirenzepine in the central nervous system. II differential effects of pirenzepine and scopolamine on performance of a representational memory task. Brain Research, 407, 37-45.

Mirza, N. R., \& Stolerman, I.P. (2000). The role of nicotinic and muscarinic acetylcholine receptors in attention. Psychopharmacology, 148, 243-250.

Moore, H., Dudchenko, P., Comer, K. S., Bruno, J. P., \& Sarter, M. (1992). Central versus peripheral effects of muscarinic antagonists: the limitations of quarternary ammonium derivatives. Psychopharmacology, 108, 241-243.

Myers, T. M., Galbicka, G., Sipos, M. L., Varadi, S., Oubre, J. L., \& Clark, M. G. (2002). Effects of anticholinergics on serial-probe recognition accuracy of rhesus macaques (Macaca mulatta). Pharmacology, Biochemistry and Behavior, 73, 829-834.

Myhrer, T., Enger, S., \& Aas, P. (2004). Cognitive side effects in rats caused by pharmacological agents used to prevent soman-induced lethality. European Journal of Pharmacology, 483, 271-279.

Myhrer, T., Enger, S., \& Aas, P. (2008). Antiparkinson drugs used as prophylactics for nerve agents: Studies of cognitive side effects in rats. Pharmacology, Biochemistry and Behavior, 89, 633-638.

Nakashima, E., Ishizaki, F., Takeda, M., Matsusushita, R., Yokogawa, K., \& Ichimura, F. (1993). Pharmacokinetics of anticholinergic drugs and brain muscarinic receptor alterations in streptozotocin diabetic rats. Biopharmaceutics \& Drug Disposition, 14, 673-684.

Ohno, M., Yamamoto, T., \& Watanabe, S. (1994). Blockade of hippocampal M1 muscarinic receptors impairs working memory performance of rats. Brain Research, 650, 260-266.

Otto, T., \& Eichenbaum, H. (1992). Complementary roles of orbital prefrontal cortex and the perirhinalentorhinal cortices in an odor-guided delayed non-matchong to sample task. Behavioral Neuroscience, 106, 763-776.

Ovsepian, S. V., Anwyl, R., \& Rowan, M. J. (2004). Endogenous acetylcholine lowers the threshold for longterm potentiation induction in the CA1 area through muscarinic receptor activation: in vivo study. European Journal of Neuroscience, 20, 1267-1275. 
Pakarinen, E. D., \& Moerschbaecher, J. M. (1993). Comparison of the effects of scopolamine and methylscopolamine on the performance of a fixed-ratio discrimination in squirrel monkeys. Pharmacology, Biochemistry and Behavior, 44, 815-819.

Phillips, J. M., McAlonan, K., Robb, W. G., \& Brown, V. J. (2000). Cholinergic neurotransmission influences covert orientation of visuospatial attention in the rat. Psychopharmacology, 150, 112-116.

Poulin, B., Butcher, A., McWilliams, P., Bourgognon, J. M., Pawlak, R., Kong, K. C., et al. (2010). The M3muscarinic receptor regulates learning and memory in a receptor phosphorylation/arrestin-dependent manner. Proceedings of the National Academy of Sciences USA, 107, 9440-9445.

Power, A. E., McIntyre, C. K., Litmanovich, A., \& McGaugh, J. L. (2003). Cholinergic modulation of memory in the basolateral amygdala involves activation of both $\mathrm{m} 1$ and $\mathrm{m} 2$ receptors. Behavioural Pharmacology, 14, 207-213.

Pradhan, S. N., \& Roth, T. (1968). Comparative behavioral effects of several anti-cholinergic agents in rats. Psychopharmacologia, 12, 358-366.

Pratt, W. E., \& Kelley, A. E. (2004). Nucleus accumbens acetylcholine regulates appetitive learning and motivation for food via activation of muscarinic receptors. Behavioral Neuroscience, 118, 730-739.

Prickaerts, J., Fahrig, T., \& Blokland, A. (1999). Cognitive performance and biochemical markers in septum, hippocampus and striatum of rats after an i.c.v. injection of streptozotocin: a correlation analysis. Behavioural Brain Research, 102, 73-88.

Quirion, R., Wilson, A., Rowe, W., Aubert, I., Richard, J., Doods, H., et al. (1995). Facilitation of acetylcholine release and cognitive performance by an $\mathrm{M} 2$-muscarinic receptor antagonist in aged memory-impaired rats. The Journal of Neuroscience, 15, 1455-1462.

Robinson, J. K., \& Mao, J. B. (1997). Differential effects on delayed non-matching-to-position in rats of microinjections of muscarinic receptor antagonist scopolamine or NMDA receptor antagonist MK-801 into the dorsal or ventral extent of the hippocampus. Brain Research, 765, 51-60.

Roldán, G., Bolaňos-Badillo, E., González-Sánchez, H., Quirarte, G.L., \& Prado-Alcalá, R.A. (1997). Selective M1 muscarinic receptor antagonists disrupt memory consolidation of inhibitory avoidance in rats. Neuroscience Letters, 230, 93-96.

Rouse, S. T., \& Levey, A. I. (1996). Expression of m1-m4 muscarinic acetylcholine receptor immunoreactivity in septohippocampal neurons and other identified hippocampal afferents. Journal of Comparative Neurology, 375, 406-416.

Ruotsalainen, S., Miettinen, R., Macdonald, E., Riekkinen, M., \& Sirviö, J. (1998). The role of the dorsal rapheserotonergic system and cholinergic receptors in the modulation of working memory. Neuroscience and Biobehavioral Reviews, 22, 21-31.

Santi, A., \& Weise, L. (1995). The effects of scopolamine on memory for time in rats and pigeons. Pharmacology, Biochemistry and Behavior, 51, 271-277.

Sarter, M., \& Bruno, J. P. (1997). Cognitive functions of cortical acetylcholine: toward a unifying hypothesis. Brain Research Reviews, 23, 28-46.

Shannon, H. E., Bymaster, F. P., Calligaro, D. O., Greenwood, B., Mitch, C. H., Sawyer, B. D., et al. (1994). Xanomeline: A novel muscarinic receptor agonist with functional selectivity for M1 receptors. The Journal of Pharmacology and Experimental Therapeutics, 269, 271-281.

Sheffler, D. J., Williams, R., Bridges, T. M., Xiang, Z., Kane, A. S., Byun, N. E., et al. (2009). A novel selective muscarinic acetylcholine receptor subtype 1 antagonist reduces seizures without impairing hippocampus-dependent learning. Molecular Pharmacology, 76, 356-368.

Shida, T., Tokunaga, A., Kondo, E., Ueda, Y., Ohno, K., Saika, T., et al. (1993). Expression of muscarinic and nicotinic receptor mRNA in the salivary gland of rats: A study by in situ hybridization histochemistry. Molecular Brain Research, 17, 335-339.

Shinoe, T., Matsui, M., Taketo, M. M., \& Manabe, T. (2005). Modulation of synaptic plasticity by physiological activation of M1 muscarinic acetylcholine receptors in the mouse hippocampus. The Journal of Neuroscience, 25, 11194-11200.

Shiraishi, K., \& Takayanagi, I. (1993). Subtype of muscarinic receptors mediating relaxation and contraction in the rat iris dilator smooth muscle. General Pharmacology, 24, 139-142.

Sipos, M. L., Burchnell, V., \& Galbicka, G. (1999). Dose-response curves and time-course effects of selected anticholinergics on locomotor activity in rats. Psychopharmacology, 147, 250-256.

Sipos, M. L., Burchnell, V., \& Galbicka, G. (2001). Effects of selected anticholinergics on acoustic startle response in rats. Journal of Applied Toxicology, 21, S95-S101. 
Spinelli, S., Ballard, T., Feldon, J., Higgins, G. A., \& Pryce, C. R. (2006). Enhancing effects of nicotine and impairing effects of scopolamine on distinct aspects of performance in computerized attention and working memory tasks in marmoset monkeys. Neuropharmacology, 51, 238-250.

Stanhope, K. J., Mclenachan, A. P., \& Dourish, C. T. (1995). Dissociation between cognitive and motor/motivational deficits in the delayed matching to position test: effects of scopolamine, 8-OH-DPAT and EAA antagonists. Psychopharmacology, 122, 268-280.

Steckler, T. (2001). Using signal detection methods for analysis of operant performance in mice. Behavioural Brain Research, 125, 237-248.

Syvälahti, E. K. G., Kunelios, R., \& Laurén, L. (1988). Effects of antiparkinsonian drugs on muscarinic receptor binding in rat brain, heart and lung. Basic \& Clinical Pharmacology \& Toxicology, 62, 90-94.

Taffe, M. A., Weed, M. R., \& Gold, L. H. (1999). Scopolamine alters rhesus monkey performance on a novel neuropsychological test battery. Cognitive Brain Research, 8, 203-212.

Tobin, G., Giglio, D., \& Götrick, B. (2002). Studies of muscarinic receptor subtypes in salivary gland function in anaesthetized rats. Autonomic Neuroscience: Basic and Clinical, 100, 1-9.

Tzavos, A., Jih, J., \& Ragozzino, M. E. (2004). Differential effects of M1 muscarinic receptor blockade and nicotinic receptor blockade in the dorsomedial striatum on response reversal learning. Behavioural Brain Research, 154, 245-253.

Vaisman, N., \& Pelled, D. (2009). $n$-3 phosphatidylserine attenuated scopolamine-induced amnesia in middle-aged rats. Progress in Neuro-Psychopharmacology \& Biological Psychiatry, 33, 952-959.

van Haaren, F., \& van Hest, A. (1989). The effects of scopolamine and methylscopolamine on visual and auditory discriminations in male and female Wistar rats. Pharmacology, Biochemistry and Behavior, 32, 707-710.

Volpicelli, L. A., \& Levey, A. I. (2004). Muscarinic acetylcholine receptor subtypes in cerebral cortex and hippocampus. Progress in Brain Research, 145, 59-66.

Wall, P. M., Flinn, J., \& Messier, C. (2001). Infralimbic muscarinic M1 receptors modulate anxiety-like behaviour and spontaneous working memory in mice. Psychopharmacology, 155, 58-68.

Wess, J. (2004). Muscarinic acetylcholine receptor knockout mice: Novel phenotypes and clinical implications. Annual Review of Pharmacology and Toxicology, 44, 423-450.

Wezenberg, E., Verkes, R. J., Sabbe, B. G., Ruigt, G. S., \& Hulstijn, W. (2005). Modulation of memory and visuospatial processes by biperiden and rivastigmine in elderly healthy subjects. Psychopharmacology, 181, 582-594.

Yeomans, J., \& Baptista, M. (1997). Both nicotinic and muscarinic receptors in ventral tegmental area contribute to brain-stimulation reward. Pharmacology, Biochemistry and Behavior, 57, 915-921.

Yokogawa, K., Nakashima, E., \& Ichimura, F. (1990). Effect of fat tissue volume on the distribution kinetics of biperiden as a function of age in rats. Drug Metabolism and Disposition, 18, 258-263.

Yokogawa, K., Nakashima, E., Ishizaki, J., Hasegawa, M., Kido, H., \& Ichimura, F. (1992). Brain regional pharmacokinetics of biperiden in rats. Biopharmaceutics \& Drug Disposition, 13, 131-140. 
CHAPTER 4

\section{The muscarinic $M_{1}$ antagonist biperiden induces verbal memory impairment in young, healthy participants} Implications for Alzheimer's disease antagonist biperiden induces verbal memory impairment in young, healthy participants: Implications for Alzheimer's disease. 


\section{INTRODUCTION}

The cholinergic hypothesis of geriatric memory dysfunction proposed in the early eighties by Bartus et al. (1982) has been highly influential, leading to a wealth of research into the involvement of acetylcholine in mnemonic processes. One of the tools used for this purpose is the non-selective muscarinic antagonist scopolamine. Experiments in animals and humans have determined that scopolamine interferes with the encoding of new information, yet leaves the retrieval of previously stored information intact - i.e., it induces anterograde but not retrograde amnesia (see Chapter 2 and Atri et al., 2004; Bishop et al., 1996; Broks et al., 1988; Green et al., 2005; Kamboj \& Curran, 2006; Mintzer \& Griffiths, 2001, 2005; 2007; Nakra et al., 1992; Pomara et al., 2004; Rasch et al., 2006; Robbins et al., 1997; Sherman et al., 2003; Snyder et al., 2005; Sperling et al., 2002; but see van Ruitenbeek et al., 2008). Furthermore, scopolamine tends to particularly affect declarative memory (e.g., episodic and working memory), while leaving procedural memory intact (e.g., Green et al., 2005; Sperling et al., 2002; but see Mintzer \& Griffiths, 2003).

However, several studies have suggested that scopolamine actually impairs attentional rather than mnemonic processes, and evidence is the strongest for sustained attention (see Chapter 2 and Brandeis et al., 1992; Broks et al., 1988; Duka et al., 1996; Dunne \& Hartley, 1986; Ellis et al., 2006; Wesnes \& Revell, 1984; Wesnes \& Warburton, 1984; Witte et al., 1997). Given the fact that scopolamine is a non-selective muscarinic antagonist which induces quite a range of side-effects (e.g., dry mouth, pupil dilation, sedation; see Chapter 2), it is unclear whether these attentional effects of the drug reflect central or peripheral actions. Drugs that block muscarinic receptors subtypes $M_{1}-M_{5}$ more selectively might be preferable over scopolamine as a means to induce specific memory impairments. In this respect, the muscarinic $M_{1}$ receptor subtype can be seen as a viable target, since this receptor is located mostly centrally instead of peripherally and in brain regions thought to be involved in learning and memory (Caulfield, 1993).

Recently we have shown that the muscarinic $M_{1}$ antagonist biperiden - at a dose of 3 $\mathrm{mg} / \mathrm{kg}$ - is capable of disrupting short-term memory performance, but not sensorimotor responding, food motivation or attention in rats (see Chapter 3). A human study by Wezenberg et al. (2005) demonstrated impairments in verbal memory, visuospatial processes and motor learning, but not picture memory after $2 \mathrm{mg}$ of biperiden. Effects of biperiden on working memory were equivocal, and there were no indications of sedation. In contrast, Nakra et al. (1992) reported disruptive effects of the muscarinic $M_{1}$ antagonist trihexyphenidyl $(2 \mathrm{mg}$ ) on immediate and delayed recall of verbal and visual material in healthy elderly participants. General orientation, attention-concentration and learning of word associations were shown to be unaffected. Pomara et al. (2004) demonstrated an association between memory impairments induced by trihexyphenidyl $(1,2 \mathrm{mg})$ and the APOE- $\varepsilon 4$ allele, which is a major genetic risk factor for Alzheimer's disease. Specifically, total recall scores of both the $\varepsilon 4$ and non- $\varepsilon 4$ carriers were affected by trihexyphenidyl, yet the non- $\varepsilon 4$ improved significantly on delay recall scores several hours later, whereas the $\varepsilon 4$ group did not. The authors concluded that $\varepsilon 4$ carriers are more vulnerable to events which impact the cholinergic system.

The current study attempts to replicate the findings of Wezenberg et al. (2005) with regards to the disruptive effects of biperiden on verbal memory. We expected that biperiden would induce lower immediate and delayed recall scores, and lower recognition scores 
on a verbal memory test. In addition, we anticipated that biperiden would not affect psychomotor performance in a choice reaction time task and would not induce side-effects on a self-report questionnaire.

\section{METHODS}

\section{Participants}

Sixteen (7 male, 9 female; mean age of 23.4 years $(S D=3.2$, range $=19-31)$ ) healthy volunteers were recruited from the University of Helsinki through email advertisements. Participants had a body mass index of 18.5 to 30 . They filled out a medical questionnaire before participation. Exclusion criteria were past or current psychiatric, neurological, cardiac, gastrointestinal, haematological, hepatic, pulmonary, or renal illness, pregnancy, lactation, excessive alcohol consumption (intake of more than 20 glasses per week), use of any medication other than oral contraceptives, having a first-degree relative with a current or past psychiatric disorder, and presence of other deficits that could be expected to influence performance. All subjects gave a signed informed consent before inclusion and were financially rewarded for their participation. The study was approved by the National Research Ethics Council of Finland, based in Helsinki.

\section{Study design and procedures}

The study was conducted according to a double-blind, placebo-controlled crossover design. In the course of the week before the actual test sessions, the participants received a training session to minimize any possible learning effects. Subjects were not allowed to use any psychoactive medication within 5 days before drug intake. Participants where asked to abstain from alcohol on a testing day and $24 \mathrm{~h}$ before testing. They were also not allowed to smoke and were requested not to consume any caffeine-, teaine- or aspartame-containing beverages on a testing day. One hour before testing the participants were asked to fill out a questionnaire on physical complaints (see below) and were given a capsule containing either a placebo, or $2 \mathrm{mg}$ biperiden hydrochloride (Akineton ${ }^{\circledR}$, instant release). They were provided lunch immediately afterwards: this was done in order to reduce the chances of participants developing any side-effects due to biperiden intake. Lunch consisted of a can of caffeine-free soda, 1-3 slices of bread and cheese, ham, or marmelade. The duration of testing was around $1.5 \mathrm{hrs}$, after which the participants were asked to fill out the questionnaire again. The test session finished about 3 hours after drug intake. We aimed to separate test sessions by about 7 days to ensure sufficient washout of biperiden.

\section{Drug treatment}

Biperiden is a muscarinic $M_{1}$ antagonist approved for the treatment of Parkinson symptoms which develop due to use of first-generation antipsychotics (e.g., Ogino et al., 2011). It has about 10-fold higher affinity for $M_{1}$ as compared to $M_{2}-M_{5}$ receptors and it is thus the most selective $M_{1}$ antagonist available for use in human participants (Bolden et al., 1992; Katayama et al., 1990). Peak plasma concentrations are reached around 1-2 hours after a single dose administration followed by a rapid initial decline to values around $12 \%$ of the peak values at 6 hours after intake. This is subsequently followed by a slow terminal elimination 
phase at 48h (Hollmann et al., 1984; 1987). The most common side effects of biperiden on the central nervous system are drowsiness, vertigo, headache, and dizziness. Peripheral side effects consist of blurred vision, mydriasis, dry mouth, impaired sweating, abdominal discomfort, and obstipation (Mintzer \& Burns, 2000; Peters, 1989; Tune et al., 1992). We chose for a dose of $2 \mathrm{mg}$ as this lies well within the range of the therapeutically recommended doses for biperiden (1-4 mg). Moreover, oral treatment with $2 \mathrm{mg}$ biperiden has been shown to impair cognitive performance in healthy elderly (Wezenberg et al., 2005). Biperiden was purchased and labelled by Yliopiston Pharmacy in Helsinki according to local guidelines.

\section{Verbal learning task (VLT)}

The VLT is an adapted version of the Rey auditory verbal learning test (Lezak, 1995), which assesses short- and long-term memory function for verbal information. The word list was extended by Riedel et al. (1999) in order to avoid ceiling effects of cognition-enhancing drugs. The adapted version of the test consists of a list of 30 monosyllabic words (18 nouns and 12 adjectives, balanced for positive, negative and neutral words) in English. The words were shown on a computer screen for $1 \mathrm{~s}$. Three trials with the same item sequence were presented and each trial ended with a free recall of the words (immediate recall). Thirty min. after the third trial, the participant was asked to recall as many words as possible (delayed recall). Subsequently, a verbal recognition test (VRT) was presented, consisting of all former words and 30 new but comparable words (distracters). The words were shown on a computer screen for $2 \mathrm{~s}$ and participants were asked to rate whether they were presented in the learning trials by a yes/no response. The inter-word interval was $2 \mathrm{~s}$.

The VLT yielded several behavioral measures. Firstly, the number of words correctly recalled in the three learning trials is a measure of short-term verbal memory learning and retrieval. Furthermore, the number of recalled words $30 \mathrm{~min}$. after learning constitutes the delayed recall score, which represents long-term verbal memory retrieval. Next to correctly recalled words, we also scored doubly and incorrectly recalled words for both the immediate and the delayed recall. For the VRT, the percentage correctly recognized old and new items were calculated. Reaction times (in $\mathrm{ms}$ ) were also recorded, which was used as a measure of speed of retrieval from long-term memory and also provides an indication of sedative side-effects of biperiden.

\section{Choice reaction time task (CRT)}

This task measures general alertness and motor speed; in the current context it was used to assess whether biperiden would impair psychomotor performance. Participants were presented with an arrow that is either shown on the left, or on the right side of the screen. There were two kinds of arrows, one pointing to the left (left arrow), the other pointing to the right (right arrow). If the participant saw the left arrow, he/she was required to press the left button. If the right arrow was presented, the participant pressed the right button. Both arrows could be presented either on the left, or on the right side of the screen. This left 4 possible stimulus sets: 1 ) left arrow presented on the left side (congruent left), 2) left arrow presented on the right side (incongruent left), 3) right arrow presented on the right side (congruent right), and 4) right arrow presented on the left side (incongruent right). Forty stimuli of each category were presented, so in total there were 160 trials. The interval 
between the presentations of two arrows was random between 2-4s and the duration of the test was around $8 \mathrm{~min}$. Dependent variables were accuracy (i.e., the average correct responses to the congruent and incongruent trials) and reaction time (i.e., for the congruent and incongruent trials, in $\mathrm{ms}$ ).

\section{Questionnaires}

Physical or mental complaints were assessed with a self-report questionnaire consisting of 31 possible complaints to be rated on a 4-point scale; a score of zero indicated that the participant was not experiencing the complaint, and a score of three meant he or she was experiencing it a great deal. A difference score of mean score $\mathrm{T}_{\mathrm{T} 1}$ (1 hour after drug intake) -

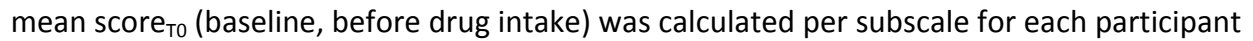
and used for analysis.

\section{Statistical analysis}

Statistical data were analysed using SPSS. For all analyses, we used $\alpha=0.05$. Post-hoc testing was performed with a Least Significant Difference (LSD) test. To determine possible treatment effects on immediate recall in the VLT, behavioral data were analyzed by parametric analysis of variance (repeated measures ANOVA) with Drug (2 levels: placebo and biperiden) and Trial ( 3 levels for the 3 trials of the immediate recall) as within-subject variables. The data of the delayed recall were analyzed with paired samples t-tests with Drug (placebo vs. biperiden) as independent variable. In the case of the VRT and CRT, we performed repeated measures ANOVAs with Drug (2 levels: placebo and biperiden) and Stimulus (VRT: 2 levels: old vs. new items; CRT: 2 levels: congruent vs. incongruent). Analyses were performed separately for the dependent variables: i.e., in the case of the VLT: correctly, doubly and incorrectly recalled words; for the VRT: correctly recognized items and reaction time; for the CRT: accuracy and reaction time.

The questionnaire data were analyzed by paired samples t-tests with Drug (placebo vs. biperiden) as independent variable. We only analyzed those side-effects relevant for biperiden intake: sleepiness, dizziness, nausea, restlessness, heart palpitations, stomach ache, bloated stomach, decreased appetite, dry mouth, tiredness, blurred vision, drowsiness, loss of concentration, nervousness, apathy, and inability to tolerate bright light. Ttests were done separately for each subscale.

\section{RESULTS}

\section{Verbal learning task (VLT)}

Figure 1 shows the effects of biperiden on immediate and delayed recall of words in the VLT. In the repeated measures analysis of the immediate recall data, the effect of Treatment on correctly recalled words did not vary per level of Trial (no Treatment * Trial interaction effect; $F(2,30)=0.83$, n.s.). Treatment was found to affect word recall (main effect of Treatment; $F(2,30)=11.79, P<0.01$ ); post-hoc analysis showed that biperiden decreased the immediate recall score by an average of about 4 words compared to placebo. Furthermore, participants were able to recall increasingly more words across the three trials of immediate recall (main effect of Trial; $F(2,30)=233.30, P<0.001$ ). There were no effects of 
Treatment and Trial on doubly or incorrectly recalled words ( $F s<1.44$, n.s.). In the paired samples t-tests of the delayed recall data, there was a significant difference in correctly recalled words after placebo $(M=20.31, S D=6.29)$ and biperiden conditions $(M=15.19, S D$ $=3.64 ; t(15)=3.42, P<0.01)$. There were no effects of biperiden on doubly $(t(15)=0.00$, n.s.) or incorrectly recalled words $(t(15)=-1.43$, n.s.)

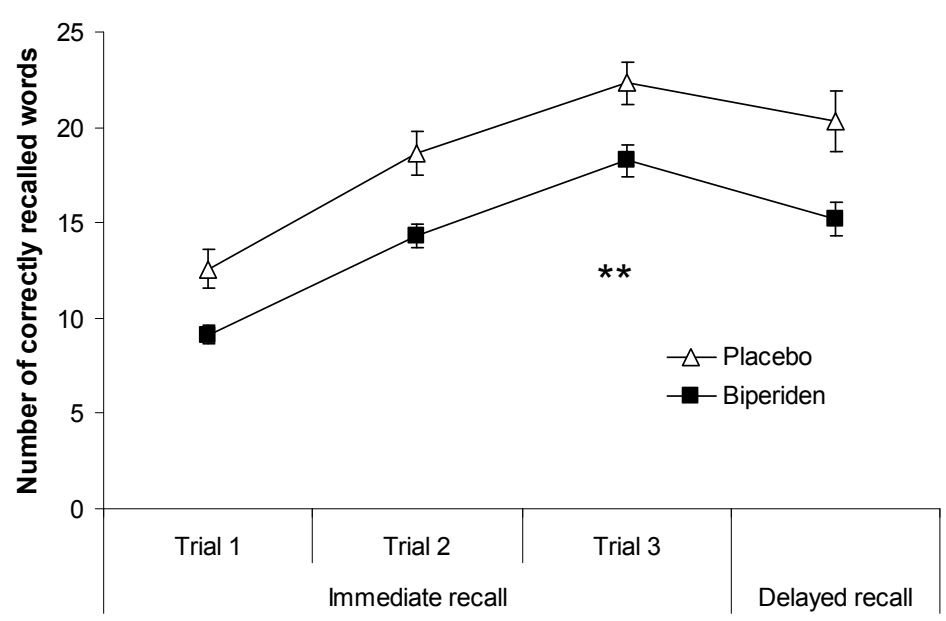

Figure 1. Effects of biperiden on immediate and delayed recall of words in the VLT. Participants were able to increasingly recall more words across the immediate trials. Biperiden decreased the immediate and delayed recall score by an average of about 4 words compared to placebo.

\section{Verbal Recognition Task (VRT)}

Figure 2 shows the effects of biperiden on percentage correctly recognized words in the VRT. The effect of Treatment on percentage correctly recognized old vs. new items did not vary per level of Stimulus (no Treatment * Stimulus interaction effect; $F(1,13)=0.42$, n.s.). Treatment was found to affect percentage correct in the recognition task (main effect of Treatment; $F(1,13)=9.87, P<0.01$ ); post-hoc analysis showed that after biperiden, the correct recognition of old and new items was reduced with approximately $8 \%$ relative to placebo. There was no main effect of Stimulus on percentage correct $(F(1,13)=0.42$, n.s.). For reaction time, there was no Treat*Stimulus interaction $(F(1,13)=0.44$, n.s.), nor a main effect of Treatment on reaction time $(F(1,13)=1.68$, n.s.). Participants reacted significantly faster to old vs. new items (main effect of Stimulus; $F(1,13)=22.91, P<0.001$ ).

\section{Choice Reaction Time Task (CRT)}

There were no interactions or main effects with Treatment or Stimulus on accuracy in the CRT $(F s<3.90$, n.s.). As for the reaction time data, there was no Treatment * Stimulus interaction $(F(1,14)=0.17$, n.s. $)$ nor a main effect of Treatment $(F(1,14)=0.48$, n.s. $)$. Stimulus was shown to affect reaction time; post-hoc analysis showed that participants reacted relatively slower to the incongruent trials. 


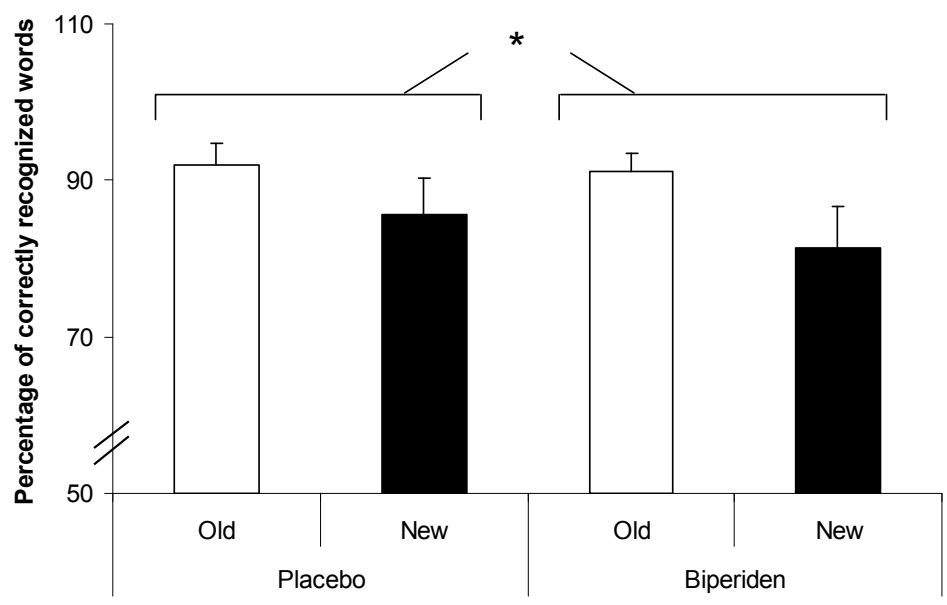

Figure 2. Effects of biperiden on percentage correctly recognized words in the VRT. After biperiden, the correct recognition of old and new items was reduced with approximately $8 \%$ relative to placebo.

\section{Complaints}

Participants did not report experiencing side-effects after intake of biperiden ( $T s>-1.96$, n.s.).

\section{DISCUSSION}

The goal of the current study was to assess whether biperiden would disrupt verbal memory, affect psychomotor performance and induce side-effects in young, healthy participants. After biperiden, participants recalled on average about 4 words less on the immediate recall and 5 words less on the delayed recall of the VLT. Word recognition scores in the VRT were reduced by $8 \%$ after biperiden. Biperiden did not influence reaction times in the VRT or the CRT, which would be indicative of a lack of psychomotor effects. There was also no effect of biperiden on accuracy in the CRT, nor did participants report experiencing any side-effects.

Our findings are in line with those found in the literature on memory-impairing effects of muscarinic antagonists in humans (Atri et al., 2004; Bishop et al., 1996; Broks et al., 1988; Green et al., 2005; Kamboj \& Curran, 2006; Mintzer \& Griffiths, 2001; 2005; 2007; Nakra et al., 1992; Pomara et al., 2004; Rasch et al., 2006; Robbins et al., 1997; Sherman et al., 2003; Snyder et al., 2005; Sperling et al., 2002; but see van Ruitenbeek et al., 2008). Specifically, the current results successfully replicated the findings of Wezenberg et al. (2005) who also showed impairments in immediate and delayed recall and recognition of verbal material. However, cognition-impairing effects of muscarinic $M_{1}$ antagonists generally do not seem to be specific for any particular memory system or sensory modality, as 
they have been found to influence not only verbal, but also visual, short-term, and working memory (Nakra et al., 1992; Wezenberg et al., 2005).

Furthermore, scopolamine has been shown to disrupt attentional processes, which might underlie its deleterious effects on memory (see Chapter 2 and Brandeis et al., 1992; Broks et al., 1988; Duka et al., 1996; Dunne \& Hartley, 1986; Ellis et al., 2006; Wesnes \& Revell, 1984; Wesnes \& Warburton, 1984; Witte et al., 1997). However, given the fact that scopolamine tends to have a high affinity for blocking muscarinic receptors regardless of receptor subtype, it might be interesting to explore whether the same holds for muscarinic antagonists which are relatively more selective for the $M_{1}$ receptor. Evidence in favor of a role for the muscarinic $M_{1}$ receptor in attention is so far quite equivocal. For instance, Wezenberg et al. (2005) reported that $2 \mathrm{mg}$ of biperiden impaired movement time in a motor learning task, which was interpreted as an attentional effect rather than a slowing of psychomotor performance. In addition, biperiden also appeared to disrupt visuospatial processes, but effects were not as strong and robust relative to those in the memory tasks. In contrast, Nakra et al. (1992) reported no effect of the muscarinic $M_{1}$ antagonist trihexyphenidyl $(2 \mathrm{mg}$ ) on attention-concentration measures in the Wechsler Memory Scale. In line with the latter finding, we recently reported a lack of effects of biperiden on accuracy performance in a visual target detection task assessing learned irrelevance (LIrr) processes (see Chapter 5). In sum, muscarinic $M_{1}$ antagonists such as biperiden do seem to affect cognition in a relatively more selective manner than scopolamine; i.e., when examining effects on mnemonic vs. psychomotor and attentional processes.

In the current study we found no evidence of psychomotor slowing after biperiden; i.e., there were not effects on reaction time in the VRT or the CRT. Wezenberg et al. (2005) reported increased reaction time in a short-term memory test, yet it is unclear whether this findings represents a central (i.e., mnemonic) rather than a peripheral (i.e., psychomotor) effect. Nakra et al. (1992) showed no increase in side-effects (i.e., no blurred vision or sedation) on a self-rating scale after biperiden. A recent study by our lab which investigated the effects of biperiden on LIrr showed that reaction time was increased after biperiden relative to placebo (see Chapter 5). Again, it is hard to determine whether this effect is due to blockade of central or peripheral muscarinic $M_{1}$ receptors; i.e., whether biperiden induced a global decrease in task performance and/or psychomotor slowing. Of note, the LIrr task was set up as a visual target detection paradigm; these types of tests might be relatively more sensitive to deleterious psychomotor effects of muscarinic $M_{1}$ antagonists as compared to recognition or CRT paradigms. In addition, participants did not report any sideeffects of biperiden on our complaints questionnaire, which is in line with previous findings by our lab (see Chapter $\mathbf{5}$ ).

In this light, muscarinic $M_{1}$ antagonists might serve as a pharmacological model for inducing mnemonic deficits present in Alzheimer's disease. Indeed, several lines of evidence point towards an involvement of aberrant muscarinic $M_{1}$ signaling in this disorder (but see Liu et al., 2005). For example, a post-mortem study by Ladner et al. (1995) demonstrated a loss of binding of the cholinergic agonist carbachol to the $M_{1}$ receptor in superior frontal and primary visual cortices, but not in the dorsal striatum. These findings would imply that in frontal and visual regions, the $M_{1}$ receptor is uncoupled from its $G$-protein, thereby impairing cholinergic signal transduction. These findings were replicated and extended by Tsang et al. (2006), who showed that $M_{1}$ receptor/G-protein uncoupling in the frontal but not temporal cortex was positively correlated with the rate of cognitive decline; 
i.e., both mild/ moderate and severe Alzheimer patients showed uncoupling in temporal regions, but only the severely affected dementia patients displayed frontal cortical uncoupling.

In sum, biperiden is capable of impairing verbal memory rather selectively, i.e., without inducing clear peripheral side-effects which could adversely affect performance. There are a few indications that muscarinic $M_{1}$ antagonists could induce psychomotor slowing; however, evidence is far from conclusive. Muscarinic $M_{1}$ antagonists might serve as a translational model for inducing selective mnemonic deficits as seen in neuropsychiatric disorders, particularly Alzheimer's disease. Future studies should determine whether there exists some degree of dissociation in the effects of muscarinic receptor subtypes $M_{1}-M_{5}$ on cognition. Moreover, it is imperative that the mnemonic effects of drugs targeting the $M_{1}$ receptor subtype are further explored for dissociations in terms of stimulus modality and memory systems affected (i.e., working, verbal, visual, or spatial). 


\section{REFERENCES}

Atri, A., Sherman, S., Norman, K. A., Kirchhoff, B. A., Nicolas, M. M., Greicius, M. D., et al. (2004). Blockade of central cholinergic receptors impairs new learning and increases proactive interference in a word paired-associate memory task. Behavioral Neuroscience, 118, 223-236.

Bartus, R. T., Dean, R. L., Beer, B., \& Lippa, A. S. (1982). The cholinergic hypothesis of geriatric memory dysfunction. Science, 217, 408-417.

Bishop, K. I., Curran, H. V., \& Lader, M. (1996). Do scopolamine and lorazepam have dissociable effects on human memory systems? A dose-response study with normal volunteers. Experimental and Clinical Psychopharmacology, 4, 292-299.

Bolden, C., Cusack, B., \& Richelson, E. (1992). Antagonism by antimuscarinic and neuroleptic compounds at the five cloned human muscarinic cholinergic receptors expressed in Chinese hamster ovary cells. The Journal of Pharmacology and Experimental Therapeutics, 260, 576-580.

Brandeis, D., Naylor, H., Halliday, R., Callaway, E., \& Yano, L. (1992). Scopolamine effects on visual information processing, attention, and event-related potential map latencies. Psychophysiology, 29, 315-336.

Broks, P., Preston, G. C., Traub, M., Poppleton, P., Ward, C., \& Stahl, S. M. (1988). Modelling dementia: effects of scopolamine on memory and attention. Neuropsychologia, 26, 685-700.

Caulfield, M. P. (1993). Muscarinic receptors - characterization, coupling and function. Pharmacology \& Therapeutics, 58, 319-379.

Duka, T., Ott, H., Rohloff, A., \& Voet, B. (1996). The effects of a benzodiazepine receptor antagonist betacarboline ZK-93426 on scopolamine-induced impairment on attention, memory and psychomotor skills. Psychopharmacology, 123, 361-373.

Dunne, M. P., \& Hartley, L. R. (1986). Scopolamine and the control of attention in humans. Psychopharmacology, 89, 94-97.

Ellis, J. R., Ellis, K. A., Bartholomeusz, C. F., Harrison, B. J., Wesnes, K. A., Erskine, F. F., et al. (2006). Muscarinic and nicotinic receptors synergistically modulate working memory and attention in humans. The International Journal of Neuropsychopharmacology, 9, 175-189.

Green, A., Ellis, K. A., Ellis, J., Bartholomeusz, C. F., Ilic, S., Croft, R. J., et al. (2005). Muscarinic and nicotinic receptor modulation of object and spatial n-back working memory in humans. Pharmacology, Biochemistry and Behavior, 81, 575-584.

Hollmann, M., Brode, E., Greger, G., Müller-Peltzer, H., \& Wetzelsberger, N. (1984). Biperiden effects and plasma levels in volunteers. European Journal of Clinical Pharmacology, 27, 619-621.

Hollmann, M., Müller-Peltzer, H., Greger, G., Brode, E., Perucca, E., Grimaldi, R., et al. (1987). Pharmacokinetic-dynamic study on different oral biperiden formulations in volunteers. Pharmacopsychiatry, 20, 7277.

Kamboj, S. K., \& Curran, H. V. (2006). Neutral and emotional episodic memory: global impairment after lorazepam or scopolamine. Psychopharmacology, 188, 482-488.

Katayama, S., Ishizaki, F., Yamamura, Y., Khoriyama, T., \& Kito, S. (1990). Effects of anticholinergic antiparkinsonian drugs on binding of muscarinic receptor subtypes in rat brain. Research Communications in Chemical Pathology and Pharmacology, 69, 261-270.

Ladner, C. J., Celesia, G. G., Magnuson, D. J., \& Lee, J. M. (1995). Regional alterations in M1 muscarinic receptor-G protein coupling in Alzheimer's disease. Journal of Neuropathology \& Experimental Neurology, 54, 783-789.

Lezak, M. D. (1995). Neuropsychological assessment (3rd ed.). Oxford: Oxford University Press.

Liu, H. C., Hong, C. J., Liu, T. Y., Chi, C. W., \& Tsai, S. J. (2005). Association analysis for the muscarinic M1 receptor genetic polymorphisms and Alzheimer's disease. Dementia and Geriatric Cognitive Disorders, $19,42-45$.

Mintzer, J., \& Burns, A. (2000). Anticholinergic side-effects of drugs in elderly people. Journal of the Royal Society of Medicine, 93, 457-462.

Mintzer, M. Z., \& Griffiths, R. R. (2001). Acute dose-effects of scopolamine on false recognition. Psychopharmacology, 153, 425-433.

Mintzer, M. Z., \& Griffiths, R. R. (2003). Lorazepam and scopolamine: A single-dose comparison of effects on human memory and attentional processes. Experimental and Clinical Psychopharmacology, 11, 56-72.

Mintzer, M. Z., \& Griffiths, R. R. (2005). Drugs, memory, and metamemory: a dose-effect study with lorazepam and scopolamine. Experimental and Clinical Psychopharmacology, 13, 336-347. 
Mintzer, M. Z., \& Griffiths, R. R. (2007). Differential effects of scopolamine and lorazepam on working memory maintenance versus manipulation processes. Cognitve, Affective \& Behavioral Neuroscience, 7, 120129.

Nakra, B. R., Margolis, R. B., Gfeller, J. D., Grossberg, G. T., \& Sata, L. S. (1992). The effect of a single low dose of trihexyphenidyl on memory functioning in the healthy elderly. International Psychogeriatrics, 4, 207214.

Ogino, S., Miyamoto, S., Tenjin, T., Kitajima, R., Ojima, K., Miyake, N., et al. (2011). Effects of discontinuation of long-term biperiden use on cognitive function and quality of life in schizophrenia. Progress in NeuroPsychopharmacology \& Biological Psychiatry, 35, 78-83.

Peters, N. L. (1989). Snipping the thread of life. Antimuscarinic side-effects of medications in the elderly. Archives of Internal Medicine, 149, 2414-2420.

Pomara, N., Willoughby, L. M., Wesnes, K., \& Sidtis, J. J. (2004). Increased anticholinergic challenge-induced memory impairment associated with the APOE-epsilon4 allele in the elderly: a controlled pilot study. Neuropsychopharmacology, 29, 403-409.

Rasch, B. H., Born, J., \& Gais, S. (2006). Combined blockade of cholinergic receptors shifts the brain from stimulus encoding to memory consolidation. Journal of Cognitive Neuroscience, 18, 793-802.

Riedel, W. J., Klaassen, T., Deutz, N. E., van Someren, A., \& van Praag, H. M. (1999). Tryptophan depletion in normal volunteers produces selective impairment in memory consolidation. Psychopharmacology, 141, 362-369.

Robbins, T. W., Semple, J., Kumar, R., Truman, M. I., Shorter, J., Ferraro, A., et al. (1997). Effects of scopolamine on delayed-matching-to-sample and paired associates tests of visual memory and learning in human subjects: comparison with diazepam and implications for dementia. Psychopharmacology, 134, 95106.

Sherman, S. J., Atri, A., Hasselmo, M. E., Stern, C. E., \& Howard, M. W. (2003). Scopolamine impairs human recognition memory: data and modeling. Behavioral Neuroscience, 117, 526-539.

Snyder, P. J., Bednar, M. M., Cromer, J. R., \& Maruff, P. (2005). Reversal of scopolamine-induced deficits with a single dose of donepezil, an acetylcholinesterase inhibitor. Alzheimer's \& Dementia, 1, 126-135.

Sperling, R., Greve, D., Dale, A., Killiany, R., Holmes, J., Rosas, H. D., et al. (2002). Functional MRI detection of pharmacologically induced memory impairment. Proceedings of the National Academy of Sciences, 99, 455-460.

Tsang, S. W. Y., Lai, M. K. P., Kirvell, S., Francis, P. T., Esiri, M. M., Hope, T., et al. (2006). Impaired coupling of muscarinic M1 receptors to G-proteins in the neocortex is associated with severity of dementia in Alzheimer's disease. Neurobiology of Aging, 27, 1216-1223.

Tune, L., Carr, S., Hoag, E., \& Cooper, T. (1992). Anticholinergic effects of drugs commonly prescribed for the elderly: Potential means for assessing risk of delirium. American Journal of Psychiatry, 149, 1393-1394.

van Ruitenbeek, P., Vermeeren, A., \& Riedel, W. (2008). Histamine H1-receptor blockade in humans affects psychomotor performance but not memory. Journal of Psychopharmacology, 22, 663-672.

Wesnes, K., \& Revell, A. (1984). The separate and combined effects of scopolamine and nicotine on human information processing. Psychopharmacology, 84, 5-11.

Wesnes, K., \& Warburton, D. M. (1984). Effects of scopolamine and nicotine on human rapid information processing performance. Psychopharmacology, 82, 147-150.

Wezenberg, E., Verkes, R. J., Sabbe, B. G., Ruigt, G. S., \& Hulstijn, W. (2005). Modulation of memory and visuospatial processes by biperiden and rivastigmine in elderly healthy subjects. Psychopharmacology, 181, 582-594.

Witte, E. A., Davidson, M. C., \& Marrocco, R. T. (1997). Effects of altering brain cholinergic activity on covert orienting of attention: comparison of monkey and human performance. Psychopharmacology, 132, 324334. 



\section{CHAPTER 5}

\section{Human electrophysiological correlates of learned irrelevance: Effects of the muscarinic $\mathrm{M}_{1}$ antagonist biperiden}

Klinkenberg, I., Blokland, A. Riedel, W., \& Sambeth, A. (2012). Human EEG correlates of learned irrelevance: Effects of the muscarinic $M_{1}$ antagonist biperiden. The International Journal of Neuropsychopharmacology, 15, 1375-1385. 


\section{INTRODUCTION}

If a conditioned stimulus (CS) and an unconditioned stimulus (US) are repeatedly presented in a random, uncorrelated manner, it is believed that an animal or human learns that the occurrence of one stimulus is irrelevant to the occurrence of the other one (e.g., Baker, 1976; Mackintosh, 1973). Next, if the former inconsequential CS becomes paired with the US, the subsequent acquisition of the CS-US association is delayed compared to stimuli which are novel. This phenomenon, the retardation of associative CS-US learning or classical conditioning after prior non-contingent exposure to the conditioning stimuli, is called learned irrelevance (LIrr: Gal et al., 2005). Of note, presenting only the CS prior to subsequent conditioning also induces a delay in CS-US learning called latent inhibition, which is viewed as closely related to LIrr (Allen et al., 2002).

In acute, first-episode schizophrenia LIrr has been found to be reduced or fully disrupted; the acquisition of associations related to preexposed stimuli occurs faster in this group of patients compared to normal controls (Gal et al., 2005; Orosz et al., 2011; Young et al., 2005). This means that LIrr is attenuated or even absent and acute schizophrenics actually outperform healthy individuals on these tasks. Furthermore, in chronic schizophrenia patients a failure to learn the CS-US association has been reported (Gal et al., 2005; Young et al., 2005), indicative of a global learning deficit rather than impaired LIrr. High-risk individuals (i.e., showing prodromal signs of psychosis) and schizotypic people also show LIrr deficits, whereas asymptomatic first-degree relatives of schizophrenics are seemingly unaffected. Combined, these findings are indicative of LIrr being a state marker for psychosis but not a trait marker for a potential schizophrenia endophenotype (Orosz et al., 2011).

There is a great lack of electrophysiological (EEG) data on human LIrr, although there are a few studies on event-related potentials (ERPs) of latent inhibition (Guterman et al., 1996). Therefore, the present study measured EEG along with LIrr in healthy individuals; the main focus was on the N1 and P3 ERPs. The N1 peak is a negative component which occurs around 70-140 ms post-stimulus at frontal and central electrode channels. This component seems to be related to the visual properties of a stimulus but can be modulated by selective attention. More specifically, its amplitude has been shown to be larger (i.e., more negative) for attended than for unattended or divided-attention stimuli (GarcíaLarrea et al., 1992; Golob et al., 2002; Jerger et al., 1992; Kho et al., 2003; Näätänen, 1990; Rockstroh et al., 1996; White \& Yee, 1997). The N1 is also important for discrimination processes, as it is absent if participants merely have to detect the presence of a stimulus (Mangun \& Hillyard, 1991). As LIrr might be interpreted as an attentional phenomenon (Lubow, 2005), we decided to focus on the N1 component in our analysis of the ERP data. The P3 peak is a large positive-going waveform occurring about 250-500 ms post-stimulus. The P3 can be divided into two subcomponents: an early occurring peak in response to novel or alerting stimuli - called the P3a - and a later component - dubbed the P3b - which occurs in most tasks requiring a decision process contingent on stimulus discrimination (Donchin, 1981).

There is a vast amount of literature on the role of the dopaminergic and glutaminergic neurotransmitter systems in schizophrenia. However, alterations in muscarinic signaling also appear to underlie the disorder (Brooks et al., 2011; Sarter et al., 2012; Tandon et al., 1991; 1999). Postmortem and in-vivo imaging studies have shown a reduction of muscarinic receptors density or binding in certain brain regions of schizophrenia patients (but see 
Garcia-Rill et al., 1995; Owen et al., 1981; Watanabe et al., 1983) and data seems most consistent for the muscarinic $\mathrm{M}_{1}$ receptor subtype (Crook et al., 2000; 2001; Dean et al., 1996; Deng \& Huang, 2005; Newell et al., 2007; Scarr et al., 2008; Zavitsanou et al., 2004; but see Scarr et al., 2007; Dean et al., 2000). However, most of these binding studies have used $[3 \mathrm{H}]$ pirenzepine as a radioligand, which also binds to the muscarinic $\mathrm{M}_{4}$ receptor subtype (Barak, 2009). Thus, differentiating between the muscarinic $M_{1}$ and $M_{4}$ receptor is not possible on the basis of these studies.

The current study is the first to assess the effects of the muscarinic $M_{1}$ antagonist biperiden in healthy, young volunteers using a within-subject LIrr paradigm suitable for ERP measurement. We expected that our LIrr paradigm would be successful in inducing LIrr in the placebo condition. We expected that the LIrr effect would be disrupted after biperiden treatment. With respect to the ERPs, we hypothesized that the LIrr conditions would be most notably reflected in the N1 and P3a/P3b components. After biperiden, LIrr would be disrupted as indicated by similar reaction times to PE-cued and NPE-cued targets (i.e., no increase in reaction time due to pre-exposure). We expected that biperiden would particularly affect the N1 and P3a/P3b peaks; i.e., biperiden is expected to reduce the amplitudes and/or increase the latencies of these components.

\section{METHODS}

\section{Participants}

Seventeen ( 7 male, 10 female; mean age of 22.4 years (SD $=3.0$, range $=19-29)$ ) healthy volunteers were recruited from Maastricht University through poster advertisements. Participants were required to be between 18-35 years of age. We decided on a restricted age range because EEG and ERPs can change with age and can be differentially sensitive to cholinergic modulation (Bennett et al., 2004; Fjell \& Walhovd, 2004; Pekkonen et al., 2005). Participants were also required to have a body mass index of 18.5 to 30 . They received an extensive medical screening before testing, consisting of a medical questionnaire, physical examination, measurement of blood pressure and pulse rate, blood samples for haematology and biochemistry, urine samples for drug screen and pregnancy test, and a resting electrocardiogram. Exclusion criteria were past or current psychiatric, neurological, cardiac, gastrointestinal, haematological, hepatic, pulmonary, or renal illness, pregnancy, lactation, excessive alcohol consumption (intake of more than 20 glasses per week), use of any medication other than oral contraceptives, having a first-degree relative with a current or past psychiatric disorder, and presence of other deficits that could be expected to influence performance. All subjects gave a signed informed consent before inclusion and were financially rewarded for their participation. The study was approved by the Medical Ethics Committee of Maastricht University.

\section{Study design and procedures}

The study was conducted according to a double-blind, placebo-controlled crossover design. In the course of the week before the actual test sessions, the participants received a training session to minimize any possible learning effects. Subjects were not allowed to use any psychoactive medication within 5 days before drug intake. Participants where asked to 
abstain from alcohol on a testing day and $24 \mathrm{~h}$ before testing. They were also not allowed to smoke and were requested not to consume any caffeine-, teaine- or aspartame-containing beverages on a testing day. One hour before testing the participants were asked to fill out some questionnaires on mood and physical complaints (see below) and were given a capsule containing either a placebo, or $2 \mathrm{mg}$ biperiden hydrochloride (Akineton ${ }^{\circledR}$, instant release). They were provided lunch immediately afterwards: this was done in order to reduce the chances of participants developing any side-effects due to biperiden intake. Lunch consisted of a can of caffeine-free soda, gluten-free bread and sweet bread toppings. After drug intake EEG electrodes and a cap were placed. After about one hour of testing, the participant had a short break, in which he or she was asked to fill out the same questionnaires again. The test session finished about 3 hours after drug intake. We aimed to separate test sessions by about 7 days to ensure sufficient washout of biperiden (average number of washout days was 9.3).

\section{Drug treatment}

Biperiden is a muscarinic $M_{1}$ antagonist approved for the treatment of Parkinson symptoms which develop due to use of first-generation antipsychotics (e.g., Ogino et al., 2011). It has about 10-fold higher affinity for $M_{1}$ as compared to $M_{2}-M_{5}$ receptors and it is thus the most selective $M_{1}$ antagonist available for use in human participants (Bolden et al., 1992; Katayama et al., 1990). Peak plasma concentrations are reached around 1-2 hours after a single dose administration followed by a rapid initial decline to values around $12 \%$ of the peak values at 6 hours after intake. This is subsequently followed by a slow terminal elimination phase at $48 \mathrm{~h}$ (Hollmann et al., 1984; 1987). The most common side effects of biperiden on the central nervous system are drowsiness, vertigo, headache, and dizziness. Peripheral side effects consist of blurred vision, mydriasis, dry mouth, impaired sweating, abdominal discomfort, and obstipation (e.g., Mintzer \& Burns, 2000; Peters, 1989; Tune et al., 1992). We chose for a dose of $2 \mathrm{mg}$ as this lies well within the range of the therapeutically recommended doses for biperiden (1-4 mg). Moreover, oral treatment with $2 \mathrm{mg}$ biperiden has been shown to impair cognitive performance in healthy elderly (Wezenberg et al., 2005). Biperiden was purchased, blinded, and labelled by the pharmacy of the University Hospital Maastricht according to the relevant GMP guidelines.

\section{Llrr task}

The within-subject LIrr paradigm was based on the one developed by Young et al. (2005), which was further modified by Gal et al. (2005) and Orosz et al. (2007; 2008; 2011). The paradigm was presented as a visual target detection task using letter characters (see Fig. 1). Capital Latin letters were shown successively on the computer screen for $1 \mathrm{~s}$ each, with an inter-stimulus interval of $1 \mathrm{~s}$. The letters were font size 250, coloured white (RGB: 255-255255) on a black background (RGB: 0-0-0) and appeared in the center of the monitor. The participants were instructed to press the spacebar as soon as the target letter $\mathrm{X}$ appeared on screen. In addition to the target, there were 10 other consonants and vowels presented during a single version of the task. These letters could either be preceding the $X-$ called predictor letters - or fill in the spaces between the predictor-target combinations - called filler letters. During one test session, 375 non-target and 75 target letters were presented, which means that the test duration was approximately $15 \mathrm{~min}$. The subjects were pre- 
sented a series of fifteen blocks of 30 letters each. The blocks were divided into 3 different conditions (with each block/condition presented 5 times):

1) non-preexposed (NPE) blocks - In NPE blocks the target $X$ was always predicted by the same letter, which was not presented before during the task. Each NPE letter acted as a target predictor in one particular NPE block and was not presented before or in later test sessions. Thus, NPE cues reliably predicted the target and enabled full prediction of it.

2) preexposed (PE) blocks - In a PE block the target was preceded five times by the same letter. However, this PE predictor letter had already been shown in previous blocks as a filler letter (i.e., uncorrelated to the target letter). In other words, whereas NPE predictors were completely novel, PE predictors were not. Therefore, prediction of the occurrence of the letter $X$ was partial in this condition.

3) random (RAN) blocks - Targets appeared randomly after different consonants or vowels which also served as PE and filler letters. Prediction of the target letter was therefore zero in the random blocks.

According to the degree of prediction, reaction time to target was expected to be the lowest for the NPE-, somewhat higher for the PE- and the highest for the RAN-cued targets. In case of LIrr, the average reaction time in PE is supposed to be significantly higher than in NPE ( $R T_{P E}>R_{N P E}$, see Orosz et al., 2008). NPE letters were always completely new; participants had not seen them before in the LIrr task at all. Our main outcome variables were reaction time (in $\mathrm{ms}$ ) to the target and a LIrr-index, which was calculated as follows:

$$
\text { LIrr }- \text { index }=\frac{R T_{P E}}{R T_{R A N}}-\frac{R T_{N P E}}{R T_{R A N}}
$$

A score greater than zero would be indicative of intact LIrr (Gal et al., 2005). In order to monitor whether participants had understood the instructions and were well motivated to perform the LIrr task, we also measured number of hits (actual target response), misses (failure of target response), false alarms (response to filler letters) and premature responses (response to predictors).

\section{Questionnaires}

To assess subjective mood changes, the Profile of Mood States (POMS) was used (McNair et al., 1971). This self-report questionnaire has 32 visual analogue scales which measure the mood states tension-anxiety, depression-dejection, anger-hostility, fatigue-inertia and vigor-activity. We also used the Bond and Lader mood scale (Bond \& Lader, 1974), which has 16 visual analogue scales that yield three mood factors; contented-discontented, alertdrowsy, and calm-excited. Physical or mental complaints were assessed with a self-report questionnaire consisting of 31 possible complaints to be rated on a 4-point scale. For all three questionnaires, a difference score of mean score $\mathrm{T}_{1}$ ( 1 hour after drug intake) - mean score $_{\text {то }}$ (baseline, before drug intake) was calculated and used for analysis. 


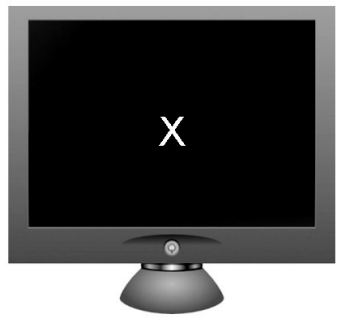

\begin{tabular}{|c|c|c|}
\hline \multirow{16}{*}{ 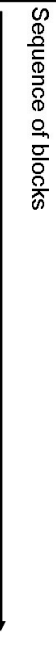 } & Block & Letter sequence \\
\hline & RAN1 & EJQYEBBXBQYEJYQEXJYJJXBYXQBQXE \\
\hline & NPE1 & YGXJYJYYQQEGXJGXEEGXQEGXBJQBBB \\
\hline & PE1 & EBXJEYQJYJBXJEYBXEYEBXQBXJQYQQ \\
\hline & RAN2 & JXYEXJYQBEBYBYXJJQYBBXQQEQXEEJ \\
\hline & PE2 & JQJYEXBQJYJQEXBQBBJEXYYEXQYBEX \\
\hline & NPE2 & $B B Y J Y A X Y E J B E Y J Q A X E Q A X B J Q E A X Q$ \\
\hline & RAN3 & EQEEXEQBJYQXJYYQBE BJXBYJYXQBXJ \\
\hline & NPE3 & EWXJJQWXBWXYBYYBEQEWXBJJQQWXYE \\
\hline & PE3 & B J JYQXEEQXBYJQXEYQXEYEBYJQXBBJ \\
\hline & NPE4 & JEMXJJEMXYBYMXJMXQQBQBEBQMXYYE \\
\hline & PE4 & QEJYXBBQYXEBEJJQYXEEBJJQYXBYXQ \\
\hline & RAN4 & QXJEJYXQYEQJXYYBEBEXJQBBXYEJBQ \\
\hline & PE5 & BBEJXQBYBJXYJXQEQEEEYJXQYBYQJX \\
\hline & RAN5 & JBEJBJXBEYXQEJEBXBYYEXJYQXQQQY \\
\hline & NPE5 & YJTXYJYTXEBEEQTXEBJBTXYQQBTXJQ \\
\hline
\end{tabular}

Figure 1. A schematic presentation of the LIrr test set-up and the letter sequences of a test session. The order of blocks is the same for all test sessions and is shown on the first column. The horizontal lines show the letter sequence of the corresponding blocks in detail. Regardless of condition, each block contains 30 letters: 5 targets (in bold), 5 target predictors (in bold, preceding the target letter $\mathrm{X}$ ) and 20 filler letters (PE letters: B, E, J, Q, Y). Adapted from Orosz et al. (2008).

\section{EEG and ERPS}

For the EEG recording, the Neuroscan Synamps system was used with sample rate set at $1000 \mathrm{~Hz}$. Data were filtered between $0.05-100 \mathrm{~Hz}$. EEG was recorded from 32 electrodes placed on the scalp using an elastic cap (Electro-Cap International, United States) and positioned according to the 10-20 system (Jasper, 1958). The horizontal electro-oculogram (HEOG) was measured with two electrodes placed on the outer canthus of the left and right eye, and two electrodes placed below and above the centre of the left eye recorded the vertical electrooculogram (VEOG). Two electrodes behind the ears served as reference electrodes. Before placing the electrodes, all locations were cleaned with alcohol and gently scrubbed with a gel, to ensure good conduction of the signal. Impedance was kept below $5 \Omega$. During the EEG recordings, the participants were sitting in an electrically shielded and sound-attenuated room with the lights dimmed.

All EEG data were analyzed with Vision Analyzer 2.0. Before data analysis, the EEG data were visually inspected offline, to check for artefacts. The EEG signal was filtered with a 
high pass filter set at $1 \mathrm{~Hz}$ (12 dB slope) and a low pass filter set at $30 \mathrm{~Hz}$ (12 dB slope). The ERP epochs were set from 100 ms prior to stimulus onset to $900 \mathrm{~ms}$ after onset, using the $100 \mathrm{~ms}$ pre-stimulus as baseline. Eye movement artefacts were filtered out of the EEG using the data of the VEOG channel and the method developed by Semlitsch et al. (1986). This way, every participant had about the same number of artifact-free trials which were combined into the ERP averages. Separate averages were calculated for the predictors and the targets, as well as for the NPE, PE, and RAN stimuli. For the predictor stimuli, N1 and P3a peaks were noted on the $\mathrm{Fz}, \mathrm{FCz}$ and $\mathrm{Cz}$ channels. In case of the targets, $\mathrm{N} 1$ and $\mathrm{P} 3 \mathrm{~b}$ peaks could be distinguished on the $\mathrm{CPz}, \mathrm{CP} 3, \mathrm{CP} 4, \mathrm{Pz}, \mathrm{P} 3$, and $\mathrm{P} 4$ electrodes. Please refer to Table 1 for the time windows chosen for ERP peak detection analysis. Peak windows were determined based on the grand averages. Peak amplitudes were calculated and latencies were computed based on when the peak was reached.

Table 1. Time windows (in ms) used for ERP analyses.

\begin{tabular}{llll}
\hline \multirow{2}{*}{ Stimulus type } & Peaks & P3a & P3b \\
\cline { 2 - 4 } & N1 & $320-500$ & N/A \\
\hline Predictors & $45-140$ & N/A & $185-500$ \\
Targets & $35-125$ & & \\
\hline
\end{tabular}

Abbreviations: N/A: not applicable

\section{Statistical analysis}

Only participants who had at least $80 \%$ target hits, i.e., 60 of the total of 75 , were included in the behavioral and ERP analyses. This criterion was used to ensure that all participants understood and were able to follow the instructions. Statistical data were analysed using SPSS. For all analyses, significant interactions were examined in more detail by doing additional ANOVA analyses split for each level of one of the interaction variables. Post-hoc testing was performed with a Least Significant Difference (LSD) post-hoc test. For both the behavioral and ERP data, the first trial of a block was always excluded from analysis under the assumption that implicit associative learning will need at least one CS-US or predictortarget pairing in order to be expressed. Subsequently, behavioral and ERP data were collapsed across Blocks.

To determine possible treatment effects on the LIrr index, behavioral data were analyzed by parametric analysis of variance (repeated measures ANOVA) with Drug (2 levels: placebo and biperiden) as within-subject variable. For the analyses of the reaction time data, LIrr Condition (3 levels: RAN, PE and NPE) was added as an additional within-subject variable. We then evaluated whether the LIrr conditions had a differential effect on the ERPs. Therefore, the placebo data were analyzed using repeated measures ANOVAs with LIrr Condition ( 3 levels: RAN, PE and NPE) and Electrode ( 3 levels for predictors: Fz, Fcz and $\mathrm{FCz}, 2$ levels for targets: $\mathrm{CPz}, \mathrm{Pz}$ ). We determined the effects of biperiden on the processing of predictor and target letters by doing the same analyses with Drug ( 2 levels: placebo and biperiden) as an extra within-subject variable. ERP analyses were done separately for amplitude and latency, stimulus type (i.e., predictors and targets) and each of the ERP peaks.

Questionnaire data were analyzed with paired samples T-tests separately for each subscale. The POMS had 5 subscales, whereas for the Bond \& Lader we only analyzed the alert-drowsy subscale, as this one is the best validated. The self-report questionnaire con- 
sisted of 31 questions, but we only analyzed those side-effects relevant for biperiden intake: sleepiness, dizziness, nausea, restlessness, heart palpitations, stomach ache, bloated stomach, decreased appetite, dry mouth, tiredness, blurred vision, drowsiness, loss of concentration, nervousness, apathy, and inability to tolerate bright light.

\section{RESULTS}

One participant did not meet the requirement of at least $80 \%$ target hits and was therefore excluded from behavioral and ERP analysis. Part of the behavioral data was missing for another subject; this person was also not included, leaving a total of 15 participants.

\section{Behavioral data: LIrr effects}

Figure 2 shows the effects of the LIrr conditons on reaction time to the target letters. In the analysis of the reaction time data, there was a main effect of LIrr Condition on reaction time $(F(2,28)=21.73, P<0.001)$. Post-hoc analysis showed that reaction times to the target letters were faster for the NPE compared to the RAN $(P<0.001)$ and PE condition $(P<$ 0.001).

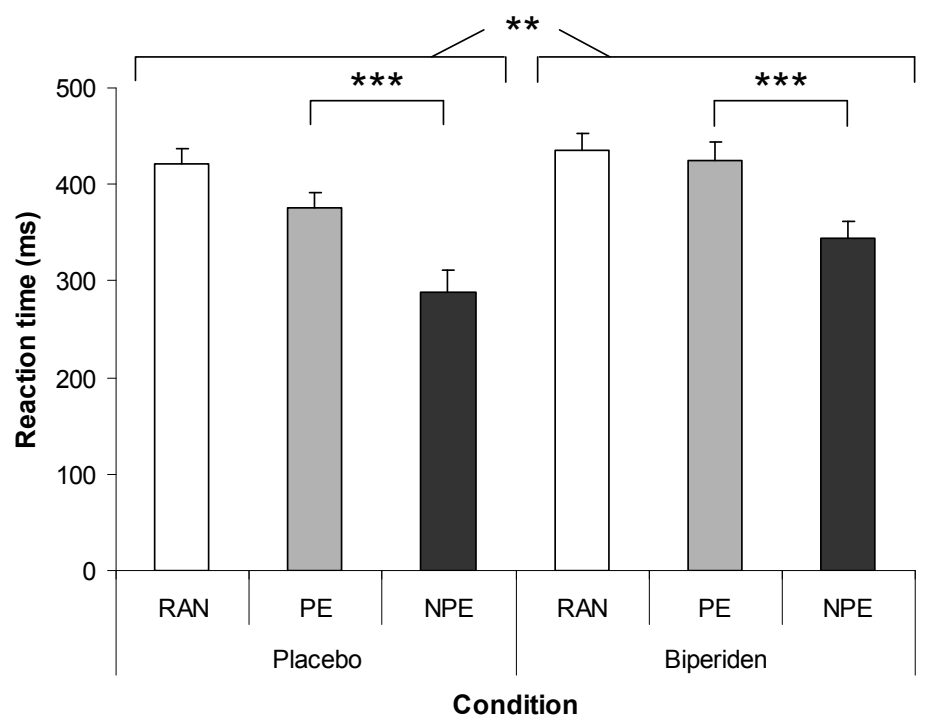

Figure 2. Effects of the LIrr conditions and biperiden on reaction time to the target letters (means + SEM, *: $P$ $<0.05, * *: P<0.01, * * *: P<0.001)$. In the placebo condition intact LIrr is present, reflected by larger reaction times for PE- than for NPE-cued target letters. Biperiden prolonged reaction time compared to placebo, but did not affect LIrr. 
ERP data: LIrr effects on predictor and target letters

In the placebo analyses of the predictor letters, there were no relevant task effects on N1 amplitude and latency ( $F s<1.69$, n.s.) or P3a amplitude and latency $(F s<2.50$, n.s.). In the placebo analyses of the target letters, there were no relevant task effects on N1 amplitude and latency $(F s<1.58$, n.s.) or on P3b amplitude $(F s<1.17$, n.s.). The effect of LIrr Condition on P3b latency did not vary per level of Electrode (no LIrr Condition * Electrode interaction effects; $F(10,130)=0.44$, n.s.), yet P3b latency was found to differ between LIrr conditions (main effect of LIrr Condition; $F(2,26)=11.99, P<0.001$ ); post-hoc analysis showed that the P3b latency of NPE-cued targets occurred earlier compared to the P3b latency of RAN-cued $(P<0.001)$ and PE-cued targets $(P<0.05)$. Figure 3 shows the effects of the LIrr conditions on the $\mathrm{P} 3 \mathrm{~b}$ component of the target letters in the placebo condition.

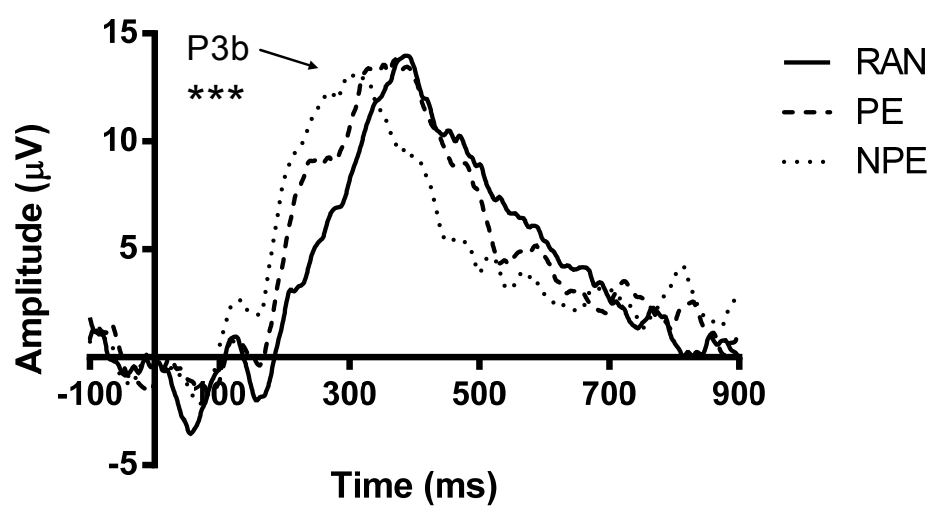

Figure 3. Effects of the LIrr conditions on the P3b component of the target letters in the placebo condition. Shown here: Pz electrode channel. P3b latency is shortest in the NPE condition, intermediate for PE-cued targets and longest for targets belonging to the RAN condition $(* * *: P<0.001)$.

\section{Behavioral data: effect of biperiden}

Figures 2 and 4 show the effects of biperiden on reaction time for the target letters and the LIrr-index. The effect of Drug did not vary per level of LIrr Condition (no Drug * LIrr Condition interaction effect; $F(2,28)=2.46$, n.s.). Reaction times were increased after biperiden treatment (main effect of Drug; $F(1,14)=12.43, P<0.01$ ). Biperiden had no effect on the LIrr-index (no main effect of Drug; $F(1,14)=0.06$, n.s.). 


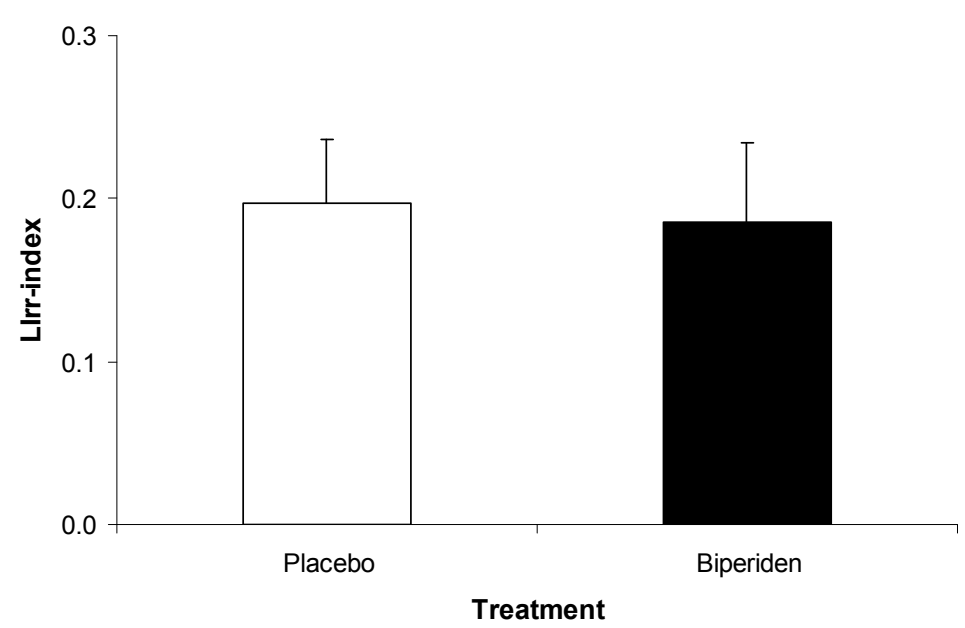

Figure 4. Effects of biperiden on the LIrr-index (means + SEM). In the placebo condition intact LIrr is present, reflected by a LIrr-index larger than zero. The same holds for the biperiden condition; in other words, biperiden failed to affect LIrr.

\section{ERP data: effects of biperiden on predictor and target letters}

Figure 5 shows the effects of biperiden on the N1 component of the PE predictor letters. The analysis of the amplitude of the N1 peak showed that the effect of biperiden varied per level of Electrode (Treatment * Electrode interaction effect; $F(2,26)=7.54, P<0.01$ ) and per level of LIrr Condition (Treatment * LIrr Condition interaction effect; $F(2,26)=3.94, P<$ 0.05). Therefore we decided to do separate repeated measures ANOVAs per LIrr condition. In the analyses of RANP and NPE predictors, there were no interaction or main effects of biperiden on $\mathrm{N} 1$ amplitude ( $F s<1.98$, n.s.). For the PE predictors, the effect of Treatment on $\mathrm{N} 1$ amplitude varied per Electrode (Treatment * Electrode interaction effect; $F(2,26)=$ 7.42, $P<0.01$ ); therefore we performed separate repeated measures ANOVAs per Electrode. Biperiden was found to increase the $\mathrm{N} 1$ amplitude at $\mathrm{Fz}$ and $\mathrm{FCz}$ ( $F s>5.77, P s<$ 0.05). There were no relevant interaction effects or main effects of biperiden on N1 latency ( $F s<2.40$, n.s.), or on P3a amplitude or latency ( $F s<2.25$, n.s.) of the predictor letters. Furthermore, for the targets there were no effects of biperiden on N1 amplitude and latency $(F s<3.25$, n.s.), or on P3b amplitude and latency $(F s<4.18$, n.s.).

\section{Questionnaire data}

There were no effects of biperiden on the subscales of the self-report questionnaire (TS > 1.87 , n.s.), the POMS (Ts $>-0.92$, n.s.) or the Bond \& Lader (Ts $>-1.52$, n.s.). 


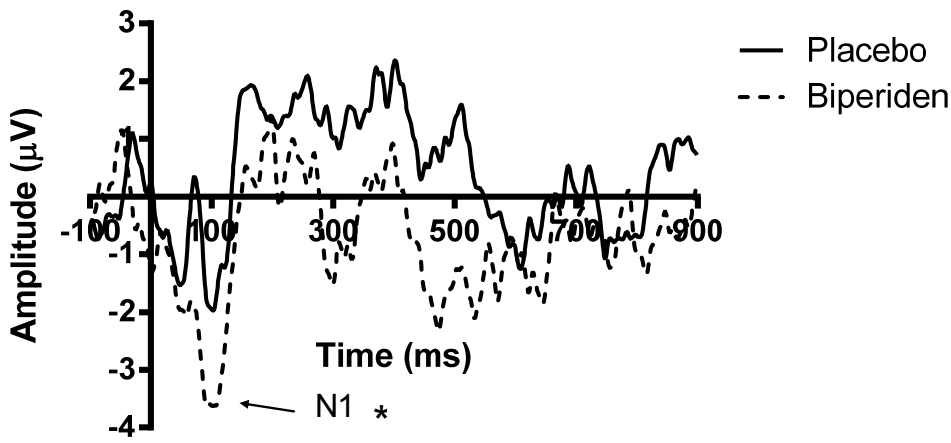

Figure 5. Effects of biperiden on the N1 component of the PE predictor letters. Shown here: Fz electrode channel. Biperiden increased N1 amplitude compared to placebo $(*: P<0.05)$.

\section{DISCUSSION}

The goal of the current study was to develop a LIrr task suitable for ERP measurement and to examine the effects of the muscarinic $M_{1}$ antagonist biperiden on behavioral performance and ERP correlates of LIrr in healthy young volunteers. The LIrr paradigm used in our current study was successful in inducing LIrr in healthy, young volunteers who received placebo medication (see Fig. 2 and Fig. 4). For the behavioral results, LIrr was reflected in shorter reaction times in relation to the degree of target predictability: fastest to NPE-cued targets which were fully predictable, slower to PE-cued targets which were partially predictable and slowest for RAN-cued targets that yielded zero prediction. These findings are in accordance with earlier reports using within-subject LIrr-paradigms in humans (Gal et al., 2005; Orosz et al., 2007; 2008; 2011; Young et al., 2005). Moreover, our results are also in line with studies investigating the facilitating effect of stimulus predictability on reaction time (Barcelo \& Knight, 2007; Fogelson et al., 2008; Suwazono et al., 2000). The LIrr-index after placebo was 0.2 in our experiment, which is well over zero and therefore indicative of a robust LIrr effect of our task. In comparison, the LIrr-index reported by Gal et al. (2005) in his group of healthy normal controls was about 0.1 .

The three LIrr conditions (RAN, PE and NPE) affected P3b latency (but not amplitude) of the target letters as a function of the participant's degree of uncertainty about the occurrence of the target letter X (see Fig. 3). The P3b occurred earliest after presentation of NPEcued targets (averaged over all electrode channels), relatively later for PE-cued targets, and was the slowest to occur for the RAN-cued targets. P3b latency is usually interpreted as an indication of stimulus evaluation speed, with shorter latencies indicative of superior cognitive performance (Polich \& Criado, 2006). The traditional view states that the P3b starts to occur when stimulus evaluation processes are completed (Sutton et al., 1965; 1967). The finding that the P3b latency of a target stimulus is shortened by a predictor stimulus signalling subsequent target presentation is supported by evidence of earlier studies (DuncanJohnson \& Donchin, 1977; 1980; Fogelson et al., 2008), which showed that P3b latency is decreased for targets which are considered highly probable than those which are less probable. Furthermore, as already suggested by Fogelson et al. (2008), the enhancement of stimulus evaluation speed of predictable targets appears to be cognitive rather than per- 
ceptual; our target stimuli were always similar (i.e., throughout the task the target stimulus was the letter $\mathrm{X}$ ) and there was no influence of LIrr conditions on early perceptual ERP components (e.g., N1). In line with our findings, previous studies utilizing discrimination tasks in which participants are instructed to favour accuracy over speed have shown a positive correlation between P3b latency and reaction time performance (Kutas et al., 1977; but see Verleger, 1997). Taken together, the effects of the LIrr conditions on P3b but not N1 latency suggest that LIrr is more related to stimulus evaluation processes rather than early perceptual/attentional mechanisms.

A behavioral disruption of LIrr after biperiden treatment was expected to be reflected by similar reaction times to NPE-cued and PE-cued targets (i.e., no increase in reaction time due to preexposure). However, biperiden did not affect LIrr as participants still showed faster reaction times to NPE-cued as opposed to PE-cued target letters (see Fig. 2). Similarly, the LIrr-index was not reduced (see Fig. 4) and participants did not report any sideeffects on our questionnaires after biperiden. The only discernible effect of biperiden was an overall increase in reaction time. In line with our results, Wezenberg et al. (2005) reported a dose of $2 \mathrm{mg}$ biperiden to increase movement time in a motor learning task. However, the authors interpreted this effect as being due to attentional deficits, rather than a general slowing of psychomotor performance.

Several studies have reported a detrimental effect of biperiden on memory processes. In the study of Guthrie et al. (2000), impairments were found in backward but not forward digit span. Both of these tasks are thought to tap into several cognitive processes, among which memory and attention (Larrabee \& Kane, 1986). In the same study biperiden also affected verbal memory; on a selective reminding task participants recalled fewer words at both immediate and delayed recall. These results were replicated and extended by Wezenberg et al. (2005). These studies thus provide support for the view that the muscarinic $M_{1}$ receptor is important for memory functions. Theories about LIrr have focused on behavioral switching (Weiner, 2003), attention (Lubow, 2005; Schmajuk, 2005) and inhibition of redundant stimuli (Gluck \& Myers, 1993). Hence, LIrr is thought of as a paradigm that measures attentional rather than mnemonic abilities, which might explain why a memoryimpairing drug such as biperiden failed to have an effect on our LIrr task.

Biperiden also increased the amplitude of the N1 component of the PE predictor letters - which were previously irrelevant but later on became partial predictors of the target stimulus (see Fig. 5). This was an unsuspected finding given our hypothesis of reduced amplitudes and/or increased latencies of the N1, P3a or P3b peaks after biperiden. It is unclear whether the biperiden-induced increment in N1 amplitude reflects cognitive/central or non-cognitive/peripheral processes. Biperiden has been known to cause blurred vision in healthy volunteers (e.g., Fleischhacker et al., 1987); however, impaired vision would be expected to reduce N1 amplitude rather than increase it. Moreover, our participants did not report visual impairments after biperiden compared to placebo. Thirdly, blurred vision would be likely to globally influence N1 amplitude: that is, also the N1 amplitude of RAN and NPE predictor letters would be affected, and not only that of the PE predictors. The only non-cognitive effect of biperiden we did find was a general slowing of psychomotor performance (see above). However, responding to a target stimulus takes place much later after presentation of that stimulus, whereas the $\mathrm{N} 1$ is an early perceptual component which is regarded as separate from response behavior (Näätänen et al., 1988). 
A cognitive explanation of the increment in N1 amplitude of PE predictor letters after biperiden intake is also not very straightforward. Given the finding that N1 amplitudes are larger for attended than for unattended stimuli (e.g., Haider et al., 1964), a drug which is known to disrupt cognition would be expected to reduce N1 amplitude rather than to increase it. It might be the case that after biperiden, there is an overcompensation of the irrelevant-to-relevant switch or, in other words, participants needed to allocate more attentional resources in order to successfully link the presentation of the previously irrelevant PE predictor with the subsequent occurrence of the target letter. Taken together, our results would argue for an attentional effect of biperiden.

Interestingly, a study examining latent inhitibion and ERPs in acute and stable, partially remitted schizophrenia patients and healthy controls reported results which were comparable to our own (Kathmann et al., 2000). All participants exhibited robust latent inhibition; in other words, schizophrenics were not impaired in this regard. Schizophrenic patients did show slower reaction times compared to the normal, healthy controls which is in accordance with our biperiden data. In contrast to the behavioral results, the electrophysiological data did differentiate between diagnostic groups. Pre-exposure affected the N1 amplitudes to CS+ stimuli, which were irrelevant during pre-exposure but subsequently served as predictors during acquisition. Thus, these stimuli were conceptually similar to our PE predictor letters. Specifically, N1 amplitudes of CS+ stimuli were decreased in healthy controls, increased in acute schizophrenics and unchanged in partially remitted schizophrenics after pre-exposure. The authors interpreted this finding as an enhancement of allocation of attention to previously irrelevant stimuli or alternatively, as a failure to inhibit previously irrelevant stimuli from gaining access to attentional processing in the acute schizophrenic patient group. Of note, all patients received neuroleptic medication, which means that an effect of these drugs on ERPs cannot be excluded.

In sum, our LIrr paradigm induced robust LIrr in healthy young volunteers. As for the ERP results, LIrr was reflected in shorter P3b latency (i.e., faster stimulus evaluation processing) in relation to the degree of target predictability. LIrr was not affected after biperiden, but the N1 amplitude of the PE predictor letters was increased (suggestive of increased allocation of attentional/behavioral switching resources). The present data are inconclusive as to the attentional or mnemonic effects of biperiden, although the ERP data suggest a role in early information processing. Changes in LIrr after drug intake might ultimately serve as a psychopharmacological model for neuropsychiatric disorders, such as schizophrenia. For translational purposes, it would be pertinent to also determine druginduced alterations in ERP correlates of LIrr. 


\section{REFERENCES}

Allen, M. T., Chelius, L., Masand, V., Gluck, M. A., Myers, C. E., \& Schnirman, G. (2002). A comparison of latent inhibition and learned irrelevance pre-exposure effects in rabbit and human eyeblink conditioning. Integrative Physiological \& Behavioral Science, 37, 188-214.

Baker, A. G. (1976). Learned irrelevance and learned helplessness: Rats learn that stimuli, reinforcers, and responses are uncorrelated. Journal of Experimental Psychology: Animal Behavior Processes, 2, 130-141.

Barak, S. (2009). Modeling cholinergic aspects of schizophrenia: Focus on the antimuscarinic syndrome. Behavioural Brain Research, 204, 335-351.

Barcelo, F., \& Knight, R. T. (2007). An information-theoretical approach to contextual processing in the human brain: Evidence from prefrontal lesions. Cerebral Cortex, 17, i51-i60.

Bennett, I. J., Golob, E. J., \& Starr, A. (2004). Age-related differences in auditory event-related potentials during a cued attention task. Clinical Neurophysiology, 115, 2602-2615.

Bolden, C., Cusack, B., \& Richelson, E. (1992). Antagonism by antimuscarinic and neuroleptic compounds at the five cloned human muscarinic cholinergic receptors expressed in Chinese hamster ovary cells. The Journal of Pharmacology and Experimental Therapeutics, 260, 576-580.

Bond, A., \& Lader, M. (1974). The use of analogue scales in rating subjective feelings. British Journal of Medical Psychology, 80, 1-46.

Brooks, J. M., Sarter, M., \& Bruno, J. P. (2011). Transient inactivation of the neonatal ventral hippocampus permanently disrupts the mesolimbic regulation of prefrontal cholinergic transmission: Implications for schizophrenia. Neuropsychopharmacology, 36, 2477-2487.

Crook, J. M., Tomaskovic-Crook, E., Copolov, D. L., \& Dean, B. (2001). Low muscarinic receptor binding in prefrontal cortex from subjects with schizophrenia: A study of Brodmann's areas 8, 9, 10, and 46 and the effects of neuroleptic drug treatment. American Journal of Psychiatry, 158, 918-925.

Crook, J. M., Tomaskovic-Crook, E., Copolov, D.L., \& Dean, B. (2000). Decreased muscarinic receptor binding in subjects with schizophrenia: A study of the human hippocampal formation. Biological Psychiatry, 48, 381-388.

Dean, B., Crook, J. M., Opeskin, K., Hill, C., Keks, N., \& Copolov, D. L. (1996). The density of muscarinic $\mathrm{M}_{1}$ receptors is decreased in the caudate-putamen of subjects with schizophrenia. Molecular Psychiatry, 1, 54-58.

Dean, B., Crook, J. M., Pavey, G., Opeskin, K., \& Copolov, D. L. (2000). Muscarinic ${ }_{1}$ and 2 receptor mRNA in the human caudate-putamen: No change in m1 mRNA in schizophrenia. Molecular Psychiatry, 5, 203-207.

Deng, C., \& Huang, X. (2005). Decreased density of muscarinic receptors in the superior temporal gyrus in schizophrenia. Journal of Neuroscience Research, 81, 883-890.

Donchin, E. (1981). Surprise! . . Surprise? Psychophysiology, 18, 493-513.

Duncan-Johnson, C. C., \& Donchin, E. (1977). On quantifying suprise: The variation of event-related potentials with subjective probability. Psychophysiology, 14, 456-467.

Duncan-Johnson, C. C., \& Donchin, E. (1980). The relation of P300 latency to reaction time as a function of expectancy. Progress in Brain Research, 54, 717-722.

Fjell, A. M., \& Walhovd, K. B. (2004). Life-span changes in P3a. Psychophysiology, 41, 575-583.

Fleischhacker, W. W., Barnas, C., Günther, V., Meise, U., Stuppäck, C., \& Unterweger, B. (1987). Mood-altering effects of biperiden in healthy volunteers. Journal of Affective Disorders, 12, 153-157.

Fogelson, N., Wang, X., Lewis, J. B., Kishiyama, M. M., Ding, M., \& Knight, R. T. (2008). Multimodal effects of local context on target detection: Evidence from P3b. Journal of Cognitive Neuroscience, 21, 1680-1692.

Gal, G., Mendlovic, S., Bloch, Y., Beitler, G., Levkovitz, Y., Young, A.M.J., Feldon, J., \& Ratzoni, G. (2005). Learned irrelevance is disrupted in first-episode but not chronic schizophrenia patients. Behavioural Brain Research, 159, 267-275.

García-Larrea, L., Lukaszewicz, A., \& Mauguiére, F. (1992). Revisiting the oddball paradigm. Non-target vs. neutral stimuli and the evaluation of ERP attentional effects. Neuropsychologia, 30, 723-741.

Garcia-Rill, E., Biedermann, J. A., Chambers, T., Skinner, R. D., Mrak, R. E., Husain, M., et al. (1995). Mesopontine neurons in schizophrenia. Neuroscience, 66, 321-335.

Gluck, M. A., \& Myers, C. E. (1993). Hippocampal mediation of stimulus presentation: A computational theory. Hippocampus, 3, 491-516.

Golob, E. J., Pratt, H., \& Starr, A. (2002). Preparatory slow potentials and event-related potentials in an auditory cued attention task. Clinical Neurophysiology, 113, 1544-1557.

Guterman, Y., Josiassen, R. C., Bashore, T. E., Johnson, M., \& Lubow, R. E. (1996). Latent inhibition effects reflected in event-related brain potentials in healthy controls and schizophrenics. Schizophrenia Research, 20, 315-326.

Guthrie, S. K., Manzey, L., Scott, D., Giordani, B., \& Tandon, R. (2000). Comparison of central and peripheral pharmacologic effects of biperiden and trihexyphenidyl in human volunteers. Journal of Clinical Psychopharmacology, 20, 77-83. 
Haider, M., Spong, P., \& Lindsley, D. B. (1964). Attention, vigilance, and cortical evoked-potentials in humans. Science, 145, 180-182.

Hollmann, M., Brode, E., Greger, G., Müller-Peltzer, H., \& Wetzelsberger, N. (1984). Biperiden effects and plasma levels in volunteers. European Journal of Clinical Pharmacology, 27, 619-621.

Hollmann, M., Müller-Peltzer, H., Greger, G., Brode, E., Perucca, E., Grimaldi, R., et al. (1987). Pharmacokineticdynamic study on different oral biperiden formulations in volunteers. Pharmacopsychiatry, 20, 72-77.

Jasper, H. (1958). The ten-twenty electrode system of the international federation. Electroencephalography and Clinical Neurophysiology, 10, 371-375.

Jerger, K., Biggins, C., \& Fein, G. (1992). P50 suppression is not affected by attentional manipulations. Biological Psychiatry, 31, 365-377.

Katayama, S., Ishizaki, F., Yamamura, Y., Khoriyama, T., \& Kito, S. (1990). Effects of anticholinergic antiparkinsonian drugs on binding of muscarinic receptor subtypes in rat brain. Research Communications in Chemical Pathology and Pharmacology, 69, 261-270.

Kathmann, N., Von Recum, S., Haag, C., \& Engel, R. R. (2000). Electrophysiological evidence for reduced latent inhibition in schizophrenic patients. Schizophrenia Research, 45, 103-114.

Kho, K. H., Verkes, R. J., Eling, P., Zwarts, M. J., Ellenbroek, B., \& Van Luijtelaar, G. (2003). P50 gating is not affected by selective attention. Journal of Psychophysiology, 17, 23-29.

Kutas, M., McCarthy, G., \& Donchin, E. (1977). Augmenting mental chronometry: The P300 as a measure of stimulus evaluation time. Science, 197, 792-795.

Larrabee, G. J., \& Kane, R. L. (1986). Reversed digit repetition involves visual and verbal processes. International Journal of Neuroscience, 30, 11-15.

Lubow, R. E. (2005). The visual search analogue of latent inhibition: Implications for theories of irrelevant stimulus processing in normal and schizophrenic groups. Psychonomic Bulletin \& Review, 12, 224-243.

Mackintosh, N. (1973). Stimulus selection: Learning to ignore stimuli that predict no change in reinforcement. In R. Hinde \& J. Stevenson-Hinde (Eds.), Constraints on learning: Limitations and predispositions (pp. 75-96). New York, NY: Academic Press.

Mangun, G. R., \& Hillyard, S. A. (1991). Modulations of sensory-evoked brain potentials indicate changes in perceptual processes during visual-spatial priming. Journal of Experimental Psychology: Human Perception \& Performance, 17, 1057-1074.

McNair, D. M., Lorr, M., \& Droppleman, L. F. (1971). Manual for the profile of mood states. San Diego, CA: Educational and Industrial Testing Service.

Mintzer, J., \& Burns, A. (2000). Anticholinergic side-effects of drugs in elderly people. Journal of the Royal Society of Medicine, 93, 457-462.

Näätänen, R. (1990). The role of attention in auditory information processing as revealed by event-related potentials and other brain measures of cognitive function. Behavioral and Brain Sciences, 13, 201-288.

Näätänen, R., Sams, M., Alho, K., Paavilainen, P., Reinikainen, K., \& Sokolov, E. N. (1988). Frequency and location specificity of the human vertex N1 wave. Electroencephalography and Clinical Neurophysiology, 69, 523-531.

Newell, K. A., Zavitsanou, K., Kum Jew, S., \& Huang, X. (2007). Alterations of muscarinic and GABA receptor binding in the posterior cingulate cortex in schizophrenia. Progress in Neuro-Psychopharmacology \& Biological Psychiatry, 31, 225-233.

Ogino, S., Miyamoto, S., Tenjin, T., Kitajima, R., Ojima, K., Miyake, N., et al. (2011). Effects of discontinuation of longterm biperiden use on cognitive function and quality of life in schizophrenia. Progress in NeuroPsychopharmacology \& Biological Psychiatry, 35, 78-83.

Orosz, A., Feldon, J., Gal, G., Simon, A., \& Cattapan-Ludewig, K. (2007). Repeated measurements of learned irrelevance by a novel within-subject paradigm in humans. Behavioural Brain Research, 180, 1-3.

Orosz, A., Feldon, J., Gal, G., Simon, A., \& Cattapan-Ludewig, K. (2008). Deficient associative learning in drug-naive first-episode schizophrenia: Results obtained using a new visual within-subjects learned irrelevance paradigm. Behavioural Brain Research, 193, 101-107.

Orosz, A. T., Feldon, J., Simon, A. E., Hilti, L. M., Gruber, K., Yee, B. K., et al. (2011). Learned irrelevance and associative learning is attenuated in individuals at risk for psychosis but not in asymptomatic first-degree relatives of schizophrenia patients: Translational state markers of psychosis? Schizophrenia Bulletin, 37, 973-981.

Owen, F., Cross, A. J., Crow, T. J., Lofthouse, R., \& Poulter, M. (1981). Neurotransmitter receptors in brain in schizophrenia. Acta Psychiatrica Scandinavics Supplementum, 291, 20-28.

Pekkonen, E., Jaaskelainen, I. P., Kaakkola, S., \& Ahveninen, J. (2005). Cholinergic modulation of preattentive auditory processing in aging. Neurolmage, 27, 387-392.

Peters, N. L. (1989). Snipping the thread of life. Antimuscarinic side-effects of medications in the elderly. Archives of Internal Medicine, 149, 2414-2420.

Polich, J., \& Criado, J. R. (2006). Neuropsychology and neuropharmacology of P3a and P3b. International Journal of Psychophysiology, 60, 172-185. 
Rockstroh, B., Müller, M., Heinz, A., Wagner, M., Berg, T., \& Elbert, T. (1996). Modulation of auditory responses during oddball tasks. Biological Psychology, 43, 41-55.

Sarter, M., Lustig, C., \& Taylor, S. F. (2012). Cholinergic contributions to the cognitive symptoms of schizophrenia and the viability of cholinergic treatments. Neuropharmacology, 62, 1544-1553.

Scarr, E., Cowie, T. F., Kanellakis, S., Sundram, S., Pantelis, C., \& Dean, B. (2008). Decreased cortical muscarinic receptors define a subgroup of subjects with schizophrenia. Molecular Psychiatry, 14, 1017-1023.

Scarr, E., Sundram, S., Keriakous, D., \& Dean, B. (2007). Altered hippocampal muscarinic M4, but not M1, receptor expression from subjects with schizophrenia. Biological Psychiatry, 61, 1161-1170.

Schmajuk, N. (2005). Brain-behaviour relationships in latent inhibition: A computational model. Neuroscience \& Biobehavioral Reviews, 29, 1001-1020.

Semlitsch, H. V., Anderer, P., Schuster, P., \& Presslich, O. (1986). A solution for reliable and valid reduction of ocular artifacts, applied to the P300 ERP. Psychophysiology, 23, 695-703.

Sutton, S., Braren, M., \& Zubin, J. (1965). Evoked-potential correlates of stimulus uncertainty. Science, 150, 11871188.

Sutton, S., Tueting, P., Zubin, J., \& John, E. R. (1967). Information delivery and the sensory evoked potential. Science, 155, 1436-1439.

Suwazono, S., Machado, L., \& Knight, R. T. (2000). Predictive value of novel stimuli modifies visual event-related potentials and behavior. Clinical Neurophysiology, 111, 29-39.

Tandon, R., Shipley, J. E., Greden, J. F., Mann, N. A., Eisner, W. H., \& Goodson, J. (1991). Muscarinic cholinergic hyperactivity in schizophrenia: Relationship to positive and negative symptoms. Schizophrenia Research, 4, 2330.

Tandon, R., Taylor, S.F., DeQuardo, J.R., Eiser, A., Jibson, M.D., \& Goldman, M. (1999). The cholinergic system in schizophrenia reconsidered: Anticholinergic modulation of sleep and symptom profiles. Neuropsychopharmacology, 21, S189-S202.

Tune, L., Carr, S., Hoag, E., \& Cooper, T. (1992). Anticholinergic effects of drugs commonly prescribed for the elderly: Potential means for assessing risk of delirium. American Journal of Psychiatry, 149, 1393-1394.

Verleger, R. (1997). On the utility of P3 latency as an index of mental chronometry. Psychophysiology, 34, 131-156.

Watanabe, S., Nishikawa, T., Takashima, M., \& Toru, M. (1983). Increased muscarinic cholinergic receptors in prefrontal cortices of medicated schizophrenics. Life Sciences, 33, 2187-2196.

Weiner, I. (2003). The "two-headed" latent inhibition model of schizophrenia: Modeling positive and negative symptoms and their treatment. Psychopharmacology, 169, 257-297.

Wezenberg, E., Verkes, R. J., Sabbe, B. G., Ruigt, G. S., \& Hulstijn, W. (2005). Modulation of memory and visuospatial processes by biperiden and rivastigmine in elderly healthy subjects. Psychopharmacology, 181, 582-594.

White, P. M., \& Yee, C. M. (1997). Effects of attentional and stressor manipulations on the P50 gating response. Psychophysiology, 34, 703-711.

Young, A. M. J., Kumari, V., Mehtrotra, R., Hemsley, D. R., Andrew, C., Sharma, T., et al. (2005). Disruption of learned irrelevance in acute schizophrenia in a novel continuous within-subject paradigm suitable for fMRI. Behavioural Brain Research, 156, 277-288.

Zavitsanou, K., Katsifis, A., Mattner, F., \& Huang, X. (2004). Investigation of M1/M4 muscarinic receptors in the anterior cingulate cortex in schizophrenia, bipolar disorder, and major depression disorder. Neuropsychopharmacology, 29, 619-625. 


\section{CHAPTER 6}

\section{Cholinergic gating of hippocampal auditory evoked potentials in freely moving rats}

Klinkenberg, I., \& Sambeth A. (in press). Cholinergic gating of hippocampal auditory evoked potentials in freely moving rats. European Neuropsychopharmacology. 


\section{INTRODUCTION}

Sensory gating is thought to be essential for filtering out background information in order to allocate sufficient processing capacity for salient and/or more important stimuli (Miyazato et al., 1999). In humans, intact sensory gating is defined as a reduction in amplitude of the P50 peak to the second of two identical, consecutive auditory clicks presented $500 \mathrm{~ms}$ apart (S1: first click or conditioning stimulus, S2: second click or test stimulus: Boutros et al., 2004; Brockhaus-Dumke et al., 2008; Oranje et al., 2006). Perturbations in auditory filtering, such as disrupted sensory gating of the P50 and N100 components, appear to be a candidate trait marker of schizophrenia (Cadenhead et al., 2000; Olincy et al., 2010; Simons et al., 2011; but see De Wilde et al., 2007). Hence, there has been considerable interest in the development of translational rat models to elucidate the underlying neural and neurochemical mechanisms involved in sensory gating.

However, there is some debate as to which component(s) in the rat auditory evoked potential (AEP) is the analogue of the human P50 (de Bruin et al., 2001). The human P50 peak displays gating at an inter-stimulus interval of $500 \mathrm{~ms}$ and has been shown to be influenced by stimulus repetition; i.e., there is a gradual decrease in P50 amplitude with increasingly more paired-click trials, especially for S1 (e.g., Lamberti et al., 1993). Moreover, the P50 is dependent on the inter-stimulus interval; i.e., there is a progressive recovery of P50 amplitude of S2 with ISIs longer than $1 \mathrm{~s}$, thereby reducing sensory gating (e.g., Adler et al., 1982). The P50 is mediated by cholinergic signaling, as administration of the non-selective muscarinic antagonist scopolamine in human participants has been shown to reduce P50 amplitude or delay the occurrence of the P50 (Buchwald et al., 1991; Pekkonen et al., 2005). Therefore, these characteristics have been used as criteria for evaluating rat equivalents of the human P50. Several early positive and later-occurring negative peaks have been put forward, such as the P13 or P17, and the N22, N40 or N50, respectively (Adler et al., 1986; Boutros et al., 1997; de Bruin et al., 2001; Miyazato et al., 1996). The source of these discrepancies in peak latencies between labs remains elusive, but can likely be attributed to methodological differences between studies.

Several pharmacological studies in rats have indicated a role for muscarinic neurotransmission in auditory processing. For instance, Miyazato et al. (1995) have reported a reduction in P13 amplitude after systemic injections of the muscarinic antagonist scopolamine at doses of 0.2, 1 and $5 \mathrm{mg} / \mathrm{kg}$ (IP). Campbell et al. (1995) revealed that the amplitudes of P18 and N40 components to auditory stimuli were markedly decreased after systemic administration of scopolamine $(0.1-10 \mathrm{mg} / \mathrm{kg}, \mathrm{SC})$. These findings were extended by the study of Sambeth et al. (2007) which showed that the amplitudes of the N1 and N2 peaks became more negative but closer to baseline after scopolamine $(0.1 \mathrm{mg} / \mathrm{kg}, \mathrm{IP})$, which was not reversed by concurrent administration of donepezil $(3 \mathrm{mg} / \mathrm{kg}, \mathrm{IP})$. The authors concluded that this was due to a decrement in arousal induced by scopolamine. Two experiments have employed central infusion of scopolamine into discrete brain areas to determine effects on sensory gating. Teneud et al. (2000) showed that injections of the cholinergic agonist carbachol $(0.2,1$ or $5 \mathrm{mM}$ bilaterally) in the pedunculopontine nucleus reduced $\mathrm{P} 13$ amplitude in a dose- and time-dependent manner, which was reversed by concurrent administration of scopolamine (20 mM bilaterally). Luntz-Leybman et al. (1992) demonstrated decrements in N40 amplitude in the CA3 layer of the hippocampus after 
cerebroventricular infusion of nicotinic antagonists, but not the muscarinic antagonist scopolamine.

It is currently unclear which muscarinic receptor subtype(s) might underlie the effects of scopolamine on auditory processing. One of the brain regions showing inhibition of response to recurrent information is the hippocampus, which unsurprisingly has been strongly implicated in rat sensory gating (e.g., Bickford-Wimer et al., 1990; Bickford et al., 1993; Krause et al., 2003). It receives cholinergic innervations from the medial septal nucleus (Mesulam et al., 1983; Woolf et al., 1984) and shows an abundance of muscarinic receptors, especially of the $M_{1}$ subtype (see Chapter 2). Hence, blockade of the muscarinic $M_{1}$ receptor subtype might underlie the effects of scopolamine on auditory processing.

Therefore, the present study investigated the effects of the non-selective muscarinic antagonist scopolamine, the more selective muscarinic $M_{1}$ antagonist biperiden and the cholinesterase inhibitor donepezil (also in combination with scopolamine and biperiden) on AEPs and sensory gating. Based on previous studies we expected that after scopolamine, all AEP components would show reduced amplitudes and/or delayed latencies. Since biperiden is a relative specific muscarinic $M_{1}$ antagonist we anticipated a more selective effect on auditory processing. Thus, not all AEP peaks will be affected after biperiden. Effects of scopolamine and biperiden would be reversible by concurrent administration of donepezil.

\section{METHODS}

\section{Subjects}

All experimental procedures were approved by the local ethical committee for animal experiments at Maastricht University and met governmental guidelines. Fourteen 3-month old male Wistar rats (Harlan, NL) served as subjects in this study. They were housed in pairs in standard type III Makrolon ${ }^{\text {TM }}$ cages on sawdust bedding in an air-conditioned room $\left(21^{\circ} \mathrm{C}\right.$, 45-55\% humidity) under a reversed light/dark cycle (lights on from 5 PM to 5 AM). After surgery, animals were singly housed in cages with a flat top which are normally used for individually ventilated conditions. This was done in order to ensure that the rats would not damage their electrodes. Rats were housed in the room in which they were tested. All testing was performed between 9 AM and 5 PM. The animals had unlimited access to food and water.

\section{Surgical procedures and EEG recording}

Rats were injected subcutaneously with the analgesic drug Temgesic $(0.1 \mathrm{mg} / \mathrm{kg})$. Next, rats were anesthetized with inhalation of isoflurane and placed into a stereotaxic frame. After making a vertical incision and exposing the skull, lidocaïne was used as a local anesthetic before removing the periosteum. Subsequently, the bregma intersection was used as a landmark in order to determine the electrode position corresponding to the dorsal hippocampus (anterior-posterior -2.8, medial-lateral -1.8, dorsal-ventral -2.6). Small holes were drilled in the skull to allow the insertion of electrodes. The reference and ground electrodes were placed in the cerebellum. In order to fixate the electrode on the skull surface three screws and dental acrylic cement were used. The animals were allowed three weeks to recover from surgery. 
During the next two weeks, the rats were habituated to the experimental procedures - i.e., the test chamber, the EEG acquisition system, the paired-click task and drug administration - before actual drug testing took place. During those habituation sessions the EEG signal was visually monitored for any abnormalities. EEG was always recorded from unrestrained, alert rats. The EEG was filtered between 1 and $133 \mathrm{~Hz}$ and sampled at $1000 \mathrm{~Hz}$. The animals underwent a total of nine testing sessions; we tested saline, scopolamine and biperiden twice, whereas donepezil, scopolamine-donepezil and biperiden-donepezil were tested once. Each session started with the injection of the drugs. Thirty min. later, the rats were attached to the EEG equipment and EEG was visually checked. Two test chambers with EEG equipment were at our disposal; therefore two rats could be tested simultaneously.

\section{Paired-click task}

The paired-click task was used as an electrophysiological technique to assess sensory gating mechanisms (Adler et al., 1982). Two identical $2500 \mathrm{~Hz}$ clicks (S1 and S2) were binaurally presented via loudspeakers. The duration of each click was $4 \mathrm{~ms}$ with a sound intensity of $80 \mathrm{~dB}$. A short inter-stimulus interval of $500 \mathrm{~ms}$ was used, as this inter-stimulus interval has been shown to provide maximum differentiation between the sensory gating capacities of healthy participants and schizophrenia patients (Nagamoto et al., 1989; Oranje et al., 2006). The pairs were presented in a random intertrial interval of 6-10 s, in order to allow neuronal recovery (Zouridakis \& Boutros, 1992). During each session 70 pairs of clicks were presented. No behavioral measures were recorded during this task.

\section{Drug administration}

Please refer to Table 1 for information on drug administration. Doses and pretreatment time were chosen based on previous scopolamine and biperiden data (see Chapter $\mathbf{3}$ and Sambeth et al., 2007). The order of doses was semi-randomized over testing days. All animals received the same treatment condition in a test session. Saline, scopolamine and biperiden were tested twice on separate testing days, whereas donepezil and the combination treatments were tested only once. Drug solutions were prepared freshly each day prior to testing. Test leaders were not blinded for the treatment conditions, as they could not influence the data (i.e., only EEG recording, no behavioral data).To ensure sufficient washout of the drug, testing days were always separated by at least one drug-free day (for halflives please refer to Legault et al., 2004; Yokogawa et al., 1992).

\section{EEG data analysis}

All EEG data was analyzed with Vision Analyzer 2.0. Before data analysis, the EEG data were visually inspected offline, to check for artefacts. The EEG signal was filtered offline with a high pass filter set at $1 \mathrm{~Hz}$ ( $12 \mathrm{~dB}$ slope) and a low pass filter set at $30 \mathrm{~Hz}$ ( $12 \mathrm{~dB}$ slope). AEP epochs were set from $100 \mathrm{~ms}$ prior to stimulus onset to $500 \mathrm{~ms}$ after onset. After manual artefact rejection, separate averages were calculated for each rat, stimulus, and treatment condition. Based on the grand averages we determined the position of the P1, N1 and P2 peaks for S1 and S2. Peak amplitudes and latencies were calculated based on when the peak was reached. Please see Table 2 for the time windows chosen for peak detection. 
Table 1. Drug administration.

\begin{tabular}{|c|c|c|c|c|c|c|}
\hline Drug & Supplier & Vehicle & $\begin{array}{l}\text { Pretreat- } \\
\text { ment time }\end{array}$ & $\begin{array}{l}\text { Admini- } \\
\text { stration } \\
\text { route }\end{array}$ & $\begin{array}{l}\text { Volume } \\
(\mathrm{mL} / \mathrm{kg})\end{array}$ & $\begin{array}{l}\text { Dose } \\
\text { conditions } \\
(\mathrm{mg} / \mathrm{kg})\end{array}$ \\
\hline $\begin{array}{l}\text { Scopolamine } \\
\text { hydrobromide } \\
\text { trihydrate } 99 \%\end{array}$ & Acros Organics & Isotonic saline & $30 \mathrm{~min}$. & IP & 1 & 0.1 \\
\hline $\begin{array}{l}\text { Biperiden lactate } \\
\text { (Akineton }{ }^{\circledR} \text { ) }\end{array}$ & $\begin{array}{l}\text { Laboratorio } \\
\text { Farmaceutico } \\
\text { S.I.T. }\end{array}$ & $\begin{array}{l}\text { Milli-Q purified } \\
\text { water }\end{array}$ & $30 \mathrm{~min}$. & IP & 1 & 1 \\
\hline $\begin{array}{l}\text { Donepezil } \\
\text { (Aricept }^{\circledR} \text { ) }\end{array}$ & Apin chemicals & $\begin{array}{l}\text { Milli-Q purified } \\
\text { water }\end{array}$ & $30 \mathrm{~min}$. & $\mathrm{PO}$ & 2 & 3 \\
\hline
\end{tabular}

Table 2. Time windows (in ms) used for analysis of the AEP data.

\begin{tabular}{|c|c|c|c|c|c|c|}
\hline \multirow[b]{2}{*}{ Peaks } & \multicolumn{6}{|c|}{ Drug condition } \\
\hline & Saline & Scopolamine & Biperiden & Donepezil & $\begin{array}{l}\text { Scopolamine- } \\
\text { Donepezil }\end{array}$ & $\begin{array}{l}\text { Biperiden- } \\
\text { Donepezil }\end{array}$ \\
\hline $\mathrm{P} 1$ & $10-50$ & $10-50$ & $10-50$ & $10-50$ & $10-40$ & $10-50$ \\
\hline N1 & $20-70$ & $20-70$ & $30-80$ & $30-80$ & $30-80$ & $20-70$ \\
\hline P2 & $50-100$ & $60-100$ & $50-110$ & $50-100$ & $50-100$ & $50-100$ \\
\hline
\end{tabular}

\section{Statistics}

In some cases a particular peak was missing in the AEP data. In order to be able to do repeated measures ANOVAs, we replaced missing values with the average of rats that did show that peak. In the case of two testing days (i.e., for saline, scopolamine and biperiden) the data were averaged before statistical analysis. All data were analyzed using SPSS.

In order to determine whether there was intact sensory gating, AEP data of the saline condition were analyzed with repeated measures ANOVAs with Stimulus (2 levels: S1 and S2) as within-subject variable. Next, we wanted to assess the effects of scopolamine and donepezil on sensory gating. Therefore we performed several repeated measures ANOVAs with Drug (4 levels: saline, scopolamine, donepezil, and scopolamine-donepezil) and Stimulus (2 levels: S1 and S2) as within-subject variables. Finally, we wanted to assess the effects of biperiden and donepezil on sensory gating. Therefore we did several repeated measures ANOVAs with Drug (4 levels: saline, biperiden, donepezil, and biperiden-donepezil) and Stimulus (2 levels: S1 and S2) as within-subject variables.

All analyses were done separately for amplitude and latency, and for each of the AEP components (i.e., P1, N1 and P2). Significant interactions between Treatment and Stimulus would be reflective of a Treatment effect on sensory gating. In this case we performed additional ANOVAs split for each level of Stimulus (i.e., S1 vs. S2) in order to examine simple effects. For reasons of brevity, we decided to not discuss main effects of Stimulus in the $4 \times 2$ Treatment analyses, as these effects were already covered by analyses on the saline data with respect to the effect of Stimulus. Post-hoc analyses were performed with a Least Significant Difference (LSD) test; we decided to only focus on treatment effects relative to the saline condition. 


\section{RESULTS}

Five rats lost their electrodes prematurely and/or did not have a clear EEG signal. These were eliminated from the final analysis, leaving a total of 9 rats.

\section{Stimulus effects in the saline condition on AEPs and sensory gating}

Figure 1 shows an overview of the effects of scopolamine, biperiden, donepezil and the combined treatments on hippocampal processing of auditory stimuli. In the analyses of the saline data, there was no main effect of Stimulus on P1 or P2 amplitude (no main effect of Stimulus; $F s<2.59$, n.s.). N1 amplitude was larger for S1 compared to S2 (main effect of Stimulus; $F(1,8)=5.78, P<0.05)$. As for the latency data, there was no main effect of Stimulus on P1 or P2 latency (no main effect of Stimulus; $F s<2.78$, n.s.). N1 latency was slowed for S1 compared to S2 (main effect of Stimulus; $F(1,8)=6.88, P<0.05$ ).

\section{Effects of scopolamine, donepezil and the combination treatment on AEPs and sensory gating}

The treatment analyses of P1 or P2 amplitude did not yield any relevant effects ( $F s<2.98$, n.s.). An overview of the effects of scopolamine, biperiden, donepezil and the combination treatments on $\mathrm{N} 1$ amplitude is shown in Figure 2. The effect of Treatment on N1 amplitude varied per level of Stimulus (Treatment $*$ Stimulus interaction effect; $F(3,24)=11.88, P<$ 0.001 ). Therefore we performed simple effects analysis per level of Stimulus. In the analysis of S1, N1 amplitude was shown to be different between treatment conditions (main effect of Treatment; $F(3,24)=5.77, P<0.01$ ); post-hoc analysis indicated that the $\mathrm{N} 1$ amplitude of the $\mathrm{S} 1$ stimulus was larger after donepezil $(P<0.01)$ and scopolamine-donepezil $(P<0.01)$ compared to the saline condition. In the analysis of S2, N1 amplitude was also different between treatment conditions (main effect of Treatment; $F(3,24)=5.26 P<0.01$ ); post-hoc analysis indicated that the $\mathrm{N} 1$ amplitude of the $\mathrm{S} 2$ stimulus was larger after scopolamine $(P$ $<0.001)$ and smaller after donepezil $(P<0.01)$ compared to saline.

The effect of Treatment on P1 latency did not vary per level of Stimulus (no Treatment

* Stimulus interaction effect; $F(3,24)=2.39$, n.s.). P1 latency was shown to be different between treatment conditions (main effect of Treatment; $F(3,24)=4.40, P<0.05$ ); post-hoc analysis indicated that $\mathrm{P} 1$ latency was smaller after scopolamine compared to saline $(P<$ 0.05). In the analysis of $\mathrm{N} 1$ latency, the effect of Treatment varied per level of Stimulus (Treatment $*$ Stimulus interaction effect; $F(3,24)=4.49, P<0.05$ ). Therefore we performed simple effects analyses per level of Stimulus. In the analysis of $S 1$, there was no main effect of Treatment on N1 latency $(F(3,24)=1.98$, n.s.). In the analysis of S2, N1 latency was shown to be different between treatment conditions (main effect of Treatment; $F(3,24)=$ $3.58 P<0.05)$; post-hoc analysis indicated that the N1 latency of the S2 stimulus was larger after scopolamine compared to saline $(P<0.05)$. The effect of Treatment on $\mathrm{P} 2$ latency did not differ per level of Stimulus (no Treatment * Stimulus interaction effect; $F(3,24)=1.09$, n.s.). P2 latency was shown to be different between treatment conditions (main effect of Treatment; $F(3,24)=5.37 P<0.01)$; post-hoc analysis indicated that $\mathrm{P} 2$ latency was larger after scopolamine $(P<0.05)$ and after scopolamine-donepezil $(P<0.01)$ compared to saline. 
a

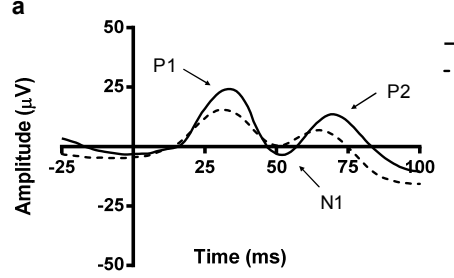

b

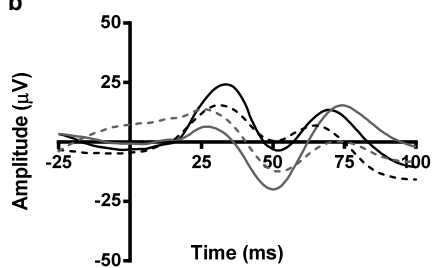

c

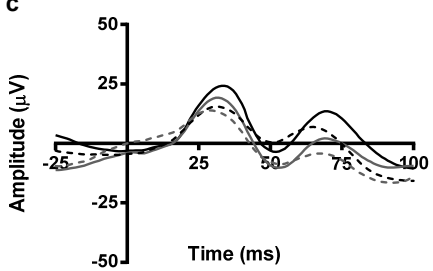

d

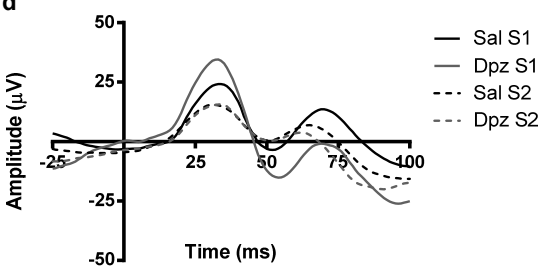

e

- Sal S1

- Scop S1

-.. Sal S2

-.. Scop S2

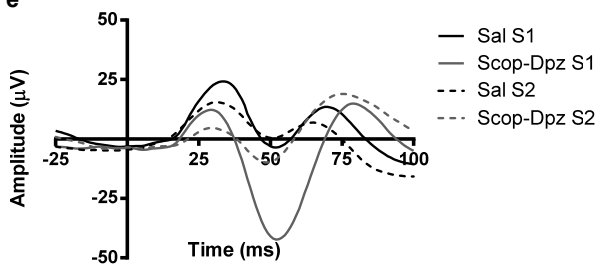

f

- Sal S1

- Bip S1

-.. Sal S2

... Bip S2
- Sal S1

- Bip-Dpz S1

-.. Sal S2

-.. Bip-Dpz S2

Figure 1. The effects of the treatment conditions on hippocampal processing of auditory stimuli. Amplitude effects: (a) After saline, N1 amplitude was larger for the S1 compared to the S2 stimulus. (b) There was a Treatment*Stimulus interaction in the analysis of the N1 amplitude data. N1 amplitude of the S2 stimulus was increased after scopolamine, which reflects a reduction in sensory gating. (c) Biperiden increased the N1 amplitude of the S2 stimulus, suggestive of a reduction in sensory gating. (d) After donepezil, N1 amplitude of the S1 stimulus was increased, whereas N1 amplitude of the S2 stimulus was reduced. This finding would suggest that donepezil increases sensory gating at the N1 peak. (e) Scopolamine-donepezil induced an increase in $\mathrm{N} 1$ amplitude of the S1 stimulus, which reflects an increase in sensory gating. (f) Biperidendonepezil did not affect auditory processing. Latency effects: (a) After saline, N1 latency was larger for the S1 compared to the S2 stimulus. (b) After scopolamine, the occurrence of the P1 peak was earlier compared to the saline condition. Scopolamine also increased the N1 latency of the S2 stimulus and P2 latency of both stimulus types. (c, d, e, f) Biperiden, donepezil, scopolamine-donepezil and biperiden-donepezil did not affect peak latencies.

\section{Effects of biperiden, donepezil and the combination treatment on AEPs and sensory gating}

The effect of Treatment on P1 amplitude did not differ per level of Stimulus (no Treatment * Stimulus interaction effect; $F(3,24)=0.27$, n.s.). There was a main effect of Treatment $(F(3,24)=4.87, P<0.01)$; however, post-hoc analysis did not yield any significant effects. In the analysis of N1 amplitude, the effect of Treatment varied per level of Stimulus (Treatment $*$ Stimulus interaction effect; $F(3,24)=9.90, P<0.001$ ). Therefore we performed simple effects analysis per level of Stimulus. In the analysis of S1, N1 amplitude was shown to be different between treatment conditions (main effect of Treatment; post-hoc analysis indicated that the $\mathrm{N} 1$ amplitude of the $\mathrm{S} 1$ stimulus was larger after donepezil compared to saline $(P<0.01)$. In the analysis of S2, N1 amplitude was shown to be different between treatment conditions (main effect of Treatment; $F(3,24)=13.44 P<0.001$ ); post-hoc analysis indicated that the N1 amplitude of the S2 stimulus was larger after biperiden $(P<0.001)$ 
and smaller after donepezil $(P<0.05)$ compared to saline. The treatment analysis of P2 amplitude, $\mathrm{P} 1$ latency or $\mathrm{P} 2$ latency did not yield any relevant interaction or main effects ( $F S$ $<1.72$, n.s.). In the analysis of $\mathrm{N} 1$ latency there was a main effect of Treatment $(F(3,24)=$ $3.30, P<0.05)$; however, post-hoc analysis did not yield any significant effects.

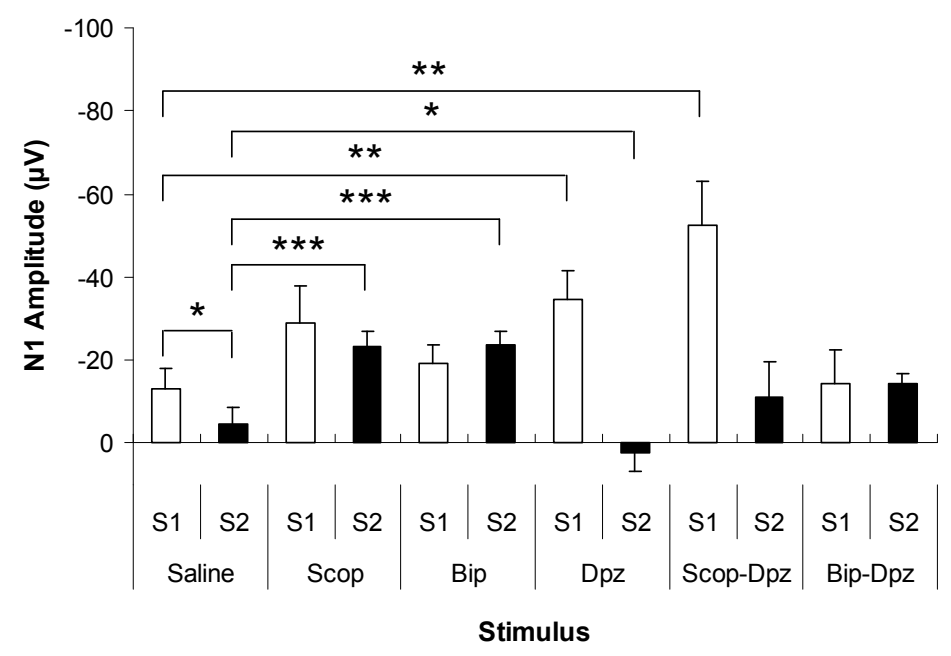

Figure 2. Effects of the treatment and stimulus conditions on $\mathrm{N} 1$ amplitude. Both scopolamine and biperiden disrupted sensory gating by increasing N1 amplitude of the S2 stimulus. Scopolamine-donepezil increased N1 amplitude of S1. This likely reflects an underlying effect of donepezil, also given the fact that donepezil by itself improved sensory gating by enhancing N1 amplitude of S1, and reducing N1 amplitude of the S2 stimulus. Moreover, after scopolamine-donepezil N1 amplitude of the S2 stimulus was similar to the saline condition, reflecting a reversal of the effects of scopolamine by donepezil. After the biperiden-donepezil combination treatment, N1 amplitude was statistically similar to the saline condition, reflecting a reversal of the effects of biperiden by donepezil.

\section{DISCUSSION}

The goal of the current study was to assess the effects of the muscarinic antagonists scopolamine and biperiden, and the cholinesterase inhibitor donepezil on auditory processing and sensory gating. In Table 3 an overview is given of the effects of our treatment conditions.

\section{Summary of results}

In the present study we saw a clear sensory gating effect at the N1 component in the saline condition. Specifically, there was a relative decrease of $\mathrm{N} 1$ amplitude to the second click (S2) compared with the first (S1), which is a measure of sensory gating. The P1 and P2 peaks did not show any sensory gating effects. This would make the N1 component a probably candidate as the rat equivalent of human sensory gating.

Scopolamine disrupted sensory gating of the N1 component (i.e., there was a Treatment * Stimulus interaction). A closer look at the data revealed that an increase in N1 am- 
plitude of the S2 stimulus relative to the saline condition was responsible for this effect. Scopolamine combined with donepezil enhanced sensory gating by increasing the $\mathrm{N} 1 \mathrm{am}$ plitude of S1. N1 amplitude of the S2 stimulus was unchanged relative to saline after scopolamine-donepezil. The former finding is likely due to an underlying effect of donepezil, also given the fact that donepezil by itself (i.e., without add-on treatment with a muscarinic antagonist) improved sensory gating by enhancing $\mathrm{N} 1$ amplitude to S1, and by decreasing $\mathrm{N} 1$ amplitude to the S2 stimulus. The lack of effect on the S2 stimulus after the combination treatment is likely reflective of a reversal of the scopolamine-induced increment in N1 amplitude of the S2 stimulus by donepezil. Scopolamine did not affect P1 or P2 amplitude.

As expected, biperiden had much more selective effects on auditory processing. It impaired sensory gating by increasing the $\mathrm{N} 1$ amplitude of the S2 stimulus (i.e., we found a Treatment * Stimulus interaction), which was fully reversed by concurrent administration of donepezil. The biperiden-donepezil combination treatment also did not influence N1 amplitude of S1. Biperiden did not influence P1 or P2 amplitude.

There were also several latency effects. In the saline condition, N1 latency was faster for S2 relative to the S1 stimulus. After scopolamine, P1 latency was decreased, which was reversed by concurrent administration of donepezil. Scopolamine also slowed N1 latency of the $\mathrm{S} 2$ stimulus relative to the saline condition, which was reversed by concurrent administration of donepezil. Lastly, P2 latency was increased after scopolamine. This was also the case for the combination treatment, which implies that donepezil was unable to reverse the effects of scopolamine on P2 latency. Biperiden did not influence peak latencies.

In sum, scopolamine induced widespread effects on auditory processing besides affecting sensory gating at the $\mathrm{N} 1$ component. Donepezil was also not able to completely counteract all these effects. In contrast, biperiden only influenced sensory gating at the N1 peak, which was fully reversed by concurrent donepezil administration. These findings are in line with the binding affinities of scopolamine and biperiden for muscarinic receptors (i.e., nonselective versus relatively selective for the muscarinic $M_{1}$ receptor subtype, Bolden et al., 1992; Katayama et al., 1990). Furthermore, our results strongly suggest that biperiden is to be preferred over scopolamine as a means for pharmacologically inducing cholinergic impairments in auditory processing in healthy rats.

\section{Effects of cholinergic drugs on AEPs in rats}

The findings of the current study are in contrast with those reported in the literature. Several articles have demonstrated a reduction in peak amplitude of early positive, but not negative components after scopolamine (Miyazato et al., 1995; Teneud et al., 2000). However, Campbell et al. (1995) found that scopolamine induced a decrement in amplitudes of both P18 and N40 peaks, which was more pronounced for the latter than the former component. Moreover, Luntz-Leybman et al. (1992) reported no effect of scopolamine on N40 gating. There are several methodological differences which might explain the discrepancies in findings between these experiments. 
Table 3. Treatment effects on AEPs and sensory gating. In case of the saline condition, a comparison is made between S1 and S2. Drug effects are always compared to the saline condition. Treat*Stim reflects an interaction effect, which implies that a particular drug influences sensory gating. In this case, drug effects are presented as simple effects (i.e., per level of Stimulus).

\begin{tabular}{|c|c|c|c|c|c|c|}
\hline \multirow[b]{3}{*}{$\begin{array}{l}\text { Treatment } \\
\text { conditions }\end{array}$} & \multicolumn{6}{|l|}{ Peaks } \\
\hline & \multicolumn{2}{|l|}{ P1 } & \multicolumn{2}{|l|}{ N1 } & \multicolumn{2}{|l|}{ P2 } \\
\hline & Amplitude & Latency & Amplitude & Latency & Amplitude & Latency \\
\hline Saline & n.s. & n.s. & $\begin{array}{l}\mathrm{S} 1>\mathrm{S} 2 \\
(P<0.05)\end{array}$ & $\begin{array}{l}\mathrm{S} 1>\mathrm{S} 2 \\
(P<0.05)\end{array}$ & n.s. & n.s. \\
\hline Scopolamine & n.s. & $\begin{array}{l}\downarrow \\
(P<0.05)\end{array}$ & $\begin{array}{l}\text { SG } \downarrow \\
\text { (Treat*Stim) } \\
\text { S1: n.s. } \\
\text { S2: } \uparrow \\
(P<0.001)\end{array}$ & $\begin{array}{l}\text { (Treat*Stim) } \\
\text { S1: n.s. } \\
\text { S2: } \uparrow \\
(P<0.05)\end{array}$ & n.s. & $\begin{array}{l}\uparrow \\
(P<0.05)\end{array}$ \\
\hline $\begin{array}{l}\text { Scopolamine- } \\
\text { donepezil }\end{array}$ & n.s. & n.s. & $\begin{array}{l}\text { SG } \uparrow \\
\text { (Treat*Stim) } \\
\text { S1: } \uparrow \\
(P<0.01) \\
\text { S2: n.s. }\end{array}$ & n.s. & n.s. & $\begin{array}{l}\uparrow \\
(P<0.01)\end{array}$ \\
\hline Biperiden & n.s. & n.s. & $\begin{array}{l}\text { SG } \downarrow \\
\text { (Treat*Stim) } \\
\text { S1: n.s. } \\
\text { S2: } \uparrow \\
(P<0.001)\end{array}$ & n.s. & n.s. & n.s. \\
\hline $\begin{array}{l}\text { Biperiden- } \\
\text { donepezil }\end{array}$ & n.s. & n.s. & n.s. & n.s. & n.s. & n.s. \\
\hline Donepezil & n.s. & n.s. & $\begin{array}{l}\text { SG } \uparrow \\
\text { (Treat*Stim) } \\
\text { S1: } \\
(P s<0.01) \\
\text { S2: } \downarrow \\
(P s<0.05)\end{array}$ & n.s. & n.s. & n.s. \\
\hline
\end{tabular}

Abbreviations: Amp: Amplitude, Lat: Latency, SG: sensory gating, Stim: Stimulus, Treat: Treatment, $\uparrow:$ increased, $\downarrow$ : decreased, n.s.: not significant. 
Firstly, we recorded EEG from freely moving rats receiving systemic injections of cholinergic drugs, whereas Luntz-Leybman et al. (1992) and Miyazato et al. (1995) used recordings from anesthetized animals in which scopolamine was injected centrally (i.e., in the lateral ventricle and in the pedunculopontine nucleus, respectively). Anesthetic drugs are likely to interact with the effects of muscarinic antagonists on auditory processing. In addition, it has been shown previously that motor behavior increases acetylcholine levels in the hippocampus (Dudar et al., 1979). Hence, hippocampal AEP recordings in freely moving animals might differ from those of immobile, anesthetized animals in terms of baseline cholinergic tone and might therefore also respond differently to disruption by anti-muscarinic agents. Moreover, systemic and central administration of drugs is not fully comparable in terms of effects on behavior and EEG. Systemic injections also induce peripheral side-effects, caused by binding of a drug outside of the central nervous system (see Chapter 2 ).

Secondly, different recording sites were used for our study and those previously reported in the literature (Campbell et al., 1995; Luntz-Leybman et al., 1992; Miyazato et al., 1995; Teneud et al., 2000). We measured EEG in the dorsal hippocampus, whereas previous studies have used area CA3 in the ventral hippocampus (Luntz-Leybman et al., 1992), the pedunculopontine nucleus (Teneud et al., 2000) or the vertex (Campbell et al., 1995; Miyazato et al., 1995) as recording sites. These brain areas comprise distinct parts of the cholinergic system (Mesulam et al., 1983; Woolf \& Butcher, 1986; Woolf et al., 1984) and might therefore be differentially sensitive to effects of (anti-)muscarinic drugs on auditory processing due to regional diversity in cholinergic innervation. In addition, within the hippocampus the muscarinic $M_{1}$ receptor has been shown to be enriched in dorsal versus ventral sites (i.e., area CA1 compared to CA3: Levey et al., 1995). The fact that in the current study we have used a muscarinic $M_{1}$ receptor antagonist and have measured AEPs in a brain region especially dense in muscarinic $M_{1}$ receptors might have contributed to the discrepancies between the current study and those reported in the literature (Campbell et al., 1995; Luntz-Leybman et al., 1992; Miyazato et al., 1995; Teneud et al., 2000). That is, blockade of muscarinic $\mathrm{M}_{2}-\mathrm{M}_{5}$ receptors might be partly responsible for the effects of scopolamine on auditory processing in previous studies. This is also the reason why a more selective muscarinic antagonist such as biperiden is preferable over scopolamine in order to be able to attribute changes in AEP components to blockade of particular muscarinic receptor subtype(s).

Of note, the study by Sambeth et al. (2007) was comparable to the current one in terms of experimental setup. They also recorded AEPs from the dorsal hippocampus in free-moving Wistar rats and used the same doses for scopolamine and donepezil. Scopolamine $(0.1 \mathrm{mg} / \mathrm{kg}$, IP) made the $\mathrm{N} 1$ amplitude more negative, which was in line with our own findings. However, the authors concluded that the N1 became closer to baseline after scopolamine. Concurrent administration of donepezil $(3 \mathrm{mg} / \mathrm{kg}, \mathrm{IP})$ failed to reverse these effects.

\section{Effects of cholinergic drugs on AEPs in humans}

Human studies on sensory gating have generally reported quite contradicting findings. For instance, Buchwald et al. (1991) and Pekkonen et al. (2005) demonstrated reduced amplitudes and/or delayed latencies of the P50 and N100 components after scopolamine. Buchwald et al. (1991) also demonstrated a reversal of the scopolamine-induced decrease in P50 amplitude by concurrent administration of physostigmine. Another study from our lab 
assessed whether biperiden and the cholinesterase inhibitor rivastigmine would influence sensory gating and mismatch negativity (MMN: see Chapter 7). Biperiden and a combination treatment of biperiden and rivastigmine both increased P50 amplitude relative to the saline condition. The latter was likely caused by an underlying effect of biperiden, also given the fact that rivastigmine alone left the P50 unchanged. There was no effect of biperiden or rivastigmine on sensory gating. Furthermore, in the same study N100 and P200 latency was delayed after biperiden, which was reversed by rivastigmine. In contrast to the current findings, biperiden did not affect the amplitude of early negative peaks.

\section{Cholinergic drugs as a model for auditory processing and sensory gating deficits in schizophrenia}

In sum, data on the effects of cholinergic drugs on auditory processing and sensory gating in rats and healthy participants are not very straightforward, which can be partly explained by species and/or methodological differences between experiments. Overall, muscarinic antagonists and cholinesterase inhibitors appear to mainly affect early positive and negative peaks in the AEP. Moreover, they influence sensory gating in the rat, but not in healthy human participants. However, the question remains whether cholinergic drugs would be useful as a translational model for aberrant auditory processing in schizophrenia. Although impairments in sensory gating are not reported consistently in schizophrenia (e.g., Jin et al., 1997; 1998; Kathmann \& Engel, 1990), the main finding is that suppression deficits can be attributed to a reduction of the P50 and N100 response to S1 (e.g., Brockhaus-Dumke et al., 2008; but see Jin et al., 1997; Patterson et al., 2000). These reports are hard to relate to our own results of disrupted sensory gating due to increased N1 amplitude of the S2 stimulus after scopolamine and biperiden.

However, the validity of auditory perturbations as an endophenotype for schizophrenia has been questioned. For instance, there are indications that auditory processing deficits might be a state instead of a trait marker (e.g., Bramon et al., 2004; Nagamoto et al., 1996). In addition, the specificity of auditory processing deficits in schizophrenia is not very high. In aging and age-related disorders such as mild cognitive impairment and Alzheimer's disease, an increase in amplitudes of early AEP components (Golob et al., 2001; Irimajiri et al., 2005) and reduced sensory gating due to an increase in P50 amplitude of the S2 click has been reported (Cancelli et al., 2006; Jessen et al., 2001; Thomas et al., 2010; but see Buchwald et al., 1989; Fein et al., 1994). These findings are thus much more in line with our current results of increased N1 amplitudes induced by scopolamine and biperiden. Therefore, we would like to suggest that changes in auditory processing and sensory gating induced by cholinergic drugs may serve as a translational model for aging instead of schizophrenia. For future research, it would be interesting to determine possible dissociations between drugs that target different muscarinic receptor subtypes in terms of their effects on auditory processing and the relation with cognitive functions. The present study suggests that this may be relevant for aging and/or Alzheimer's dementia but probably not for schizophrenia. 


\section{REFERENCES}

Adler, L. E., Pachtman, E., Franks, R. D., Pecevich, M., Waldo, M. C., \& Freedman, R. (1982). Neurophysiological evidence for a defect in neuronal mechanisms involved in sensory gating in schizophrenia. Biological Psychiatry, 17, 639-654.

Adler, L. E., Rose, G., \& Freedman, R. (1986). Neurophysiological studies of sensory gating in rats: effects of amphetamine, phencyclidine, and haloperidol. Biological Psychiatry, 21, 787-798.

Bickford-Wimer, P. C., Nagamoto, H., Johnson, R., Adler, L. E., Egan, M., Rose, G. M., et al. (1990). Auditory sensory gating in hippocampal neurons: a model system in the rat. Biological Psychiatry, 27, 183-192.

Bickford, P. C., Luntz-Leybman, V., \& Freedman, R. (1993). Auditory sensory gating in the rat hippocampus: modulation by brainstem activity. Brain Research, 607, 33-38.

Boutros, N. N., Bonnet, K. A., Millana, R., \& Liu, J. (1997). A parametric study of the $\mathrm{N} 40$ auditory evoked response in rats. Biological Psychiatry, 42, 1051-1059.

Boutros, N. N., Korzyukov, O., Jansen, B., Feingold, A., \& Bell, M. (2004). Sensory gating deficits during the midlatency phase of information processing in medicated schizophrenia patients. Psychiatry Research, 126, 203215.

Bramon, E., Croft, R. J., McDonald, C., Virdi, G. K., Gruzelier, J. G., Baldeweg, T., et al. (2004). Mismatch negativity in schizophrenia: a family study. Schizophrenia Research, 67, 1-10.

Brockhaus-Dumke, A., Schultze-Lutter, F., Mueller, R., Tendolkar, I., Bechdolf, A., Pukrop, R., et al. (2008). Sensory gating in schizophrenia: P50 and N100 gating in antipsychotic-free subjects at risk, first-episode, and chronic patients. Biological Psychiatry, 64, 376-384.

Buchwald, J. S., Erwin, R. J., Read, S., Van Lancker, D., \& Cummings, J. L. (1989). Midlatency auditory evoked responses: differential abnormality of P1 in Alzheimer's disease. Electroencephalography and Clinical Neurophysiology, 74, 378-384.

Buchwald, J. S., Rubinstein, E. H., Schwafel, J., \& Strandburg, R. J. (1991). Midlatency auditory evoked responses: differential effects of a cholinergic agonist and antagonist. Electroencephalography and Clinical Neurophysiology, 80, 303-309.

Cadenhead, K. S., Light, G. A., Geyer, M. A., \& Braff, D. L. (2000). Sensory gating deficits assessed by the P50 eventrelated potential in subjects with schizotypal personality disorder. American Journal of Psychiatry, 157, 55-59.

Campbell, K. A., Kalmbacher, C. E., Specht, C. D., \& Gregg, T. R. (1995). Dependence of rat vertex auditory evoked potentials on central muscarinic receptor activation. Brain Research, 702, 110-116.

Cancelli, I., Cadore, I. P., Merlino, G., Valentinis, L., Moratti, U., Bergonzi, P., et al. (2006). Sensory gating deficit assessed by $\mathrm{P} 50 / \mathrm{Pb}$ middle latency event related potential in Alzheimer's disease. Journal of Clinical Neurophysiology, 23, 421-425.

de Bruin, N. M. W. J., Ellenbroek, B.A., Van Schaijk, W.J., Cools, A.R., Coenen, A.M.L., \& Van Luijtelaar, E.L.J.M. (2001). Sensory gating of auditory evoked potentials in rats: Effects of repetitive stimulation and the interstimulus interval. Biological Psychology, 55, 195-213.

De Wilde, O. M., Bour, L. J., Dingemans, P. M., Koelman, J. H. T. M., \& Linszen, D. H. (2007). Failure to find P50 suppression deficits in young first-episode patients with schizophrenia and clinically unaffected siblings. Schizophrenia Bulletin, 33, 1319-1323.

Dudar, J. D., Wishaw, I. Q., \& Szerb, J. C. (1979). Release of acetylcholine from the hippocampus of freely moving rats during sensory stimulation and running. Neuropsychopharmacology, 18, 673-678.

Fein, G., Biggins, C., \& Van Dyke, C. (1994). The auditory P50 response is normal in Alzheimer's disease when measured via a paired click paradigm. Electroencephalography and Clinical Neurophysiology, 92, 536-545.

Golob, E. J., Johnson, J. K., \& Starr, A. (2001). Auditory event-related potentials during target detection are abnormal in mild cognitive impairment. Clinical Neurophysiology, 113, 151-161.

Irimajiri, R., Golob, E. J., \& Starr, A. (2005). Auditory brain-stem, middle- and long-latency evoked potentials in mild cognitive impairment. Clinical Neurophysiology, 116, 1918-1929.

Jessen, F., Kucharski, C., Fries, T., Papassotiropoulos, A., Hoenig, K., Maier, W., et al. (2001). Sensory gating deficit expressed by a disturbed suppression of the P50 event-related potential in patients with Alzheimer's disease. American Journal of Psychiatry, 158, 1319-1321.

Jin, Y., Bunney Jr., W. E., Sandman, C. A., Patterson, J. V., Fleming, K., Moenter, J. R., et al. (1998). Is P50 suppression a measure of sensory gating in schizophrenia? Biological Psychiatry, 43, 873-878.

Jin, Y., Potkin, S. G., Patterson, J. V., Sandman, C. A., Hetrick, W. P., \& Bunney, W. E., Jr. (1997). Effects of P50 temporal variability on sensory gating in schizophrenia. Psychiatry Research, 70, 71-81.

Kathmann, N., \& Engel, R. R. (1990). Sensory gating in normals and schizophrenics: a failure to find strong P50 suppression in normals. Biological Psychiatry, 27, 1216-1226. 
Krause, M., Hoffmann, W. E., \& Hajos, M. (2003). Auditory sensory gating in hippocampus and reticular thalamic neurons in anesthetized rats. Biological Psychiatry, 53, 244-253.

Lamberti, J. S., Schwarzkopf, S. B., Boutros, N., Crilly, J. F., \& Martin, R. (1993). Within-session changes in sensory gating assessed by P50 evoked potentials in normal subjects. Progress in Neuropsychopharmacology \& Biological Psychiatry, 17, 781-791.

Legault, G., Smith, C. T., \& Beninger, R. J. (2004). Scopolamine during the paradoxical sleep window impairs radial arm maze learning in rats. Pharmacology, Biochemistry and Behavior, 79, 715-721.

Levey, A. I., Edmunds, S. M., Koliatsos, V., Wiley, R. G., \& Heilman, C. J. (1995). Expression of m1-m4 muscarinic acetylcholine receptor proteins in rat hippocampus and regulation by cholinergic innervation. The Journal of Neuroscience, 15, 4077-4092.

Luntz-Leybman, V., Bickford, P. C., \& Freedman, R. (1992). Cholinergic gating of response to auditory stimuli in rat hippocampus. Brain Research, 587, 130-136.

Mesulam, M. M., Mufson, E. J., Wainer, B. H., \& Levey, A. I. (1983). Central cholinergic pathways in the rat: an overview based on an alternative nomenclature (ch1-ch6). Neuroscience, 10, 1185-1201.

Miyazato, H., Skinner, R. D., \& Garcia-Rill, E. (1999). Sensory gating of the P13 midlatency auditory evoked potential and the startle response in the rat. Brain Research, 822, 60-71.

Miyazato, H., Skinner, R. D., Reese, N. B., Boop, F. A., \& Garcia-Rill, E. (1995). A middle-latency auditory-evoked potential in the rat. Brain Research Bulletin, 37, 247-255.

Miyazato, H., Skinner, R. D., Reese, N. B., Mukawa, J., \& Garcia-Rill, E. (1996). Midlatency auditory evoked potentials and the startle response in the rat. Neuroscience, 75, 289-300.

Nagamoto, H. T., Adler, L. E., Hea, R. A., Griffith, J. M., McRae, K. A., \& Freedman, R. (1996). Gating of auditory P50 in schizophrenics: unique effects of clozapine. Biological Psychiatry, 40, 181-188.

Nagamoto, H. T., Adler, L. E., Waldo, M. C., \& Freedman, R. (1989). Sensory gating in schizophrenics and normal controls: effects of changing stimulation interval. Biological Psychiatry, 25, 549-561.

Olincy, A., Braff, D. L., Adler, L. E., Cadenhead, K. S., Calkins, M. E., Dobie, D. J., et al. (2010). Inhibition of the P50 cerebral evoked response to repeated auditory stimuli: results from the Consortium on Genetics of Schizophrenia. Schizophrenia Research, 119, 175-182.

Oranje, B., Geyer, M. A., Bocker, K. B. E., Kenemans, J. L., \& Verbaten, M. N. (2006). Prepulse inhibition and P50 suppression: Commonalities and dissociations. Psychiatry Research, 143, 147-158.

Patterson, J. V., Jin, Y., Gierczak, M., Hetrick, W. P., Potkin, S., Bunney, W. E., Jr., et al. (2000). Effects of temporal variability on $\mathrm{p} 50$ and the gating ratio in schizophrenia: a frequency domain adaptive filter single-trial analysis. Archives of General Psychiatry, 57, 57-64.

Pekkonen, E., Jaaskelainen, I. P., Kaakkola, S., \& Ahveninen, J. (2005). Cholinergic modulation of preattentive auditory processing in aging. Neurolmage, $27,387-392$.

Sambeth, A., Riedel, W., Smits, L., \& Blokland, A. (2007). Cholinergic drugs affect novel object recognition in rats: Relation with hippocampal EEG? European Journal of Pharmacology, 572, 151-159.

Simons, C. J. P., Sambeth, A., Krabbendam, L., Pfeifer, S., Van Os, J., \& Riedel, W. J. (2011). Auditory P300 and N100 components as intermediate phenotypes for psychotic disorder: Familial liability and reliability. Clinical Neurophysiology, 122, 1984-1990.

Teneud, L., Miyazato, H., Skinner, R. D., \& Garcia-Rill, E. (2000). Cholinergic modulation of the sleep state-dependent P13 midlatency auditory evoked potential in the rat. Brain Research, 884, 196-200.

Thomas, C., vom Berg, I., Rupp, A., Seidl, U., Schroder, J., Roesch-Ely, D., et al. (2010). P50 gating deficit in Alzheimer dementia correlates to frontal neuropsychological function. Neurobiology of Aging, 31, 416-424.

Woolf, N. J., \& Butcher, L. L. (1986). Cholinergic systems in the rat brain: III. Projections from the pontomesencephalic tegmentum to the thalamus, tectum, basal ganglia, and basal forebrain. Brain Research Bulletin, 16, 603-637.

Woolf, N. J., Eckenstein, F., \& Butcher, L. L. (1984). Cholinergic systems in the rat brain: I. projections to the limbic telencephalon. Brain Research Bulletin, 13, 751-784.

Yokogawa, K., Nakashima, E., Ishizaki, J., Hasegawa, M., Kido, H., \& Ichimura, F. (1992). Brain regional pharmacokinetics of biperiden in rats. Biopharmaceutics \& Drug Disposition, 13, 131-140.

Zouridakis, G., \& Boutros, N. N. (1992). Stimulus parameter effects on the P50 evoked response. Biological Psychiatry, 32, 839-841. 


\section{Cholinergic modulation of auditory processing and novelty detection in human participants}

Klinkenberg, I., \& Sambeth A. (accepted). Cholinergic modulation of auditory processing, sensory gating and novelty detection in human participants. Psychopharmacology. 


\section{INTRODUCTION}

Suppression of redundant auditory information and facilitation of deviant, novel or salient sounds can be assessed with electrophysiological paradigms such as paired-click and oddball tasks, respectively. Both of these make use of the automatic processing of auditory stimuli in the absence of effortful attention, yielding so-called auditory evoked potentials (AEPs) typically consisting of a P50-N100-P200 complex (e.g., Javitt et al., 2008; Leiser et al., 2011; Lijfijt et al., 2009). It has been suggested by Boutros et al. (2004) that these three components reflect distinct stages of information processing - i.e., P50; pre-attentive, N100; early-attentive, and P200; late-attentive mechanisms. In paired-click paradigms, participants are presented with two identical auditory stimuli temporally spaced $500 \mathrm{~ms}$ apart (Boutros et al., 2004). The amplitude of the P50 peak to the first click - also termed S1 or conditioning stimulus - is usually larger than that to the second click - called S2 or the test stimulus (Oranje et al., 2006); this is indicative of inhibition of redundant input and intact sensory gating (Brockhaus-Dumke et al., 2008). Oddball paradigms can elicit several AEP components in addition to the P50-N100-P200 complex, such as the mismatch negativity (MMN) and P3a. In these tasks, infrequent deviant and/or novel sounds are embedded within a string of repetitive standard tones (Garrido et al., 2009; Näätänen et al., 2004; Pekkonen et al., 2005).

In schizophrenia, mechanisms of redundancy suppression and change detection are disrupted, resulting in an overflow of sensory input and associated symptomatology such as cognitive fragmentation and thought disorder (Ford, 1999; McGhie \& Chapman, 1961). Impaired sensory filtering mechanisms in schizophrenia patients have been linked to several electrophysiological findings, such as deficient sensory gating reflected by attenuated $\mathrm{N} 100$ and P50 amplitude suppression in the paired-click paradigm (Boutros et al., 2004; Brockhaus-Dumke et al., 2008; Erwin, 1998; Olincy et al., 2010), decreased MMN during a novelty oddball task, and reduced amplitudes and delayed latencies of N100, P200 and P300 components (Bramon et al., 2004a; 2004b; Jeon \& Polich, 2001; Patterson et al., 2008; Simons et al., 2011; Souza et al., 1995; Umbricht \& Krljes, 2005; but see De Wilde et al., 2007). ${ }^{3}$ Studies of unaffected family members of schizophrenia patients, schizotypical and high-risk individuals have indicated that electrophysiological correlates of perturbed auditory processing are likely to be a trait marker, or candidate endophenotype for schizophrenia (Cadenhead et al., 2000; Olincy et al., 2010; Price et al., 2006; Simons et al., 2011; but see Bramon et al., 2004a; De Wilde et al., 2007; Umbricht et al., 2003).

Besides the strong involvement of the dopaminergic and glutaminergic neurotransmitter systems in schizophrenia, alterations in muscarinic $M_{1}$ signaling also appear to underlie the disorder (e.g., Sarter et al., 2012). For example, administration of the muscarinic $M_{1}$ antagonists biperiden or procyclidine has been shown to increase positive symptoms (Johnstone et al., 1983; Tandon et al., 1990), yet reduce negative symptoms in schizophrenia patients (Tandon et al., 1992). In addition, cholinesterase inhibitors and muscarinic $M_{1}$ agonists have been found to modestly improve various measures of cognitive function, particularly attention and short-term memory (Bora et al., 2005; Buchanan et al., 2002;

\footnotetext{
${ }^{3}$ Of note, the existing literature on P300 abnormalities in schizophrenia has focused mostly on the P3b subcomponent, although a limited number of studies have also reported reduced P3a amplitudes (Grillon et al., 1990; Turetsky et al., 2000).
} 
2008; Friedman, 2004; Lee et al., 2007; Risch et al., 2007; Schubert et al., 2006; Shekhar et al., 2008; but see Friedman et al., 2002;).

Despite a vast amount of research on the role of nicotinic receptors (e.g., Adler et al., 1998; Pritchard et al., 2004), data on the role of muscarinic neurotransmission in human AEPs is relatively limited. The non-selective muscarinic antagonist scopolamine has been found to reduce the amplitudes of the P50, N100, P200 and P300 components (Buchwald et al., 1991; Curran et al., 1998). A MEG study by Pekkonen et al. (2001) also reported a reduction of MMNm amplitude after scopolamine. Moreover, delayed P50, N100 and P300, but not P200 or MMN latencies have been demonstrated after scopolamine administration (Knott et al., 1999; Pekkonen et al., 2005). A few studies have looked into the effects of cholinesterase inhibitors on AEPs and sensory gating. For instance, a reduction in P50 amplitude by scopolamine was shown to be reversible by administration of physostigmine (Buchwald et al., 1991). Furthermore, in a study by Buchanan et al. (2002), donepezil was shown to modestly improve P50 suppression in schizophrenia patients. Lastly, physostigmine was able to partially counteract the effects of scopolamine on the P300 component (i.e., reduced amplitude and delayed latency: Meador et al., 1987; 1988). Given the involvement of the muscarinic $M_{1}$ receptor in schizophrenia, it would be interesting to find out whether drugs that target this receptor would affect AEP components.

The current study is the first to assess the effects of the muscarinic $M_{1}$ antagonist biperiden and the cholinesterase inhibitor rivastigmine on AEPs, sensory gating and MMN in young, healthy volunteers. We expected that after biperiden, AEPs would be affected in a manner similar to scopolamine, i.e., reduced amplitudes of the P50, N100, P200, P3a and MMN peaks, and increased latencies of the P50, N100 and P3a components. Effects on the amplitudes and latencies of the P50 and P3a peaks will be reversible by administration of rivastigmine. Moreover, given the cognition-deteriorating effects of biperiden (e.g., Wezenberg et al., 2005), we anticipated that biperiden would disrupt P50 suppression and that rivastigmine would be able to counteract this. Lastly, paired-click and novelty oddball tasks measure discrete sensory filtering processes (i.e., redundancy suppression and change detection, respectively); hence, we did expect to find some dissociations between these paradigms in terms of drug effects on AEPs.

\section{METHODS}

\section{Participants}

Nineteen ( 7 male, 12 female; mean age of 21.89 years $(S D=2.8$, range $=18-28)$ ) healthy volunteers were recruited from Maastricht University through poster advertisements. Participants had a body mass index between 18.5 and 30. They received a medical screening before testing, consisting of a medical questionnaire, physical examination, measurement of blood pressure and pulse rate, blood samples for haematology and biochemistry, urine samples for drug screen and pregnancy test, and a resting electrocardiogram. Exclusion criteria were past or current psychiatric, neurological, cardiac, gastrointestinal, haematological, hepatic, pulmonary, or renal illness, pregnancy, lactation, excessive alcohol consumption (intake of more than 20 glasses per week), use of any medication other than oral contraceptives, having a first-degree relative with a current or past psychiatric disorder, and presence of other deficits that could be expected to influence performance. All sub- 
jects gave a signed informed consent before inclusion and were financially rewarded for their participation. The study was approved by the Medical Ethics Committee of Maastricht University and therefore performed in accordance with the ethical standards laid down in the 1964 declaration of Helsinki.

\section{Study design and procedures}

The study was conducted according to a double-blind, placebo-controlled cross-over design. Subjects were not allowed to use any psychoactive medication within 5 days before drug intake. One hour before testing, participants were asked to fill out questionnaires on mood and physical complaints (see below). Immediately afterwards, they were given two capsules for oral intake. These included either: 1) placebo; i.e., two placebo capsules; 2) biperiden; i.e., one biperiden hydrochloride capsule of $2 \mathrm{mg}$ (Akineton ${ }^{\circledR}$, instant release) and one placebo capsule; 3) rivastigmine; i.e., one rivastigmine tartrate capsule of $3 \mathrm{mg}$ $\left(\right.$ Exelon $\left.^{\circledR}\right)$ and one placebo capsule; or 4 ) a combination treatment of biperiden and rivastigmine; i.e., one biperiden hydrochloride capsule of $2 \mathrm{mg}$ (Akineton ${ }^{\circledR}$, instant release) and one rivastigmine tartrate capsule of $3 \mathrm{mg}$ (Exelon $\left.{ }^{\circledR}\right)$.

Participants were provided lunch immediately afterwards: this was done in order to reduce the chances of participants developing any side-effects due to biperiden and rivastigmine intake. Lunch consisted of a theine-free tea, and bread with savory or sweet bread toppings. Next, EEG electrodes and a cap were placed. Exactly 60 min. after drug intake behavioral testing and EEG recording started. After about one hour of testing, the participant had a short break, in which he or she was asked to fill out the same questionnaires again. The test session finished about $3 \mathrm{~h}$ after drug intake. Participants underwent four testing days and on each testing day one of the four treatments was administered. To prevent order effects participants were randomly assigned to one of twenty balanced treatment sequences. All treatments were administered with a washout period of seven days.

\section{Drug treatment}

Biperiden is a muscarinic $M_{1}$ antagonist approved for the adjunctive treatment of Parkinson's disease and for extrapyramidal symptoms related to antipsychotic drug therapy (e.g., Ogino et al., 2011). It has about 10-fold higher affinity for $M_{1}$ as compared to $M_{2}-M_{5}$ receptors and it is thus the most selective $M_{1}$ antagonist available for use in human participants (Bolden et al., 1992; Katayama et al., 1990). In humans, peak plasma concentrations are reached around $1-2 \mathrm{~h}$ after a single dose administration followed by a rapid initial decline to values around $12 \%$ of the peak values at $6 \mathrm{~h}$ after intake. This is subsequently followed by a slow terminal elimination phase at 48h (Hollmann et al., 1984; 1987). The most common side effects of biperiden on the central nervous system are drowsiness, vertigo, headache, and dizziness. Peripheral side effects consist of blurred vision, dry mouth, impaired sweating, abdominal discomfort, and obstipation. Biperiden also causes some degree of mydriasis (e.g., Mintzer \& Burns, 2000).

Rivastigmine is an intermediate-acting cholinesterase inhibitor approved for symptomatic treatment of mild to moderate Alzheimer's disease (Jann et al., 2002; Lefevre et al., 2008). It stimulates cholinergic neurotransmission by preventing the breakdown of acetylcholine in the synaptic cleft. Specifically, it inhibits the enzymes acetylcholinesterase and butyrylcholinesterase which metabolize acetylcholine (Jann et al., 2002). Peak plasma con- 
centrations are reached around 50-70 min. and the half-life is around 60-90 min. (Farlow, 2003; Jann et al., 2002). The duration of cholinesterase inhibition is suggested to be around 8-10 hours after drug intake. The most common side effects seen in association with the use of rivastigmine occur in the gastrointestinal tract and central nervous system; these include abdominal pain, nausea, vomiting, diarrhea, headache and dizziness. Dose conditions of biperiden and rivastigmine were chosen based on the study by Wezenberg et al. (2005). Both drugs were purchased, blinded, and labelled by the pharmacy of the University Hospital Maastricht according to relevant GMP guidelines.

\section{Questionnaires}

To assess subjective mood changes, we used the Profile of Mood States (POMS: McNair et al., 1971) and the Bond and Lader mood scale (Bond \& Lader, 1974). Physical or mental complaints were assessed with a self-report questionnaire consisting of 31 possible complaints to be rated on a 4-point scale; a score of zero indicates that the participant is not experiencing the complaint, and a score of three means he or she is experiencing it a great deal. For all three questionnaires, a difference score of mean score $\mathrm{T}_{1}$ (1 hour after drug

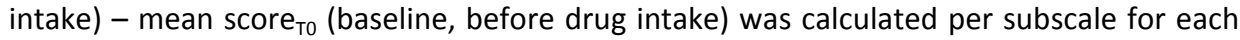
participant and used for analysis.

\section{Paired-click paradigm}

The paired-click task was used as an electrophysiological technique to assess sensory gating mechanisms (Adler et al., 1982). Two identical $1000 \mathrm{~Hz}$ clicks (S1 and S2) were binaurally presented via loudspeakers. The duration of each click was $4 \mathrm{~ms}$ with a sound intensity of 60 $\mathrm{dB}$. A short inter-stimulus interval of $500 \mathrm{~ms}$ was used, as this inter-stimulus interval has been shown to provide maximum differentiation between the sensory gating capacities of healthy participants and schizophrenia patients (Nagamoto et al., 1989; Oranje et al., 2006). The pairs were presented in a random intertrial interval of 6-10s, in order to allow neuronal recovery (Zouridakis \& Boutros, 1992). During each session 75 pairs of clicks were presented. Participants viewed a silent animated movie whilst listening to the paired-clicks. No behavioral measures were recorded during this task.

\section{Novelty oddball paradigm}

The novelty oddball task was used as an assessment of involuntary attention processes such as the MMN. Three types of auditory stimuli were presented, consisting of frequent standard, infrequent deviant and infrequent novel stimuli. The standard and deviant stimuli were $750 \mathrm{~Hz}$ and $500 \mathrm{~Hz}$ tones, each with two upper harmonic components (1500 and 2250; 1000 and $1500 \mathrm{~Hz}$, respectively). The intensity of the first and second harmonic components was decreased compared to the fundamental by 3 and $6 \mathrm{~dB}$, respectively. Novel stimuli consisted of three stimulus categories of 20 different auditory stimuli, namely animal, human, and mechanical sounds. The deviant and novel stimuli were each presented in $12.5 \%$ of the trials. All sounds had a duration of 300 ms with $10 \mathrm{~ms}$ rise and fall times. The tones were presented with a 1000 ms stimulus-onset asynchrony and equal intensities. Participants viewed a silent animated movie whilst listening to the auditory stimuli. No behavioral measures were recorded during this task, making this a passive novelty oddball task. 


\section{EEG acquisition}

For the EEG recording, the Neuroscan Synamps system was used, with sample rate set at $1000 \mathrm{~Hz}$. Data were filtered between 0.05-100 Hz. EEG was recorded from 32 electrodes placed on the scalp using an elastic cap (Electro-Cap International, United States) and positioned according to the 10-20 system (Jasper, 1958). The horizontal electro-oculogram (HEOG) was measured with two electrodes placed on the outer canthus of the left and right eye, and two electrodes placed below and above the centre of the left eye recorded the vertical electro-oculogram (VEOG). Two electrodes behind the ears served as reference electrodes. Before placing the electrodes, all locations were cleaned with alcohol and gently scrubbed with a gel, to ensure good conduction of the signal. Impedance was kept below $5 \Omega$. During the EEG recordings, the participants were sitting in an electrically shielded and sound-attenuated room with the lights dimmed.

\section{EEG analysis}

All EEG data was analyzed with Vision Analyzer 2.0. Before data analysis, the EEG data were visually inspected offline, to check for artefacts. The EEG signal was filtered offline with a high pass filter set at $1 \mathrm{~Hz}$ ( $12 \mathrm{~dB}$ slope) and a low pass filter set at $30 \mathrm{~Hz}$ ( $12 \mathrm{~dB}$ slope). Eye movement artefacts were filtered out of the EEG using the data of the VEOG channel and the method developed by Semlitsch et al. (1986). This way, every participant had about the same number of artifact-free trials which were combined into the AEP averages.

In case of the paired-click task, we decided to segment the EEG according to click-pairs instead of separately for each stimulus. Thus, the EEG epochs were set from 100 ms prior to S1 onset to $1000 \mathrm{~ms}$ after onset. One segment included both S1 and S2, using the $100 \mathrm{~ms}$ preceding the first click in the stimulus-pair as baseline. Segmenting the data for S1 and S2 separately would have implied using the 100 ms preceding S2 as a baseline for this stimulus. However, at this point the EEG signal had not yet returned to its default value, which would have skewed the baseline correction used for S2. After automatic artefact rejection, averages were calculated. Based on the grand averages we determined the position of the P50, N100 and P200 peaks for S1 and S2. Peak amplitudes were calculated and latencies were computed based on when the peak was reached. Of note, since we chose to analyze S1 and S2 within the same segment, the peaks for S2 were actually P550, N600 and P700. Please see Table 1 for the time windows chosen for the paired-click peak detection.

For the novelty oddball data, the EEG epochs were set from $100 \mathrm{~ms}$ prior to stimulus onset to $900 \mathrm{~ms}$ after onset, using the $100 \mathrm{~ms}$ pre-stimulus as baseline. After automatic artefact rejection, averages were calculated for each stimulus separately (standards, deviants and novels). Based on the grand averages we determined the position of the P50, $\mathrm{N} 100$ and P200 peaks for the standard, deviant and novel stimuli. Moreover, two difference waves were calculated by subtracting the response to the standard from the deviant and novel stimuli. For these difference waves, we determined the position of the MMN and P3a peaks. Peak amplitudes were calculated and latencies were computed based on when the peak was reached. Please see Table 2 for the time windows chosen for novelty oddball peak detection. 
Table 1. Time windows (in ms) used for AEP analyses of the paired-click data.

\begin{tabular}{llll}
\hline & Peaks & & \\
\cline { 2 - 4 } Stimulus type & Pre-attentive: P50 & Early-attentive: N100 & Late-attentive: P200 \\
\hline S1 & $20-90$ & $70-150$ & $150-240$ \\
S2 & $520-590$ & $570-650$ & $650-740$ \\
\hline
\end{tabular}

Table 2. Time windows (in ms) used for AEP analyses of the novelty oddball data.

\begin{tabular}{llll}
\hline & Peaks & & \\
\cline { 2 - 4 } Stimulus type & Pre-attentive: P50 & Early-attentive: N100 & Late-attentive: P200 \\
\hline Standards & $20-120$ & $90-150$ & $140-240$ \\
Deviants & $20-120$ & $90-150$ & $180-260$ \\
Novels & $20-120$ & $90-150$ & $180-260$ \\
\hline Stimulus type & Change detection: MMN & Novelty processing: P3a & \\
\hline Dev - Stand & $110-170$ & $170-300$ & \\
Nov - Stand & $110-170$ & $170-300$ & \\
\hline
\end{tabular}

Abbreviations: Dev - Stand: difference wave of the deviant versus the standard stimuli, MMN: mismatch negativity, Nov - Stand: difference wave of the novel versus the standard stimuli.

\section{Rationale for electrode selection}

In total we recorded and analyzed EEG from 32 electrodes, but we only included the data of the $\mathrm{Fz}, \mathrm{FCz}$ and $\mathrm{Cz}$ electrode channels in our final statistical analysis. In the literature, the $\mathrm{Cz}$ electrode is usually taken for measurement of sensory gating (e.g., Boutros et al., 2004). However, since the prefrontal cortex is also involved in sensory gating (Grunwald et al., 2003; Williams et al., 2011), we chose to also include the Fz and FCz electrode channels. As for the novelty oddball task, we were mainly interested in the novelty P3a, which is a frontocentral component (Comerchero \& Polich, 1999; Donchin, 1981). Hence, the Fz, FCz and $\mathrm{Cz}$ electrode channels were the obvious choice and in accordance with other studies evaluating the same ERP components in these paradigms. Of note, the participants were presented with a test battery containing additional paradigms besides the paired-click and novelty oddball task. We chose to measure EEG from a total of 32 electrodes, because different paradigms would elicit different ERPs, each with a different scalp distribution. Thus, electrode channels other than the Fz, FCz and $\mathrm{Cz}$ would be employed for the ERP analysis of these additional paradigms.

\section{Statistics}

All data were analyzed using SPSS. To determine possible treatment effects on the processing of the paired-click task, AEP data were analyzed by several repeated measures ANOVAs with Drug (4 levels: placebo, biperiden, rivastigmine and the combination treatment), Stimulus ( 2 levels: S1 and S2) and Electrode ( 3 levels: Fz, FCz and Cz) as within-subject variables. Effects on P50 suppression would be reflected by a significant Treatment ${ }^{*}$ Stimulus interaction. Next, we wanted to see if our treatment conditions would affect overall stimulus processing in the novelty oddball task. Therefore, we ran repeated measures ANOVAs on the AEP data of the standard stimuli, with Drug (4 levels: placebo, biperiden, rivastigmine and the combination) and Electrode ( 3 levels: $F z, F C z$ and $C z$ ) as within-subject variables. Next we sought to determine if our treatment conditions influenced the difference scores we calculated (also see previous section). Therefore we performed several repeated 
measures ANOVAs with Drug (4 levels: placebo, biperiden, rivastigmine and the combination), Stimulus ( 2 levels: Diff deviant $_{\text {and Diff }}$ novel) and Electrode ( 3 levels: Fz, FCz and $\mathrm{Cz}$ ) as within-subject variables.

For the AEP data, all analyses were done separately for amplitude and latency, and for each of the AEP components. Most of the repeated measures analyses yielded significant interactions with the variables Electrode and Stimulus. In these cases, we performed additional ANOVAs split for each level of Electrode in order to examine simple effects. For reasons of brevity, we decided to only discuss these simple effects analyses in the results section, and to leave out the overall analysis. If one of the overall repeated measures ANOVA did not yield a significant interaction term, or if a Treatment $*$ Stimulus interaction was present, this is stated clearly in the results section. For all analyses, we used $\alpha=0.05$. Posthoc analysis was performed with a Least Significant Difference (LSD) test. We chose to only compare the data of the treatment conditions with placebo, so per analysis a total of 3 post-hoc comparisons were made.

The questionnaire data were analyzed by repeated measures ANOVAs with Drug (4 levels: placebo, biperiden, rivastigmine and the combination treatment), as within-subject variable. These analyses were done separately for each subscale. Post-hoc analysis was performed with a Least Significant Difference (LSD) test. We chose to only compare the data of the treatment conditions with placebo, so per analysis a total of 3 post-hoc comparisons were made. The POMS had 5 subscales, whereas for the Bond and Lader we only analyzed the best validated subscale: alert-drowsy. For the self-report questionnaire we only analyzed those side-effects which would be expected after biperiden and/or rivastigmine intake.

\section{RESULTS}

Four participants dropped out prematurely due to side-effects of the drugs, leaving a total of 15 participants. Two participants withdrew immediately after the first testing session. They had received biperiden and rivastigmine, respectively. The other two participants resigned after three testing sessions. One person got first the combination treatment, then biperiden, and lastly rivastigmine, whereas the other had received the combination treatment, rivastigmine and placebo, respectively. In sum, this indicates that especially rivastigmine was prone to induce participant dropout due to side-effects.

\section{Treatment effects on auditory processing and redundancy suppression in the paired-click task}

Figure 1 shows the S1 and S2 AEP responses of the placebo condition, whilst Figures 2 and 3 display the effects of the treatment and stimulus conditions on P50 amplitude and N100 latency in the paired-click task, respectively.

In the simple effects analyses of all three electrode channels (i.e., $\mathrm{Fz}, \mathrm{FCz}$ and $\mathrm{Cz}$ ), the effect of Treatment on P50 amplitude did not vary per level of Stimulus (no Treatment * Stimulus interaction effect; $F s<1.21$, n.s.). The P50 amplitude of S2 was smaller compared to that of S1 (main effect of Stimulus; Fs $>28.24$, $P s<0.001$ ). Furthermore, P50 amplitude was shown to be different between treatment conditions (main effect of Treatment; Fs > 
4.75, $P s<0.01)$; post-hoc analysis indicated that P50 amplitude was larger after biperiden $(P s<0.01)$ and the combination treatment $(P s<0.05)$ compared to placebo.

In the simple effects analysis of the Fz electrode data, there were no interactions or main effects on P50 latency ( $F s<0.68$, n.s.). For the analyses of the $\mathrm{FCz}$ and $\mathrm{Cz}$ electrodes, the effect of Treatment did not vary per level of Stimulus (no Treatment * Stimulus interaction effect; Fs < 1.90, n.s.). The P50 latency of S2 occurred earlier compared to the P50 latency of S1 (main effect of Stimulus; $F s>4.67, P s<0.05$ ), yet Treatment did not influence $\mathrm{P} 50$ latency on $\mathrm{FCz}$ and $\mathrm{Cz}$ (no main effect of Treatment; $F s<2.61$, n.s.).

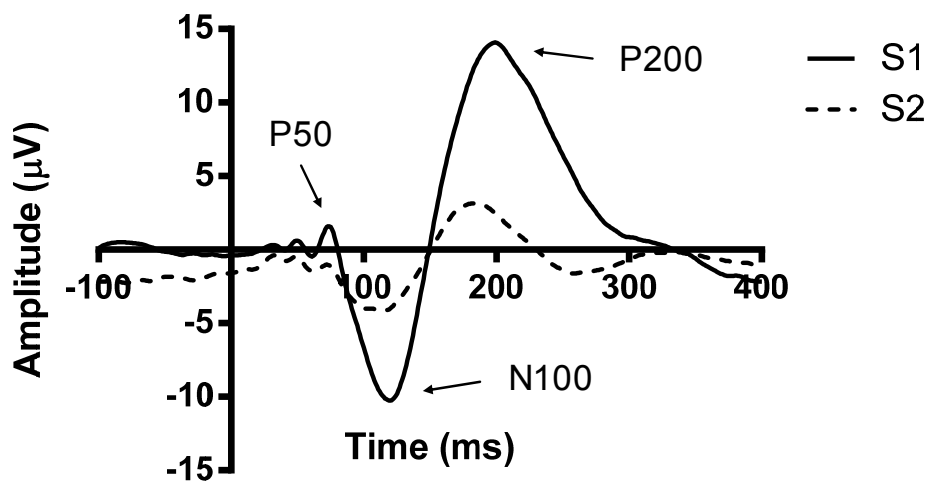

Figure 1. AEP responses to S1 and S2 of the paired-click task (shown here: Cz electrode). The amplitude and latency of the P50, N100 and the P200 peaks were smaller for S2 compared to S1 (Ps $<0.05)$.

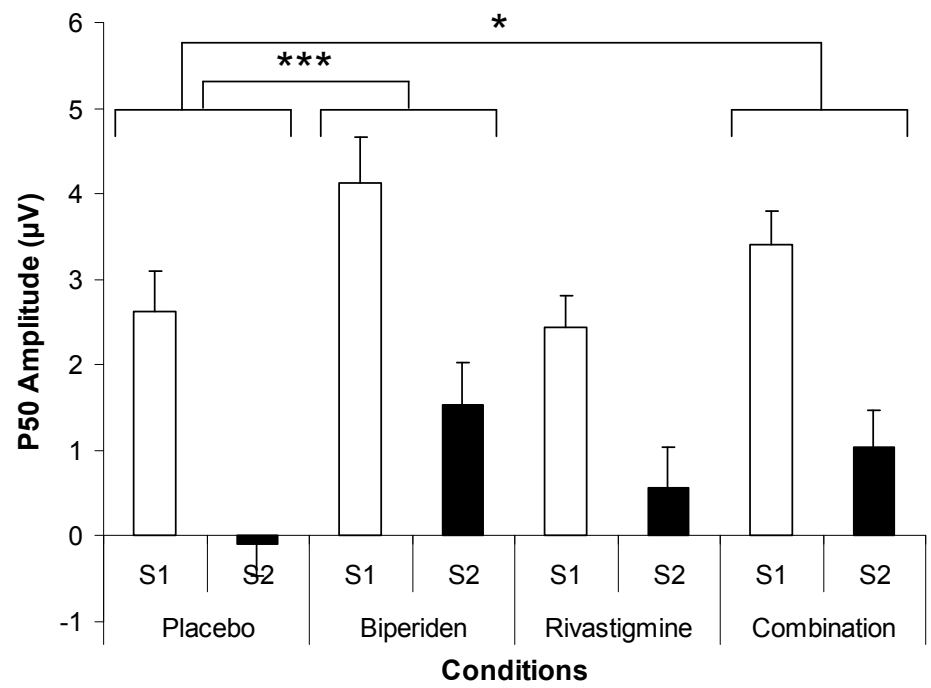

Figure 2. Effects of the treatment and stimulus conditions on $P 50$ amplitude of the paired-click task (shown here: Fz electrode, means + SEM, *: Ps < 0.05, ***: Ps < 0.001). P50 amplitude was larger after biperiden (Ps $<0.01)$ and the combination treatment $(P s<0.05)$ compared to placebo. There was no Treatment $*$ Stimulus interaction, and therefore no effect on sensory gating. 
In the simple effects analyses of all three electrode channels (i.e., Fz, FCz and Cz), the effect of Treatment on N100 amplitude did not vary per level of Stimulus (no Treatment * Stimulus interaction effect; $F s<0.50$, n.s.). The $\mathrm{N} 100$ amplitude of S2 was smaller compared to that of S1 (main effect of Stimulus; $F s>89.76, P s<0.001$ ), yet Treatment did not influence N100 amplitude (no main effect of Treatment; $F s<2.59$, n.s.).

In the simple effects analyses of all three electrode channels (i.e., $\mathrm{Fz}, \mathrm{FCz}$ and $\mathrm{Cz}$ ), the effect of Treatment on N100 latency did not vary per level of Stimulus (no Treatment * Stimulus interaction effect; $F s<1.79$, n.s.). The N100 peak of S2 occurred earlier compared to the $\mathrm{N} 100$ of $\mathrm{S} 1$ for $\mathrm{Fz}, \mathrm{FCz}$ and $\mathrm{Cz}$ (main effect of Stimulus; $F(1,18)=5.48, P<0.05$ ). Moreover, in the simple effects analysis of the Fz electrode, N100 latency was shown to be different between treatment conditions (main effect of Treatment; $F s>3.16, P s<0.05$ ); post-hoc analysis showed that the N100 occurred later after biperiden compared to placebo $(P<0.05)$. For the $\mathrm{FCz}$ and $\mathrm{Cz}$ electrodes, Treatment did not influence N100 latency (no main effect of Treatment; Fs $<2.70$, n.s.).

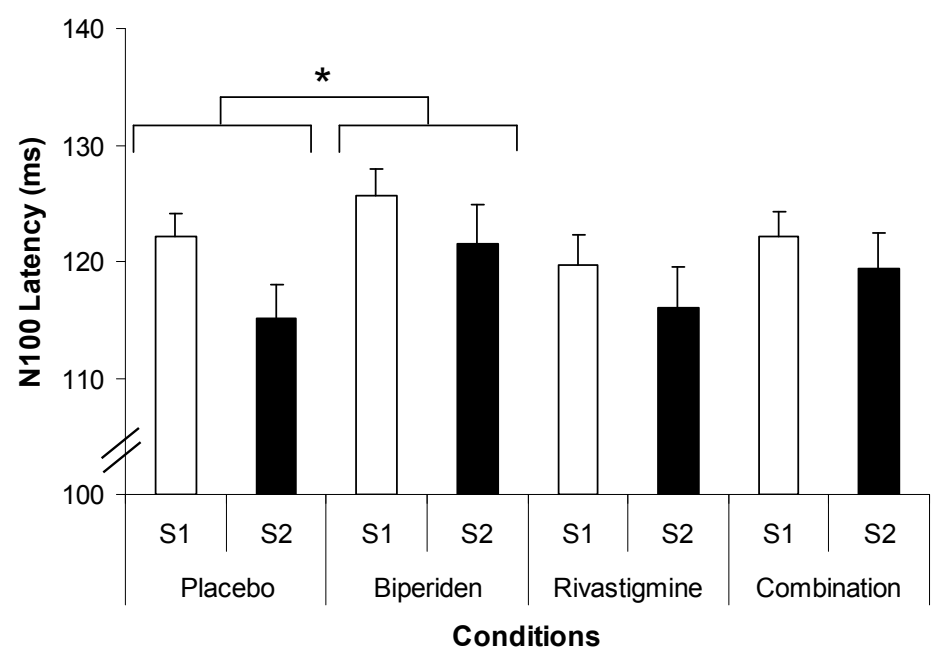

Figure 3. Effects of the treatment and stimulus conditions on N100 latency of the paired-click task (shown here: Fz electrode, means + SEM, $*: P<0.05)$. N100 latency was larger after biperiden compared to placebo $(P s<0.05)$; this effect was reversed by concurrent administration of rivastigmine (i.e., after the combination treatment N100 latency was statistically similar to placebo).

In the simple effects analyses of all three electrode channels (i.e., Fz, FCz and Cz), the effect of Treatment on P200 amplitude did not vary per level of Stimulus (no Treatment * Stimulus interaction effect; $F s<1.47$, n.s.). The P200 amplitude of S2 was smaller compared to that of S1 (main effect of Stimulus; $F s>100.40, P s<0.001$ ), yet Treatment did not influence P200 amplitude for Fz, FCz and Cz (no main effect of Treatment; $F s<1.35$, n.s.).

In the simple effects analyses of the $\mathrm{Fz}$ and $\mathrm{FCz}$ electrode channels, the effect of Treatment on P200 latency did not vary per level of Stimulus (no Treatment * Stimulus interaction effect; $F s<1.39$, n.s.). The P200 latency of S2 was shorter compared to that of S1 (main effect of Stimulus; $F s>7.71, P s<0.05$ ), yet Treatment did not influence P200 latency at $\mathrm{Fz}$ and $\mathrm{FCz}$ (no main effect of Treatment; $F s<1.16$, n.s.). For the simple effects 
analysis of the $\mathrm{Cz}$ electrode, the effect of Treatment varied per level of Stimulus (Treatment * Stimulus interaction effect; $F(3,54)=3.09, P<0.05)$. Hence we did separate repeated measures analyses per level of Stimulus. For the data of the S1 stimulus, P200 latency was shown to be different between treatment conditions (main effect of Treatment; $F(3,54)=$ 4.23, $P<0.01)$; post-hoc analysis showed that the P200 occurred later after biperiden $(P<$ $0.05)$ and after the combination treatment $(P<0.05)$ compared to placebo. There were no effects in the analysis of the $S 2$ data $(F(3,54)=0.50$, n.s. $)$.

\section{Treatment effects on auditory processing of the standard stimuli in the novelty oddball task}

Figure 4 shows the AEP responses to the standard, deviant and novel stimuli of the placebo condition, whereas Figure 5 displays the effects of the four treatment conditions on N100 latency of the standard stimuli in the novelty oddball task.

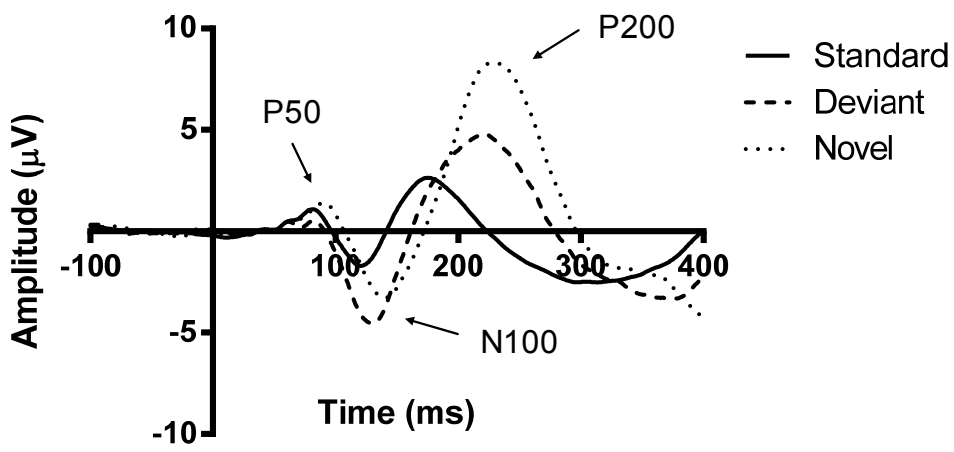

Figure 4. AEP responses to the standard, deviant and novel stimuli of the novelty oddball task (shown here: $\mathrm{Cz}$ electrode). Generally, deviant and novel sounds elicited larger amplitudes than standards $(P s<0.05)$.

In the overall analysis of P50 amplitude of the standard stimuli, the effect of Treatment did not vary per level of Electrode (no Electrode * Treatment interaction effect; $F(6,108)=0.32$, n.s.). P50 amplitude was shown to differ according to treatment conditions (main effect of Treatment; $F(3,54)=5.43, P<0.01$ ); however, post-hoc analysis did not yield any significant results.

The overall analysis of P50 latency demonstrated that the effect of Treatment did not vary per level of Electrode (no Electrode ${ }^{*}$ Treatment interaction effect; $F(6,108)=0.43$, n.s.). P50 latency was shown to be different between treatment conditions (main effect of Treatment; $F(3,54)=3.02, P<0.05)$; post-hoc analysis showed that the $\mathrm{P} 50$ occurred later after biperiden compared to placebo $(P<0.05)$.

The repeated measures ANOVA of N100 amplitude of the standard stimuli did not yield any relevant effects ( $F s<2.38$, n.s.). With regards to the overall analysis of N100 latency, the effect of Treatment did not vary per level of Electrode (no Electrode * Treatment interaction effect; $F(6,108)=1.34$, n.s.). N100 latency was shown to differ according to treatment conditions (main effect of Treatment; $F(3,54)=6.83, P<0.01$ ); post-hoc analysis showed that the N100 occurred earlier after rivastigmine compared to placebo $(P<0.05)$.

The repeated measures analysis of P200 amplitude of the standard stimuli did not yield any relevant effects ( $F s<1.43$, n.s.). The overall analysis of P200 latency demonstrated that 
the effect of Treatment did not vary per level of Electrode (no Electrode * Treatment interaction effect; $F(6,108)=1.20$, n.s.). P200 latency was shown to be different between treatment conditions (main effect of Treatment; $F(3,54)=3.45, P<0.05$ ); however, post-hoc analysis did not yield any Treatment effects compared to placebo.

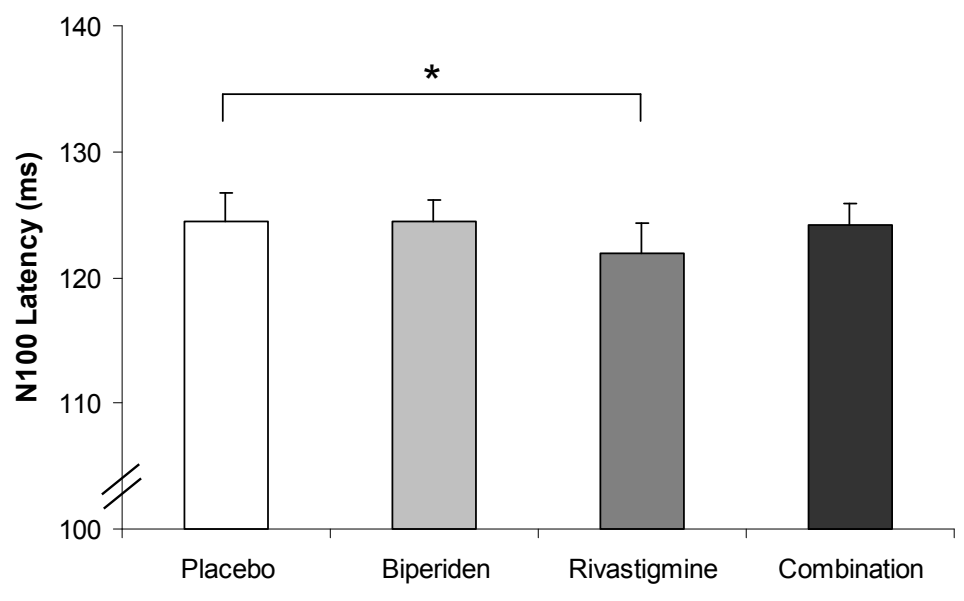

Stimulus

Figure 5. Effects of the treatment conditions on N100 latency of the novelty oddball task (shown here: Fz electrode, means + SEM, * $P<0.05)$. N100 latency was shorter after rivastigmine compared to placebo $(P S<$ 0.05 ); this effect was reversed by concurrent administration of biperiden (i.e., after the combination treatment N100 latency was statistically similar to placebo).

\section{Treatment effects on change detection and novelty processing in the novelty oddball task}

Figure 6 visualizes the deviant-standard and novel-standard difference waves of the novelty oddball task, whereas Figure 7 shows the effects of the treatment and stimulus difference scores on P3a amplitude in the novelty oddball task. In the simple effects analysis of the Fz electrode data, the effect of Treatment did not vary per level of Stimulus (no Stimulus * Treatment interaction effect; $F(3,54)=0.14$, n.s.). The $M M N$ amplitude of the Diff $_{\text {novel }}$ wave

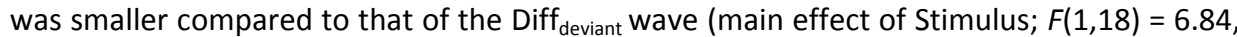
$P<0.05$ ), yet Treatment did not influence MMN amplitude (no main effect of Treatment; $F(3,54)=1.20$, n.s.). The simple effects analyses of the $\mathrm{FCz}$ and $\mathrm{Cz}$ electrode channels did not yield any relevant effects on $\mathrm{MMN}$ amplitude ( $F s<1.52$, n.s.).

There were no interaction effects in the overall repeated measures analysis of $M M N$

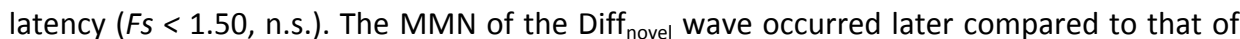

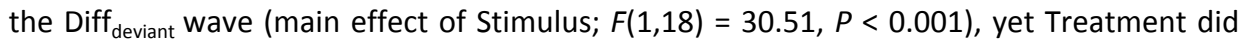
not influence MMN amplitude (no main effect of Treatment; $F(3,54)=0.69$, n.s.).

The simple effects analyses of all three electrode channels (i.e., $\mathrm{Fz}, \mathrm{FCz}$ and $\mathrm{Cz}$ ) did not yield any interaction effects on P3a amplitude ( $F s<0.22$, n.s.). The P3a amplitude of the Diff $_{\text {novel }}$ wave was larger compared to that of the Diff deviant wave (main effect of Stimulus; $F s$ $>10.68, P s<0.01)$. Furthermore, Treatment influenced $\mathrm{P} 3 \mathrm{a}$ amplitude for $\mathrm{Fz}, \mathrm{FCz}$ and $\mathrm{Cz}$ (main effect of Treatment; Fs $>3.42$, Ps $<0.05$ ); however, post-hoc analysis of the Fz and $\mathrm{FCz}$ electrodes did not yield any significant results. The post-hoc analysis of the $\mathrm{Cz}$ electrode demonstrated that $\mathrm{P3}$ a amplitude was increased after rivastigmine $(P<0.05)$. 


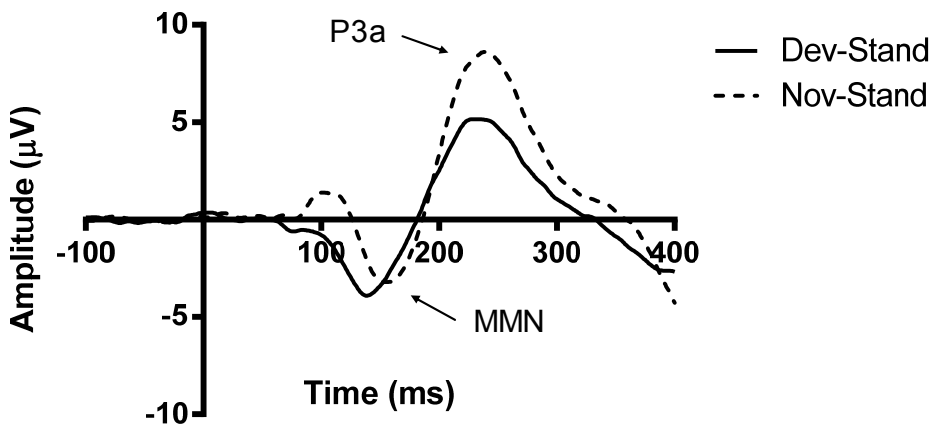

Figure 6. Deviant-standard and novel-standard difference waves of the novelty oddball task (shown here: FCz electrode). The MMN amplitude of the novel-standard was smaller compared to that of the deviantstandard difference score (only at the Fz electrode; $P<0.05$ ). Moreover, the MMN occurred later for the novel-standard compared to that of the deviant-standard difference score $(P<0.001)$. The P3a amplitude of the novel-standard was larger compared to that of the deviant-standard difference score $(P s<0.01)$. There were no effects of the difference scores on P3a latency.

In the simple effects analyses of the $\mathrm{Fz}$ and $\mathrm{Cz}$ electrode channels, there were no interactions or main effects on P3a latency ( $F s<2.36$, n.s.). For the $\mathrm{FCz}$ electrode, the effect of treatment on P3a latency did not vary per level of Stimulus (no Stimulus * Treatment interaction effect; $F(3,54)=1.25$, n.s.). Furthermore, P3a latency was statistically similar be-

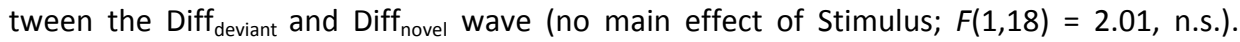
Treatment was found to affect P3a latency (main effect of Treatment; $F(3,54)=3.00, P<$ 0.05); however, post-hoc analysis did not yield any significant results.

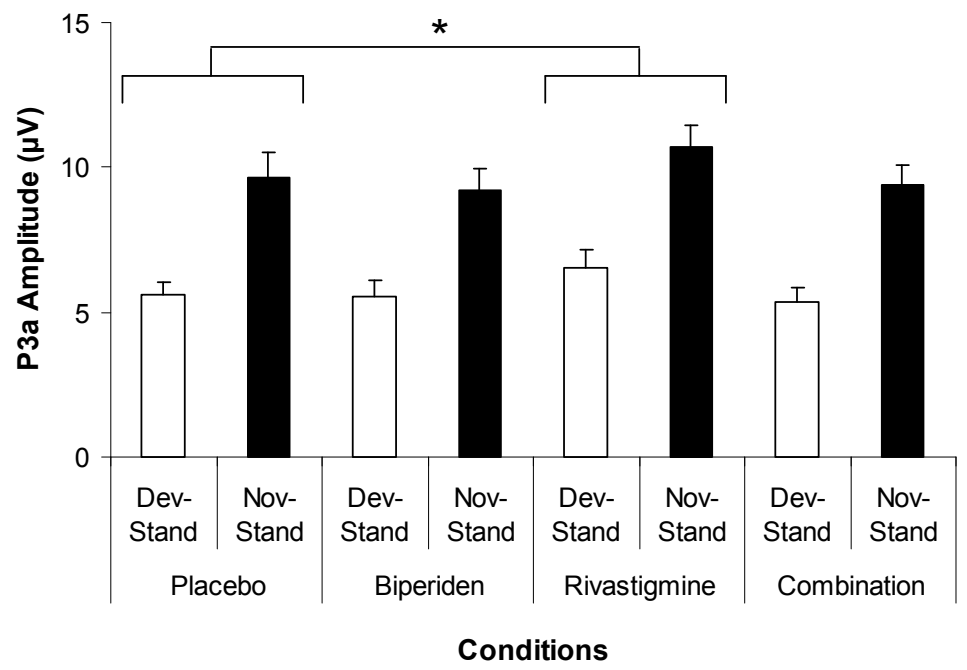

Figure 7. Effects of the treatment conditions on $\mathrm{P} 3 \mathrm{a}$ amplitude of the difference scores in the novelty oddball task (shown here: $\mathrm{C} z$ electrode, means $+\mathrm{SEM},{ }^{*}: P<0.05$ ). P3a amplitude was larger after rivastigmine compared to placebo $(P s<0.05)$; this effect was reversed by concurrent administration of biperiden (i.e., after the combination treatment P3a amplitude was statistically similar to placebo). 


\section{Treatment effects on questionnaires}

Table 3 shows the average difference scores $\left(T_{1}-T_{0}\right)$ for the four treatment conditions on the POMS subscales. The analysis of the POMS data revealed that Treatment had an effect on the depression-dejection scale (main effect of Treatment; $F(3,54)=7.36, P<0.001$ ); post-hoc analysis showed that after biperiden, participants felt happier compared to placebo $(P<0.01)$. Moreover, Treatment also influenced the fatigue-interia scale (main effect of Treatment; $F(3,54)=20.59, P<0.001$ ); post-hoc analysis showed that participants felt less tired after biperiden $(P<0.001)$ and after rivastigmine $(P<0.01)$ compared to the placebo condition. Furthermore, Treatment also affected the vigor-activity scale (main effect of Treatment); post-hoc analysis showed that participants felt less energetic after biperiden $(P<0.01)$ and after rivastigmine $(P<0.01)$ compared to the placebo condition. There were no Treatment effects on the POMS scales anger-hostility and tension-anxiety ( $F s<2.09$, n.s.). Treatment also did not influence the Bond and Lader Alertness scale $(F(3,54)=2.42$, n.s.) nor any of the self-report scales ( $F s<2.71$, n.s.).

Table 3. Treatment effects on the difference scores $\left(T_{1}-T_{0}\right)$ of the POMS subscales; means (+ SEMs). Significance asterisks reflect Treatment effects compared to the placebo condition.

\begin{tabular}{lllll}
\hline \multirow{5}{*}{ POMS subscales } & \multicolumn{4}{l}{ Treatment conditions } \\
\cline { 2 - 5 } Placebo & Biperiden & Rivastigmine & Combination \\
\hline Depression-Dejection & 20.26 & $-34.37^{* *}$ & -14.05 & 32.68 \\
& $(12.77)$ & $(10.61)$ & $(10.34)$ & $(9.30)$ \\
Anger-Hostility & 51.37 & -14.16 & -15.47 & -19.58 \\
& $(34.91)$ & $(11.06)$ & $(11.18)$ & $(26.50)$ \\
Fatigue-Inertia & 47.84 & $-54.42 * * *$ & $-32.53 * *$ & 71.11 \\
& $(13.80)$ & $(12.85)$ & $(12.07)$ & $(12.74)$ \\
Vigor-Activity & 43.11 & $-49.47 * *$ & $-28.37 * *$ & 69.37 \\
& $(11.83)$ & $(14.97)$ & $(12.94)$ & $(17.30)$ \\
Tension-Anxiety & 3.37 & 0.95 & -1.95 & 0.68 \\
& $(8.82)$ & $(11.04)$ & $(10.61)$ & $(5.71)$ \\
\hline
\end{tabular}

Abbreviations and symbols: POMS: Profile of Mood States, **: $P<0.01, * * *: P<0.001$

\section{DISCUSSION}

The goal of the current study was to assess the effects of biperiden and rivastigmine on sensory gating and MMN in young, healthy participants. In Table 4 an overview is given of the effects of both drugs on the various AEPs.

\section{Paired-click task}

For the paired-click task, both biperiden and the combination treatment enlarged the amplitude of the P50 peak (see Fig. 2). The latter is likely due to an underlying effect of biperiden, also given the fact that rivastigmine did not change the $\mathrm{P} 50$ relative to placebo. This would argue for a role of the muscarinic $M_{1}$ receptor in pre-attentive processing. Further- 
more, P50 gating was unaffected by any of the treatments (i.e., no interaction between Treatment and Stimulus), which suggests that the effects of biperiden and the combination treatment on P50 amplitude were statistically similar for S1 and S2. These results were quite unexpected in light of our hypothesis stating reduced AEP peak amplitudes after biperiden and reversal by rivastigmine. Moreover, they are in contrast with studies on the muscarinic antagonist scopolamine which have reported a disappearance of the P50 and reversal by concomitant administration of a cholinesterase inhibitor (Buchwald et al., 1991), or a delay of the P50 (Pekkonen et al., 2005). However, a study by Pekkonen et al. (2001) which investigated the effects of scopolamine on a novelty oddball paradigm using MEG, also reported an enhancement of P50m amplitude. Furthermore, very modest effects of donepezil on P50 gating were reported by Buchanan et al. (2002).

Relating our findings to the P50 suppression deficits reported in schizophrenia is not very straightforward. Indeed, impairments of P50 gating have not been found consistently in the schizophrenia literature, which has been ascribed to differences in methodology and low test-retest reliability between studies (e.g., Jin et al., 1997; 1998; Kathmann \& Engel, 1990). Furthermore, in contrast to the effects of biperiden, impaired P50 suppression (i.e., inflated S2/S1 ratio) in schizophrenia has generally been attributed to a reduction of the initial P50 response to S1. Some authors have argued that this decrement might be due to higher P50 latency variability (e.g., Jin et al., 1997; Patterson et al., 2000). However, this cannot explain our results of larger P50 amplitude after biperiden, as high temporal variability in P50 latency would cause a reduction in P50 amplitude. Arguably, effects of schizophrenia status and (anti-)cholinergic drugs on the P50 as reported in the literature are likely mediated by a muscarinic receptor subtype other than $M_{1}$ (i.e., $M_{2}-M_{5}$ ), or alternatively, by nicotinic receptors (Adler et al., 1998). Of note, in aging, mild cognitive impairment and Alzheimer's disease, P50 amplitude is also progressively enhanced (Golob et al., 2001a; 2001b; Irimajiri et al., 2005; Thomas et al., 2010; but see Buchwald et al., 1989; Fein et al., 1994), which is in line with our current findings. This would suggest that the increment in P50 amplitude seen in healthy aging and age-related neurodegenerative disorders might mirror those seen after biperiden and hence, might be muscarinic $M_{1}$-mediated.

An additional effect we found in the paired-click task was a delay in N100 latency after biperiden, which was reversed by concurrent treatment with rivastigmine (see Fig. 3). Rivastigmine by itself did not affect N100 latency in the paired-click task. These findings would suggest that the effect of biperiden on $\mathrm{N} 100$ latency is $\mathrm{M}_{1}$-mediated. Furthermore, it is likely that changes in neurotransmission at $M_{2}-M_{5}$ receptors can interact with the effects of biperiden at the $M_{1}$ receptor, given the fact that rivastigmine was able to reverse the biperiden-induced delay in N100 latency. Our findings are in accordance with those reported on scopolamine (Pekkonen et al., 2001; 2005). Furthermore, a study by Simons et al. (2011) also demonstrated increased N100 latency in schizophrenia patients and their siblings, which the authors concluded might be regarded as a manifestation of familial liability for psychosis. Of note, delays in N100 latency are not specific for schizophrenia, as these have also been reported in aged participants (Iragui et al., 1993; but see Amenedo \& Diaz, 1998). In contrast, in a previous study using a learned irrelevance (LIrr) task we found an enhancement of N100 amplitude after biperiden, and no effect on peak latency (see Chapter 5). We concluded that this effect was due to an increased allocation of attentional/behavioral switching resources. However, this involved a visual N100 which might partly explain the discrepancy in effects of biperiden between studies. 
Table 4. Treatment effects on AEPs in the paired-click paradigm and novelty oddball task. A significance definition of $\alpha=0.05$ was used for all analyses. Effects at specific electrode channels are stated in the Table; if no such statement is added, the particular effect was found at all electrode channels. In case of the AEP analysis of the standard stimuli in the novelty oddball task, we did not examine Stimulus effects (i.e., only one Stimulus type was included in the analysis). As for Treatment, there was a Treatment * Stimulus interaction in the analysis of P200 latency in the paired-click task. All other table entries reflect main effects of Treatment.

\begin{tabular}{|c|c|c|c|c|c|}
\hline \multirow[b]{2}{*}{ Paradigm } & \multirow[b]{2}{*}{ ERPs } & \multirow{2}{*}{$\begin{array}{l}\text { Stimulus effects } \\
\text { Saline }\end{array}$} & \multicolumn{3}{|l|}{ Treatment effects } \\
\hline & & & Biperiden & Rivastigmine & Combination \\
\hline \multirow[t]{12}{*}{ Paired-click } & P50 & Amplitude: & Amplitude $\uparrow(\mathrm{Fz})$ & $=$ & Amplitude $\uparrow$ \\
\hline & & $\mathrm{S} 1>\mathrm{S} 2$ & & & \\
\hline & & Latency: & & & \\
\hline & & $\mathrm{S} 1>\mathrm{S} 2(\mathrm{FCz}, \mathrm{Cz})$ & & & \\
\hline & N100 & Amplitude: & Latency $\uparrow$ & $=$ & $=$ \\
\hline & & $\mathrm{S} 1>\mathrm{S} 2$ & & & \\
\hline & & Latency: & & & \\
\hline & & $\mathrm{S} 1>\mathrm{S} 2$ & & & \\
\hline & P200 & Amplitude: & Treat * Stim $(\mathrm{Cz}):$ & $=$ & $=$ \\
\hline & & $\mathrm{S} 1>\mathrm{S} 2$ & S1: Latency $\uparrow$ & & \\
\hline & & Latency: & S2: Latency = & & \\
\hline & & $\mathrm{S} 1>\mathrm{S} 2(\mathrm{Fz}, \mathrm{FCz})$ & & & \\
\hline \multirow{3}{*}{$\begin{array}{l}\text { Novelty oddball: } \\
\text { standards }\end{array}$} & P50 & $\mathrm{N} / \mathrm{A}$ & Latency $\uparrow$ & $=$ & $=$ \\
\hline & N100 & $\mathrm{N} / \mathrm{A}$ & $=$ & Latency $\downarrow$ & $=$ \\
\hline & P200 & $\mathrm{N} / \mathrm{A}$ & $=$ & $=$ & $=$ \\
\hline \multirow{8}{*}{$\begin{array}{l}\text { Novelty oddball: } \\
\text { difference scores }\end{array}$} & MMN & Amplitude: & $=$ & $=$ & $=$ \\
\hline & & Diff $_{\text {deviant }}>$ Diff $_{\text {novel }}$ & & & \\
\hline & & $(F z)$ & & & \\
\hline & & Latency: & & & \\
\hline & & Diff $_{\text {novel }}>$ Diff $_{\text {deviant }}$ & & & \\
\hline & P3a & Amplitude: & $=$ & Amplitude $\uparrow(\mathrm{Cz})$ & $=$ \\
\hline & & Diff $_{\text {novel }}>$ Diff $_{\text {deviant }}$ & & & \\
\hline & & Latency: = & & & \\
\hline
\end{tabular}

Abbreviations and symbols: Treat * Stim: Treatment * Stimulus interaction, MMN: mismatch negativity, N/A: not applicable, $\uparrow$ : increase, $\downarrow$ : decrease, =: not significant.

In the paired-click task biperiden induced a delay in P200 latency of the S1, but not S2 stimulus, which was reversed by concurrent administration of rivastigmine. Rivastigmine by itself did not affect P200 latency in the paired-click task. Based on our hypothesis which focused on P200 amplitude, we did not expect to find an effect of biperiden on latency. Thus, our finding is in contrast with studies reported no change in P200 latency after scopolamine (Pekkonen et al., 2005) or decreased P200 amplitude after scopolamine (Curran et al., 1998). However, as Simons et al. (2011) indicated, slowing of initial auditory processing might have downstream consequences for later peaks; i.e., delayed latency of the N100 component might also retard the occurrence of the P200. Again, the psychopathological 
specificity for delayed P200 latency is low; besides schizophrenia and healthy siblings of schizophrenia patients (Karoumi et al., 2000; Ogura et al., 1991), the same finding has also been reported in aged volunteers (e.g., Bertoli et al., 2002; Iragui et al., 1993; but see Amenedo \& Diaz, 1998). Also, some studies have reported decreased P200 amplitudes rather than a latency effect in schizophrenia (e.g., Boutros et al., 2004; Shenton et al., 1989) or even no effects on the P200 component in schizophrenia patients (e.g., Karoumi et al., 2000).

\section{Novelty oddball task}

Biperiden induced a slowing of pre-attentive auditory processing, reflected by a delay in P50 latency which was reversed by concurrent treatment with rivastigmine. Rivastigmine by itself did not affect P50 latency in the novelty oddball task. These findings would suggest that the effect of biperiden on P50 latency is $M_{1}$-mediated. Furthermore, it is likely that changes in neurotransmission at $\mathrm{M}_{2}-\mathrm{M}_{5}$ receptors can interact with the effects of biperiden at the $M_{1}$ receptor, given the fact that rivastigmine was able to reverse the biperideninduced delay in P50 latency. Pekkonen et al. (2005) also found a delayed auditory P50 after administration of scopolamine (but see Buchwald et al., 1991). Moreover, clinical studies usually focus on P50 amplitude, as P50 latency of schizophrenia patients is generally unchanged relative to normal controls (e.g., Bramon et al., 2004b). However, Jin et al. (1997) and Patterson et al. (2000) demonstrated a high temporal variability in P50 latency of the S1, but not S2 stimulus in schizophrenia patients. This variability contributed significantly to the averaged P50 amplitude and to the S2/S1 ratio used as a measure for sensory gating, and hence might partly underlie the usually reported finding of disrupted P50 gating in schizophrenia patients. Our results of delayed P50 latency after biperiden in the novelty oddball task suggest that the muscarinic $M_{1}$ receptor might underlie findings of high temporal variability in $\mathrm{P} 50$ latency in schizophrenia patients.

After rivastigmine the N100 peak to standard stimuli occurred earlier compared to the placebo condition (see Fig. 5). This finding was unexpected, as we anticipated that rivastigmine would mainly affect the P50 and P3a peaks. Studies on cholinesterase inhibitors have generally reported effects on components other than the N100, such as enhanced P50 suppression (e.g., Buchanan et al., 2002). Concurrent treatment with biperiden reversed the rivastigmine-induced effects, whereas biperiden by itself did not affect N100 latency in the novelty oddball paradigm. The fact that biperiden failed to influence N100 latency suggests an effect of rivastigmine which is mediated by a cholinergic receptor different than the $M_{1}$; i.e., $M_{2}-M_{5}$ or nicotinic receptors. Rivastigmine enhances cholinergic signalling non-selectively, which means that nicotinergic and/or muscarinic receptors other than $M_{1}$ might also instigate changes in the N100 component (Kadir et al., 2007; but see Inami et al., 2005). However, it is likely that $M_{1}$-mediated neurotransmission can interact with the effects of rivastigmine, given the fact that biperiden was able to reverse the rivastigmineinduced decrease in N100 latency. Findings of delayed N100 latency in schizophrenia patients and their siblings (e.g., Simons et al., 2011) suggest that rivastigmine might be beneficial for alleviating deficits in attentional processing. This is in accordance with studies reporting beneficial effects of cholinesterase inhibitors on tests of attention and memory (Friedman, 2004; Schubert et al., 2006; but see Dyer et al., 2008; Friedman et al., 2002; Lee et al., 2007). There were no effects of biperiden, rivastigmine or the combination treatment on the P200 component. 
Unexpectedly, we did not find an effect of biperiden or rivastigmine on the MMN, which suggests that muscarinic $M_{1}$ receptors are not involved in the frontal MMN component. Our findings are in contrast with pharmacological studies on cholinergic signalling and MMN. For instance, a MEG study by Pekkonen et al. (2001) reported a reduction of MMNm amplitude by the non-selective muscarinic antagonist scopolamine. However, this discrepancy might be partly explained by differences in sensitivity between MEG and EEG (e.g., Hämäläinen et al., 1993). Specifically, the MMN seen in MEG originates in the auditory cortex and occurs relatively earlier than the EEG-based MMN, which is mainly generated by the frontal cortex (Rinne et al., 2000).

In the novelty oddball task rivastigmine increased novelty processing, reflected by an enhancement of P3a amplitude of the difference wave at the $\mathrm{Cz}$ electrode (see Fig. 7). Concurrent treatment with biperiden reversed the rivastigmine-induced effects, whereas biperiden by itself did not affect P3a amplitude in the novelty oddball paradigm. The fact that biperiden failed to influence the P3a suggests an effect of rivastigmine which is mediated by a cholinergic receptor different than the $M_{1}$, i.e., $M_{2}-M_{5}$ or nicotinic receptors. However, it is likely that $M_{1}$-mediated neurotransmission can interact with the effects of rivastigmine, given the fact that biperiden was able to reverse the rivastigmine-induced increase in $\mathrm{P} 3 \mathrm{a}$ amplitude. Since this is the first study reporting effects of cholinergic drugs on P3a amplitude using a passive novelty oddball task, it is difficult to relate our findings to those found in the literature. There do exist a few studies on the effects of scopolamine which have reported a smaller P300 amplitude (Curran et al., 1998; Meador et al., 1989; but see Knott et al., 1999; Potter et al., 2000) and subsequent reversal by the cholinesterase inhibitor physostigmine (Meador et al., 1987). Others have demonstrated an effect of scopolamine on P300 latency (Meador et al., 1988; 1989; but see Knott et al., 1999), which could be (partially) counteracted by physostigmine administration (Meador et al., 1987; 1988). However, all of these studies used an active oddball paradigm, in which participants are instructed to give a behavioral response to target stimuli. Due to the higher attentional effort which must be paid, active oddball paradigms generally induce a parietal P3b reflecting context updating/working memory function, instead of a frontocentral P3a peak indicative of novelty/attentional processes (Comerchero \& Polich, 1999; Donchin, 1981).

In schizophrenia, decreased P3a amplitude has been reported, which is generally interpreted as a reduction in attentional capacity, or alternatively, as a change in allocation of processing resources (Grillon et al., 1990; Turetsky et al., 2000). Again, the clinical specificity for P3a abnormalities is low; the P3a is also smaller and delayed in aged subjects (Fjell \& Walhovd, 2004; Fjell et al., 2007; Knight, 1987; Pontifex et al., 2009). Findings of P3a abnormalities in schizophrenia and aging could be indicative of a common underlying frontal impairment sensitive to treatment by cholinesterase inhibitors.

\section{Paired-click vs. novelty oddball task}

We found several dissociations in terms of treatment effects between the two auditory paradigms used in the current study. Overall, it appears that the paired-click paradigm was relatively more sensitive to changes in muscarinic neurotransmission, especially those induced by biperiden. It is difficult to account for the discrepancies in treatment effects between the tasks. Paired-click paradigms present participants with a repetitive sequence consisting of uniform sounds and thus assess the sensory filtering of incoming stimuli which 
are deemed uninformative. Novelty oddball tasks provide participants with stimuli which differ in terms of frequency of occurrence (i.e., deviants and novels) embedded in a string of familiar sounds (i.e., standards) and hence measure auditory deviation from familiarity. Although we chose to analyze treatment effects on the P50, N100 and P200 AEPs of just the standard stimuli in the novelty oddball task, the presence of infrequently occurring deviant or novel sounds might already change the auditory processing of the standards compared to a task which uses uniform stimuli (as was the case for the paired-click task). For instance, the presence of infrequent sounds in the novelty oddball task might have reduced the impact of sensory filtering mechanisms on the frequent stimuli, simply because participants show less habituation to these sounds. In short, although both pairedclick paradigms and novelty oddball tasks employ auditory stimuli, they assess distinct sensory processes. Biperiden and rivastigmine have differential effects on the AEPs generated by these paradigms.

\section{Questionnaires}

With regards to the questionnaires, participants were found to be less energetic on the POMS after biperiden and rivastigmine (see Table 3). However, the POMS questionnaire also indicated that biperiden and rivastigmine made the volunteers feel less tired, and that biperiden made them even feel happier. This latter finding is in line with previous studies reporting an antidepressant effect of scopolamine (Furey \& Drevets, 2006; Furey et al., 2010). In contrast, the Bond \& Lader subscale we used, alert-drowsy, did not yield any treatment effects. Furthermore, our self-report questionnaire also included some questions pertaining to energy level of the participants (i.e., sleepiness, tiredness, drowsiness, listlessness). However, no changes in self-report complaints were noted after our treatment conditions. On basis of the questionnaire data it is therefore unclear whether the participants experienced any significant sedative side-effects. However, four participants dropped out of the study prematurely, so this cannot be excluded.

\section{Conclusions}

Biperiden increased P50 amplitude and prolonged N100 and P200 latency in the pairedclick task. However, we presume that the delayed latency of later-occurring peaks (i.e., P200) is likely due to slowing of initial auditory processing after biperiden (i.e., N100). Rivastigmine was able to reverse the biperiden-induced delay in N100 and P200 latency in the paired-click task, but was unable to do so for the increment in P50 amplitude after biperiden. As for the novelty oddball task, biperiden increased P50 latency which was reversed by concurrent administration of rivastigmine. Rivastigmine shortened N100 latency and enhanced $\mathrm{P} 3 \mathrm{a}$ amplitude, both of which were reversed by biperiden.

Overall, attributing specific treatment effects on AEPs to the muscarinic $M_{1}$ receptor is not very straightforward. The only exception is the effect of biperiden on pre-attentive processing (i.e., P50 amplitude) in the paired-click task, which was truly independent from that of rivastigmine. There also seems to be a role for the $M_{1}$ receptor in early-attentive mechanisms (i.e., N100 latency) in the paired-click task, and in pre-attentive processing (i.e., P50 latency) in the novelty oddball paradigm. However, reversal of effects of biperiden by concurrent rivastigmine treatment makes the evidence in favor of $M_{1}$-mediation much more equivocal. Muscarinic receptors other than $M_{1}$ (i.e., $M_{2}-M_{5}$ ) and nicotinic receptors 
appear to be important for early-attentive (N100 latency) and novelty processing (i.e., P3a amplitude) in the novelty oddball paradigm. Yet again, reversal of effects of rivastigmine by concurrent biperiden treatment is not fully reflective of a role for $M_{2}-M_{5}$ and/or nicotinic, but not $M_{1}$ receptors.

It remains to be seen whether the effects of cholinergic drugs on AEPs are specifically related to the abnormalities found in schizophrenia. Indeed, the usefulness of some of these markers as endophenotypes for schizophrenia has been questioned (e.g., Simons et al., 2011). Alternatively, aberrant auditory processing could also be indicative of a general disturbance in frontal functioning shared by several neuropsychiatric disorders and/or neurodegenerative changes seen in aging. Future experimental research should focus on determining whether there exists some degree of dissociation between muscarinic receptor subtypes in terms of their involvement in normal and pathological auditory processing. This would be beneficial for discovering specific trait markers of different neuropsychiatric disorders. Furthermore, new studies investigating the role of muscarinic receptors in auditory processing should look into dissociations between effects of muscarinic $M_{1}$ antagonists and cholinesterase inhibitors on redundancy suppression versus change detection. This can be done by experimentally varying the task parameters of paired-click and/or novelty oddball paradigms (e.g., stimulus intensity, duration, and/or pitch, inter-stimulus or inter-pair interval, stimulus frequency) to determine which aspects of these tasks are most sensitive to changes in muscarinic signaling. 


\section{REFERENCES}

Adler, L. E., Olincy, A., Waldo, M., Harris, J. G., Griffith, J., Stevens, K., et al. (1998). Schizophrenia, sensory gating, and nicotinic receptors. Schizophrenia Bulletin, 24, 189-202.

Adler, L. E., Pachtman, E., Franks, R. D., Pecevich, M., Waldo, M. C., \& Freedman, R. (1982). Neurophysiological evidence for a defect in neuronal mechanisms involved in sensory gating in schizophrenia. Biological Psychiatry, 17, 639-654.

Amenedo, E., \& Diaz, F. (1998). Aging-related changes in processing of non-target and target stimuli during an auditory oddball task. Biological Psychology, 48, 235-267.

Bertoli, S., Smurzynski, J., \& Probst, R. (2002). Temporal resolution in young and elderly subjects as measured by mismatch negativity and a psychoacoustic gap detection task. Clinical Neurophysiology, 113, 396-406.

Bolden, C., Cusack, B., \& Richelson, E. (1992). Antagonism by antimuscarinic and neuroleptic compounds at the five cloned human muscarinic cholinergic receptors expressed in Chinese hamster ovary cells. The Journal of Pharmacology and Experimental Therapeutics, 260, 576-580.

Bond, A., \& Lader, M. (1974). The use of analogue scales in rating subjective feelings. British Journal of Medical Psychology, 80, 1-46.

Bora, E., Veznedaroglu, B., \& Kayahan, B. (2005). The effect of galantamine added to clozapine on cognition of five patients with schizophrenia. Clinical Neuropharmacology, 28, 139-141.

Boutros, N. N., Korzyukov, O., Jansen, B., Feingold, A., \& Bell, M. (2004). Sensory gating deficits during the mid-latency phase of information processing in medicated schizophrenia patients. Psychiatry Research, 126, 203-215.

Bramon, E., Croft, R. J., McDonald, C., Virdi, G. K., Gruzelier, J. G., Baldeweg, T., et al. (2004a). Mismatch negativity in schizophrenia: a family study. Schizophrenia Research, 67, 1-10.

Bramon, E., Rabe-Hesketh, S., Sham, P., Murray, R. M., \& Frangou, S. (2004b). Meta-analysis of the P300 and P50 waveforms in schizophrenia. Schizophrenia Research, 70, 315-329.

Brockhaus-Dumke, A., Schultze-Lutter, F., Mueller, R., Tendolkar, I., Bechdolf, A., Pukrop, R., et al. (2008). Sensory gating in schizophrenia: P50 and N100 gating in antipsychotic-free subjects at risk, first-episode, and chronic patients. Biological Psychiatry, 64, 376-384.

Buchanan, R. W., Conley, R. R., Dickinson, D., Ball, M. P., Feldman, S., Gold, J. M., et al. (2008). Galantamine for the treatment of cognitive impairments in people with schizophrenia. American Journal of Psychiatry, 165, 82-89.

Buchanan, R. W., Summerfelt, A., Tek, C., \& Gold, J. (2002). An open-label trial of adjunctive donepezil for cognitive impairments in patients with schizophrenia. Schizophrenia Research, 59, 29-33.

Buchwald, J. S., Erwin, R. J., Read, S., Van Lancker, D., \& Cummings, J. L. (1989). Midlatency auditory evoked responses: differential abnormality of P1 in Alzheimer's disease. Electroencephalography and Clinical Neurophysiology, 74, 378-384.

Buchwald, J. S., Rubinstein, E. H., Schwafel, J., \& Strandburg, R. J. (1991). Midlatency auditory evoked responses: differential effects of a cholinergic agonist and antagonist. Electroencephalography and Clinical Neurophysiology, 80, 303-309.

Cadenhead, K. S., Light, G. A., Geyer, M. A., \& Braff, D. L. (2000). Sensory gating deficits assessed by the P50 event-related potential in subjects with schizotypal personality disorder. American Journal of Psychiatry, 157, 55-59.

Comerchero, M. D., \& Polich, J. (1999). P3a and P3b from typical auditory and visual stimuli. Clinical Neurophysiology, 110, 24-30.

Curran, H. V., Pooviboonsuk, P., Dalton, J. A., \& Lader, M. H. (1998). Differentiating the effects of centrally acting drugs on arousal and memory: an event-related potential study of scopolamine, lorazepam and diphenhydramine. Psychopharmacology, 135, 27-36.

De Wilde, O. M., Bour, L. J., Dingemans, P. M., Koelman, J. H. T. M., \& Linszen, D. H. (2007). Failure to find P50 suppression deficits in young first-episode patients with schizophrenia and clinically unaffected siblings. Schizophrenia Bulletin, 33, 1319-1323.

Donchin, E. (1981). Surprise! . . Surprise? Psychophysiology, 18, 493-513.

Dyer, M. A., Freudenreich, O., Culhane, M. A., Pachas, G. N., Deckersbach, T., Murphy, E., et al. (2008). Highdose galantamine augmentation inferior to placebo on attention, inhibitory control and working memory performance in nonsmokers with schizophrenia. Schizophrenia Research, 102, 88-95. 
Erwin, R. J., Turetsky, B.I., Moberg, P., Gur, R.C., \& Gur, R.E. (1998). P50 abnormalities in schizophrenia: Relationship to clinical and neuropsychological indices of attention. Schizophrenia Research, 33, 157167.

Farlow, M. R. (2003). Update on rivastigmine. Neurologist, 9, 230-234.

Fein, G., Biggins, C., \& Van Dyke, C. (1994). The auditory P50 response is normal in Alzheimer's disease when measured via a paired click paradigm. Electroencephalography and Clinical Neurophysiology, 92, 536545.

Fjell, A. M., \& Walhovd, K. B. (2004). Life-span changes in P3a. Psychophysiology, 41, 575-583.

Fjell, A. M., Walhovd, K. B., Fischl, B., \& Reinvang, I. (2007). Cognitive function, P3a/P3b brain potentials, and cortical thickness in aging. Human Brain Mapping, 28, 1098-1116.

Ford, J. M. (1999). Schizophrenia: the broken P300 and beyond. Psychophysiology, 36, 667-682.

Friedman, J. I. (2004). Cholinergic targets for cognitive enhancement in schizophrenia: focus on cholinesterase inhibitors and muscarinic agonists. Psychopharmacology, 174, 45-53.

Friedman, J. I., Adler, D. N., Howanitz, E., Harvey, P. D., Brenner, G., Temporini, H., et al. (2002). A double blind placebo controlled trial of donepezil adjunctive treatment to risperidone for the cognitive impairment of schizophrenia. Biological Psychiatry, 51, 349-357.

Furey, M. L., \& Drevets, W. C. (2006). Antidepressant efficacy of the antimuscarinic drug scopolamine: a randomized, placebo-controlled clinical trial. Archives of General Psychiatry, 63, 1121-1129.

Furey, M. L., Khanna, A., Hoffman, E. M., \& Drevets, W. C. (2010). Scopolamine produces larger antidepressant and antianxiety effects in women than in men. Neuropsychopharmacology, 35, 2479-2488.

Garrido, M. I., Kilner, J. M., Stephan, K. E., \& Friston, K. J. (2009). The mismatch negativity: A review of underlying mechanisms. Clinical Neurophysiology, 120, 453-463.

Golob, E. J., Johnson, J. K., \& Starr, A. (2001a). Auditory event-related potentials during target detection are abnormal in mild cognitive impairment. Clinical Neurophysiology, 113, 151-161.

Golob, E. J., Miranda, G. G., Johnson, J. K., \& Starr, A. (2001b). Sensory cortical interactions in aging, mild cognitive impairment, and Alzheimer's disease. Neurobiology of Aging, 22, 755-763.

Grillon, C., Courchesne, E., Ameli, R., Geyer, M. A., \& Braff, D. L. (1990). Increased distractibility in schizophrenic patients. Electrophysiologic and behavioral evidence. Archives of General Psychiatry, 47, 171179.

Grunwald, T., Boutros, N. N., Pezer, N., von Oertzen, J., Fernandez, G., Schaller, C., et al. (2003). Neuronal substrates of sensory gating within the human brain. Biological Psychiatry, 53, 511-519.

Hämäläinen, M., Hari, R., Ilmoniemi, R. J., Knuutila, J., \& Lounasmaa, O. V. (1993). Magnetoencephalography - Theory, instrumentation, and applications to noninvasive studies of the working human brain. Review of Modern Physics, 65, 413-497.

Hollmann, M., Brode, E., Greger, G., Müller-Peltzer, H., \& Wetzelsberger, N. (1984). Biperiden effects and plasma levels in volunteers. European Journal of Clinical Pharmacology, 27, 619-621.

Hollmann, M., Müller-Peltzer, H., Greger, G., Brode, E., Perucca, E., Grimaldi, R., et al. (1987). Pharmacokinetic-dynamic study on different oral biperiden formulations in volunteers. Pharmacopsychiatry, 20, 72 77.

Inami, R., Kirino, E., Inoue, R., \& Arai, H. (2005). Transdermal nicotine administration enhances automatic auditory processing reflected by mismatch negativity. Pharmacology, Biochemistry and Behavior, 80, 453-461.

Iragui, V. J., Kutas, M., Mitchiner, M. R., \& Hillyard, S. A. (1993). Effects of aging on event-related brain potentials and reaction times in an auditory oddball task. Psychophysiology, 30, 10-22.

Irimajiri, R., Golob, E. J., \& Starr, A. (2005). Auditory brain-stem, middle- and long-latency evoked potentials in mild cognitive impairment. Clinical Neurophysiology, 116, 1918-1929.

Jann, M. W., Shirley, K. L., \& Small, G. W. (2002). Clinical pharmacokinetics and pharmacodynamics of cholinesterase inhibitors. Clinical Pharmacokinetics, 41, 719-739.

Jasper, H. (1958). The ten-twenty electrode system of the international federation. Electroencephalography and Clinical Neurophysiology, 10, 371-375.

Javitt, D. C., Spencer, K. M., Thaker, G. K., Winterer, G., \& Hajós, M. (2008). Neurophysiological biomarkers for drug development in schizophrenia. Nature reviews Drug Discovery, 7, 68-83.

Jeon, Y. W., \& Polich, J. (2001). P300 asymmetry in schizophrenia: a meta-analysis. Psychiatry Research, 104, $61-74$ 
Jin, Y., Bunney Jr., W. E., Sandman, C. A., Patterson, J. V., Fleming, K., Moenter, J. R., et al. (1998). Is P50 suppression a measure of sensory gating in schizophrenia? Biological Psychiatry, 43, 873-878.

Jin, Y., Potkin, S. G., Patterson, J. V., Sandman, C. A., Hetrick, W. P., \& Bunney, W. E., Jr. (1997). Effects of P50 temporal variability on sensory gating in schizophrenia. Psychiatry Research, 70, 71-81.

Johnstone, E. C., Crow, T. J., Ferrier, I. N., Frith, C. D., Owens, D. G. C., Bourne, R. C., et al. (1983). Adverse effects of anticholinergic medication on positive schizophrenic symptoms. Psychological Medicine, 13, 513-527.

Kadir, A., Darreh-Shori, T., Almkvist, O., Wall, A., Langstrom, B., \& Nordberg, A. (2007). Changes in brain 11Cnicotine binding sites in patients with mild Alzheimer's disease following rivastigmine treatment as assessed by PET. Psychopharmacology, 191, 1005-1014.

Karoumi, B., Laurent, A., Rosenfeld, F., Rochet, T., Brunon, A. M., Dalery, J., et al. (2000). Alteration of event related potentials in siblings discordant for schizophrenia. Schizophrenia Research, 41, 325-334.

Katayama, S., Ishizaki, F., Yamamura, Y., Khoriyama, T., \& Kito, S. (1990). Effects of anticholinergic antiparkinsonian drugs on binding of muscarinic receptor subtypes in rat brain. Research Communications in Chemical Pathology and Pharmacology, 69, 261-270.

Kathmann, N., \& Engel, R. R. (1990). Sensory gating in normals and schizophrenics: a failure to find strong P50 suppression in normals. Biological Psychiatry, 27, 1216-1226.

Knight, R. T. (1987). Aging decreases auditory event-related potentials to unexpected stimuli in humans. Neurobiology of Aging, 8, 109-113.

Knott, V. J., Harr, A., \& Ilivitsky, V. (1999). Separate and combined effects of scopolamine and mecamylamine on human event-related brain potentials. Human Psychopharmacology - Clinical and Experimental, 14, 307-317.

Lee, B. J., Lee, J. G., \& Kim, Y. H. (2007). A 12-week, double-blind, placebo-controlled trial of donepezil as an adjunct to haloperidol for treating cognitive impairments in patients with chronic schizophrenia. Journal of Psychopharmacology, 21, 421-427.

Lee, S. W., Lee, J. G., Lee, B. J., \& Kim, Y. H. (2007). A 12-week, double-blind, placebo-controlled trial of galantamine adjunctive treatment to conventional antipsychotics for the cognitive impairments in chronic schizophrenia. International Clinical Psychopharmacology, 22, 63-68.

Lefevre, G., Sedek, G., Jhee, S. S., Leibowitz, M. T., Huang, H. L., Enz, A., et al. (2008). Pharmacokinetics and pharmacodynamics of the novel daily rivastigmine transdermal patch compared with twice-daily capsules in Alzheimer's disease patients. Clinical Pharmacology \& Therapeutics, 83, 106-114.

Leiser, S. C., Dunlop, J., Bowlby, M. R., \& Devilbiss, D. M. (2011). Aligning strategies for using EEG as a surrogate biomarker: A review of preclinical and clinical research. Biochemical Pharmacology, 81, 1408-1421.

Lijffijt, M., Lane, S. D., Meier, S. L., Boutros, N. N., Burroughs, S., Steinberg, J. L., et al. (2009). P50, N100 and P200 sensory gating: Relationships with behavioral inhibition, attention, and working memory. Psychophysiology, 46, 1059-1068.

McGhie, A., \& Chapman, J. (1961). Disorders of attention and perception in early schizophrenia. British Journal of Medical Psychology, 34, 103-116.

McNair, D. M., Lorr, M., \& Droppleman, L. F. (1971). Manual for the profile of mood states. San Diego, CA: Educational and Industrial Testing Service.

Meador, K. J., Loring, D. W., Adams, R. J., Patel, B. R., Davis, H. C., \& Hammond, E. J. (1987). Central cholinergic systems and the P3 evoked potential. International Journal of Neuroscience, 33, 199-205.

Meador, K. J., Loring, D. W., Davis, H. C., Sethi, K. D., Patel, B. R., Adams, R. J., et al. (1989). Cholinergic and serotonergic effects on the $\mathrm{P} 3$ potential and recent memory. Journal of Clinical and Experimental Neuropsychology, 11, 252-260.

Meador, K. J., Loring, D. W., Lee, G. P., Taylor, H. S., Hughes, D. R., \& Feldman, D. S. (1988). In vivo probe of central cholinergic systems. Journal of Gerontology, 43, M158-162.

Mintzer, J., \& Burns, A. (2000). Anticholinergic side-effects of drugs in elderly people. Journal of the Royal Society of Medicine, 93, 457-462.

Näätänen, R., Pakarinen, S., Rinne, T., \& Takegata, R. (2004). The mismatch negativity (MMN): towards the optimal paradigm. Clinical Neurophysiology, 115, 140-144.

Nagamoto, H. T., Adler, L. E., Waldo, M. C., \& Freedman, R. (1989). Sensory gating in schizophrenics and normal controls: effects of changing stimulation interval. Biological Psychiatry, 25, 549-561. 
Ogino, S., Miyamoto, S., Tenjin, T., Kitajima, R., Ojima, K., Miyake, N., et al. (2011). Effects of discontinuation of long-term biperiden use on cognitive function and quality of life in schizophrenia. Progress in NeuroPsychopharmacology \& Biological Psychiatry, 35, 78-83.

Ogura, C., Nageishi, Y., Matsubayashi, M., Omura, F., Kishimoto, A., \& Shimokochi, M. (1991). Abnormalities in event-related potentials, N100, P200, P300 and slow wave in schizophrenia. Japanese Journal of Psychiatry Neurology, 45, 57-65.

Olincy, A., Braff, D. L., Adler, L. E., Cadenhead, K. S., Calkins, M. E., Dobie, D. J., et al. (2010). Inhibition of the P50 cerebral evoked response to repeated auditory stimuli: results from the Consortium on Genetics of Schizophrenia. Schizophrenia Research, 119, 175-182.

Oranje, B., Geyer, M. A., Bocker, K. B. E., Kenemans, J. L., \& Verbaten, M. N. (2006). Prepulse inhibition and P50 suppression: Commonalities and dissociations. Psychiatry Research, 143, 147-158.

Patterson, J. V., Hetrick, W. P., Boutros, N. N., Jin, Y., Sandman, C., Stern, H., et al. (2008). P50 sensory gating ratios in schizophrenics and controls: A review and data analysis. Psychiatry Research, 158, 226-247.

Patterson, J. V., Jin, Y., Gierczak, M., Hetrick, W. P., Potkin, S., Bunney, W. E., Jr., et al. (2000). Effects of temporal variability on p50 and the gating ratio in schizophrenia: a frequency domain adaptive filter single-trial analysis. Archives of General Psychiatry, 57, 57-64.

Pekkonen, E., Hirvonen, J., Jaaskelainen, I. P., Kaakkola, S., \& Huttunen, J. (2001). Auditory sensory memory and the cholinergic system: implications for Alzheimer's disease. Neurolmage, 14, 376-382.

Pekkonen, E., Jaaskelainen, I. P., Kaakkola, S., \& Ahveninen, J. (2005). Cholinergic modulation of preattentive auditory processing in aging. Neurolmage, 27, 387-392.

Pontifex, M. B., Hillman, C. H., \& Polich, J. (2009). Age, physical fitness, and attention: P3a and P3b. Psychophysiology, 46, 379-387.

Potter, D. D., Pickles, C. D., Roberts, R. C., \& Rugg, M. D. (2000). The effect of cholinergic receptor blockade by scopolamine on memory performance and the auditory P3. Journal of Psychophysiology, 14, 11-23.

Price, G. W., Michie, P. T., Johnston, J., Innes-Brown, H., Kent, A., Clissa, P., et al. (2006). A multivariate electrophysiological endophenotype, from a unitary cohort, shows greater research utility than any single feature in the Western Australian family study of schizophrenia. Biological Psychiatry, 60, 1-10.

Pritchard, W., Sokhadze, E., \& Houlihan, M. (2004). Effects of nicotine and smoking on event-related potentials: a review. Nicotine \& Tobacco Research, 6, 961-984.

Rinne, T., Alho, K., Ilmoniemi, R. J., Virtanen, J., \& Naatanen, R. (2000). Separate time behaviors of the temporal and frontal mismatch negativity sources. Neurolmage, 12, 14-19.

Risch, S. C., Horner, M. D., McGurk, S. R., Palecko, S., Markowitz, J. S., Nahas, Z., et al. (2007). Double-blind donepezil-placebo crossover augmentation study of atypical antipsychotics in chronic, stable schizophrenia: a pilot study. Schizophrenia Research, 93, 131-135.

Sarter, M., Lustig, C., \& Taylor, S. F. (2012). Cholinergic contributions to the cognitive symptoms of schizophrenia and the viability of cholinergic treatments. Neuropharmacology, 62, 1544-1553.

Schubert, M. H., Young, K. A., \& Hicks, P. B. (2006). Galantamine improves cognition in schizophrenic patients stabilized on risperidone. Biological Psychiatry, 60, 530-533.

Semlitsch, H. V., Anderer, P., Schuster, P., \& Presslich, O. (1986). A solution for reliable and valid reduction of ocular artifacts, applied to the P300 ERP. Psychophysiology, 23, 695-703.

Shekhar, A., Potter, W. Z., Lightfoot, J., Lienemann, J., Dubé, S., Mallinckrodt, C., et al. (2008). Selective muscarinic receptor agonist xanomeline as a novel treatment approach for schizophrenia. American Journal of Psychiatry, 165, 1033-1039.

Shenton, M. E., Faux, S. F., McCarley, R. W., Ballinger, R., Coleman, M., \& Duffy, F. H. (1989). Clinical correlations of auditory P200 topography and left temporo-central deficits in schizophrenia: a preliminary study. Journal of Psychiatry Research, 23, 13-34.

Simons, C. J. P., Sambeth, A., Krabbendam, L., Pfeifer, S., Van Os, J., \& Riedel, W. J. (2011). Auditory P300 and N100 components as intermediate phenotypes for psychotic disorder: Familial liability and reliability. Clinical Neurophysiology, 122, 1984-1990.

Souza, V. B., Muir, W. J., Walker, M. T., Glabus, M. F., Roxborough, H. M., Sharp, C. W., et al. (1995). Auditory P300 event-related potentials and neuropsychological performance in schizophrenia and bipolar affective disorder. Biological Psychiatry, 37, 300-310.

Tandon, R., DeQuardo, J. R., Goodson, J., Mann, N. A., \& Greden, J. F. (1992). Effect of anticholinergics on positive and negative symptoms in schizophrenia. Psychopharmacology Bulletin, 28, 297-302. 
Tandon, R., Mann, N. A., Eisner, W. H., \& Coppard, N. (1990). Effect of anticholinergic medication on positive and negative symptoms in medication-free schizophrenic patients. Psychiatry Research, 31, 235-241.

Thomas, C., vom Berg, I., Rupp, A., Seidl, U., Schroder, J., Roesch-Ely, D., et al. (2010). P50 gating deficit in Alzheimer dementia correlates to frontal neuropsychological function. Neurobiology of Aging, 31, 416424.

Turetsky, B. I., Cannon, T. D., \& Gur, R. E. (2000). P300 subcomponent abnormalities in schizophrenia: III. Deficits In unaffected siblings of schizophrenic probands. Biological Psychiatry, 47, 380-390.

Umbricht, D., Koller, R., Schmid, L., Skrabo, A., Grubel, C., Huber, T., et al. (2003). How specific are deficits in mismatch negativity generation to schizophrenia? Biological Psychiatry, 53, 1120-1131.

Umbricht, D., \& Krljes, S. (2005). Mismatch negativity in schizophrenia: a meta-analysis. Schizophrenia Research, 76, 1-23.

Wezenberg, E., Verkes, R. J., Sabbe, B. G., Ruigt, G. S., \& Hulstijn, W. (2005). Modulation of memory and visuospatial processes by biperiden and rivastigmine in elderly healthy subjects. Psychopharmacology, 181, 582-594.

Williams, T. J., Nuechterlein, K. H., Subotnik, K. L., \& Yee, C. M. (2011). Distinct neural generators of sensory gating in schizophrenia. Psychophysiology, 48, 470-478.

Zouridakis, G., \& Boutros, N. N. (1992). Stimulus parameter effects on the P50 evoked response. Biological Psychiatry, 32, 839-841. 

CHAPTER 8

General Discussion 


\section{AIM OF THE DISSERTATION}

The main aim of the current dissertation was to investigate the role of the muscarinic $M_{1}$ receptor in cognition. To summarize and interpret the findings, the following questions were addressed: 1 ) Does biperiden induce selective effects on cognition? 2) Are effects of cholinergic drugs (i.e., biperiden and cholinesterase inhibitors donepezil and rivastigmine) comparable with respect to behavior vs. EEG? 3) Are effects of cholinergic drugs on cognition and EEG comparable in humans vs. rats? 4) How do effects of cholinergic drugs on cognition and EEG relate to findings in patient groups which are presumed to have cholinergic dysfunction (i.e., Alzheimer's disease and schizophrenia)? Of note, we chose to only refer to studies using scopolamine and/or biperiden. Discussion of muscarinic drugs other than these is considered beyond the scope of this dissertation, as differences in pharmacodynamic and pharmacokinetic properties might complicate interpretation of the outcome of different studies. ${ }^{4}$

\section{SELECTIVITY OF BIPERIDEN}

\section{Behavior and cognition}

In Tables 1 and 2, an overview is provided of the effects of biperiden in rats and humans, respectively. As delineated in Chapter 2, besides affecting learning and memory processes scopolamine can induce a wide range of effects on cognition and behavior. This is line with the assumption that scopolamine induces non-selective, extensive blockade of muscarinic signaling throughout the brain and body - i.e., without much regard for muscarinic receptor subtype or brain region. In Chapter 3 we have demonstrated that at a dose of $3 \mathrm{mg} / \mathrm{kg}$ (IP) biperiden can induce selective effects on working memory but not psychomotor responding, food motivation or attention in rats. In contrast, scopolamine had widespread effects on all of these measures.

In humans, it seems that biperiden displayed the most robust effects on memory (Chapter 4), but did not influence attentional parameters (i.e., LIrr; Chapter 5). Effects on self-report questionnaires and psychomotor performance were equivocal (Chapters 4, 5 and 7), but are in line with the view that biperiden induces only minor side-effects. Thus, findings so far indicate that biperiden has relatively more selective effects on cognition compared to scopolamine (i.e., on learning/memory but not attention, see Chapters 4, 5 and Atri et al., 2004; Bahro et al., 1995; Bishop et al., 1996; Blin et al., 1994; Broks et al., 1988; Duka et al., 1996; Ellis et al., 2006; Fredrickson et al., 2008; Ghoneim \& Mewaldt, 1975; Grasby et al., 1995; Green et al., 2005; Kamboj \& Curran, 2006; Leopold \& Comroe, 1948; Little et al., 1998; Mintzer \& Griffiths, 2003; Thienel et al., 2009).

\footnotetext{
${ }^{4}$ In short, biperiden is the only selective $M_{1}$ antagonist approved for treatment of anti-psychotic-induced extrapyramidal symptoms in the Netherlands (e.g., Wezenberg et al., 2005). Besides biperiden, trihexyphenidyl, benztropine, and procyclidine also are available for anticholinergic treatment in the USA and are hence also the most commonly used drugs in the research literature. Of these four, biperiden exhibits the greatest relative specificity for $M_{1}$ compared to $M_{2}$ receptors, whereas affinity for $M_{3}$ and $M_{4}$ receptors is comparable between these drugs. Of note, the muscarinic antagonist pirenzepine is considered the most selective for muscarinic $M_{1}$ receptors. However, due to the fact that it does not readily cross the blood-brain barrier, its use is limited to central drug infusion in animal studies (Guthrie et al., 2000).
} 
Taken together, effects of biperiden on cognition in rats and humans can be characterized as follows: 1) primary effects on learning/memory- which are likely mediated by blockade of postsynaptic muscarinic $M_{1}$ receptors in hippocampus (Chapters 2, 3 and 4), 2) nonspecific central effects on psychomotor slowing - which are likely mediated via muscarinic $\mathrm{M}_{1}$-dopamine interactions in striatum (see Chapters 2-5 and De Klippel et al., 1993; Gerber et al., 2001; Thomsen et al., 2010). Peripheral side-effects are limited compared to scopolamine - i.e., at low doses there are minor to no effects on salivation or sedation (Chapters 2-5 and 7, but see: Doods et al., 1987; Liang et al., 2010). Although these effects appear dissociable in our studies based on dose conditions, a review of the literature shows that this is not always the case (see Tables 1 and 2), and more effort is needed to corroborate our results. Findings of effects of biperiden on other central (e.g., attention, visuospatial processing, motor learning, prepulse inhibition, mood, anxiety, and sedation) or peripheral processes (e.g., pupil dilation, pain perception, body temperature, smooth muscle tissue) need replication and/or are equivocal (see Tables 1 and 2).

\section{$E E G$}

In Chapter 6, the effects of scopolamine, biperiden and the acetylcholinesterase inhibitor donepezil on hippocampal auditory evoked potentials (AEPS) and sensory gating in rats were investigated. ${ }^{5}$ Scopolamine and biperiden both disrupted sensory gating by enhancing N1 amplitude of the S2 stimulus. In contrast to biperiden, scopolamine also had several latency effects. Thus, scopolamine globally affected auditory processing, whereas effects of biperiden were relatively more selective (i.e., restricted to N1 sensory gating). Studies on effects of scopolamine on rat AEPs in the literature have generally reported reductions in peak amplitude of early positive, but not negative components (Luntz-Leybman et al., 1992; Miyazato et al., 1995; Teneud et al., 2000; but see Campbell et al., 1995), which might be due to differences in muscarinic binding affinity between scopolamine vs. biperiden (see Chapters 2, 3 and 6). Unfortunately, biperiden has only been tested quantitatively (i.e., on EEG frequency bands), which makes the study in Chapter 6 the very first to describe effects of biperiden on AEPs in rats.

The studies described in Chapters $\mathbf{5}$ and $\mathbf{7}$ are the very first to report effects of biperiden on ERPs in humans. In Chapter 5 we have assessed the effects of biperiden on a LIrr task. Biperiden affected early perceptual processing, as it increased the N1 amplitude of preexposed (PE) predictor letters. In Chapter 7, we tested the effects of biperiden in a paired-click and novelty oddball paradigm. Again, biperiden affected early processing components. ${ }^{6}$ In contrast, scopolamine has been shown to affect both early and late ERP components in visual (Brandeis et al., 1992; Callaway et al., 1991; Donchin, 1981; but see Knott et al., 1999) and auditory paradigms.(Buchwald et al., 1991; Curran et al., 1998; Meador et al., 1987; but see Pekkonen et al., 2005).

Effects of biperiden on latencies of pre- and early attentional components (i.e., P50, N1) suggest that similar findings after scopolamine might be mediated by muscarinic $M_{1}$ receptor blockade (e.g., Pekkonen et al., 2005). However, amplitude effects of biperiden

\footnotetext{
${ }^{5}$ For scopolamine vs. biperiden comparison purposes, we will put relatively less focus on interpretation of the effects of acetylcholinesterase inhibitors donepezil and rivastigmine. These will be discussed in the parts of the discussion pertaining to the behavior vs. EEG and human vs. rat comparisons.

${ }^{6}$ The effect on P200 latency in the paired-click task in Chapter 7 was interpreted as reflective of a downstream effect on the N100 (cf. Simons et al., 2011).
} 
appear to be characterized by increments, whereas scopolamine generally induces decrements in ERP amplitudes in humans (Buchwald et al., 1991; Curran et al., 1998; but see Meador et al., 1987; Pekkonen et al., 2005). Lastly, effects of scopolamine on late ERP components (e.g., P200, P300) are likely due to blockade of muscarinic $M_{2}-M_{5}$ receptors. $A$ cognitive interpretation of these effects (i.e., reflective of memory vs. attention) will be provided in the sections below.

\section{CHOLINERGIC DRUG EFFECTS: BEHAVIOR VS. EEG}

In Chapters 3 and 4, we have seen that biperiden induced deficits in working memory in rats, and verbal learning and memory in human volunteers, respectively. Attentional processes - i.e., visual attention and LIrr; see Chapters $\mathbf{3}$ and 5, respectively - were shown to be unaffected in both species after biperiden. In contrast to the behavioral data, the EEG data suggests an effect of biperiden on pre- and early attentional processing (see Chapters 5, 6 and 7). This discrepancy in effects of biperiden on behavior vs. EEG could be explained by 1 ) exclusive effects of biperiden on attention, which underlie those on memory performance, 2) exclusive effects of biperiden on memory, whereas attentional effects on ERPs can be explained by an additional central or peripheral process which is affected, or 3) primary effects of biperiden on memory, and secondary on attention.

Findings of muscarinic $M_{1}$ receptors in a wide range of cortical areas (Caulfield, 1993) could serve as evidence corroborating the first hypothesis - i.e., mnemonic effects of biperiden on behavior can be explained by underlying effects on attention. However, the first hypothesis cannot account for the fact that we failed to find an effect of biperiden on attentional paradigms in Chapters $\mathbf{3}$ and $\mathbf{5}$, whereas disruptions of mnemonic functions after biperiden were relatively robust in both rats and humans in Chapters $\mathbf{3}$ and $\mathbf{4}$. Furthermore, in Chapter $\mathbf{3}$ we have shown that the impairment in working memory after biperiden in rats could be characterized as delay-dependent, and that performance at the zero-delay was statistically similar to saline. Intact performance at the zero-delay but not at longer delays would indicate an exclusive effect of biperiden on memory, whereas an underlying deficit in attention after biperiden would likely give rise to a working memory impairment across all delays.

However, the possibility remains that our paradigms in Chapters $\mathbf{3}$ and $\mathbf{5}$ were not sensitive enough to pick up attentional deficits after biperiden. As for the visual attention paradigm used for the rat study in Chapter 3, it was able to detect scopolamine-induced impairments, which would contradict this line of reasoning. However, underlying effects of scopolamine on psychomotor responding and/or food motivation could also have been responsible for the disruption in performance on the visual attention paradigm in Chapter 3. The LIrr task used in the human study described in Chapter $\mathbf{5}$ was set up as a visual target detection paradigm. Theories about LIrr have focused on behavioral switching (Weiner, 2003), attention (Lubow, 2005; Schmajuk, 2005) and inhibition of redundant stimuli (Gluck \& Myers, 1993). Hence, LIrr is thought of as a paradigm that measures attentional (or implicit associative learning) rather than mnemonic abilities. In sum, on basis of the findings in the current dissertation it is unlikely that the muscarinic $M_{1}$ receptor has a strong involvement in attention, but further studies are warranted. 
Alternatively, the second hypothesis on the discrepancy of effects of biperiden on behavior vs. EEG emphasizes an exclusive effect of biperiden on memory, whereas attentional effects on ERP data are caused by an additional central or peripheral process. Scopolamine has been shown to induce blurry vision due to pupil dilation, and some studies have indicated that muscarinic $\mathrm{M}_{1}$ blockade by biperiden might also affect ocular function (Almasieh et al., 2010; Gupta et al., 1994; but see Shiraishi \& Takayanagi, 1993). Indeed, at $5 \mathrm{mg}$ (IV) biperiden has been shown to cause blurred vision in healthy volunteers (e.g., Fleischhacker et al., 1987). However, our participants did not report visual impairments on the self-report questionnaires after biperiden in the studies described in Chapters 4, 5, and 7. Secondly, blurred vision would be likely to globally influence ERP peaks, and not just those belonging to one particular stimulus type (i.e, not only preexposed predictor letters, see Chapter 5). In addition, changes in ocular function after biperiden cannot explain why in Chapters 6 and 7 we have also found changes in pre- and early attentional ERP components using auditory paradigms.

Since biperiden influences attentional ERPs across modalities, this would argue for the possibility of a central process which is affected. For instance, these could be caused by sedative effects of biperiden. However, this is also not very plausible, as participants usually did not report feeling tired or drowsy on our self-report questionnaires in Chapters $\mathbf{4}$ and $\mathbf{5}$ (but see Chapter 7). Furthermore, reductions in arousal are associated with a decrease in N1 amplitude (Hillyard et al., 1973), which is in contrast with our findings in Chapter 5.

This line of reasoning leads us to the third hypothesis regarding the discrepancy between mnemonic effects of biperiden on behavior vs. attentional effects on ERP components: i.e., primary effects of biperiden on memory, and secondary on attention. This hypothesis would implicate that memory processes are more sensitive to disruption by biperiden and are hence already apparent at low doses at a behavioral level, whereas attentional functions are less easily affected, i.e., at low doses only effects on ERP components but not behavior. This argumentation would be consistent with the central distribution of the muscarinic $M_{1}$ receptor, which is present not only in the hippocampus, but also in cortical areas. Of note, our findings described in Chapter 6, i.e., deficits in hippocampal sensory gating after biperiden would argue against this line of reasoning. That is, muscarinic $M_{1}$ receptors in the hippocampus do not appear to be specifically involved in mnemonic processes.

\section{CHOLINERGIC DRUG EFFECTS: HUMAN VS. RAT}

With regards to our behavioral data, biperiden had fairly consistent effects in humans and rats, i.e., effects on memory but not attention (Chapters 3 and 4). However, our ERP findings were much less straightforward in terms of translational comparability. In human participants, biperiden enhanced the amplitudes and latencies of early perceptual peaks across modalities (Chapter 5 and 7), whereas in rats it only had amplitude effects in an auditory paradigm (Chapter 6 ). Moreover, in human volunteers biperiden did not influence sensory gating (Chapter 7), yet in rats we have shown a disruption of sensory gating after biperiden (Chapter 6). In the human study described in Chapter 7, concurrent intake of the cholinesterase inhibitor rivastigmine was able to undo only some of the effects of biperiden. In contrast, in the rat study in Chapter 6 the cholinesterase inhibitor donepezil was 
able to fully reverse the effects of biperiden on sensory gating. In humans, rivastigmine by itself affected both early and late AEP components (i.e, N100 and P3a; see Chapter 7), whereas in rats donepezil only affected early perceptual processing (i.e, N1; see Chapter 6).

Several methodological differences between these studies could account for the discrepancy in effects of biperiden on ERP components in humans vs. rats. First of all, EEG is measured in a distinctively different way between species. In humans, intermediate tissues - i.e., blood vessels, cerebrospinal fluid, brain meninges, skull and skin - all distort the EEG signal recorded at the scalp. Moreover, the EEG signal which is picked up by a single electrode likely reflects the sum of electrical field activity occurring synchronously in neurons which are located in cortical layers close to the scalp (Cacioppo et al., 2000). Given the relative thickness of the cortex in humans relative to that of rats, this implies that neuronal activity occurring in deeper regions such as the hippocampus is not readily picked up by scalp electrodes. That is, source localization with EEG would require a higher number of electrodes than the 32 channels we have used in our human studies (Chapters 5 and 7). In the rat study described in Chapter 6, we inserted electrodes locally in the dorsal hippocampus. Since the hippocampus is an important generator of sensory gating in both humans and rats (e.g., Bickford-Wimer et al., 1990; Bickford et al., 1993; Boutros et al., 2005; Grunwald et al., 2003; Krause et al., 2003; Williams et al., 2011), it might have been the case that the scalp electrodes used in our human studies were not sensitive enough to pick up biperiden-induced impairment of sensory gating and possible reversal of this deficit by acetylcholinesterase inhibitors (i.e., statistical type II error).

Of note, the doses we used were also very different between species; i.e., $3 \mathrm{mg} / \mathrm{kg}$ and $10 \mathrm{mg} / \mathrm{kg}$ induced behavioral impairments in rats (Chapter 3), and changes in AEP components were present after $1 \mathrm{mg} / \mathrm{kg}$ of biperiden (Chapter 6). In contrast, for our human studies we used a biperiden dose of $2 \mathrm{mg}$ (Chapters 4, 5, and 7). Formulas used for the translation of drug doses from animals to humans are usually based on body surface area (see Fig. 1 and Reagan-Shaw et al., 2008). For instance, a human dose of $2 \mathrm{mg}$ would be equivalent to $0.03 \mathrm{mg} / \mathrm{kg}$ (using an average human weight of $60 \mathrm{~kg}$, also see Reagan-Shaw et al., 2008). Although this number is much lower than the 1 and $3 \mathrm{mg} / \mathrm{kg}$ biperiden doses we have used in rats, it does correspond well with the scopolamine doses of 0.01 and 0.03 $\mathrm{mg} / \mathrm{kg}$ (Chapters 3 and 6 ).

In order to calculate the human doses which are equivalent to 1 and $3 \mathrm{mg} / \mathrm{kg}$ biperiden in rats (Chapters $\mathbf{3}$ and 6), we have used the conversion data for guinea pigs (see Table 1 in Reagan-Shaw et al., 2008). Namely, the weights of the rats in our study were more akin to those of guinea pigs (i.e., 400 grams for guinea pigs vs. 150 grams for rats, as listed in Reagan-Shaw et al., 2008). Using these data and the formula given below (formula for dose translation based on body surface area, taken from Reagan-Shaw et al., 2008), a rat dose of $1 \mathrm{mg} / \mathrm{kg}$ biperiden would be similar to a human dose of $0.21 \mathrm{mg} / \mathrm{kg}$, which equals about 13 $\mathrm{mg}$ for an average human being (using an average weight of $60 \mathrm{~kg}$, see Table 1 in ReaganShaw et al., 2008). A rat dose of $3 \mathrm{mg} / \mathrm{kg}$ biperiden would be equivalent to a dose of 0.65 $\mathrm{mg} / \mathrm{kg}$ and hence approximately $39 \mathrm{mg}$ for a human participant. These human equivalent doses of 13 and $39 \mathrm{mg}$ are obviously much higher than the $2 \mathrm{mg}$ of biperiden we have used in our human study, which would suggest that human participants, or alternatively, that human behavioral and EEG paradigms are relatively much more sensitive to the disruptive effects of biperiden. 
$H E D(m g / k g)=$ animal dose $(m g / k g) * \frac{\text { Animal Km}}{\text { Human Km}}$

However, this formula does not take into account any species differences between humans and rats in terms of pharmacokinetics or pharmacodynamics. A variety of papers have assessed pharmacokinetic properties of scopolamine and biperiden (in rats: Yokogawa et al., 1990; 1992; Lenz et al., 2012; Nakashima et al., 1987; 1993; in humans: Ebert et al., 2001; Grimaldi et al., 1986; Guthrie et al., 2000; Hollmann et al., 1984; 1987). For example, in normal control rats (9-21 weeks old), serum concentrations of $1 \mathrm{mg} / \mathrm{kg}$ scopolamine (1 $\mathrm{mg} / \mathrm{kg}$, IV, half an hour after injection) have been shown to be between $80-100 \mathrm{ng} / \mathrm{mL}$, whereas those of biperiden $(3.2 \mathrm{mg} / \mathrm{kg}$, IV, half an hour after injection) were found to be $400-600 \mathrm{ng} / \mathrm{mL}$ (Nakashima et al., 1993, and personal communication with J. Ishizaki, June $19^{\text {th }}, 2012$ ). Unfortunately, given the differences in dose conditions (in our studies we used $0.1,0.3$, and $1 \mathrm{mg} / \mathrm{kg}$ scopolamine and 1,3 , and $10 \mathrm{mg} / \mathrm{kg}$ biperiden) and route of administration (i.e., IP instead of IV injections), it is hard to relate these findings to those of our experiments (see Chapters 3 and 6).

The same holds for human studies on the pharmacokinetics of biperiden. For instance, in a study by Hollmann et al. (1987) participants who received a light breakfast and $4 \mathrm{mg}$ instant-release tablets of biperiden, plasma concentrations were $3.48 \mathrm{ng} / \mathrm{mL}$ (biperiden base) $1 \mathrm{~h}$ after intake (i.e., this is also the time at which we started testing in our human studies; see Chapters 4, 5 and 7). However, given that we have used a much lower dose of $2 \mathrm{mg}$, these plasma concentrations are not representative for our human experiments.

With respect to pharmacodynamics, several studies have assessed the binding of scopolamine and biperiden to muscarinic receptors in the rat and human brain (e.g., in rats: Ishizaki et al., 1998; Kimura et al., 1999; Nakashima et al., 1993; in humans: Sudo et al., 1999). For example, Nakashima et al. (1993) has shown that inhibition of $\left[{ }^{3} \mathrm{H}\right]$-QNB binding by scopolamine ( $1 \mathrm{mg} / \mathrm{kg}$, IV) and biperiden $(3.2 \mathrm{mg} / \mathrm{kg}$, IV) in the rat brain is highly comparable (albeit at lower doses; about a factor 3). Moreover, Ishizaki et al. (1998) demonstrated that drug concentrations in various brain regions in the rat decreased parallel to those in plasma after biperiden administration $(3.2 \mathrm{mg} / \mathrm{kg}$, IV). In a human study by Sudo et al. (1999) it has been found that after intake of biperiden (4 mg, PO), there was a good relationship between plasma concentration and muscarinic receptor occupancy in frontal cortex and striatum. Thus, in both species concentrations of biperiden in the periphery (i.e., blood plasma) appear to be reflective of those in the brain. However, there exist several differences between studies in the literature and our current experiments with respect to dose conditions (i.e., doses used in our studies are lower) and route of administration (PO instead of IV), which complicates interpretation.

In sum, biperiden had relatively consistent effects with respect to behavior in humans and rats, as it disrupted memory but not attentional processes. Regarding our EEG data, biperiden seemed to particularly affect early ERP components. We presume that differences in methodology, especially with respect to the sensitivity of the EEG equipment to pick up on hippocampal activity, underlie the discrepancies between human and rat studies. Furthermore, some progress has been made with respect to determining the pharmacodynamic and pharmacokinetic properties of scopolamine and biperiden in humans vs. rats. However, a direct comparison of plasma and brain concentrations at various doses of 
scopolamine and biperiden and in several species is currently lacking, which is pertinent in order to be able to compare effective dose ranges used in translational research.

\section{ROLE MUSCARINIC $M_{1}$ RECEPTOR IN NEUROPSYCHIATRIC DISORDERS}

One of the aims of the current dissertation was to relate findings of cognitive dysfunction after biperiden to neuropsychiatric disorders known to exhibit aberrant cholinergic signaling, such as Alzheimer's disease and schizophrenia (Bartus et al., 1982; Sarter et al., 2012). This discussion will be split into three sections: memory, LIrr, and auditory processing.

\section{Memory}

Memory deficits are common to both dementia and schizophrenia. Specifically, Alzheimer patients generally display lower scores on immediate and delayed recall trials, and higher forgetting rates (Estevez-Gonzalez et al., 2003; Greenaway et al., 2006). However, in Alzheimer patients an increase in only false positive errors has been reported with respect to word recognition (Greenaway et al., 2006). This is in contrast with our findings in Chapter 4, where we showed reduced recognition scores after biperiden regardless for old or new items- i.e., participants reported both more false positives (incorrectly identifying a new word as old) and false negatives (incorrectly labeling an old word as new).

Schizophrenia patients have also been shown to have impairments in word learning and recall (e.g., Hill et al., 2004). Evidence with respect to word recognition in schizophrenia patients is inconclusive, as both a higher rate of false positives (Weiss et al., 2004) but also false negatives (Jessen et al., 2003) has been reported. In sum, the reduction in recall scores after biperiden appears to be in line with findings of verbal memory impairment in both Alzheimer and schizophrenia patients. However, decreases in word recognition regardless for stimulus type (old vs. new) after biperiden does not reflect findings in the clinical literature.

In Chapter $\mathbf{3}$ we demonstrated an impairment in working memory after biperiden in rats. Working memory deficits appear to be one of the core features of schizophrenia (e.g., Abi-Dargham et al., 2002; Manoach, 2003). However, a quite recent meta-analysis showed that delay periods beyond $1 \mathrm{~s}$ did not worsen working memory deficits in schizophrenia patients (Lee \& Park, 2005). This is in disagreement with our findings in Chapter $\mathbf{3}$ where we have demonstrated a deterioration of working memory after biperiden which got progressively worse as an increasingly longer delay was interspersed between the sample and choice phase of the delayed non-matching to position (DNMTP) task. While this line of reasoning does not exclude the possibility of a role for the cholinergic system in working memory problems in schizophrenia, it does suggest a lack of involvement of the muscarinic $M_{1}$ receptor. In contrast, deficits in working memory in Alzheimer's disease have been reported previously (e.g, Baddeley et al., 1999), especially in early-onset Alzheimer patients (e.g., Kalpouzos et al., 2005). In sum, our result of a delay-dependent deficit in working memory performance after biperiden in rats is more in line with the findings in Alzheimer's disease rather than schizophrenia. 


\section{Learned irrelevance (LIrr)}

In Chapter 5 we have demonstrated that after biperiden human LIrr performance was still intact, showing that the muscarinic $M_{1}$ receptor is likely not involved in implicit learning. The only behavioral effect of biperiden was an overall increase in reaction time to the targets, regardless of the type of predictor letter preceding the target (RAN, PE, or NPE). With respect to the ERP data, biperiden increased the amplitude of the N1 component of the PE predictor letters, which we interpreted as an overcompensation of the irrelevant-torelevant switch. Our findings of a lack of effect of biperiden on LIrr are in strong contrast with those in the literature reporting LIrr deficits in acute schizophrenics and a failure to learn the cue-target association in chronic schizophrenics (Gal et al., 2005; Orosz et al., 2008; Young et al., 2005).

Interestingly, one report by Kathmann et al. (2000) found results comparable to our own; i.e., in acute and stable, partially remitted schizophrenic patients, there was no impairment of latent inhibition - a phenomenon closely related to LIrr. Moreover, schizophrenic patients did show slower RTs compared to the normal, healthy controls which is in accordance with our biperiden data. In addition, N1 amplitudes of CS+ stimuli - which were conceptually similar to our PE predictor letters - were decreased in healthy controls, increased in acute schizophrenics and unchanged in partially remitted schizophrenics after pre-exposure. In sum, the findings of Chapter $\mathbf{5}$ are only partially in line with those reported in the schizophrenia literature on LIrr and visual ERPs. Deficits in LIrr in schizophrenia are likely related to changes in dopaminergic (e.g., Slabosz et al., 2006), rather than cholinergic signaling.

\section{Auditory processing}

Most studies investigating sensory gating in schizophrenia have reported impaired P50 suppression due to a reduction of the initial P50 response to S1 (e.g., Jin \& Potkin, 1996; but see Jin et al., 1997; Patterson et al., 2000). These reports are thus in contrast with our findings of an enhancement of P50 amplitude but no effects on sensory gating after biperiden in human volunteers (Chapter 7), or with our results of disrupted sensory gating due to an enhancement of N1 amplitude at the S2 click after biperiden in rats (Chapter 6). However, in aging and age-related disorders such as mild cognitive impairment and Alzheimer's disease, an increase in amplitudes of early AEP components (Golob et al. 2001a; 2001b; Irimajiri et al., 2005) and reduced sensory gating due to an increase in P50 amplitude of the S2 click have also been reported (Cancelli et al., 2006; Jessen et al., 2001; Thomas et al., 2010; but see Buchwald et al., 1989; Fein et al., 1994).

In the human study in Chapter 7, we have shown that biperiden delayed the latencies of both early positive and negative peaks (i.e., N100 latency in the paired-click task and P50 latency in the novelty oddball paradigm). In schizophrenia, it seems that only early negative components are slowed (i.e., delayed latencies of N100, but not P50: Bramon et al., 2004; Karoumi et al., 2000; Ogura et al., 1991; Pekkonen et al., 2001; 2005), whereas aged participants and people with mild cognitive impairment display delayed latencies of early processing peaks regardless for polarity (Bertoli et al., 2002; Golob et al., 2001a; Iragui et al., 1993; but see Amenedo \& Diaz, 1998). In sum, our data are in line with a role for muscarinic $M_{1}$ signaling in cognitive impairments seen in aging and age-related disorders rather than schizophrenia. Moreover, neurodegenerative changes in muscarinic $M_{1}$ signaling giv- 
ing rise to early perceptual/attentional processing deficits may be early indicators of dementia.

\section{Directions for future research}

Future research should try to scrutinize the selective effects of biperiden compared to scopolamine, especially with respect to findings of mnemonic but not attentional deficits after biperiden. Given that low doses of biperiden are capable of affecting early perceptual/attentional ERP components across modalities, it would be interesting to determine whether higher doses of biperiden might be able to also induce attentional impairments at a behavioral level. However, at higher dose levels biperiden might have the tendency to also induce more peripheral side-effects, thereby complicating the interpretation of behavioral data. Moreover, it is pertinent that biperiden is tested in memory paradigms along with recording of EEG, to assesses whether it would influence mnemonic ERP components such as the P300 (particularly the P3b: Polich \& Criado, 2006).

In this respect, the development of ligands which are more selective for a particular muscarinic receptor subtype would be an important step in determining muscarinic receptor modulation of cognition. However, this has been challenging due to the highly conserved orthosteric acetylcholine binding site of muscarinic receptors (Bolden et al., 1992; Heinrich et al., 2009). Drugs that act at allosteric sites might provide a better means to selectively disrupt or enhance muscarinic $M_{1}$ signaling (e.g., Digby et al., 2012; Mohr et al., 2004; Ragozzino et al., 2012). However, these might activate or inhibit different regulatory pathways compared to drugs binding to orthosteric receptor sites (Davis et al., 2009) and have generally not yet been approved for use in human research. The question remains how we can link cognitive effects of partially selective muscarinic $M_{1}$ antagonists to blockade of a particular muscarinic receptor subtype in a particular brain region. An additional way to tackle this issue is to examine effects of selective muscarinic $M_{2}-M_{5}$ antagonists, and to combine animal and human psychopharmacological studies with central drug infusion and/or imaging methods (EEG, fMRI). For instance, the effects of scopolamine on attentional processes are likely mediated via muscarinic receptors other than $M_{1}$. Hence, selective muscarinic $M_{1}-M_{5}$ antagonists need to be perceived as additional pharmacological tools besides the golden standard scopolamine to elucidate muscarinic receptor modulation of cognition and behavior. 
\begin{tabular}{l|l} 
GENERAL DISCUSSION & 201
\end{tabular}

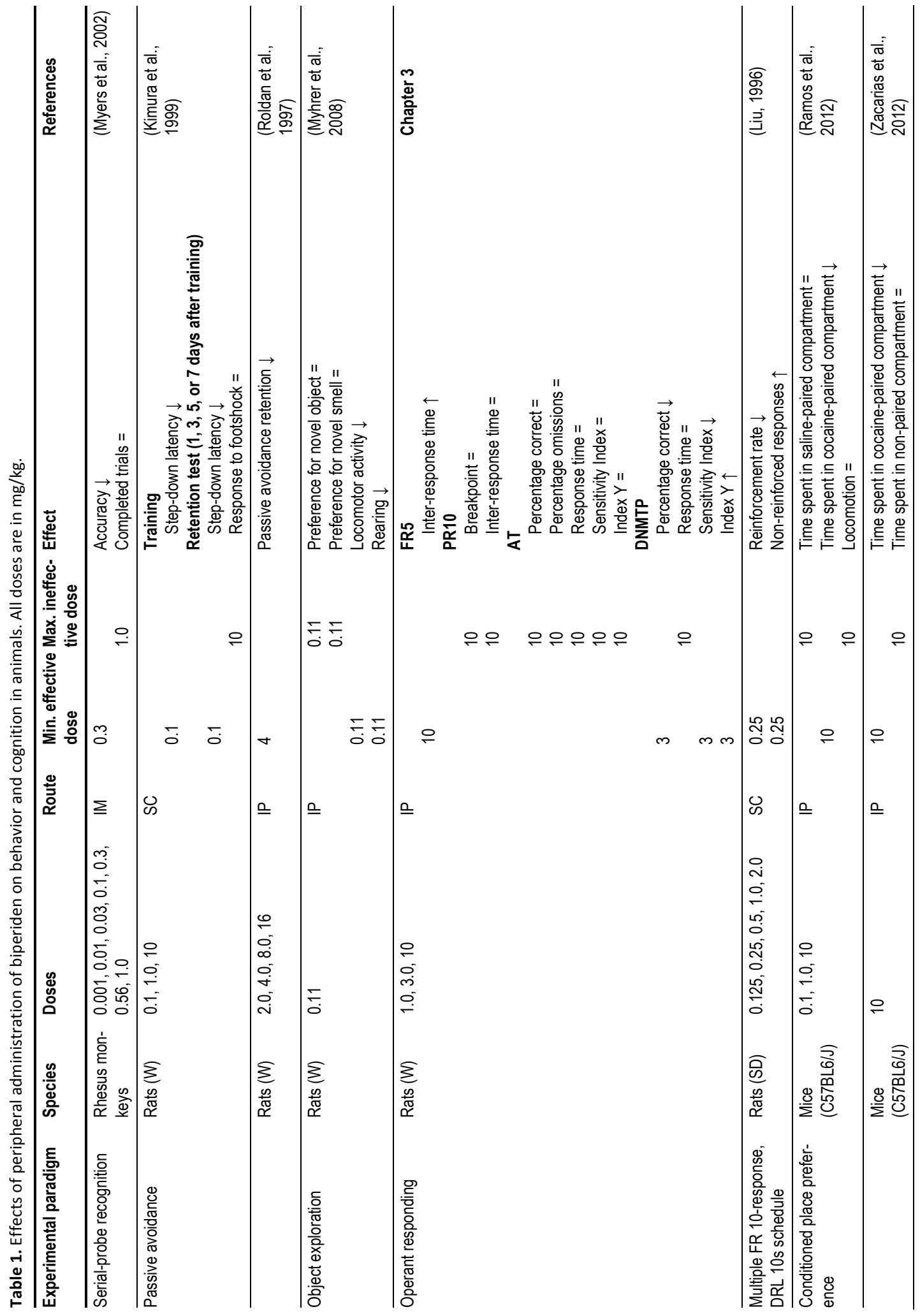




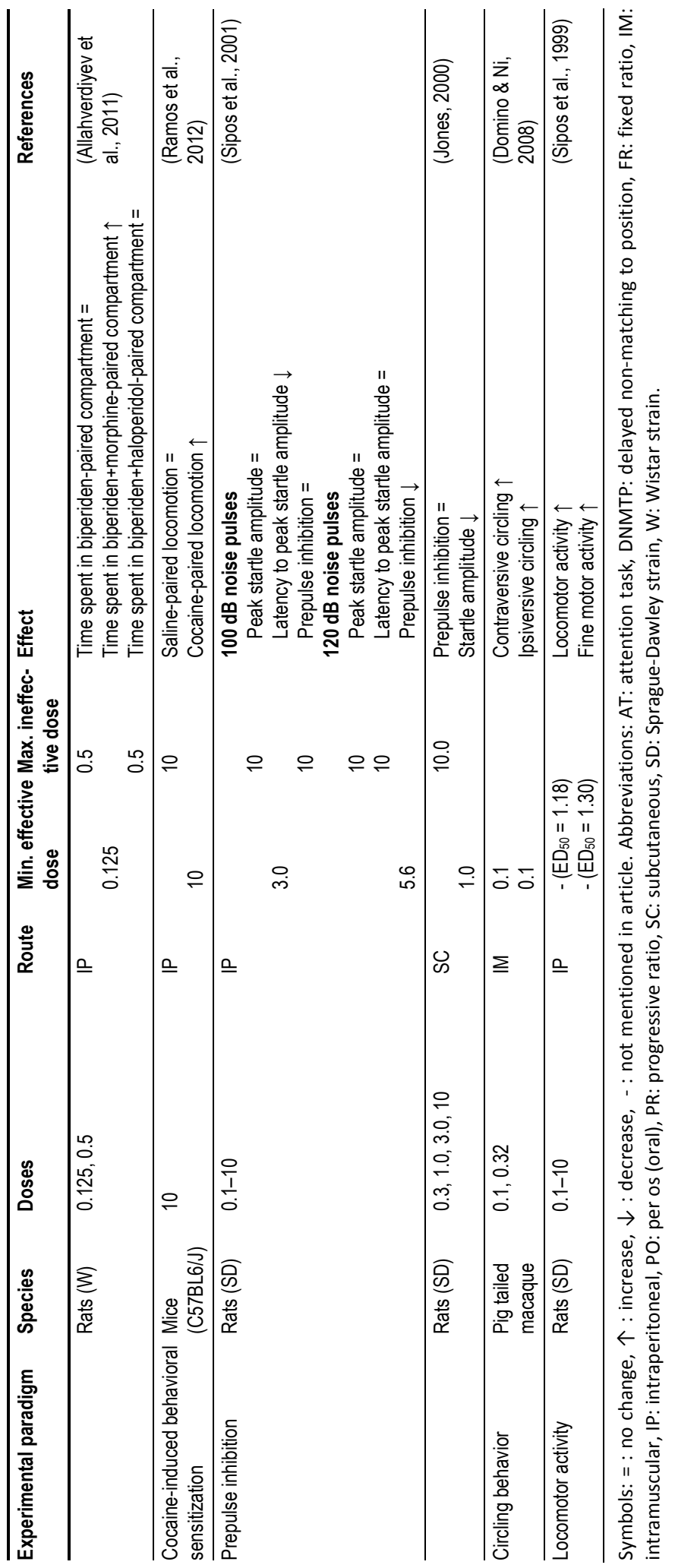




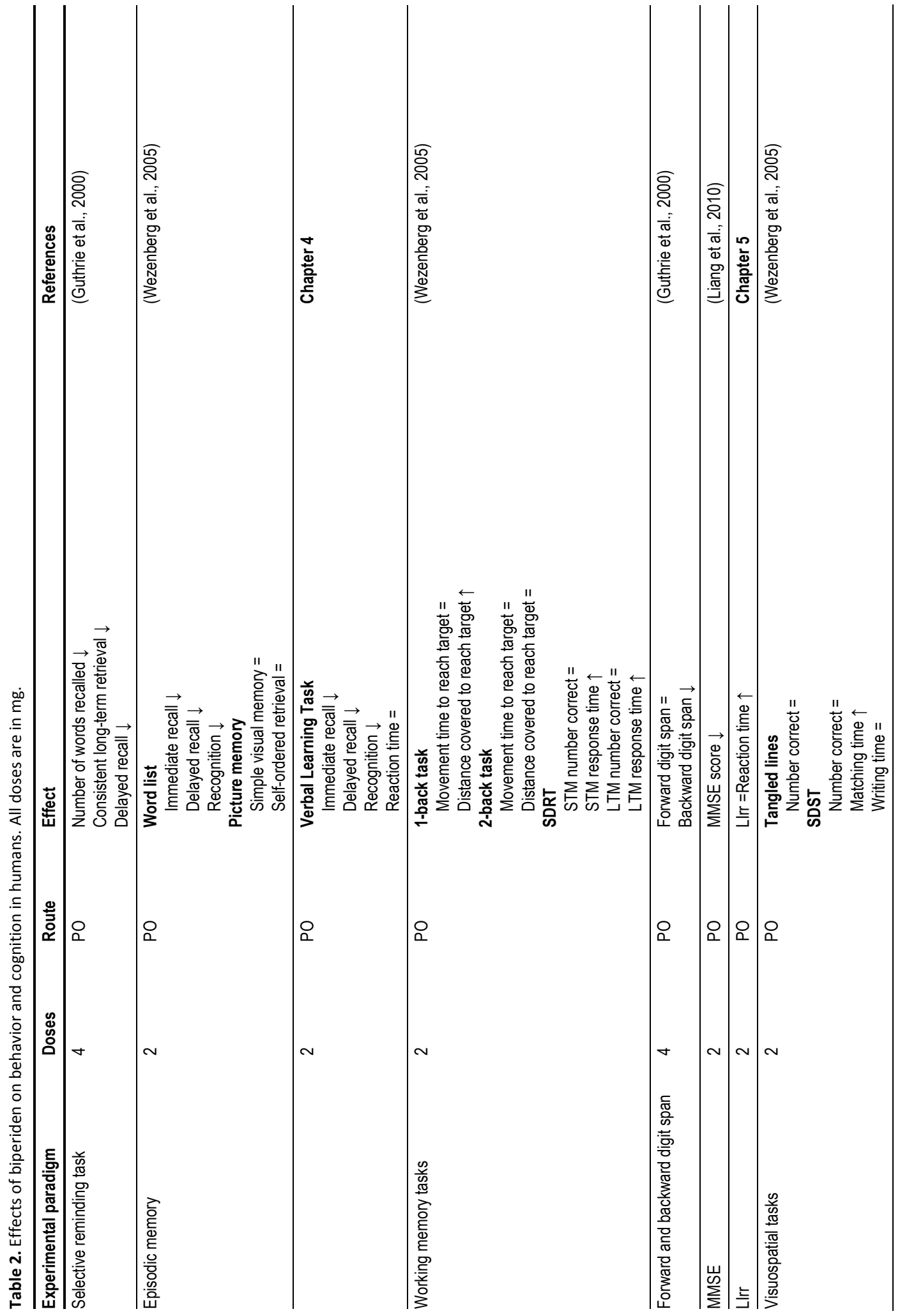



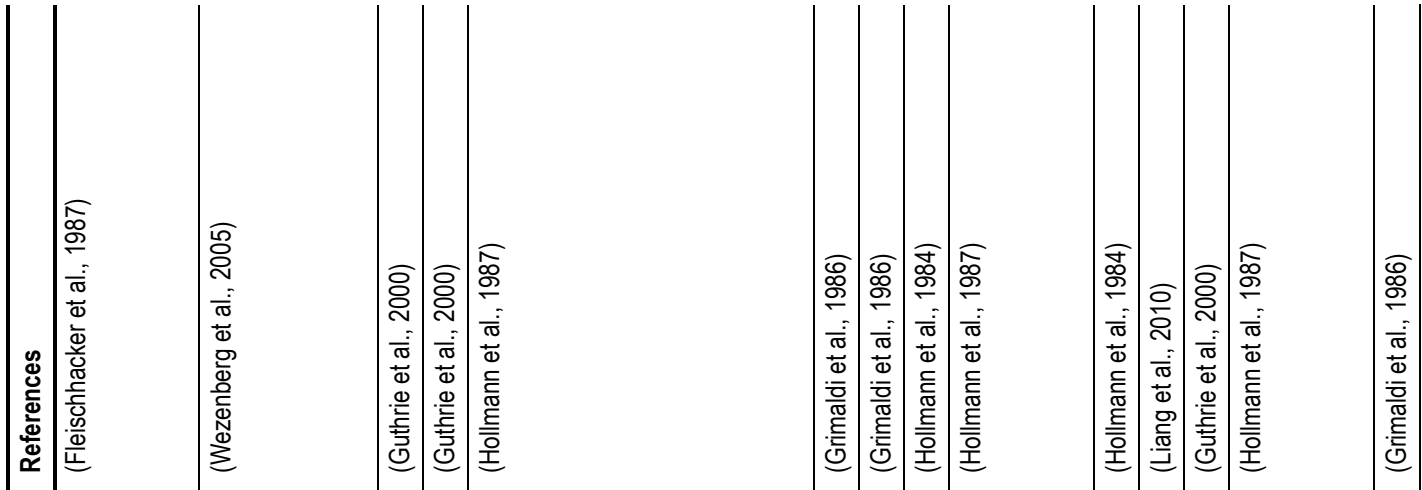

1.
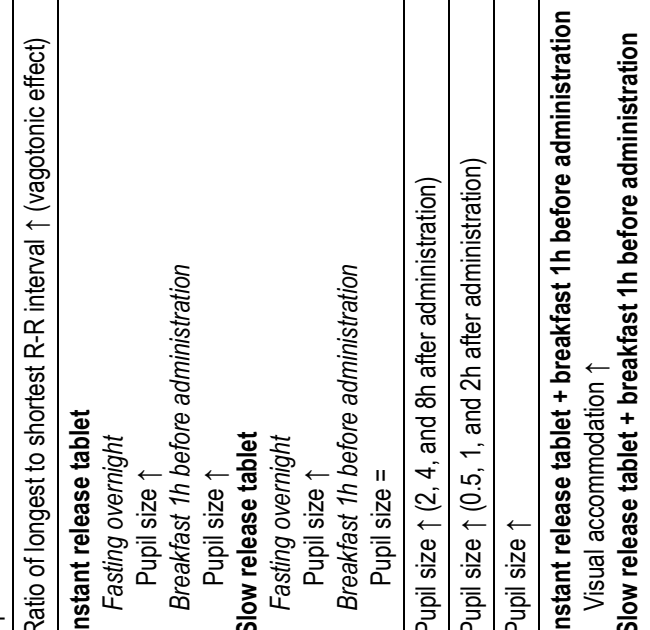

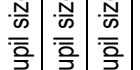

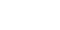

$$
\text { . }
$$
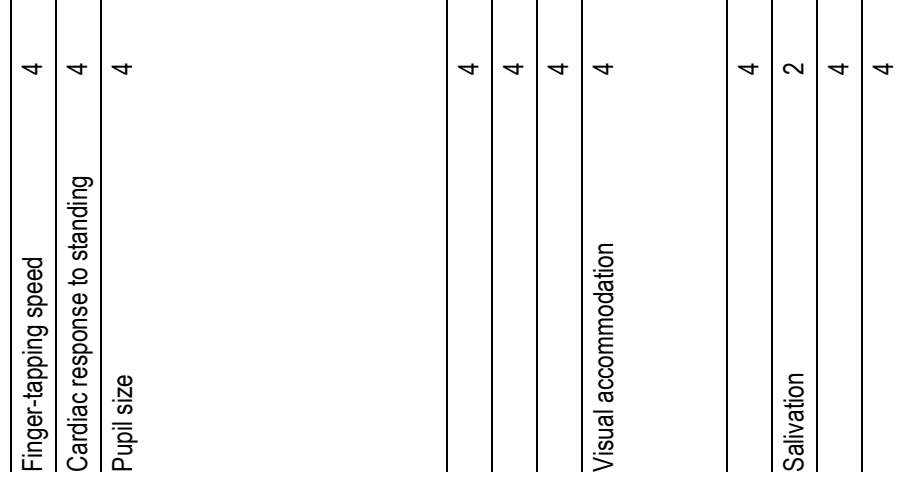


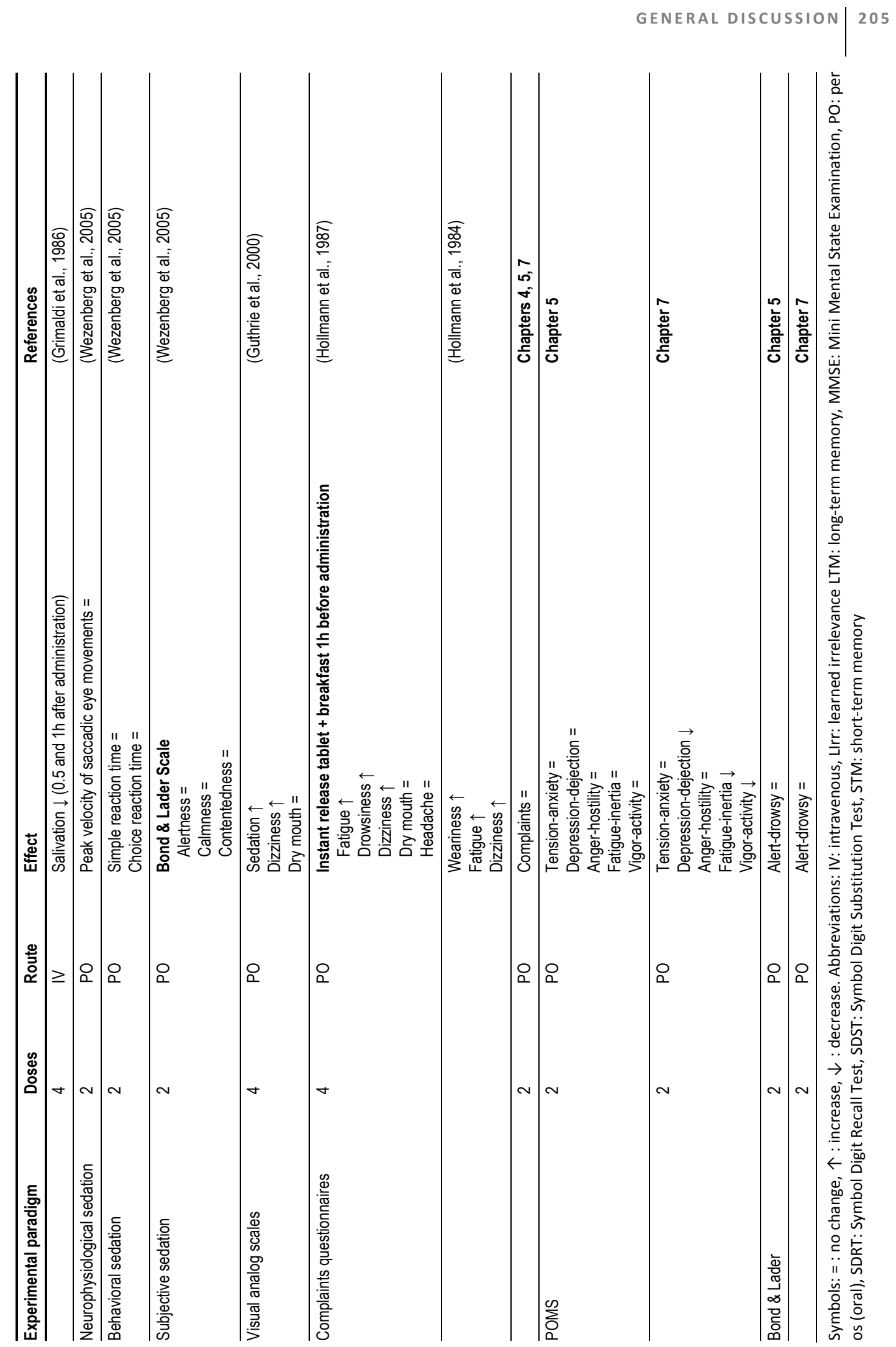




\section{REFERENCES}

Abi-Dargham, A., Mawlawi, O., Lombardo, I., Gil, R., Martinez, D., Huang, Y., et al. (2002). Prefrontal dopamine D1 receptors and working memory in schizophrenia. The Journal of Neuroscience, 22, 3708-3719.

Allahverdiyev, O., Nurten, A., \& Enginar, N. (2011). Assessment of rewarding and reinforcing properties of biperiden in conditioned place preference in rats. Behavioural Brain Research, 225, 642-645.

Almasieh, M., Zhou, Y., Kelly, M. E., Casanova, C., \& Di Polo, A. (2010). Structural and functional neuroprotection in glaucoma: role of galantamine-mediated activation of muscarinic acetylcholine receptors. Cell Death \& Disease, 1 , e27.

Amenedo, E., \& Diaz, F. (1998). Aging-related changes in processing of non-target and target stimuli during an auditory oddball task. Biological Psychology, 48, 235-267.

Atri, A., Sherman, S., Norman, K. A., Kirchhoff, B. A., Nicolas, M. M., Greicius, M. D., et al. (2004). Blockade of central cholinergic receptors impairs new learning and increases proactive interference in a word paired-associate memory task. Behavioral Neuroscience, 118, 223-236.

Baddeley, A., Cocchini, G., Della Sala, S., Logie, R. H., \& Spinnler, H. (1999). Working memory and vigilance: evidence from normal aging and Alzheimer's disease. Brain and Cognition, 41, 87-108.

Bahro, M., Schreurs, B. G., Sunderland, T., \& Molchan, S. E. (1995). The effects of scopolamine, lorazepam, and glycopyrrolate on classical conditioning of the human eyeblink response. Psychopharmacology, 122, 395-400.

Bartus, R. T., Dean, R. L., Beer, B., \& Lippa, A. S. (1982). The cholinergic hypothesis of geriatric memory dysfunction. Science, 217, 408-417.

Bertoli, S., Smurzynski, J., \& Probst, R. (2002). Temporal resolution in young and elderly subjects as measured by mismatch negativity and a psychoacoustic gap detection task. Clinical Neurophysiology, 113, 396-406.

Bickford-Wimer, P. C., Nagamoto, H., Johnson, R., Adler, L. E., Egan, M., Rose, G. M., et al. (1990). Auditory sensory gating in hippocampal neurons: a model system in the rat. Biological Psychiatry, 27, 183-192.

Bickford, P. C., Luntz-Leybman, V., \& Freedman, R. (1993). Auditory sensory gating in the rat hippocampus: modulation by brainstem activity. Brain Research, 607, 33-38.

Bishop, K. I., Curran, H. V., \& Lader, M. (1996). Do scopolamine and lorazepam have dissociable effects on human memory systems? A dose-response study with normal volunteers. Experimental and Clinical Psychopharmacology, 4, 292-299.

Blin, J., Ray, C. A., Piercy, M. F., Bartko, J. J., Mouradian, M. M., \& Chase, T. N. (1994). Comparison of cholinergic drug effects on regional brain glucose consumption in rats and humans by means of autoradiography and positron emission tomography. Brain Research, 635, 196-202.

Bolden, C., Cusack, B., \& Richelson, E. (1992). Antagonism by antimuscarinic and neuroleptic compounds at the five cloned human muscarinic cholinergic receptors expressed in Chinese hamster ovary cells. The Journal of Pharmacology and Experimental Therapeutics, 260, 576-580.

Boutros, N. N., Trautner, P., Rosburg, T., Korzyukov, O., Grunwald, T., Schaller, C., et al. (2005). Sensory gating in the human hippocampal and rhinal regions. Clinical Neurophysiology, 116, 1967-1974.

Bramon, E., Rabe-Hesketh, S., Sham, P., Murray, R. M., \& Frangou, S. (2004). Meta-analysis of the P300 and P50 waveforms in schizophrenia. Schizophrenia Research, 70, 315-329.

Brandeis, D., Naylor, H., Halliday, R., Callaway, E., \& Yano, L. (1992). Scopolamine effects on visual information processing, attention, and event-related potential map latencies. Psychophysiology, 29, 315-336.

Broks, P., Preston, G. C., Traub, M., Poppleton, P., Ward, C., \& Stahl, S. M. (1988). Modelling dementia: effects of scopolamine on memory and attention. Neuropsychologia, 26, 685-700.

Buchwald, J. S., Erwin, R. J., Read, S., Van Lancker, D., \& Cummings, J. L. (1989). Midlatency auditory evoked responses: differential abnormality of P1 in Alzheimer's disease. Electroencephalography and Clinical Neurophysiology, 74, 378-384.

Buchwald, J. S., Rubinstein, E. H., Schwafel, J., \& Strandburg, R. J. (1991). Midlatency auditory evoked responses: differential effects of a cholinergic agonist and antagonist. Electroencephalography and Clinical Neurophysiology, 80, 303-309.

Cacioppo, J. T., Tassinary, L. G., \& Berntson, G. G. (2000). Handbook of Psychophysiology (2nd ed.). Cambridge: Cambridge University Press. 
Callaway, E., Halliday, R., Naylor, H., \& Brandeis, D. (1991). Clonidine and scopolamine: differences and similarities in how they change human information processing. Progress in Neuro-psychopharmacology \& Biological Psychiatry, 15, 497-502.

Campbell, K. A., Kalmbacher, C. E., Specht, C. D., \& Gregg, T. R. (1995). Dependence of rat vertex auditory evoked potentials on central muscarinic receptor activation. Brain Research, 702, 110-116.

Cancelli, I., Cadore, I. P., Merlino, G., Valentinis, L., Moratti, U., Bergonzi, P., et al. (2006). Sensory gating deficit assessed by $\mathrm{P} 50 / \mathrm{Pb}$ middle latency event related potential in Alzheimer's disease. Journal of Clinical Neurophysiology, 23, 421-425.

Caulfield, M. P. (1993). Muscarinic receptors - characterization, coupling and function. Pharmacology \& Therapeutics, 58, 319-379.

Curran, H. V., Pooviboonsuk, P., Dalton, J. A., \& Lader, M. H. (1998). Differentiating the effects of centrally acting drugs on arousal and memory: an event-related potential study of scopolamine, lorazepam and diphenhydramine. Psychopharmacology, 135, 27-36.

Davis, C. N., Bradley, S. R., Schiffer, H. H., Friberg, M., Koch, K., Tolf, B. R., et al. (2009). Differential regulation of muscarinic $\mathrm{M} 1$ receptors by orthosteric and allosteric ligands. BMC Pharmacology, 9, 14.

De Klippel, N., Sarre, S., Ebinger, G., \& Michotte, Y. (1993). Effect of M1- and M2-muscarinic drugs on striatal dopamine release and metabolism: An in vivo microdialysis study comparing normal and 6hydroxydopamine-lesioned rats. Brain Research, 630, 57-64.

Digby, G. J., Noetzel, M. J., Bubser, M., Utley, T. J., Walker, A. G., Byun, N. E., et al. (2012). Novel allosteric agonists of $M_{1}$ muscarinic acetylcholine receptors induce brain region-specific responses that correspond with behavioral effects in animal models. The Journal of Neuroscience, 32, 8532-8544.

Domino, E. F., \& Ni, L. (2008). Biperiden enhances L-DOPA methyl ester and dopamine D(I) receptor agonist SKF-82958 but antagonizes $D(2) / D(3)$ receptor agonist rotigotine antihemiparkinsonian actions. European Journal of Pharmacology, 599, 81-85.

Donchin, E. (1981). Surprise! . . Surprise? Psychophysiology, 18, 493-513.

Doods, H. N., Mathy, M. J., Davidesko, D., van Charldorp, K. J., de Jonge, A., \& van Zwieten, P. A. (1987). Selectivity of muscarinic antagonists in radioligand and in vivo experiments for the putative M1, M2 and M3 receptors. Journal of Pharmacology and Experimental Therapeutics, 242, 257-262.

Duka, T., Ott, H., Rohloff, A., \& Voet, B. (1996). The effects of a benzodiazepine receptor antagonist betacarboline ZK-93426 on scopolamine-induced impairment on attention, memory and psychomotor skills. Psychopharmacology, 123, 361-373.

Ebert, U., Grossmann, M., Oertel, R., Gramatte, T., \& Kirch, W. (2001). Pharmacokinetic-pharmacodynamic modeling of the electroencephalogram effects of scopolamine in healthy volunteers. Journal of Clinical Pharmacology, 41, 51-60.

Ellis, J. R., Ellis, K. A., Bartholomeusz, C. F., Harrison, B. J., Wesnes, K. A., Erskine, F. F., et al. (2006). Muscarinic and nicotinic receptors synergistically modulate working memory and attention in humans. The International Journal of Neuropsychopharmacology, 9, 175-189.

Estevez-Gonzalez, A., Kulisevsky, J., Boltes, A., Otermin, P., \& Garcia-Sanchez, C. (2003). Rey verbal learning test is a useful tool for differential diagnosis in the preclinical phase of Alzheimer's disease: comparison with mild cognitive impairment and normal aging. International Journal of Geriatric Psychiatry, 18, 1021 1028.

Fein, G., Biggins, C., \& Van Dyke, C. (1994). The auditory P50 response is normal in Alzheimer's disease when measured via a paired click paradigm. Electroencephalography and Clinical Neurophysiology, 92, 536545.

Fleischhacker, W. W., Barnas, C., Günther, V., Meise, U., Stuppäck, C., \& Unterweger, B. (1987). Moodaltering effects of biperiden in healthy volunteers. Journal of Affective Disorders, 12, 153-157.

Fredrickson, A., Snyder, P. J., Cromer, J., Thomas, E., Lewis, M., \& Maruff, P. (2008). The use of effect sizes to characterize the nature of cognitive change in psychopharmacological studies: an example with scopolamine. Human Psychopharmacology, 23, 425-436.

Gal, G., Mendlovic, S., Bloch, Y., Beitler, G., Levkovitz, Y., Young, A.M.J., Feldon, J., \& Ratzoni, G. (2005). Learned irrelevance is disrupted in first-episode but not chronic schizophrenia patients. Behavioural Brain Research, 159, 267-275.

Gerber, D. J., Sotnikova, T. D., Gainetdinov, R. R., Huang, S. Y., Caron, M. G., \& Tonegawa, S. (2001). Hyperactivity, elevated dopaminergic transmission and response to amphetamine in $\mathrm{M} 1$ muscarinic acetylcholine receptor-deficient mice. Proceedings of the National Academy of Sciences, 98, 15312-15317. 
Gluck, M. A., \& Myers, C. E. (1993). Hippocampal mediation of stimulus presentation: A computational theory. Hippocampus, 3, 491-516.

Golob, E. J., Johnson, J. K., \& Starr, A. (2001a). Auditory event-related potentials during target detection are abnormal in mild cognitive impairment. Clinical Neurophysiology, 113, 151-161.

Golob, E. J., Miranda, G. G., Johnson, J. K., \& Starr, A. (2001b). Sensory cortical interactions in aging, mild cognitive impairment, and Alzheimer's disease. Neurobiology of Aging, 22, 755-763.

Grasby, P. M., Frith, C. D., Paulesu, E., Friston, K. J., Frackowiak, R. S., \& Dolan, R. J. (1995). The effect of the muscarinic antagonist scopolamine on regional cerebral blood flow during the performance of a memory task. Experimental Brain Research, 104, 337-348.

Green, A., Ellis, K. A., Ellis, J., Bartholomeusz, C. F., Ilic, S., Croft, R. J., et al. (2005). Muscarinic and nicotinic receptor modulation of object and spatial n-back working memory in humans. Pharmacology, Biochemistry and Behavior, 81, 575-584.

Greenaway, M. C., Lacritz, L. H., Binegar, D., Weiner, M. F., Lipton, A., \& Munro Cullum, C. (2006). Patterns of verbal memory performance in mild cognitive impairment, Alzheimer disease, and normal aging. Cognitive and Behavioral Neurology, 19, 79-84.

Grimaldi, R., Perucca, E., Ruberto, G., Gelmi, C., Trimarchi, F., Hollmann, M., et al. (1986). Pharmacokinetic and pharmacodynamic studies following the intravenous and oral administration of the antiparkinsonian drug biperiden to normal subjects. European Journal of Clinical Pharmacology, 29, 735-737.

Grunwald, T., Boutros, N. N., Pezer, N., von Oertzen, J., Fernandez, G., Schaller, C., et al. (2003). Neuronal substrates of sensory gating within the human brain. Biological Psychiatry, 53, 511-519.

Gupta, N., McAllister, R., Drance, S. M., Rootman, J., \& Cynader, M. S. (1994). Muscarinic receptor M1 and M2 subtypes in the human eye: QNB, pirenzipine, oxotremorine, and AFDX-116 in vitro autoradiography. British Journal of Ophthalmology, 78, 555-559.

Guthrie, S. K., Manzey, L., Scott, D., Giordani, B., \& Tandon, R. (2000). Comparison of central and peripheral pharmacologic effects of biperiden and trihexyphenidyl in human volunteers. Journal of Clinical Psychopharmacology, 20, 77-83.

Heinrich, J. N., Butera, J. A., Carrick, T., Kramer, A., Kowal, D., Lock, T., et al. (2009). Pharmacological comparison of muscarinic ligands: Historical versus more recent muscarinic M1-preferring receptor agonists. European Journal of Pharmacology, 605, 53-56.

Hill, S. K., Beers, S. R., Kmiec, J. A., Keshavan, M. S., \& Sweeney, J. A. (2004). Impairment of verbal memory and learning in antipsychotic-naive patients with first-episode schizophrenia. Schizophrenia Research, $68,127-136$.

Hillyard, S. A., Hink, R. F., Schwent, V. L., \& Picton, T. W. (1973). Electrical signs of selective attention in the human brain. Science, 182, 177-180.

Hollmann, M., Brode, E., Greger, G., Müller-Peltzer, H., \& Wetzelsberger, N. (1984). Biperiden effects and plasma levels in volunteers. European Journal of Clinical Pharmacology, 27, 619-621.

Hollmann, M., Müller-Peltzer, H., Greger, G., Brode, E., Perucca, E., Grimaldi, R., et al. (1987). Pharmacokinetic-dynamic study on different oral biperiden formulations in volunteers. Pharmacopsychiatry, 20, 72 77.

Iragui, V. J., Kutas, M., Mitchiner, M. R., \& Hillyard, S. A. (1993). Effects of aging on event-related brain potentials and reaction times in an auditory oddball task. Psychophysiology, 30, 10-22.

Irimajiri, R., Golob, E. J., \& Starr, A. (2005). Auditory brain-stem, middle- and long-latency evoked potentials in mild cognitive impairment. Clinical Neurophysiology, 116, 1918-1929.

Ishizaki, J., Yokogawa, K., Nakashima, E., Ohkuma, S., \& Ichimura, F. (1998). Characteristic subcellular distribution, in brain, heart and lung, of biperiden, trihexyphenidyl, and (-)-quinuclidinyl benzylate in rats. Biological and Pharmaceutical Bulletin, 21, 67-71.

Jessen, F., Kucharski, C., Fries, T., Papassotiropoulos, A., Hoenig, K., Maier, W., et al. (2001). Sensory gating deficit expressed by a disturbed suppression of the P50 event-related potential in patients with Alzheimer's disease. American Journal of Psychiatry, 158, 1319-1321.

Jessen, F., Scheef, L., Germeshausen, L., Tawo, Y., Kockler, M., Kuhn, K. U., et al. (2003). Reduced hippocampal activation during encoding and recognition of words in schizophrenia patients. American Journal of Psychiatry, 160, 1305-1312.

Jin, Y., \& Potkin, S. G. (1996). P50 changes with visual interference in normal subjects: a sensory distraction model for schizophrenia. Clinical Electroencephalography, 27, 151-154. 
Jin, Y., Potkin, S. G., Patterson, J. V., Sandman, C. A., Hetrick, W. P., \& Bunney, W. E., Jr. (1997). Effects of P50 temporal variability on sensory gating in schizophrenia. Psychiatry Research, 70, 71-81.

Jones, C. K., \& Shannon, H.E. (2000). Muscarinic cholinergic modulation of prepulse inhibition of the acoustic startle reflex. The Journal of Pharmacology and Experimental Therapeutics, 294, 1017-1023.

Kalpouzos, G., Eustache, F., de la Sayette, V., Viader, F., Chetelat, G., \& Desgranges, B. (2005). Working memory and FDG-PET dissociate early and late onset Alzheimer disease patients. Journal of Neurology, 252, 548-558.

Kamboj, S. K., \& Curran, H. V. (2006). Neutral and emotional episodic memory: global impairment after lorazepam or scopolamine. Psychopharmacology, 188, 482-488.

Karoumi, B., Laurent, A., Rosenfeld, F., Rochet, T., Brunon, A. M., Dalery, J., et al. (2000). Alteration of event related potentials in siblings discordant for schizophrenia. Schizophrenia Research, 41, 325-334.

Kathmann, N., Von Recum, S., Haag, C., \& Engel, R. R. (2000). Electrophysiological evidence for reduced latent inhibition in schizophrenic patients. Schizophrenia Research, 45, 103-114.

Kimura, Y., Ohue, M., Kitaura, T., \& Kihira, K. (1999). Amnesic effects of the anticholinergic drugs, trihexyphenidyl and biperiden: differences in binding properties to the brain muscarinic receptor. Brain Research, 834, 6-12.

Knott, V. J., Harr, A., \& Ilivitsky, V. (1999). Separate and combined effects of scopolamine and mecamylamine on human event-related brain potentials. Human Psychopharmacology - Clinical and Experimental, 14, 307-317.

Krause, M., Hoffmann, W. E., \& Hajos, M. (2003). Auditory sensory gating in hippocampus and reticular thalamic neurons in anesthetized rats. Biological Psychiatry, 53, 244-253.

Lee, J., \& Park, S. (2005). Working memory impairments in schizophrenia: a meta-analysis. Journal of Abnormal Psychology, 114, 599-611.

Lenz, R. A., Baker, J. D., Locke, C., Rueter, L. E., Mohler, E. G., Wesnes, K., et al. (2012). The scopolamine model as a pharmacodynamic marker in early drug development. Psychopharmacology, 220, 97-107.

Leopold, I. H., \& Comroe, J. H. (1948). Effect of intramuscular administration of morphine, atropine, scopolamine and neostigmine on the human eye. Archives of Ophthalmology, 46, 361-364.

Liang, C. S., Ho, P. S., Shen, L. J., Lee, W. K., Yang, F. W., \& Chiang, K. T. (2010). Comparison of the efficacy and impact on cognition of glycopyrrolate and biperiden for clozapine-induced sialorrhea in schizophrenic patients: a randomized, double-blind, crossover study. Schizophrenia Research, 119, 138-144.

Little, J. T., Johnson, D. N., Minichiello, M., Weingartner, H., \& Sunderland, T. (1998). Combined nicotinic and muscarinic blockade in elderly normal volunteers: cognitive, behavioral and physiological reponses. Neuropsychopharmacology, 19, 60-69.

Liu, W. (1996). Effects of antimuscarinic antiparkinsonian drugs on brightness discrimination performance in rats. Pharmacology, Biochemistry and Behavior, 54, 425-430.

Lubow, R. E. (2005). The visual search analogue of latent inhibition: Implications for theories of irrelevant stimulus processing in normal and schizophrenic groups. Psychonomic Bulletin \& Review, 12, 224-243.

Luntz-Leybman, V., Bickford, P. C., \& Freedman, R. (1992). Cholinergic gating of response to auditory stimuli in rat hippocampus. Brain Research, 587, 130-136.

Manoach, D. S. (2003). Prefrontal cortex dysfunction during working memory performance in schizophrenia: reconciling discrepant findings. Schizophrenia Research, 60, 285-298.

Meador, K. J., Loring, D. W., Adams, R. J., Patel, B. R., Davis, H. C., \& Hammond, E. J. (1987). Central cholinergic systems and the P3 evoked potential. International Journal of Neuroscience, 33, 199-205.

Mintzer, M. Z., \& Griffiths, R. R. (2003). Lorazepam and scopolamine: A single-dose comparison of effects on human memory and attentional processes. Experimental and Clinical Psychopharmacology, 11, 56-72.

Miyazato, H., Skinner, R. D., Reese, N. B., Boop, F. A., \& Garcia-Rill, E. (1995). A middle-latency auditoryevoked potential in the rat. Brain Research Bulletin, 37, 247-255.

Mohr, M., Heller, E., Ataie, A., Mohr, K., \& Holzgrabe, U. (2004). Development of a new type of allosteric modulator of muscarinic receptors: hybrids of the antagonist AF-DX 384 and the hexamethonio derivative W84. Journal of Medicinal Chemistry, 47, 3324-3327.

Myers, T. M., Galbicka, G., Sipos, M. L., Varadi, S., Oubre, J. L., \& Clark, M. G. (2002). Effects of anticholinergics on serial-probe recognition accuracy of rhesus macaques (Macaca mulatta). Pharmacology, Biochemistry and Behavior, 73, 829-834.

Myhrer, T., Enger, S., \& Aas, P. (2008). Antiparkinson drugs used as prophylactics for nerve agents: Studies of cognitive side effects in rats. Pharmacology, Biochemistry and Behavior, 89, 633-638. 
Nakashima, E., Ishizaki, F., Takeda, M., Matsusushita, R., Yokogawa, K., \& Ichimura, F. (1993). Pharmacokinetics of anticholinergic drugs and brain muscarinic receptor alterations in streptozotocin diabetic rats. Biopharmaceutics \& Drug Disposition, 14, 673-684.

Nakashima, E., Yokogawa, K., Ichimura, F., Hashimoto, T., Yamana, T., \& Tsuji, A. (1987). Effects of fasting on biperiden pharmacokinetics in the rat. Journal of Pharmeutical Sciences, 76, 10-13.

Ogura, C., Nageishi, Y., Matsubayashi, M., Omura, F., Kishimoto, A., \& Shimokochi, M. (1991). Abnormalities in event-related potentials, N100, P200, P300 and slow wave in schizophrenia. Japanese Journal of Psychiatry and Neurology, 45, 57-65.

Orosz, A., Feldon, J., Gal, G., Simon, A., \& Cattapan-Ludewig, K. (2008). Deficient associative learning in drugnaive first-episode schizophrenia: Results obtained using a new visual within-subjects learned irrelevance paradigm. Behavioural Brain Research, 193, 101-107.

Patterson, J. V., Jin, Y., Gierczak, M., Hetrick, W. P., Potkin, S., Bunney, W. E., Jr., et al. (2000). Effects of temporal variability on $\mathrm{p} 50$ and the gating ratio in schizophrenia: a frequency domain adaptive filter single-trial analysis. Archives of General Psychiatry, 57, 57-64.

Pekkonen, E., Hirvonen, J., Jaaskelainen, I. P., Kaakkola, S., \& Huttunen, J. (2001). Auditory sensory memory and the cholinergic system: implications for Alzheimer's disease. Neurolmage, 14, 376-382.

Pekkonen, E., Jaaskelainen, I. P., Kaakkola, S., \& Ahveninen, J. (2005). Cholinergic modulation of preattentive auditory processing in aging. Neurolmage, 27, 387-392.

Polich, J., \& Criado, J. R. (2006). Neuropsychology and neuropharmacology of P3a and P3b. International Journal of Psychophysiology, 60, 172-185.

Ragozzino, M. E., Artis, S., Singh, A., Twose, T. M., Beck, J. E., \& Messer, W. S., Jr. (2012). The selective M1 muscarinic cholinergic agonist CDD-0102A enhances working memory and cognitive flexibility. Journal of Pharmacology and Experimental Therapeutics, 340, 588-594.

Ramos, A. C., Andersen, M. L., Oliveira, M. G., Soeiro, A. C., \& Galduroz, J. C. (2012). Biperiden (M(1) antagonist) impairs the expression of cocaine conditioned place preference but potentiates the expression of cocaine-induced behavioral sensitization. Behavioural Brain Research, 231, 213-216.

Reagan-Shaw, S., Nihal, M., \& Ahmad, N. (2008). Dose translation from animal to human studies revisited. The FASEB Journal, 22, 659-661.

Roldan, G., Bolanos-Badillo, E., Gonzalez-Sanchez, H., Quirarte, G. L., \& Prado-Alcala, R. A. (1997). Selective M1 muscarinic receptor antagonists disrupt memory consolidation of inhibitory avoidance in rats. Neuroscience Letters, 230, 93-96.

Sarter, M., Lustig, C., \& Taylor, S. F. (2012). Cholinergic contributions to the cognitive symptoms of schizophrenia and the viability of cholinergic treatments. Neuropharmacology, 62, 1544-1553.

Schmajuk, N. (2005). Brain-behaviour relationships in latent inhibition: A computational model. Neuroscience \& Biobehavioral Reviews, 29, 1001-1020.

Shiraishi, K., \& Takayanagi, I. (1993). Subtype of muscarinic receptors mediating relaxation and contraction in the rat iris dilator smooth muscle. General Pharmacology, 24, 139-142.

Simons, C. J. P., Sambeth, A., Krabbendam, L., Pfeifer, S., Van Os, J., \& Riedel, W. J. (2011). Auditory P300 and N100 components as intermediate phenotypes for psychotic disorder: Familial liability and reliability. Clinical Neurophysiology, 122, 1984-1990.

Sipos, M. L., Burchnell, V., \& Galbicka, G. (1999). Dose-response curves and time-course effects of selected anticholinergics on locomotor activity in rats. Psychopharmacology, 147, 250-256.

Sipos, M. L., Burchnell, V., \& Galbicka, G. (2001). Effects of selected anticholinergics on acoustic startle response in rats. Journal of Applied Toxicology, 21, S95-S101.

Slabosz, A., Lewis, S. J., Smigasiewicz, K., Szymura, B., Barker, R. A., \& Owen, A. M. (2006). The role of learned irrelevance in attentional set-shifting impairments in Parkinson's disease. Neuropsychology, 20, 578588.

Sudo, Y., Suhara, T., Suzuki, K., Okubo, Y., Yoshikawa, K., Uchida, S., et al. (1999). Muscarinic receptor occupancy by biperiden in living human brain. Life Sciences, 64, PL99-104.

Teneud, L., Miyazato, H., Skinner, R. D., \& Garcia-Rill, E. (2000). Cholinergic modulation of the sleep statedependent P13 midlatency auditory evoked potential in the rat. Brain Research, 884, 196-200.

Thienel, R., Kellermann, T., Schall, U., Voss, B., Reske, M., Halfter, S., et al. (2009). Muscarinic antagonist effects on executive control of attention. The International Journal of Neuropsychopharmacology, 12, 1307-1317. 
Thomas, C., vom Berg, I., Rupp, A., Seidl, U., Schroder, J., Roesch-Ely, D., et al. (2010). P50 gating deficit in Alzheimer dementia correlates to frontal neuropsychological function. Neurobiology of Aging, 31, 416424.

Thomsen, M., Conn, P. J., Lindsley, C., Wess, J., Boon, J. Y., Fulton, B. S., et al. (2010). Attenuation of cocaine's reinforcing and discriminative stimulus effects via muscarinic M1 acetylcholine receptor stimulation. Journal of Pharmacology and Experimental Therapeutics, 332, 959-969.

Weiner, I. (2003). The "two-headed" latent inhibition model of schizophrenia: Modeling positive and negative symptoms and their treatment. Psychopharmacology, 169, 257-297.

Weiss, A. P., Zalesak, M., DeWitt, I., Goff, D., Kunkel, L., \& Heckers, S. (2004). Impaired hippocampal function during the detection of novel words in schizophrenia. Biological Psychiatry, 55, 668-675.

Wezenberg, E., Verkes, R. J., Sabbe, B. G., Ruigt, G. S., \& Hulstijn, W. (2005). Modulation of memory and visuospatial processes by biperiden and rivastigmine in elderly healthy subjects. Psychopharmacology, $181,582-594$.

Williams, T. J., Nuechterlein, K. H., Subotnik, K. L., \& Yee, C. M. (2011). Distinct neural generators of sensory gating in schizophrenia. Psychophysiology, 48, 470-478.

Yokogawa, K., Nakashima, E., \& Ichimura, F. (1990). Effect of fat tissue volume on the distribution kinetics of biperiden as a function of age in rats. Drug Metabolism and Disposition, 18, 258-263.

Yokogawa, K., Nakashima, E., Ishizaki, J., Hasegawa, M., Kido, H., \& Ichimura, F. (1992). Brain regional pharmacokinetics of biperiden in rats. Biopharmaceutics \& Drug Disposition, 13, 131-140.

Young, A. M. J., Kumari, V., Mehtrotra, R., Hemsley, D. R., Andrew, C., Sharma, T., et al. (2005). Disruption of learned irrelevance in acute schizophrenia in a novel continuous within-subject paradigm suitable for fMRI. Behavioural Brain Research, 156, 277-288.

Zacarias, M. S., Ramos, A. C., Alves, D. R., \& Galduroz, J. C. (2012). Biperiden (an M1 antagonist) reduces memory consolidation of cocaine-conditioned place preference. Neuroscience Letters, 513, 129-131. 


\section{SUMMARY}

One of the main research themes in psychology and neuroscience is cognitive dysfunction, which usually occurs as an epiphenomenon of brain diseases and/or neuropsychiatric disorders. Unfortunately, patient heterogeneity makes it difficult to correlate cognitive deficits with specific neurobiological findings. Therefore, a lot of effort is dedicated to mimicking cognitive impairments with pharmacological tools that temporarily impact neurotransmission in healthy animals and young volunteers (Gilles \& Luthringer, 2007).

The non-selective cholinergic (i.e., muscarinic) antagonist scopolamine has been employed extensively as a standard/reference drug to induce age- and dementia-related impairments in cognitive function. The guiding principle for its use has been the cholinergic hypothesis of geriatric memory dysfunction, which assumes that the age-related decline in cognitive functions is predominantly related to a decrease in the integrity of cholinergic neurotransmission (Bartus et al., 1982). However, an exclusive role for acetylcholine in geriatric memory dysfunction can be viewed as too restrictive, as cholinergic impairments have also been noted in schizophrenia (Sarter et al., 2012). Thus, the question arises whether aberrant cholinergic signaling might be a common neuropathological pathway underlying aging, dementia and schizophrenia, and whether administration of cholinergic (i.e., muscarinic) antagonists might hence serve as a model for cognitive impairments associated with these disorders.

Chapter $\mathbf{2}$ has provided an overview of the effects of scopolamine on animal behavior. It appears that behavioral paradigms which assess stimulus discrimination and/or (sustained) attention processes are relatively more sensitive to impairments induced by the muscarinic antagonist scopolamine compared to tasks which measure learning/memory functions (i.e., effects at relatively lower doses). These findings have spurred a lot of debate on the specific role of acetylcholine in cognition - i.e. on learning/memory vs. attention (Hasselmo, 1999; 2006; Hasselmo et al., 2002; Hasselmo \& McGaughy, 2004; Sarter et al., $2003 ; 2005 ; 2009)$. It is concluded that effects on learning and memory performance which are observed after higher doses of scopolamine are mediated by 1) primary effects on attention and sensory/stimulus discrimination, 2) non-specific effects on behavior (locomotor activity, anxiety), and 3) peripheral side-effects (pupil dilation, salivation). Finally, the validity of scopolamine as a pharmacological model for cognitive impairment is questionable, as its non-selectivity with regards to muscarinic receptors complicates interpretation of behavioral findings. On the basis of the distribution of the muscarinic $M_{1}$ receptor in the brain and body (Caulfield, 1993), muscarinic $M_{1}$ antagonists are put forward as a more selective and effective way of inducing cholinergic deficits.

The study in Chapter 3 investigated in rats whether the muscarinic $M_{1}$ receptor antagonist biperiden would induce more selective effects on a battery of operant tasks: i.e., fixed ratio and progressive ratio schedules of reinforcement, an attention paradigm and delayed non-matching to position task. Scopolamine was found to disrupt performance in all behavioral paradigms. Biperiden induced relatively more selective deficits; it had no effect on food motivation or attention, and effects on psychomotor performance and working memory were dissociable based on dose conditions (i.e., $10 \mathrm{mg} / \mathrm{kg}$ and $3 \mathrm{mg} / \mathrm{kg}$, respectively). It was concluded that muscarinic $M_{1}$ antagonists such as biperiden should be considered as a pharmacological model for cholinergic mnemonic deficits in animals, due to their selectivity with regards to mnemonic effects. 
The goal of the study in Chapter 4 was to assess the selectivity of the muscarinic $M_{1}$ antagonist biperiden with regards to verbal memory, psychomotor performance and selfreports of side-effects in young, healthy human volunteers. After biperiden, participants recalled on average about 4 words less on the immediate and delayed recall of the verbal learning task. Word recognition scores in the verbal recognition task were reduced by $8 \%$ after biperiden. Biperiden did not influence reaction times in a verbal recognition task or a choice reaction time task, which is indicative of a lack of psychomotor effects. There was also no effect of biperiden on accuracy in the choice reaction time task, nor did participants report experiencing any side-effects. It was concluded that biperiden is capable of impairing verbal memory rather selectively, i.e., without inducing clear peripheral side-effects which could adversely affect performance.

The study in Chapter 5 investigated the effects of the muscarinic $M_{1}$ antagonist biperiden on a within-subject learned irrelevance (LIrr) paradigm and event-related potentials (ERPs) in humans. LIrr refers to a reduction in associative learning after pre-exposure of the conditioned (CS) and unconditioned stimulus (US) in a non-contingent fashion (Baker, 1976; Mackintosh, 1973). This paradigm might serve as a translational model for (pre)attentive information processing deficits in schizophrenia controls (Gal et al., 2005; Orosz et al., 2011; Young et al., 2005). Given the involvement of the cholinergic system in the pathophysiology of schizophrenia (Sarter et al., 2012), it was hypothesized that biperiden would disrupt LIrr performance. Unexpectedly, biperiden had no effect on the behavioral LIrr measures, although prolonged reaction times were evident. The N1 amplitude of the preexposed (PE) predictor letters was increased after biperiden, suggesting an effect of this drug on early perceptual processing. In conclusion, the within-subject paradigm used in the current study in combination with ERPs can reveal brain mechanisms involved in LIrr. $\mathrm{M}_{1}$ antagonism does not appear to be involved in LIrr deficits as reported in schizophrenia.

The study described in Chapter 6 assessed the effects of the non-selective muscarinic antagonist scopolamine, the muscarinic $M_{1}$ antagonist biperiden, the cholinesterase inhibitor donepezil and their combination on auditory evoked potentials (AEPs) and sensory gating in rats. As perturbations in auditory filtering appear to be a candidate trait marker of schizophrenia (Cadenhead et al., 2000; Olincy et al., 2010; Simons et al., 2011), there has been considerable interest in the development of translational rat models to elucidate the underlying neural and neurochemical mechanisms involved. Scopolamine and biperiden both disrupted sensory gating by increasing $\mathrm{N} 1$ amplitude for the S2 click. Scopolamine also affected the latencies of the P1, N1 and P2 peaks. Donepezil was able to fully reverse the effects of biperiden on N1 sensory gating, but had residual effects when combined with scopolamine (i.e., enhancement of sensory gating). Donepezil by itself improved sensory gating by increasing N1 amplitude of S1, and reducing N1 amplitude of the S2 click. In conclusion, due to its relatively more selective effects, biperiden is to be preferred over scopolamine as a means for pharmacologically inducing impairments in auditory processing in healthy rats.

The goal of the study in Chapter 7 was to investigate the effects of the muscarinic $M_{1}$ antagonist biperiden and the cholinesterase inhibitor rivastigmine on AEPs, sensory gating and mismatch negativity (MMN) in young, healthy volunteers. Suppression of redundant auditory information and facilitation of deviant, novel or salient sounds can be assessed with paired-click and oddball tasks, respectively (Boutros et al., 2004; Garrido et al., 2009; Näätänen et al., 2004; Pekkonen et al., 2005). Electrophysiological correlates of perturbed 
auditory processing found in these paradigms are likely to be a trait marker for schizophrenia (Cadenhead et al., 2000; Olincy et al., 2010; Price et al., 2006; Simons et al., 2011). Biperiden increased P50 amplitude and prolonged N100 and P200 latency in the pairedclick task. ${ }^{7}$ Rivastigmine was able to reverse the effects of biperiden on N100 and P200 latency. Biperiden increased P50 latency in the novelty oddball task, which was reversed by concurrent administration of rivastigmine. Rivastigmine shortened N100 latency and enhanced P3a amplitude in the novelty oddball paradigm, both of which were reversed by biperiden. It was concluded that the muscarinic $M_{1}$ receptor appears to be involved in preattentive processing of auditory information.

Taken together, effects of biperiden on behavior in rats and humans can be characterized as follows: 1) primary effects on learning/memory- which are likely mediated by blockade of postsynaptic muscarinic $M_{1}$ receptors in the hippocampus (Chapters 2, $\mathbf{3}$ and 4) and 2) non-specific central effects on psychomotor slowing - which are likely mediated via muscarinic $\mathrm{M}_{1}$-dopamine interactions in striatum (see Chapters 2-5 and De Klippel et al., 1993; Gerber et al., 2001; Thomsen et al., 2010). Peripheral side-effects are limited compared to scopolamine - i.e., at low doses there are minor to no effects on salivation or sedation (Chapters 2-5 and 7).

With respect to ERPs, biperiden generally induces increments in the amplitudes of early perceptual components (i.e., N1 in rats, and P50 and N100 in humans, see Chapters 6 and 7). Thus, effects of biperiden on behavior appear to be focused on mnemonic functions, whereas those on ERPs seem to be more related to attentional processes. This discrepancy is possibly due to primary effects of biperiden on memory, and secondary on attention. It appears that muscarinic $M_{1}$ modulation of cognition is complex and dependent on brain region.

We have also found some different findings between species with respect to our EEG studies - i.e., disruption of hippocampal sensory gating in rats vs. a lack of effect of biperiden on human sensory gating. We presume that differences in methodology, especially with respect to the sensitivity of the EEG equipment to pick up on hippocampal activity, underlie the discrepancies between species. Furthermore, some progress has been made with respect to determining the pharmacodynamic and pharmacokinetic properties of scopolamine and biperiden in humans vs. rats. However, a direct comparison of plasma and brain concentrations at various doses of scopolamine and biperiden and in several species is currently lacking, which is pertinent in order to be able to compare effective dose ranges used in translational research.

In contrast to our findings in Chapters 6 and 7, most studies investigating sensory gating in schizophrenia have reported impaired P50 suppression due to a reduction of the initial P50 response to S1 (Jin \& Potkin, 1996). However, in aging and age-related disorders such as mild cognitive impairment and Alzheimer's disease, an increase in amplitudes of early AEP components (Golob et al., 2001a; 2001b; Irimajiri et al., 2005) and reduced sensory gating due to an increase in P50 amplitude of the S2 click has also been reported (Cancelli et al., 2006; Jessen et al., 2001; Thomas et al., 2010). Therefore, changes in auditory processing and sensory gating induced by muscarinic drugs may serve as a translational model for aging rather than schizophrenia.

\footnotetext{
${ }^{7}$ The effect on P200 latency in the paired-click task in Chapter 7 was interpreted as reflective of a downstream effect on the N100 (cf. Simons et al., 2011).
} 
Future research should replicate/confirm the selective effects of biperiden compared to scopolamine, especially with respect to findings of mnemonic but not attentional deficits after biperiden. Moreover, it is pertinent that biperiden is tested in memory paradigms along with recording of EEG, to assess whether it would influence mnemonic ERP components such as the P300 (particularly the P3b: Polich \& Criado, 2006). In this respect, the development of ligands which are more selective for a particular muscarinic receptor subtype would be an important step in determining muscarinic receptor modulation of cognition. However, this has been challenging due to the highly conserved orthosteric acetylcholine binding site of muscarinic receptors (Bolden et al., 1992; Heinrich et al., 2009). Nevertheless, selective muscarinic $M_{1}-M_{5}$ antagonists need to be perceived as additional pharmacological tools besides the golden standard scopolamine to elucidate muscarinic receptor modulation of cognition and behavior. 


\section{REFERENCES}

Baker, A. G. (1976). Learned irrelevance and learned helplessness: Rats learn that stimuli, reinforcers, and responses are uncorrelated. Journal of Experimental Psychology: Animal Behavior Processes, 2, 130-141.

Bartus, R. T., Dean, R. L., Beer, B., \& Lippa, A. S. (1982). The cholinergic hypothesis of geriatric memory dysfunction. Science, 217, 408-417.

Bolden, C., Cusack, B., \& Richelson, E. (1992). Antagonism by antimuscarinic and neuroleptic compounds at the five cloned human muscarinic cholinergic receptors expressed in Chinese hamster ovary cells. The Journal of Pharmacology and Experimental Therapeutics, 260, 576-580.

Boutros, N. N., Korzyukov, O., Jansen, B., Feingold, A., \& Bell, M. (2004). Sensory gating deficits during the mid-latency phase of information processing in medicated schizophrenia patients. Psychiatry Research, 126, 203-215.

Cadenhead, K. S., Light, G. A., Geyer, M. A., \& Braff, D. L. (2000). Sensory gating deficits assessed by the P50 event-related potential in subjects with schizotypal personality disorder. American Journal of Psychiatry, 157, 55-59.

Cancelli, I., Cadore, I. P., Merlino, G., Valentinis, L., Moratti, U., Bergonzi, P., et al. (2006). Sensory gating deficit assessed by $\mathrm{P} 50 / \mathrm{Pb}$ middle latency event related potential in Alzheimer's disease. Journal of Clinical Neurophysiology, 23, 421-425.

Caulfield, M. P. (1993). Muscarinic receptors - characterization, coupling and function. Pharmacology \& Therapeutics, 58, 319-379.

De Klippel, N., Sarre, S., Ebinger, G., \& Michotte, Y. (1993). Effect of M1- and M2-muscarinic drugs on striatal dopamine release and metabolism: An in vivo microdialysis study comparing normal and 6hydroxydopamine-lesioned rats. Brain Research, 630, 57-64.

Gal, G., Mendlovic, S., Bloch, Y., Beitler, G., Levkovitz, Y., Young, A.M.J., Feldon, J., \& Ratzoni, G. (2005). Learned irrelevance is disrupted in first-episode but not chronic schizophrenia patients. Behavioural Brain Research, 159, 267-275.

Garrido, M. I., Kilner, J. M., Stephan, K. E., \& Friston, K. J. (2009). The mismatch negativity: A review of underlying mechanisms. Clinical Neurophysiology, 120, 453-463.

Gerber, D. J., Sotnikova, T. D., Gainetdinov, R. R., Huang, S. Y., Caron, M. G., \& Tonegawa, S. (2001). Hyperactivity, elevated dopaminergic transmission and response to amphetamine in M1 muscarinic acetylcholine receptor-deficient mice. Proceedings of the National Academy of Sciences, 98, 15312-15317.

Gilles, C., \& Luthringer, R. (2007). Pharmacological models in healthy volunteers: their use in the clinical development of psychotropic drugs. Journal of Psychopharmacology, 21, 272-282.

Golob, E. J., Johnson, J. K., \& Starr, A. (2001a). Auditory event-related potentials during target detection are abnormal in mild cognitive impairment. Clinical Neurophysiology, 113, 151-161.

Golob, E. J., Miranda, G. G., Johnson, J. K., \& Starr, A. (2001b). Sensory cortical interactions in aging, mild cognitive impairment, and Alzheimer's disease. Neurobiology of Aging, 22, 755-763.

Hasselmo, M. E. (1999). Neuromodulation: Acetylcholine and memory consolidation. Trends in Cognitive Sciences, 3, 351-359.

Hasselmo, M. E. (2006). The role of acetylcholine in learning and memory. Current Opinion in Neurobiology, $16,710-715$.

Hasselmo, M. E., Bodelón, C., \& Wyble, B. P. (2002). A proposed function for hippocampal theta rhythm: Separate phases of encoding and retrieval enhance reversal of prior learning. Neural Computation, 14, 793-817.

Hasselmo, M. E., \& McGaughy, J. (2004). High acetylcholine levels set circuit dynamics for attention and encoding and low acetylcholine levels set dynamics for consolidation. Progress in Brain Research, 145, 207-231.

Heinrich, J. N., Butera, J. A., Carrick, T., Kramer, A., Kowal, D., Lock, T., et al. (2009). Pharmacological comparison of muscarinic ligands: Historical versus more recent muscarinic M1-preferring receptor agonists. European Journal of Pharmacology, 605, 53-56.

Irimajiri, R., Golob, E. J., \& Starr, A. (2005). Auditory brain-stem, middle- and long-latency evoked potentials in mild cognitive impairment. Clinical Neurophysiology, 116, 1918-1929.

Jessen, F., Kucharski, C., Fries, T., Papassotiropoulos, A., Hoenig, K., Maier, W., et al. (2001). Sensory gating deficit expressed by a disturbed suppression of the P50 event-related potential in patients with Alzheimer's disease. American Journal of Psychiatry, 158, 1319-1321. 
Jin, Y., \& Potkin, S. G. (1996). P50 changes with visual interference in normal subjects: a sensory distraction model for schizophrenia. Clinical Electroencephalography, 27, 151-154.

Mackintosh, N. (1973). Stimulus selection: Learning to ignore stimuli that predict no change in reinforcement. In R. Hinde \& J. Stevenson-Hinde (Eds.), Constraints on learning: Limitations and predispositions (pp. 75-96). New York, NY: Academic Press.

Näätänen, R., Pakarinen, S., Rinne, T., \& Takegata, R. (2004). The mismatch negativity (MMN): towards the optimal paradigm. Clinical Neurophysiology, 115, 140-144.

Olincy, A., Braff, D. L., Adler, L. E., Cadenhead, K. S., Calkins, M. E., Dobie, D. J., et al. (2010). Inhibition of the P50 cerebral evoked response to repeated auditory stimuli: results from the Consortium on Genetics of Schizophrenia. Schizophrenia Research, 119, 175-182.

Orosz, A. T., Feldon, J., Simon, A. E., Hilti, L. M., Gruber, K., Yee, B. K., et al. (2011). Learned irrelevance and associative learning is attenuated in individuals at risk for psychosis but not in asymptomatic firstdegree relatives of schizophrenia patients: Translational state markers of psychosis? Schizophrenia Bulletin, 37, 973-981.

Pekkonen, E., Jaaskelainen, I. P., Kaakkola, S., \& Ahveninen, J. (2005). Cholinergic modulation of preattentive auditory processing in aging. Neurolmage, 27, 387-392.

Polich, J., \& Criado, J. R. (2006). Neuropsychology and neuropharmacology of P3a and P3b. International Journal of Psychophysiology, 60, 172-185.

Price, G. W., Michie, P. T., Johnston, J., Innes-Brown, H., Kent, A., Clissa, P., et al. (2006). A multivariate electrophysiological endophenotype, from a unitary cohort, shows greater research utility than any single feature in the Western Australian family study of schizophrenia. Biological Psychiatry, 60, 1-10.

Sarter, M., Bruno, J.P., \& Givens, B. (2003). Attentional functions of cortical cholinergic inputs: What does it mean for learning and memory? Neurobiology of Learning and Memory, 80, 245-256.

Sarter, M., Hasselmo, M. E., Bruno, J. P., \& Givens, B. (2005). Unraveling the attentional functions of cortical cholinergic inputs: interactions between signal-driven and cognitive modulation of signal detection. Brain Research Reviews, 48, 98-111.

Sarter, M., Lustig, C., \& Taylor, S. F. (2012). Cholinergic contributions to the cognitive symptoms of schizophrenia and the viability of cholinergic treatments. Neuropharmacology, 62, 1544-1553.

Sarter, M., Parikh, V., \& Howe, W. M. (2009). Phasic acetylcholine release and the volume transmission hypothesis: Time to move on. Nature Reviews Neuroscience, 10, 383-390.

Simons, C. J. P., Sambeth, A., Krabbendam, L., Pfeifer, S., Van Os, J., \& Riedel, W. J. (2011). Auditory P300 and N100 components as intermediate phenotypes for psychotic disorder: Familial liability and reliability. Clinical Neurophysiology, 122, 1984-1990.

Thomas, C., vom Berg, I., Rupp, A., Seidl, U., Schroder, J., Roesch-Ely, D., et al. (2010). P50 gating deficit in Alzheimer dementia correlates to frontal neuropsychological function. Neurobiology of Aging, 31, 416424.

Thomsen, M., Conn, P. J., Lindsley, C., Wess, J., Boon, J. Y., Fulton, B. S., et al. (2010). Attenuation of cocaine's reinforcing and discriminative stimulus effects via muscarinic $M 1$ acetylcholine receptor stimulation. Jounral of Pharmacology and Experimental Therapeutics, 332, 959-969.

Young, A. M. J., Kumari, V., Mehtrotra, R., Hemsley, D. R., Andrew, C., Sharma, T., et al. (2005). Disruption of learned irrelevance in acute schizophrenia in a novel continuous within-subject paradigm suitable for fMRI. Behavioural Brain Research, 156, 277-288. 


\section{ABBREVIATIONS}

\begin{tabular}{|c|c|c|c|}
\hline A: & albino & LIrr: & learned irrelevance \\
\hline AEP: & auditory-evoked potential & LSD: & least significant difference \\
\hline AT: & attention task & LTM: & long-term memory \\
\hline Bip: & biperiden & LTP: & long-term potentiation \\
\hline CRF: & continuous reinforcement & MMN: & mismatch negativity \\
\hline CRT: & choice reaction time task & MMSE: & Mini Mental State Examination \\
\hline CTA: & conditioned taste aversion & NMTP: & non-matching to position \\
\hline CS: & conditioned stimulus & Nov: & novel stimuli \\
\hline D: & Druckray strain & NPE: & non-preexposed \\
\hline Dev: & deviant stimuli & NZ: & New Zealand white albino rabbits \\
\hline DNMTP: & $\begin{array}{l}\text { delayed non-matching to posi- } \\
\text { tion }\end{array}$ & PDA: & pigmented dark agouti \\
\hline Dpz: & donepezil & PE: & preexposed \\
\hline DRL: & $\begin{array}{l}\text { differential reinforcement of } \\
\text { low rate }\end{array}$ & PO: & per os, oral \\
\hline EDS: & extradimensional shift & PR: & progressive ratio \\
\hline ERP: & event-related potential & RAN: & random \\
\hline F344: & Fischer-derived F344 strain & RT: & reaction time \\
\hline $\mathrm{Fl}:$ & fixed interval & Sal: & saline \\
\hline Fig.: & Figure & SC: & subcutaneous \\
\hline FR: & fixed ratio & Scop: & scopolamine \\
\hline $\mathrm{H}:$ & Hooded strain & SD: & Sprague-Dawley strain \\
\hline HBS: & Hooded Blue Spruce strain & SDRT: & Symbol Digit Recall Test \\
\hline HM: & Holtzman strain & SDST: & Symbol Digit Substitution Test \\
\hline IDS: & intradimensional shift & SI: & sensitivity index \\
\hline IM: & intramuscular & Stand: & standard stimuli \\
\hline IP: & intraperitoneal & STM: & short-term memory \\
\hline IV: & intravenous & SW: & Swiss Webster strain \\
\hline KM: & Kunming strain & US: & unconditioned stimulus \\
\hline KW: & Kuo:Wistar strain & VLT: & verbal learning task \\
\hline L: & Lewis strain & VRT: & verbal recognition task \\
\hline LB: & London Black strain & W: & Wistar strain \\
\hline LE: & Long-Evans (Hooded) strain & WC: & White Carneaux pigeons \\
\hline LH: & Lister Hooded strain & WR: & $\begin{array}{l}\text { Wistar-derived Walter Reed } \\
\text { strain }\end{array}$ \\
\hline
\end{tabular}




\section{CURRICULUM VITAE}

Inge Klinkenberg was born on December 18, 1983 in Kerkrade. In 2002, she graduated from secondary school (VWO) at College Rolduc in Kerkrade. In September 2002, she started studying General Health Sciences at Maastricht University, but after a few months switched to Psychology. After obtaining her Bachelor's degree in Biological Psychology in 2005, she was admitted to the Research Master track Neuropsychology. During the completion of her Master thesis she worked as a student assistant at Maastricht University. In March 2008, she received her Master's degree in Neuropsychology with honors and started working as a PhD student in the department of Neuropsychology and Psychopharmacology at Maastricht University. During her PhD she had the opportunity to visit the preclinical CNS Research lab at F.Hoffmann-La Roche where she attained additional experience with behavioral testing. 


\section{PUBLICATIONS}

Klinkenberg, I., \& Blokland, A. (2010). The validity of scopolamine as a pharmacological model for cognitive impairment: A review of animal studies. Neuroscience and Biobehavioral Reviews, 34, 1307-1350.

Klinkenberg, I., \& Blokland, A. (2011). A comparison of scopolamine and biperiden as a rodent model for cholinergic cognitive impairment. Psychopharmacology, 215, 549-566.

Klinkenberg, I., Blokland, A. Riedel, W., \& Sambeth, A. (2012). Human EEG correlates of learned irrelevance: Effects of the muscarinic $\mathrm{M}_{1}$ antagonist biperiden. The International Journal of Neuropsychopharmacology, 15, 1375-1385.

Klinkenberg, I., \& Sambeth A. (in press). Cholinergic gating of hippocampal auditory evoked potentials in freely moving rats. European Neuropsychopharmacology.

Klinkenberg, I., \& Sambeth A. (accepted). Cholinergic modulation of auditory processing, sensory gating and novelty detection in human participants. Psychopharmacology.

Sambeth, A., Klinkenberg I., Riedel, W.J., \& Blokland, A. (in preparation). The muscarinic $\mathrm{M}_{1}$ antagonist biperiden induces verbal memory impairment in young, healthy participants: Implications for Alzheimer's disease.

Klinkenberg, I., Sambeth, A., \& Blokland, A. (2011). Acetylcholine and attention. Behavioural Brain Research, 221, 430-442.

Blokland, A., Ten Oever, S., Van Gorp, D., Van Draanen, M., Schmidt, T., Nguyen, E., Krugliak, A., Napoletano, A., Keuter, S., Klinkenberg, I. (2012). The use of a test battery assessing affective behavior in rats: Order effects. Behavioural Brain Research, 228, 16-21. 


\section{ACKNOWLEDGEMENTS}

De jaren zijn werkelijk omgevlogen en opeens ligt het dan voor je neus. Het proefschrift. Gezien het feit dat er maar één naam op de voorkant staat, lijkt het misschien alsof ik het allemaal in mijn eentje gedaan heb. Niet is minder waar! Bij dezen wil ik iedereen bedanken die me tijdens mijn promotietraject geholpen heeft.

Allereerst mijn promotieteam; Prof Dr. Wim J. Riedel, Dr. Arjan Blokland en Dr. Anke Sambeth. Beste Wim, heel erg bedankt voor al je advies en goede raad ten opzichte van de humane experimenten, en de stukken voor het proefschrift. Ook al heb ik soms gezucht als je suggereerde dat ik een schrijfsel helemaal over een andere boeg moest gooien, uiteindelijk werd de kwaliteit alleen maar beter. Beste Arjan en Anke, bedankt dat ik altijd even mocht langskomen met een vraagje. Jullie hebben me voortdurend gestimuleerd om meer zelfvertrouwen te krijgen in mijn eigen kunnen en om op mijn eigen benen te staan. Daar ben ik jullie heel erg dankbaar voor! Ik zal onze discussies over ERPs, scopolamine, biperiden, geheugen, learned irrelevance en diergedrag gaan missen. Zonder jullie hulp was het allemaal niet gelukt, dat weet ik zeker. Ik had me geen betere begeleiders kunnen wensen!

Daarnaast wil ik ook Dr. Jos Prickaerts en Dr. Marlies van Duinen bedanken voor de mogelijkheid om mijn contract te kunnen verlengen. Ook al had het roflumilast-onderzoek inhoudelijk niets te maken met dit proefschrift, dankzij jullie heb ik wel meer ervaring kunnen opdoen met humane EEG-experimenten. Dat is mooi meegenomen!

Next, I'd like to offer a big thanks to my lovely colleagues from the UNS40.! Luciana and Joep, thanks for all those coffee breaks! Somehow you always seemed to sense when I needed a shot of caffeine and a good laugh. Silke, thank you for sharing the experience with me. We both started our PhDs on the $1^{\text {st }}$ of April 2008, and we will finish it a few weeks apart from each other. We can do it!! Also thanks for the Diet Coke breaks; my view of handymen will never be the same. ;) Aimee, thank you for sharing my passion for LOLcat pictures. I am still convinced it is one of the best things the internet has created! Maria, thank you for our excellent conversations and movie nights. I really hope we can catch up sometime soon! The rest of my (former) fellow PhD students: Stefan, Ellen, Alexandros, Rosa, Zoe, Janelle, Anique and Anne, thank you for all the "gezelligheid" (for lack of a good English word) and best of luck with your PhDs and/or your careers outside of uni!

Mijn roomies Anke L., Wendy, Eliza en Katja, door jullie heb ik me thuis gevoeld op ons stekkie in de UNS40. Wat hebben we veel gelachen, wetenschappelijke discussies gevoerd, over koetjes en kalfjes gepraat, grappige internetfilmpjes gekeken en geknotterd bij tegenvallende data of ander gedoe op het werk. Ik zal jullie dagelijkse aanwezigheid missen!

Ik wil ook nog enkele collega's van de UNS50 bedanken: Sven Akkerman, Eva Bollen, Kris Rutten, Denise Hermes, Hellen Steinbusch en alle anderen die me wel eens hebben geholpen met injecties en experimenten. De In-Vivo uitjes waren onvergetelijk (ondanks dat de alcohol rijkelijk vloeide). 
Although my work in the preclinical CNS Research lab at F.Hoffmann-La Roche did not end up in my thesis, I still think it was an essential part of my PhD. Dear Dr. Theresa BallardYardy, thanks you for inviting me over to Basel and giving me the opportunity to attain more experience with genetic mouse models and behavior. Sean Durkin, Melanie Kessler, Patrick Mortas, Marie Haman, and Roger Wyler, I enjoyed working with you!

Cees van Leeuwen, bedankt voor het keuren van de proefpersonen voor de humane studies. De mannen van instrumentatie: bedankt dat ik elke keer mocht langskomen in het geval van een defecte Skinner box of problemen met de EEG apparatuur (ook al was het soms een gevalletje "vrouwen en techniek"). Ook ben ik veel dank verschuldigd aan de medewerkers van het CPV voor alle hulp met de rattenexperimenten!

Martie Wanders en Susanne Niesten, bedankt voor al jullie hulp en advies. Frans Willems en Sophie van Roon, ik ben blij dat jullie me de middelen hebben gegeven om uit te vogelen wat ik na mijn PhD wilde gaan doen.

Daarnaast wil ik ook alle stagiair(e)s en student-assistenten die me bij de experimenten geholpen hebben in het voetlicht zetten: Kyle Roddick, Jasmijn Kromhout, Inge Timmers, Suzanne Holthuijsen, Karin Joanknecht, Natalie Valle Y Guzman, Moos Peeters, Conny Quaedflieg, Floriaan Demeester, Ili Ma, Kim Weijland en Syenna Schievink.

Ook dank aan de proefpersonen voor hun medewerking! Verder was dit proefschrift er niet geweest zonder de labratten en -muizen. Ik heb altijd met eer en geweten proberen te handelen. Dank voor hun bijdrage aan de wetenschap. Ramon Kool, bedankt voor het ontwerpen van de toffe illustratie op de cover van mijn proefschrift!

Alex, Ron and Michiel, ik ben blij dat jullie mijn nerd-lidmaatschap goedgekeurd hebben (en soms hebben gedreigd om het weer af te nemen). Ondanks dat ik door mijn wetenschappelijke achtergrond elke vorm van bijgeloof zou moeten afweren, hebben jullie me van het fenomeen "dobbelsteen-karma" weten te overtuigen. Ik zou niet weten hoe mijn leven eruit zou zien zonder initiative rolls, character sheets, metagaming and experience points. Alex, ik ben wel nog steeds van mening dat dat paard aan mij toehoorde! ;) Ook bedankt voor alle gezamenlijke vakanties in Berlijn, Schotland, München en Wenen.

Martijn en Suus, bedankt voor alle gezellige borrels in Loui's (en recentelijk in Jules) de afgelopen jaren!

Olga en Lieke, super dat jullie mijn paranimfen zijn. Ik ben blij dat jullie letterlijk achter me zullen staan tijdens de verdediging! Olga, we kennen ons al heel wat jaren en we zijn nog lang niet uitgekletst! Ik ken niemand die mijn interesse voor zombie films, rock festivals, musicals, fantasy fairs, high teas, spelletjes en pub quizen deelt zoals jij dat doet. Hopelijk zijn binnenkort de rollen omgedraaid en mag ik jou bijstaan als paranimf! Lieke, bedankt voor al je hulp, en de spreekwoordelijke "schop onder de kont" die ik soms nodig heb! 
Tenslotte wil ik Rianne en Martijn Bischoff bedanken voor hun interesse in wat ik doe! Pap en mam: zonder jullie praktische, emotionele, en soms ook financiële hulp was dit alles er niet geweest. Ik ben blij dat ik op jullie mag rekenen!

To make a long story short: thank you, thank you, thank you! It's been one hell of a ride. :) 